\title{
Testing Unsaturated Soil for Plane Strain Conditions: A New Double-Wall Biaxial Device
}

\author{
Dissertation \\ as a requirement for the degree of \\ Doktor - Ingenieur \\ at the Faculty of Civil Engineering \\ Bauhaus-University Weimar
}

submitted by

Jamal Alabdullah

from Homs / Syria

Reviewers:

1. Prof. Dr.-Ing. habil. Tom Schanz

2. Prof. Dr.-Ing. Karl Josef Witt

3. Prof. Dr.-Ing. habil. Eugen Perau

Weimar 2010 
This work is dedicated to my beloved father

$$
\text { إلى أستاذي الأول ..... إلى و الدي }
$$




\begin{abstract}
In geotechnical practice most soils are in unsaturated conditions, for instance the compacted soils used in several engineering constructions (such as earth dams, highways, embankments, and airport runways). In fact, testing the soil in unsaturated conditions is not common in soil mechanics laboratory.

Plane-strain (biaxial) test is also not common in soil mechanics laboratory tests. Even though, in reality, the state of deformation of several structures (e.g., long retaining walls and strip foundations) is plane-strain state. The biaxial testing procedures are more complex compared to triaxial tests. Several researchers have extensively studied the strain localization in biaxial tests for dry or saturated soils. But there is no study concerning the effect of soil suction on the characteristics of shear bands in unsaturated conditions.

In the available literature, most of the biaxial devices are not capable to test unsaturated soil, but only dry or fully saturated soils. As known to the author, there is just one biaxial device in an on going research which is capable of testing unsaturated soil specimens in plane-strain conditions. It is evident that there is a lack in the knowledge about unsaturated soil behavior in plane-strain conditions.

In this dissertation, a new, unique and original biaxial device for testing unsaturated soil was designed and developed. A study on the mechanical behaviour of unsaturated sand in plane-strain conditions using the new device is presented. The tests were mainly conducted on Hostun sand specimens. A series of experiments including basic characterisation, soil water characteristic curves, and compression biaxial tests on dry, saturated, and unsaturated sand were conducted. A set of bearing capacity tests of strip model footing on unsaturated sand were performed. Additionally, since the presence of fine content (i.e., clay) influences the behavior of soils, soil water characteristic tests were also performed for sand-kaolin mixtures specimens.

The experimental results obtained are analysed and several characteristics of the materials are brought out in this thesis. Factors influencing the friction angle, dilatancy angle, and shear band inclination angle are outlined and discussed. The effect of the matric suction on the shear strength and the ultimate bearing capacity of unsaturated sand is discussed and the experimental results are compared to the predicted ones. The characteristics of the wetting and drying curves of the sand-kaolin mixtures influenced by the fine content are discussed. Finally, general conclusions regarding the mechanical behaviour of the Hostun sand and sand-kaolin mixtures are drawn and suggestions for future studies are presented.
\end{abstract}




\section{ZUSAMMENFASSUNG}

In der geotechnischen Praxis befinden sich die meisten Böden in ungesättigtem Zustand, wie z. B. die verdichteten Böden, die bei einer Vielzahl von Ingenieurbauwerken (Erddämme, Strassen, Schüttungsdämme und Start- und Landebahnen im Flughafenbau u.a.) eingesetzt werden. Allgemein ist es jedoch nicht üblich, die Eigenschaften von Böden im ungesättigten Zustand mit gewöhnlichen bodenmechanischen Laborversuchen zu untersuchen.

Ebenso bilden zweiachsige Verformungsversuche (Biaxialversuche) eher die Ausnahme. Demgegenüber herrscht jedoch bei vielen Bauwerken (z.B. langen Stützmauern und Streifenfundamenten) ein ebener (biaxialer) Dehnungszustand. Im Vergleich zu den Triaxialversuchen ist die Methode der Biaxialversuche weitaus komplexer. Die Lokalisierung der Dehnungen in Biaxialversuchen wurde von einer Vielzahl von Wissenschaftlern in umfangreichen Studien ausführlich für trockene und gesättigte Böden untersucht. Jedoch existieren bislang keine Untersuchungen über die Wirkung von Saugspannungen auf die Scherbandcharakteristik ungesättigter Böden.

In der zur Verfügung stehenden Literatur wird von biaxialen Versuchsgeräten berichtet, die im Allgemeinen nur für die Analyse trockener oder gesättigter, nicht aber für Untersuchungen ungesättigter Bodenproben geeignet sind. Soweit dem Autor bekannt, ist im Rahmen eines laufenden Forschungsprojektes lediglich ein biaxiales Versuchsgerät zur Untersuchung ungesättigter Böden erwähnt worden. Daraus wird offensichtlich, dass auf Grund fehlender Informationen, über das Verhalten ungesättigter Böden für den ebenen Dehnungszustand, noch ein erheblicher Forschungsbedarf besteht.

In der vorliegenden Dissertation wird durch den Autor ein neuer, einzigartiger biaxialer Versuchsstand für die Untersuchung ungesättigter Böden entwickelt und die an Proben von ungesättigtem Sand gewonnenen Versuchsergebnisse vorgestellt. Im Wesentlichen werden die Versuche an Proben von Hostun-Sand-Proben durchgeführt. Die Versuchsreihen umfassen die Charakterisierung (Klassifizierung) des Bodens, die Ausarbeitung von Wasserretentionskennlinien (Soil Water Characteristic Curves) und die Durchführung von biaxialen Kompressionsversuchen an trockenen, gesättigten und ungesättigten Proben. Desweiteren werden Modellversuche an Streifenfundamenten zur Untersuchung der Tragfähigkeit durchgeführt. Begründet durch die Veränderung des Bodenverhaltens durch geringe Anteile von bindigem Material, werden zusätzlich Versuche mit einer Mischung aus Sand und Kaolinit analysiert.

Die unter Verwendung des neuen Versuchsstandes erzielten experimentellen Ergebnisse werden analysiert und daraus eine Vielzahl von Eigenschaften abgeleitet. Die 
verschiedenen Merkmale des untersuchten Materials sind in dieser Arbeit dargestellt. Die den Reibungswinkel, den Dilatanzwinkel und den Scherbandneigungswinkel beeinflussenden Faktoren, werden aufgezeigt und diskutiert. Der Einfluss von Saugspannungen auf die Scherfestigkeit und die Grenztragfähigkeit von ungesättigtem Sand wird erörtert und die Ergebnisse der Versuche mit den prognostizierten Werten verglichen. Zusätzlich wird der Einfluss von feinem Material auf die charakteristischen Merkmale der Feucht- und Trockenkurven der Sand-Kaolinit-Mischungen diskutiert.

Abschließend werden allgemeine Schlussfolgerungen bezüglich des mechanischen Verhaltens von Hostun-Sand und Sand-Kaolinit Mischungen gezogen und Vorschläge für zukünftigen Forschungsbedarf aufgeführt. 


\section{ACKNOWLEDGEMENTS}

Praise be to God, the most gracious and the most merciful, for giving me the ability, the health, and the strength to finish this work.

First and foremost, I would like to thank my supervisor and mentor Prof. Tom Schanz for his guidance, valuable advices, and patience throughout this research. His wide knowledge and his logical way of thinking have been of great value for me. I am really proud that I have had an opportunity to work closely with such a wonderful person.

Many thanks go to Prof. Karl Josef Witt and Prof. Eugen Perau for their agreement to be reviewers of this dissertation.

I want to express my deep and sincere gratitude to Prof. Sai Vanapalli for his continues advices and encouraging which helped me in my study; I shall ever remember and respect him. Special thanks are due to Dr. Snehasis Tripathy for many interesting discussions during his stay in Weimar.

My gratitude also goes to my colleagues at Bauhaus-University Weimar. Special thanks to Ms. Gabriel Tscheschlok, Dr. Yvonne Lins, and Mr. Yasir Al-Badran for their assistance in the experiments, discussion, and sharing the ideas.

Over the past five years I got to know some very special people. Sincere thanks to all my friends who have made my stay in Germany pleasant and successful.

In particular, there are two persons with whom I shared room and long hours in the laboratory and who deserve special mention. I would like to thank my dear friend Dr. Yulian Arifin for shearing ideas and comments. Also I have to say a big thank you to the best technician Mr. Frank Hoppe (Alma) who helped me when I was in trouble trying to perform my tests. I thank them for their entertaining, cheerful, and perfect behaviour at office.

I wish to express my unending gratitude to my family, specially my parents for their support and encouragement throughout my life. Without their help, I would not have been able to continue my study.

Last but most certainly not least, I would like to express my deepest gratitude, which can not be put into words, for the continuous caring and understanding which I received from my wife Rasha.

Jamal

Weimar, 25 January 2010 
Acknowledgements 


\section{LIST OF CONTENTS}

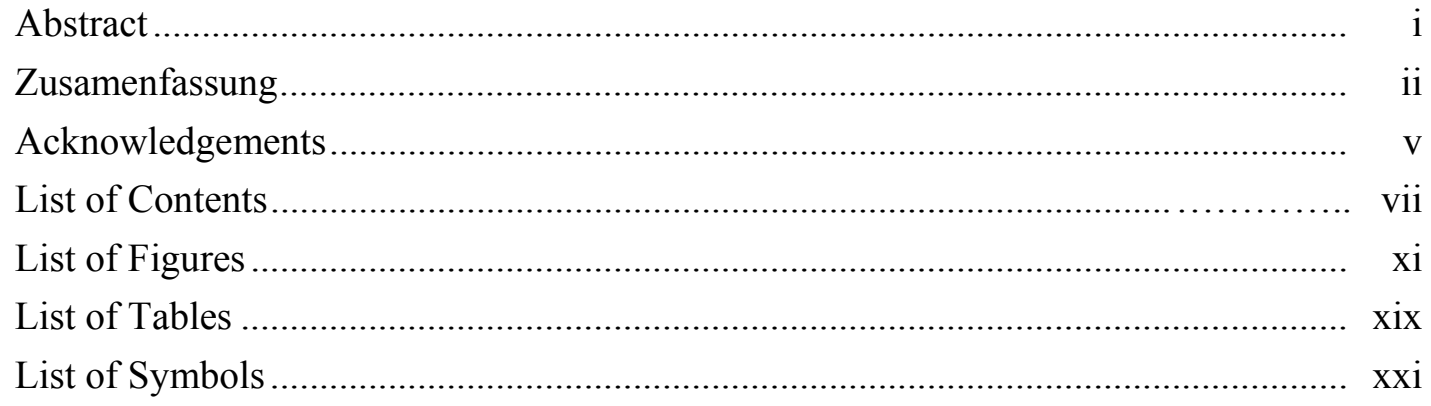

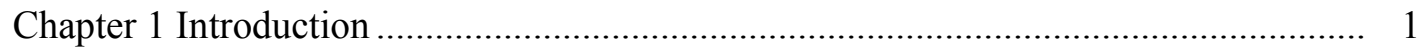

1.1 Background and motivations ..................................................... 1

1.2 Objectives and Scopes .............................................................. 2

1.3 Organization of the Dissertation .................................................... 3

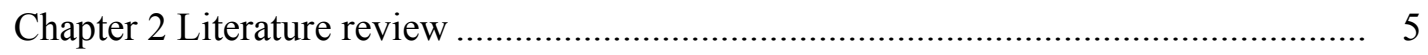

$2.1 \quad$ Introduction ........................................................................... 5

2.2 Unsaturated soil .................................................................. 5

2.2.1 Concept of suction............................................................ 5

2.2.2 Stress state variables for unsaturated soil................................ 6

2.2.3 Shear strength of unsaturated soil ......................................... 7

2.2.3.1 Theory of shear strength of unsaturated soil.............. 7

2.2.3.2 Laboratory measurement of shear parameters for unsaturated soil .................................................... 8

2.2.4 Volume changes of unsaturated soil ...................................... 9

2.2.4.1 Dilatancy in unsaturated soil.................................... 9

2.2.4.2 Laboratory measurement of volume changes in unsaturated soil ................................................... 12

2.2.4.3 Review of double-wall cells................................. 12

2.3 Plane-strain state .................................................................. 15

2.3.1 Plane strain concept in geotechnical engineering .................. 15

2.3.2 Literature review of plane-strain devices .............................. 17 
2.3.2.1 General

2.3.2.2 Literature review of plane-strain devices for saturated and dry soil testing.....

2.3.2.3 Literature review of plane-strain devices for unsaturated soil testing......................................... 29

2.3.3 Literature review of plane-strain results .............................. 30

2.3.3.1 Literature review of plane-strain results concerning shear strength

2.3.3.2 Literature review of plane-strain results concerning shear banding 36

2.4 Strain localization in Granular material ......................................... 41

2.4.1 Angle of shear band inclination ........................................ 42

2.4.2 Thickness of shear band ...................................................... 45

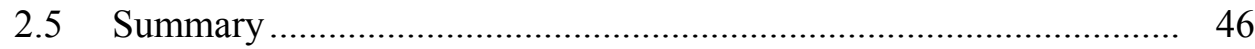

Chapter 3 Material used and experimental program............................................ 47

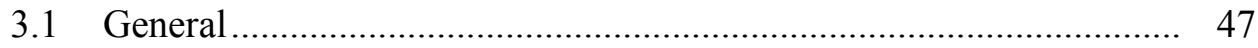

3.2 Basic properties of the materials used ......................................... 47

3.3 Experimental program ............................................................. 49

3.3.1 Experimental program for biaxial tests ............................... 50

3.3.2 Experimental program for bearing capacity tests .................. 51

3.3.3 Experimental program for determination of SWCCs ............ 51

3.4 Summary ........................................................................... 52

Chapter 4 Experiential techniques and procedures ............................................ 53

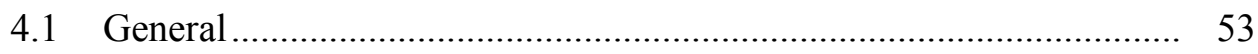

4.2 The new double-wall biaxial device ............................................. 53

4.2.1 Sample description .......................................................... 54

4.2.2 The inner and outer cells .................................................. 54

4.2.3 The top cap and bottom platen ............................................ 59

4.2.4 The side platens and ball bearings ........................................ 63

4.2.5 The split mould and membrane ......................................... 65

4.2.6 System calibrations ........................................................ 66

4.2.6.1 Air pressure controller ........................................ 66

4.2.6.2 Calibration of volume change indicator.................... 68

4.2.6.3 Permeability of ceramic discs ............................... 69

4.2.6.4 Inner cell expansion due to the application of cell pressure 
4.2.6.5 Calibration of the inner cell using a saturated soil specimen

4.2.6.6 Verification of the concept of stress state variables using the new double-wall biaxial device ............................. 75

4.3 Sample preparation and procedures used....................................... 77

4.3.1 Flushing pore-water pressure lines and assembling the top and base platens ................................................................... 77

4.3.2 Sample preparation........................................................ 79

4.3.2.1 Dry sample preparation ...................................... 79

4.3.2.2 Saturated sample preparation .................................. 81

4.3.3 Test procedure................................................................. 82

4.3.3.1 Test procedure for dry specimens ......................... 82

4.3.3.2 Test procedure for unsaturated specimens ............... 83

4.4 Repeatability in test results........................................................ 84

4.5 Techniques and procedures used for SWCCs tests ......................... 86

4.5.1 Sample preparation ........................................................ 86

4.5.2 Pressure plate Extractor ....................................................... 87

4.5.3 Modified pressure plate (MPP) .......................................... 88

4.5.4 Vapor equilibrium technique (VET) .................................... 90

4.6 Techniques and procedures used in bearing capacity tests ................. 92

4.6.1 Sand box................................................................... 92

4.6.2 Sample preparation and testing procedure ............................... 95

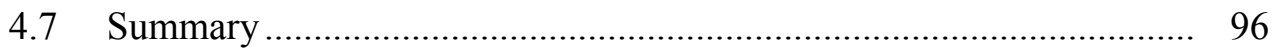

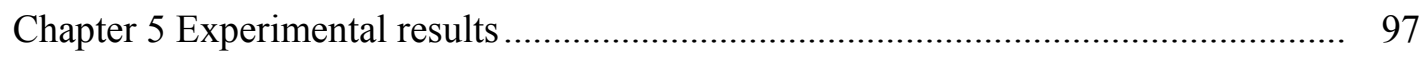

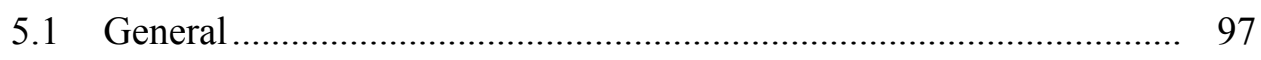

5.2 Biaxial tests results .................................................................... 97

5.2.1 Results for loose and dense dry Huston sand......................... 98

5.2.2 Results of unsaturated dense Hostun sand ............................ 109

5.3 Results of bearing capacity tests of strip footing .............................. 113

5.4 Soil water characteristic curves (SWCCs) ..................................... 115

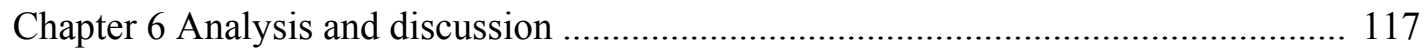

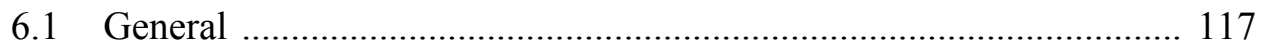

6.2 Discussion of the biaxial tests' results on dry Hostun sand .............. 117

6.2.1 Stress-strain behavior of dry Hostun sand ............................. 117

6.2.2 Shear banding in dry Hostun sand ..................................... 128 
6.3 Discussion of the biaxial tests' results on unsaturated Hostun sand.... 134

6.3.1 Stress-strain behavior of unsaturated Hostun sand .................. 134

6.3.2 Shear banding in unsaturated Hostun sand ............................. 139

6.4 Discussion of the of the bearing capacity tests's results................... 139

6.5 Prediction of shear strength and bearing capacity of unsaturated sand 141 6.5.1 Prediction of shear strength of unsaturated sand .................... 141

6.5.2 Prediction of bearing capacity of unsaturated sand ................ 145

6.6 Discussion of the results of soil water characteristic curves tests...... 153

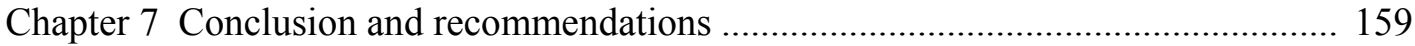

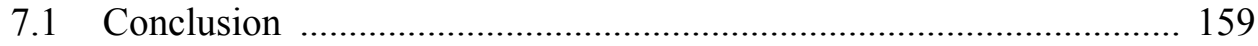

7.1.1 The new developed double-wall biaxial device...................... 159

7.1.2 Biaxial tests on Hostun sand ................................................. 160

7.1.3 Bearing capacity tests of strip model footing on Hostun sand. 161

7.1.4 Effect of fine contest on SWCCs ......................................... 162

7.2 Recommendations and future work ............................................... 162

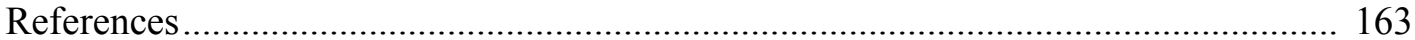




\section{LIST OF FIGURES}

Figure (2.1) Normal and shear stresses in unsaturated element soil: (a) independent stress state variable approach; (b) effective stress approach (Lu and Likos, 2004)

Figure (2.2) Mohr-Coulomb criterion: (a) failure envelope for saturated soil; (b) failure surface for unsaturated soil (Lu and Likos, 2004)

Figure (2.3) Taylor's shear box analogy 10

Figure (2.4) The saw blades model of dilatancy (Bolton, 1986) .............................. 10

Figure (2.5) Matric suction versus dilatancy (Ng and Chiu, 2003) .......................... 11

Figure (2.6) Matric suction versus maximum dilatancy (Ng and Zhou, 2005) ........... 11

Figure (2.7) Variation of maximum dilatancy with suction for natural and recompacted expansive clay (Zahn and $\mathrm{Ng}, 2006$ )

Figure (2.8) Double-wall triaxial cell (Wheeler, 1986) ......................................... 14

Figure (2.9) Double-wall triaxial cell (Ng et al., 2002) ......................................... 14

Figure (2.10) Plane-strain problems in geotechnical engineering ............................ 15

Figure (2.11) Plane-strain state: stresses and strains (Bishop, 1966) ....................... 15

Figure (2.12) Stress path for different values of $\theta$ in true triaxial tests (Nakai, 2007). 15

Figure (2.13) Failure criterion in deviatoric plane (Lade and Duncan, 1975)............ 16

Figure (2.14) Stress path: (a) triaxial; (b) biaxial test (Sterpi, 2000) ........................ 16

Figure (2.15) Imperial college plane-strain apparatus: (a) loading system;

(b) specimen at the end of the test (Wood, 1958; Conforth, 1961) ....

Figure (2.16) Schematic diagram and specimen arrangement of the biaxial apparatus (Vardoulakis, 1977; Vardoulakis et al., 1978).

Figure (2.17) The plane-strain specimen (a) Geometry and test conditions;

(b) the method adopted to prepare a specimen with a tilting angle $(\delta)$ (oda et al., 1978) 
Figure (2.18) The plane-strain apparatus (Desrues and Hammad, 1989)................... 25

Figure (2.19) The plane-strain apparatus (Wanatowski, 2005) ............................... 26

Figure (2.20) Biaxial device (Fauziah and Nikraz, 2008) ..................................... 29

Figure (2.21) Plane-strain versus triaxial failure characteristics (Conforth, 1961) ..... 31

Figure (2.22) Plane-strain versus triaxial: variation of tangent modulus and Poisson's ratio $($ Lee, 1970) ........................................................................ 32

Figure (2.23) Plane-strain test versus triaxial test (Marachi et al., 1981) ................... 32

Figure (2.24) Axial strain at failure in biaxial and triaxial tests (Marachi et al., 1981) 33

Figure (2.25) Variation of the angle of shearing resistance with the intermediate principle stress for standard Leighton sand, $\sigma_{3}^{{ }_{3}}=42 \mathrm{kN} / \mathrm{m}^{2}$ (Arthur et al.,

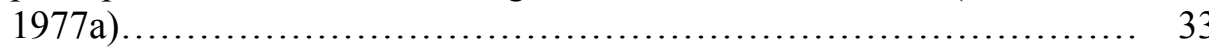

Figure (2.26) The effect of the pressure level on the angle of internal friction of Toyoura sand in plane-strain compression tests

(Tatsuoka et al. 1986a, 1991) ........................................................... 34

Figure (2.27) The effect of bedding angle $\delta$ on the intermediate stress $\left(\sigma_{2}\right)$ (Oda et al., 1978)

Figure (2.28) Mohr's failure envelops in the plane-strain and triaxial compression tests (Oda et al., 1978)

Figure (2.29) Loading cap: (a) clamped; (b) hinged (Vardoulakis et al., 1978)......... 36

Figure (2.30) Shear band orientation versus confining pressure for dense and loose specimens (Desrues and Hammad, 1989; Hammad, 1991)................... 37

Figure (2.31) Shear band angle versus confining pressure (Alshibli and Sture, 2000) 39

Figure (2.32) Sketches of the X-ray images (a) Toyoura sand; (b) Ticino sand (Oda and Kazama, 1998).

Figure (3.1) Grain size distribution of Hostun sand and Spergauer kaolin ................ 49

Figure (3.2) Standard proctor compaction curves of the material used

Figure (4.1) The concept of double-wall cell ..................................................... 53

Figure (4.2) Geometry of the specimen and stress and strain conditions .................. 54 
Figure (4.3) Double-wall biaxial cell (schematic diagram)

Figure (4.4) Photograph of the double-wall biaxial device (outer wall is not shown). 55

Figure (4.5) The base of the cell and the controlling valves..................................... 56

Figure (4.6) The outer and inner pistons......................................................... 56

Figure (4.7) Layout of the double-wall biaxial system......................................... 57

Figure (4.8) Biaxial test set up: the cell seated in loading frame............................ 58

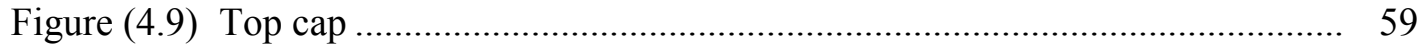

Figure (4.10) Bottom platen ............................................................................ 59

Figure (4.11) Assembled top cap and bottom platen .............................................. 59

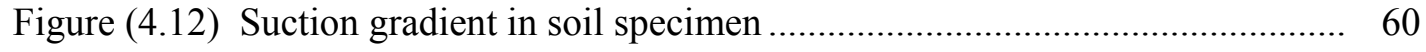

Figure (4.13) Plan view and cross section in the top cap..................................... 61

Figure (4.14) Plan view and cross section in the bottom platen .............................. 62

Figure (4.15) Side platens: (a) plane view and cross section; (b) photograph of the side platens covered with Teflon sheets; and (c) close view of the ball

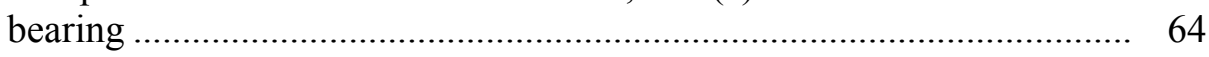

Figure (4.16) The split mould: (a) before assemblage; (b) full assemblage of the mould

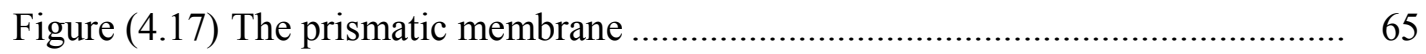

Figure (4.18) Metal plates at the bottom platen of the specimen .............................. 65

Figure (4.19) Calibration of the air pressure controller for low pressures.................. 67

Figure (4.20) Calibration of air pressure controllers: (a) calibration for low pressures; (b, c, and d) calibration for high pressures

Figure (4.21) Photograph of volume change indicator and the reading unit ............... 68

Figure (4.22) Calibration of the volume change indicator.................................... 68

Figure (4.23) Setup of permeability test of ceramic discs under low water pressure ... 70

Figure (4.24) Setup of permeability test of ceramic discs under high water pressure.. 70

Figure (4.25) Permeability of the ceramic discs (a) steady sate flow through the ceramic discs at the top cap; (b) at the bottom platen; (c) hydraulic conductivity versus applied water pressure 
Figure (4.26) Calibration of the inner cell due to the application of cell pressure ........

Figure (4.27) Volume changes of saturated sample measured by two methods:

$\mathrm{A}$ and $\mathrm{B}$

Figure (4.28) Error in the volume change of saturated soil sample measured by two

method $(\mathrm{A}$ and $\mathrm{B})$ versus confining pressure

Figure (4.29) Volume change versus elapsed time in Null test No. 1

Figure (4.30) Volume change versus elapsed time in Null test No. 2

Figure (4.31) Flushing procedure adopted in saturating water pressure lines 78

Figure (4.32) Installing the membrane and the metal plates. 79

Figure (4.33) The membrane and the mould: (a) the membrane stretched in the mould; (b) the membrane is sealed around the top cap

Figure (4.34) Typical specimen: (a) the specimen under vacuum; (b) the specimen between the two side walls

Figure (4.35) The installation of the inner and outer cell

Figure (4.36) Loading piston with two load cell

Figure (4.37) Stress-strain curves in three biaxial tests (B1, B2, and B3) on dense dry sand specimens under confining pressure of $300 \mathrm{kPa}\left(\mathrm{e}_{0}=0.66\right)$ : (a) axial strain versus deviator stress; (b) axial strain versus volumetric strain ..... 85

Figure (4.38) Mobilized angle of dilatancy versus shear strain in tests B1, B2, and B3 85

Figure (4.39) Photograph of the pressure plate

Figure (4.40) Schematic sketch of the pressure plate device.

Figure (4.41) Cross section of the modified pressure plate (MPP) (Lins et al., 2009). 88

Figure (4.42) Modified pressure plate: (a) a photograph of the cell; (b) test setup ...... 89

Figure (4.43) Photograph of chilled-mirror hygrometer device

Figure (4.44) Vapor equilibrium technique: (a) photograph of the desiccators used;

(b) schematic diagram of vapor equilibrium technique.

Figure (4.45) Schematic diagram of the bearing capacity test. 92

Figure (4.46) Bearing capacity test 93

Figure (4.47) Photograph of the model strip footing 93

Figure (4.48) Photograph of the tensiometer (type T5) and the reading unit 94 
Figure (4.49) Failure mechanism below the model strip footing.

Figure (4.50) Bearing capacity test: the location of the tensiometers

Figure (5.1) Experimental results of biaxial test on dense dry specimen $\left(\sigma_{3}=15 \mathrm{kPa}\right)$

Figure (5.2) Experimental results of the tests on dense sand specimens: (a) deviator stress versus axial strain; (b) volumetric strain versus axial strain

Figure (5.3) Experimental results of the tests on loose sand specimens: (a) deviator stress versus axial strain; (b) volumetric strain versus axial strain

Figure (5.4) Stress paths in biaxial tests: (a) loose sand; (b) dense sand

Figure (5.5) Shear band characteristics

Figure (5.6) Angle of shear band inclination versus confining pressure of dry dense and loose Hostun sand

Figure (5.7) Specimen at the end of the test, $\sigma_{3}=5 \mathrm{kPa}, \mathrm{e}_{0}=0.66$ : (a) shear band in $\sigma_{2}$-plane; (b) shear band in $\sigma_{3}$-plane; (c) displacement of the bottom platen.

Figure (5.8) Specimen at the end of the test, $\sigma_{3}=50 \mathrm{kPa}, \mathrm{e}_{0}=0.66$ : (a) shear band in $\sigma_{2}$-plane; (b) shear band in $\sigma_{3}$-plane; (c) displacement of the bottom platen.

Figure (5.9) Specimen at the end of the test, $\sigma_{3}=300 \mathrm{kPa}, \mathrm{e}_{0}=0.66$ : (a) shear band in $\sigma_{2}$-plane; (b) shear band in $\sigma_{3}$-plane; (c) displacement of the bottom platen.

Figure (5.10) Shear band with two inclinations on the $\sigma_{2}$ plane

Figure (5.11) Noticeable thickness of the shear band at the end of biaxial test on dry dense specimen tested under confining pressure of $100 \mathrm{kPa}$ :

(a) shear band in $\sigma_{2}$-plane; (b) zoom up of the shear band.

Figure (5.12) Stretching of membrane due to a single-plane slip (Head, 1986)

Figure (5.13) Stress-strain curves for set B10, $\left(\sigma_{3}-u_{a}\right)=10 \mathrm{kPa}$ : (a) axial strain-deviator stress; (b) axial strain-volumetric strain

Figure (5.14) Stress-strain curves for set B50, $\left(\sigma_{3}-u_{a}\right)=50 \mathrm{kPa}$ : (a) axial strain-deviator stress; (b) axial strain-volumetric strain

Figure (5.15) Stress-strain curves for set B100, $\left(\sigma_{3}-u_{a}\right)=100 \mathrm{kPa}$ : (a) axial strain-deviator stress; (b) axial strain-volumetric strain 
Figure (5.16) Matric suction versus the angle of shear band inclination of saturated and unsaturated dense Hostun sand specimens

Figure (5.17) Load-settlement relationship of strip footing on Hostun sand

Figure (5.18) Location of the tensiometers in bearing capacity test.

Figure (5.19) The changes in the applied matric suction during the bearing capacity test of strip footing on dense unsaturated Hostun sand $\left(\mathrm{e}_{0}=0.66\right.$, Suction $=2.1 \mathrm{kPa}$ )

Figure (5.20) Suction profiles under the strip footing in the bearing capacity tests...

Figure (5.21) Measured mass of mixture B specimen due to applied suction during drainage path in the pressure plate extractor....

Figure (5.22) Measured mass of mixture B specimen due to applied suction during drainage path using vapour equilibrium technique.

Figure (5.23) SWCCs (drying \& wetting) of the materials used

Figure (6.1) Angle of internal friction at peak versus confining pressure

Figure (6.2) Variation of peak friction angle with mean normal stress at failure for two sands (Kutter et al., 1988)....

Figure (6.3) Mobilized angle of dilatancy versus axial strain $\left(\sigma_{3}=15 \mathrm{kPa}\right)$

Figure (6.4) Maximum angle of dilatancy versus confining pressure

Figure (6.5) Mobilized angle of dilatancy ( $\left.\psi_{\mathrm{m}}\right)$ calculated using Equations (6.2) and (6.3) versus shear strain $\left(\gamma=\varepsilon_{1}-\varepsilon_{3}\right)$ in biaxial compression test on dry Hostun sand specimen tested under confining pressure of $100 \mathrm{kPa}$..

Figure (6.6) Maximum angle of dilatancy calculated using Equations (6.2) and (6.3) versus confining pressure for dense and loose specimens

Figure (6.7) Differences in maximum dilatancy angle using both equations versus confining pressure for dense and loose specimens.....

Figure (6.8) Maximum angle of dilatancy versus maximum angle of friction with comparison with Bolton's equation: (a) the results of the present study: the dilatancy angle was calculated using Equations (6.2) and (6.3); (b) the results of the present study with other biaxial results from the literatures

Figure (6.9) Axial strain at peak, $\varepsilon_{1 \mathrm{p}}$, versus confining pressure for dense Hostun sand (data of present study and from Grenoble). 
Figure (6.10) Shear strain at peak versus the shear strain at maximum dilation

125

Figure (6.11) Confining pressure versus the difference between the shear strain at peak and the shear strain at maximum dilation $(\delta \gamma)$

Figure (6.12) Stress ratio at peak and the confining pressure in the present study and in Grenoble's tests.....

Figure (6.13) Secant modulus of stiffness $\left(\mathrm{E}_{50}\right)$ versus confining pressure

Figure (6.14) Secant modulus of stiffness $\left(\mathrm{E}_{100}\right)$ versus confining pressure

Figure (6.15) Comparison between the measured angle of shear band inclination in this study and other experimental measurements from the literatures (Hammad, 1991; Han, 1991; Alshibli and Sture, 2000; and Tatsuoka et al. 1986, 1990)

Figure (6.16) Theoretical and experimental shear band inclination versus confining pressure for the loose Hostun sand specimens

Figure (6.17) Theoretical and experimental shear band inclination versus confining pressure for the dense Hostun sand specimens

Figure (6.18) Theoretical and experimental shear band inclination versus confining pressure for loose sand specimens (data of Grenoble's biaxial tests) ....

Figure (6.19) Theoretical and experimental shear band inclination versus confining pressure for dense sand specimens (data of Grenoble's biaxial tests)....

Figure (6.20) Comparison between the modified measured angle of shear band in the current study $\left(\theta_{\mathrm{m}}+7^{\circ}\right)$ and the results obtained in Grenoble $\left(\theta \mathrm{g}_{\mathrm{m}}\right)$

Figure (6.21) Effect of the matric suction on the maximum deviator stress.

Figure (6.22) Results of direct shear tests on sands under low matric suctions (modified from Donald, 1956), Fredlund and Rahardjo (1993)

Figure (6.23) Peak shear strength versus suction envelope (Fredlund et al., 1996; Gan and Fredlund, 1996)

Figure (6.24) Stress-strain curves for sand at various matric suctions under the effect of $50 \mathrm{kPa}$ net confining pressure (Farouk et al., 2004).

Figure (6.25) Effect of the matric suction on the maximum angle of dilatancy ..........

Figure (6.26) Matric suction versus axial strain at peak in the three sets of tests ....... 138

Figure (6.27) Shear strain at maximum rate of dilation versus shear strain at peak... 138

Figure (6.28) Ultimate bearing capacity versus matric suction 140 
Figure (6.29) Settlement at maximum load versus matric suction

Figure (6.30) Measured and predicted shear strength versus matric suction for different net confining pressures: (a) $10 \mathrm{kPa}$; (b) $50 \mathrm{kPa}$; (c) $100 \mathrm{kPa}$..

Figure (6.31) Fitting parameter, $\kappa$, versus plasticity index for naturally, compacted soils (Vanapalli and Mohamed, 2007).

Figure (6.32) Measured and predicted ultimate bearing capacity of unsaturated Hostun sand versus matric suction

Figure (6.33) Bearing capacity factor $\left(\mathrm{N}_{\gamma}\right)$ versus friction angle

Figure (6.34) Large voids (dark spots) visible inside a shear band of Ticino sand (Oda and Iwashita, 2000)

Figure (6.35) Shear banding under footing in bearing capacity test on unsaturated sand

Figure (6.36) Experimental results of bearing capacity tests on Toyoura sand with comparison to the results of FEM analyses (Ttasuoka et al., 1991).......

Figure (6.37) Effect of fitting parameter $(\kappa)$ on the predicted ultimate bearing capacity of strip footing on unsaturated sand.....

Figure (6.38) Idealized soil-water characteristic curves modified after Fredlund and Xing (1994) (Yang et al., 2004).

Figure (6.39) Influence of fine content on SWCC parameters

Figure (6.40) Sand particles coated partially with bentonite in sand-bentonite mixture (10\% bentonite) (Montañes, 2002)

Figure (6.41) Scanned electron microscope (SEM) images for specimens with different clay content: (a) $10 \%$ clay; (b) $30 \%$ clay; and (c) $40 \%$ clay (Ghahremani et al., 2007). 


\section{LIST OF TABLES}

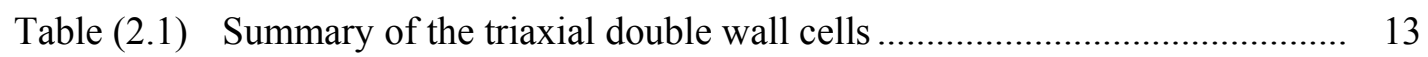

Table (2.2) Summary of plane-strain devices .......................................................... 27

Table (3.1) Basic properties of Hostun sand ....................................................... 48

Table (3.2) Basic properties of Spergauer kaolin ................................................ 48

Table (3.3) Mixtures used in the study ................................................................. 49

Table (3.4) Summary of biaxial tests performed on dry sand ............................... 50

Table (3.5) Summary of the stresses in biaxial tests on dense unsaturated sand ........ 51

Table (3.6) Summary of bearing capacity tests on dense unsaturated sand ............... 51

Table (4.1) The dimensions of the inner and outer cells ....................................... 56

Table (4.2) Pressures applied $(\mathrm{kPa})$ in the null-tests ............................................ 75

Table (4.3) Summary of accuracy of load cells and LVDT …................................ 82

Table (4.4) Results of three validation biaxial tests: B1, B2, and B3 ..................... 84

Table (6.1) Summary of the maximum angles of friction and dilatancy for the dense and loose Hostun sand .............................................................. 120

Table (6.2) Comparison of fitting equations form several researches..................... 123

Table (6.3) Summary of the measured angles of shear band inclination ................. 131

Table (6.4) Thickness of shear band (this study and data from the literatures) ....... 134

Table (6.5) Axial strain at peak in the three set of tests ..................................... 138

Table (6.6) Angle of shear band inclination, $\theta_{\mathrm{m}}$, in unsaturated dense sand........... 139 
List of tables

XX 


\section{LIST OF SYMBOLS}

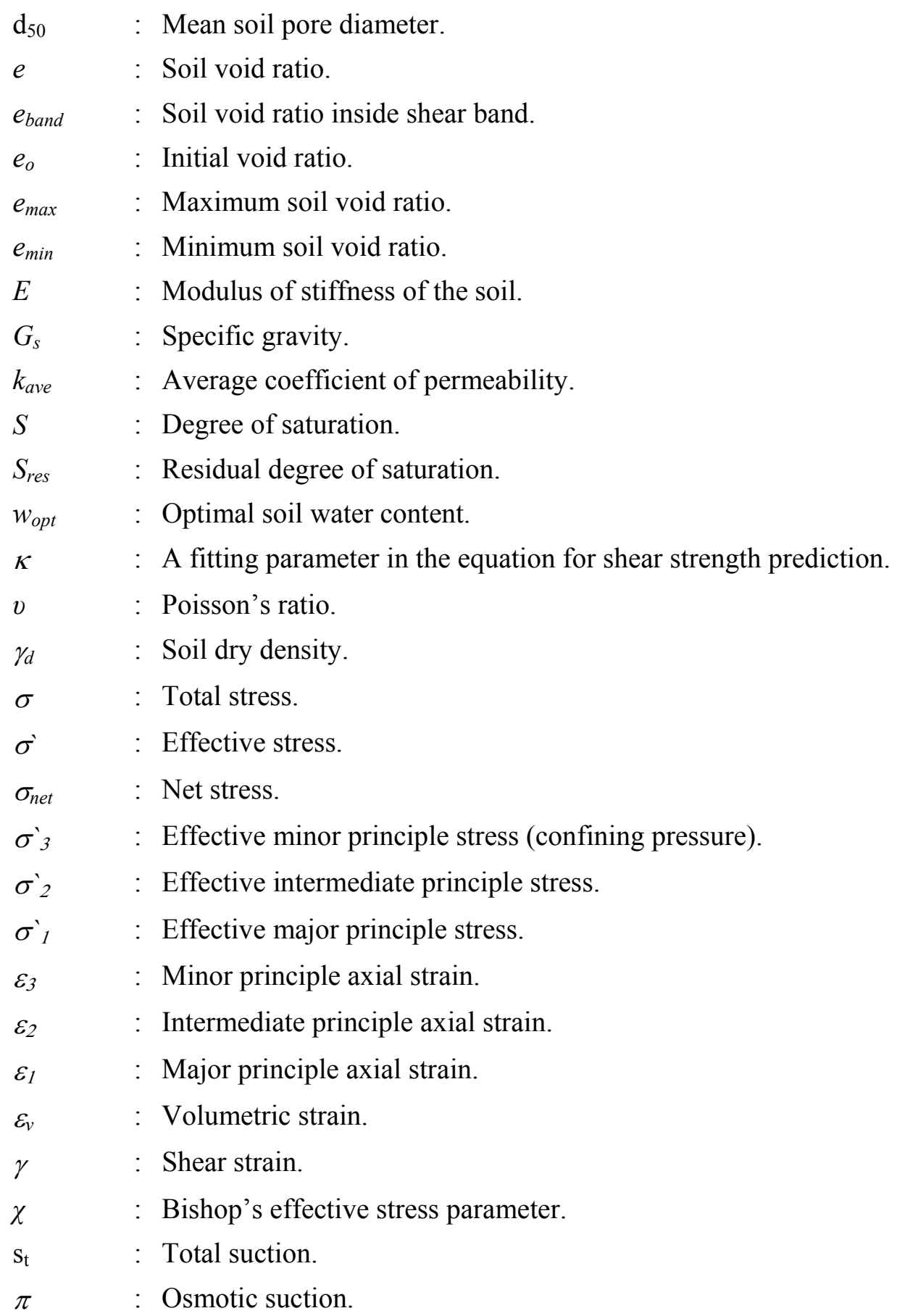




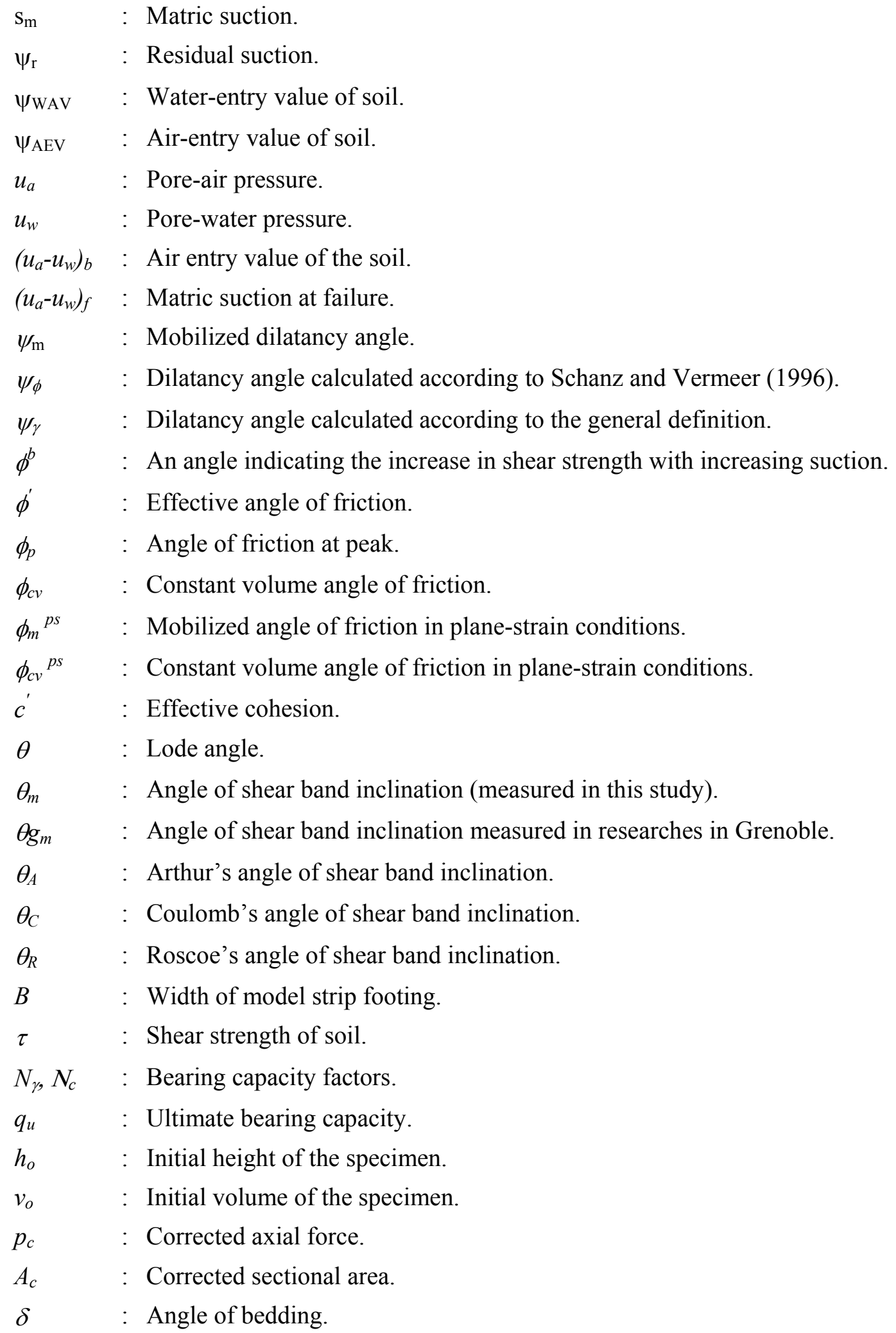




\section{CHAPTER 1}

\section{INTRODUCTION}

\subsection{Background and motivations}

The state of deformation in several structures (e.g., slopes, long retaining walls, strip foundations, embankments) is plane strain state. In most cases, the water table is at considerable depth, and the soil below the footings has a negative pore-water pressure (i.e., suction). Additionally, most of the potential slip surface may pass through unsaturated soils. The influence of the suction on the stability of the soil in bearing capacity or slope stability problems will arise from its contribution to the shear strength of the soil.

Significant developments and achievements were done in the field of traditional soil mechanics where the soil is considered to be dry or fully saturated. The developments of the unsaturated soil were mainly limited to the fact that unsaturated soil testing needs special techniques and well equipped laboratories. In unsaturated soil, the pore-water pressure is negative relative to the pore-air pressure. Testing unsaturated soils in laboratory is complicated and time consuming task.

Volume change measurements are essential to study the stress-strain behavior of the soil. Measuring the volume change of unsaturated sample is a challenging topic. Several techniques were proposed for this purpose. The proposed approaches can be used individually or combination of two methods or more for more accurate measurement. One of these methods is to measure the volume changes of unsaturated soil specimens indirectly by the double-wall cell concept which is adopted in this study.

Plane-strain (biaxial) devices are not common in geotechnical investigations. This type of test is more complicated to conduct than triaxial test. The difficulties are mainly related to the need for special mold, membrane, accessories, and the preparation of a prismatic soil specimen.

In the available literature, almost all the biaxial devices were designed to test saturated or dry soils. As known to authors, there is just one biaxial device in an on going research is capable of testing unsaturated soil specimen in plane-strain conditions. 
Additionally, the strain localization and shear banding in dry or saturated soils have been extensively studied in a lot of researches. But, there are no studies concerning the effect of soil suction on the shear bands characteristics in unsaturated soil. The need for more studies on these issues is crucial.

It is evident from the above discussion that there is a lack in the knowledge about unsaturated soil behaviour in plane-strain conditions. Therefore, for better understanding of unsaturated soil behaviour in general and in plane-strain state in particular; the current biaxial device was developed and used in this experimental program.

\subsection{Objectives and Scopes}

The main objective of the study is to investigate the mechanical behaviour of sand (i.e., shear strength, dilatancy, and shear banding) at failure conditions. The change in bearing capacity of unsaturated sand has been studied as well. Additionally, the thesis has an objective to study the influence of the fine content on the soil water characteristic curve by testing different sand-kaolin mixtures.

The research programs primarily consist of a series of biaxial tests on dry, saturated, and unsaturated Hostun sand, series of bearing capacity tests, and the SWCCs tests. The main objectives of this research are as follows:

- Determination of the basic properties of the Hostun sand, Spergauer kaolin, and sand-kaolin mixtures.

- Determination of soil water characteristic curves for Hostun sand, Spergauer kaolin, and three sand-kaolin mixtures with 5, 10, and 30\% kaolin.

- Developing a new double wall biaxial device. Details of the new device, system calibration, and the initial validation tests are presented.

- Investigating the effect of matric suction on the shear strength, volume change behaviour, and shear band characteristics of Hostun sand in plane-strain conditions.

- Investigating the effect of matric suction on the bearing capacity of a model strip footing on unsaturated Hostun sand.

- Investigating the effect of the fine content (i.e., kaolin content) on the parameters of the soil water characteristic curve. 


\subsection{Organisation of the Dissertation}

The dissertation is composed by seven chapters. The first chapter describes the background and motivations, objectives of the thesis, and the organization of the thesis.

The second chapter is devoted to presenting the literature review of the issues relevant to this study. An overview of the plane-strain state, unsaturated soil, suction concept, dilatancy in soil, and shear banding are given. Then a review of the biaxial devices and double wall cells cited in the literature is presented. Selected results from biaxial tests performed by different researches groups from literature are reviewed.

The third chapter presents the basic physical properties of the materials used. Two materials were used in this study (i.e., Hostun sand and Spergauer kaolin). Additionally three sand-kaolin mixtures were used to investigate the influence of fine content on soil water characteristic curve of the soil. Then the testing programs for biaxial tests, bearing capacity tests, and SWCC tests are presented.

In the fourth chapter, the testing devices used in this work (the new double-wall biaxial device, pressure plate apparatus, modified pressure plate, chilled mirror device, bearing capacity box) are introduced. The main parts of the new developed double-wall biaxial device, the calibrations, validation tests of the concept of two stress state variables, and the device's repeatability tests are presented as well.

The fifth chapter presents the results of the biaxial tests, bearing capacity tests, and tests of determination of soil water characteristic curves. In Section 5.2 the biaxial results for dry and unsaturated sand are presented. In Section 5.3 the experimental results of bearing capacity tests of model strip footing on unsaturated dense Hostun sand for different values of applied matric suction are presented. Section 5.4 describes the soil water characteristic curves of the soil tested. Hostun sand, Spergauer kaolin and three sand-kaolin mixture (with 5, 10, and $30 \%$ kaolin) were tested.

In the sixth chapter, the experimental results are analyzed, discussed, and compared to other results in the literatures. Firstly the biaxial results for the dry, saturated, and unsaturated Hostun sand are analyzed and compared to other results, placing emphasis to compare the current results with the biaxial results obtained in Grenoble by Prof. Desrues and his co-workers in several works for the same material (i.e., Hostun sand). Then, the effect of the matric suction on the bearing capacity of model strip footing on unsaturated sand is discussed. The measured shear strength and ultimate bearing capacity were compared to the predicted ones. The discrepancy between the measured and predicted values is discussed and explained. Finally, the results of the tests 
performed to determine the soil water characteristic curves for different soils were analyzed to show the influence of the fine content on the parameters of the soil water characteristic curves (i.e., the air-entry value, the water-entry value, and the residual suction).

Finally, Chapter 7 summarizes the main results and the related conclusions of this study and provides an outlook for further studies in this field. 


\section{CHAPTER 2}

\section{LITERATURE REVIEW}

\subsection{Introduction}

This chapter presents literature review of the issues relevant to soil testing in plane-strain conditions. A review of the devices used to test the soil under plane-strain condition is presented. In addition, a review of biaxial results from different studies over the last four decades is also presented. Dilatancy phenomenon and shear banding in soils are elaborated. Suction concept and shear strength of unsaturated soil are briefly presented with the laboratory techniques used to determine the shear strength parameters. Techniques used for measuring the volume change of unsaturated soil are also elaborated and emphasis is given to the double wall concept.

\subsection{Unsaturated soil}

In unsaturated soil, the pore-water pressure is negative relative to the pore-air pressure. The compacted soils used in several engineering constructions, such as earth dams, highways, embankments, and airport runways, are unsaturated soils.

\subsubsection{Concept of suction}

The concept of suction was developed by several researches (e.g., Buckingham, 1907; Edlefsen and Anderson, 1943; Bolt and Miller, 1958; Aitchison, 1965). Total suction has two components (i.e., matric suction $\left(s_{\mathrm{m}}\right)$ and osmotic suction $(\pi)$ ).

$s_{t}=s_{m}+\pi$

Total suction $\left(\mathrm{s}_{\mathrm{t}}\right)$ is the total free energy of the soil water determined as the ratio of the partial pressure of the water vapour in equilibrium with a solution identical in composition to the soil water, to the partial pressure of the water vapour in equilibrium with a pool of free pure water.

Matric suction $\left(\mathrm{s}_{\mathrm{m}}\right)$ is the component of free energy of the soil water, which is determined as the ratio of partial pressure of the water vapour in equilibrium with the soil water, relative to partial pressure of the water vapour in equilibrium with a solution identical in composition with a pool of soil water (Aitchison, 1965). 
In soil, generally, matric suction consists of two components; namely, the hydration forces and capillary forces. The two forces are available in highly plastic clays such as bentonite (Pusch and Yong, 2003; Arifin and Schanz, 2009). In case of sands and low plastic clays, matric suction is related to capillary forces (Fredlund and Rahardjo, 1993). Matric suction is usually defined as the difference between pore-air pressure $\left(u_{\mathrm{a}}\right)$ and pore-water pressure $\left(u_{\mathrm{w}}\right)$ in the soil.

\subsubsection{Stress state variables for unsaturated soil}

For a saturated soil, one stress state variable is enough to describe the behavior of two phases (solid and fluid/or gas) of soil mass. The stress state variable $\sigma^{`}$ is defined as $\sigma^{`}=\sigma-u_{\mathrm{w}}$, where $\sigma^{\prime}$ is the effective stress, $\sigma$ is the total stress, and $u_{\mathrm{w}}$ is the pore-water pressure (Terzaghi, 1943).

Unsaturated soil is normally considered as a three-phase system, i.e., solid, gas (air), fluid (water). In 1977, Fredlund and Morgenstern added the contractile skin as a fourth phase and these four phases were used by these two authors in the stress analysis of unsaturated soil on the basis of continuum mechanics. Several authors tried to define a single stress state variable for unsaturated soil but soil properties were involved in the proposed equations (Croney et al., 1958; Bishop, 1959; Richards, 1966; Aitchison, 1965; 1973). State variables used to describe the state of the stress have to be independent of soil properties (Fung, 1977; Fredlund and Morgenstern, 1977). Bishop (1959) proposed the following single effective stress equation for unsaturated soil:

$$
\sigma^{`}=\left(\sigma-u_{a}\right)+\chi\left(u_{a}-u_{w}\right)
$$

where $\sigma^{\prime}$ is the effective stress, $\sigma$ is total stress and $\chi$ is a parameter depends on the degree of saturation (effective stress parameter) (Lu and Likos, 2004). In 1961, Bishop and Donald performed a set of triaxial shear tests on unsaturated silt where the total stress (i.e., cell pressure), pore-air pressure, and pore-water pressure were varied by equal amount keeping $\left(\sigma_{3}-u_{\mathrm{a}}\right)$ and $\left(u_{\mathrm{a}}-u_{\mathrm{w}}\right)$ constant. The result of these tests substantiate the using of $\left(\sigma_{3}-u_{\mathrm{a}}\right)$ and $\left(u_{\mathrm{a}}-u_{\mathrm{w}}\right)$ as valid stress state variables for this type of test.

Fredlund and Morgenstern (1977) discussed the stress state variables controlling the behavior of unsaturated soil. They stated that the stress state variables have to be created from the individual forces components acting on the solid, water and air phases, and the air-water contractile skin. The proposed variables are the net stress $\left(\sigma-u_{\mathrm{a}}\right)$ and the matric suction $\left(u_{\mathrm{a}}-u_{\mathrm{w}}\right)$. In the same work, Fredlund and Morgenstern (1977) validated the concept of stress state variables by a set of null tests. In these tests it has been proven that changing the air, water, and the total pressures causes no changes in the 
state of the soil as long as the state variables remain constant. Tarantino et al. (2000) investigated these variables using a new laboratory apparatus. The results confirmed the use of the net stress and matric suction as stress state variables. Figure (2.1) shows the stress state in unsaturated soil element.

\subsubsection{Shear strength of unsaturated soil}

The factors affect the shear strength of sands includes void ratio, confining pressure, loading conditions, type of minerals, and the size, shape, and gradation of the particles (Lamb and Whitman, 1979). In the absence of any bonds between the grains, the shear strength of sand can be defined by the Mohr-Coulomb failure criterion with zero cohesive intercept (Wang, 2005). For unsaturated soil, matric suction provides additional shear strength component which normally is referred to as apparent cohesion.

\subsubsection{Theory of shear strength of unsaturated soil}

Using the concept of one effective stress, Bishop (1959) proposed an equation to determine the shear strength of unsaturated soil as follow:

$$
\tau=c^{`}+\left(\sigma-u_{a}\right) \tan \phi+\left(u_{a}-u_{w}\right) \chi \tan \phi
$$

where $\tau$ is the shear strength of unsaturated soil, $c^{\prime}$ is the effective cohesion, $\phi^{\prime}$ is effective angle of friction and $\left(\sigma-u_{\mathrm{a}}\right)$ is the net normal stress.

Fredlund et al. (1978) proposed the following equation to explain the shear strength of unsaturated soils as an extension of the shear strength equation of saturated soil:

$$
\tau=c^{`}+\left(\sigma-u_{a}\right) \tan \phi{ }^{`}+\left(u_{a}-u_{w}\right) \tan \phi^{b}
$$

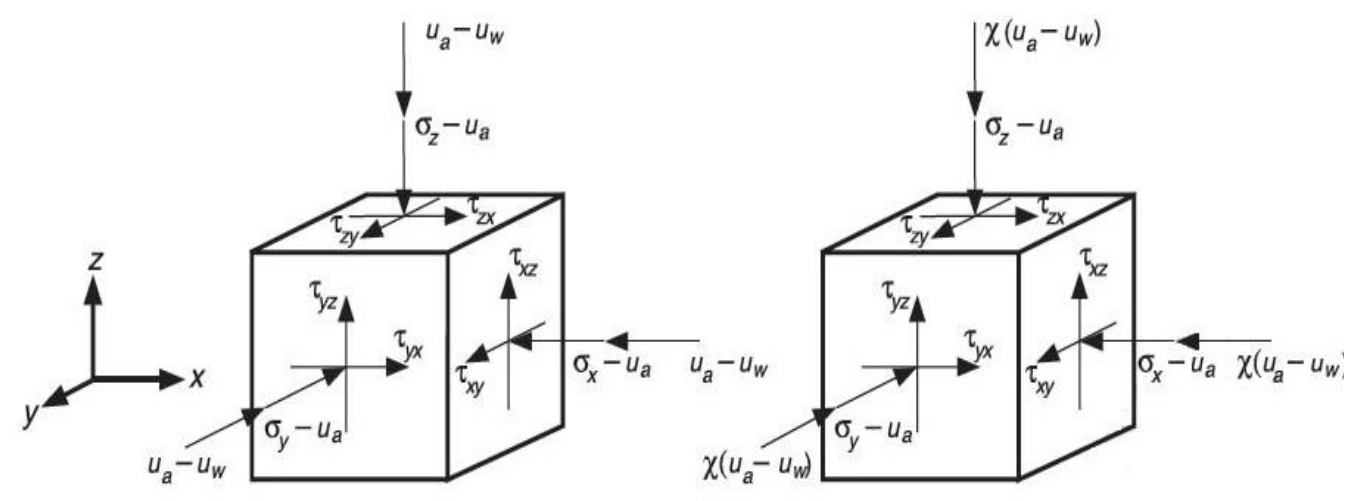

(a)

(b)

Figure (2.1) Normal and shear stresses in unsaturated soil element: (a) independent stress state variable approach; (b) effective stress approach (Lu and Likos, 2004) 


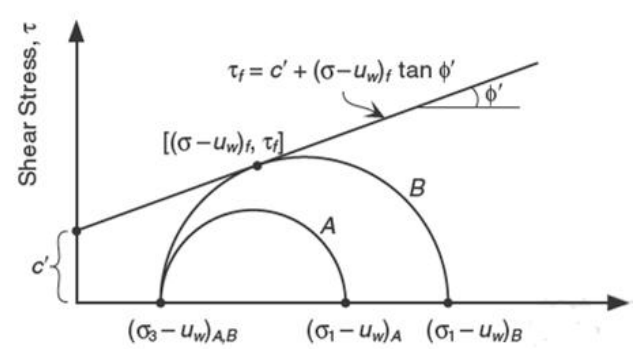

(a)

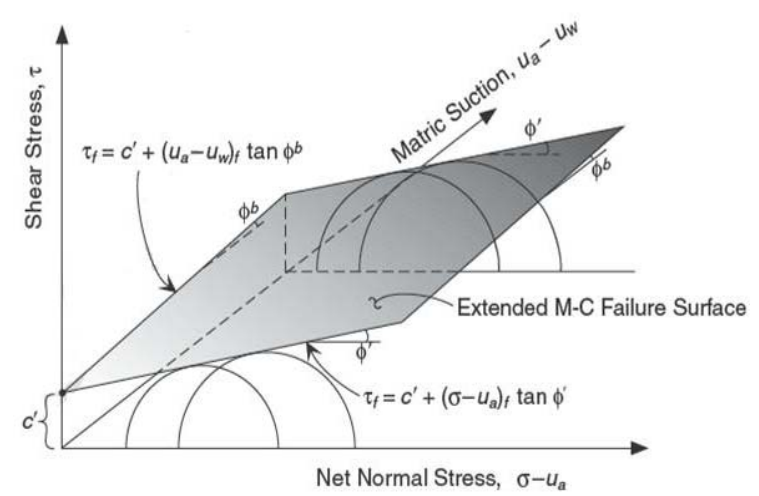

(b)

Figure (2.2) Mohr-Coulomb criterion: (a) failure envelope for saturated soil; (b) failure surface for unsaturated soil (Lu and Likos, 2004)

In Equation (2.4), the changes in the shear strength relative to the changes in matric suction are represented by the angle $\phi^{b}$. Figure (2.2) shows the Mohr-Coulomb failure envelope for saturated soil and the extended failure surface for unsaturated soil.

\subsubsection{Laboratory measurement of shear parameters for unsaturated soil}

In unsaturated soil testing it is essential to control the pore-air pressure within the sample independently of the pore-water pressure. This can be achieved by using ceramic discs which in the case of full saturation enable water to pass but prevent air from passing through it. This value of air pressure at which the air can pass through the ceramic disc is called the air entry value of the disc (AEV). Ceramic discs are available with deferent diameters, thicknesses, and air-entry values.

The other issue of concern is how to apply high values of matric suction (i.e. how to apply high negative pore-water pressure within the spoil specimen). This can also be overcomed by using the axis translation technique (ATT) proposed by Hilf (1956).

Modification should be applied to the conventional direct shear device and triaxial cell prior to use in unsaturated soil testing. The main modification is to provide ceramic discs to facilitate the application of the matric suction. Donald (1956) conducted a series of direct shear tests of sand and silt subjected to negative pore-water pressure. Bishop et al. (1960) proposed several techniques to measure the shear strength parameters in triaxial cell. Modified direct shear devices and triaxial cells were used to measure the shear parameter of unsaturated soil (e.g., Bishop et al., 1960; Satija, 1979; Ho and Fredlund, 1982; Krahn et al., 1987; Gan et al., 1988, Cliffton et al., 1999). 


\subsubsection{Volume changes of unsaturated soil}

Measuring of the overall volume change of the soil specimen is an important topic when testing an unsaturated soil specimen. There is a substantial difference when comparing saturated soil testing with unsaturated soil testing. In a saturated soil specimen the change in void ratio is due to the volume change of the water phase, so the soil volume change can be computed purely on the basis of variation in water volume.

Whereas, in unsaturated soil, which can be considered as a four phase body, soil, water, air, and contractile membrane, the volume changes occur due to the changes in both the gas and the liquid phases (i.e., air and water). The total volume change of an unsaturated specimen is equal to the sum of the volume change of water and volume change of air by assuming that the soil skeleton is incompressible.

\subsubsection{Dilatancy in unsaturated soil}

The strength of sand is usually characterized by the peak friction angle, dilatancy angle, and critical state angle. The volumetric expansion angle in soils was first introduced by Hansen (1958). The dilatancy phenomenon was firstly observed by Reynolds (1885). This phenomenon was demonstrated by Reynolds (1902) in the famous rubber balloon test.

The term interlocking was used by Taylor (1948) to describe the effect of the dilatancy in one of the earliest attempts to account for the increase in shear strength due to the dilatation in sand. Taylor's shear box analogy is shown in Figure (2.3). Figure (2.4) shows the saw blades model of dilatancy represented by Bolton (1986). The term dilatancy is used to describe the increase in volume of dense sand during shearing and the rate of dilation can be represented by the gradient $d \varepsilon_{\mathrm{v}} / \mathrm{d} \gamma$ where $\mathrm{d} \varepsilon_{\mathrm{v}}$ and $\mathrm{d} \gamma$ are the changes in volumetric strain and shear strain, respectively (Craig, 1997).

A great deal of attention has been focused on the relationship between the angle of friction and the dilatancy angle (e.g., Rowe, 1962; Bolton, 1986; Wood, 1990; Been et al., 1991; Schanz and Vermeer, 1996). Rowe (1962) proposed that the mobilized friction angle for dense sands can be presented as the sum of the sliding resistance, particle rearrangement, and dilation. 

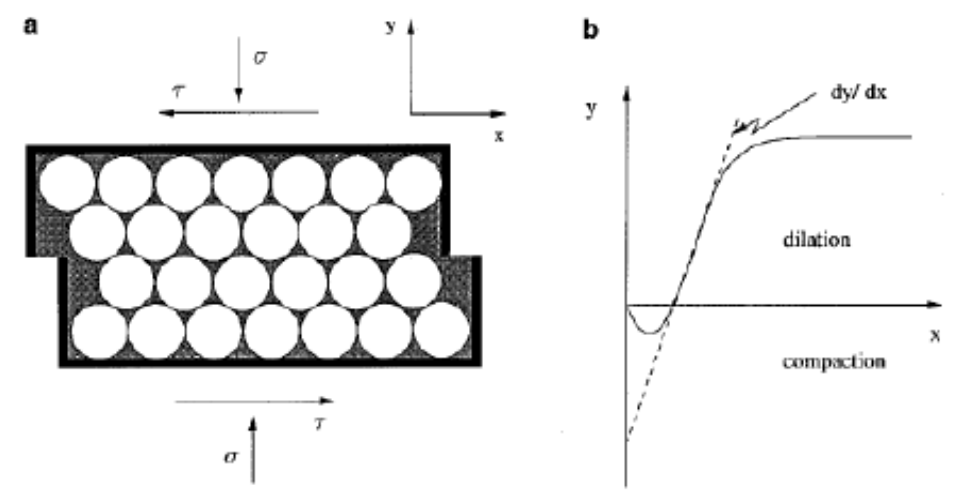

Figure (2.3) Taylor's shear box analogy

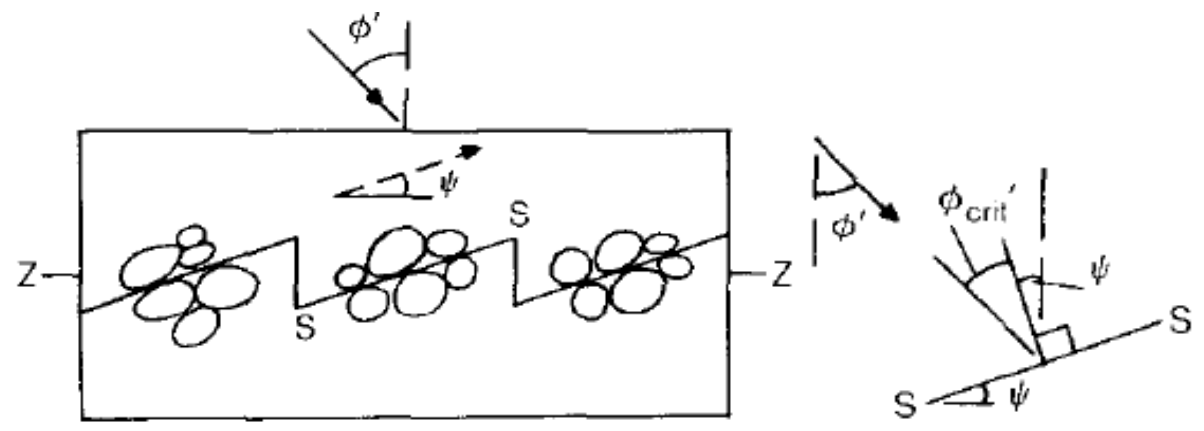

Figure (2.4) The saw blades model of dilatancy (Bolton, 1986)

The effect of soil suction on dilatancy of unsaturated soil was studied by $\mathrm{Ng}$ and Chiu (2003) by performing series of triaxial tests on unsaturated loose decomposed granitic soil. The variation of the dilatancy (presented as $\mathrm{d} \varepsilon_{\mathrm{v}} / \mathrm{d} \varepsilon_{\mathrm{p}}$ where $\mathrm{d} \varepsilon_{\mathrm{v}}$ is the volumetric strain increment, and $\mathrm{d} \varepsilon_{\mathrm{p}}$ is the shear strain increment) with matric suction is shown in Figure (2.5). For specimens tested under net mean stress higher than or equal to $100 \mathrm{kPa}$, the dilatancy reduces with the suction. Whereas for other specimens tested under low net mean stress (i.e., $25-50 \mathrm{kPa}$ ) the dilatancy increases with the suction.

$\mathrm{Ng}$ and Zhou (2005) presented the results of direct shear tests on two soils were presented. As shown in Figure (2.6) the maximum dilatancy $(\delta y / \delta x)_{\max }$ depends on matric suction for the compacted decomposed granite (DCG). The maximum dilatancy increases with matric suction and the relationship between the maximum dilatancy and the matric suction is highly nonlinear. For comparison, experimental data from unsaturated shear box on silt performed by Nishmura (2000) are also shown in Figure (2.6). On contrary to the results of (DCG), the maximum dilatancy of the silt decreases linearly with matric suction.

Zhan and $\mathrm{Ng}$ (2006) presented results of tests on unsaturated expansive clay using suction-controlled direct shear apparatus. The relationships between the applied matric suction with the maximum dilatancy $(\delta y / \delta x)_{\max }$ for both natural and recompacted 
specimens are shown in Figure (2.7). They concluded that the dilatancy of the expansive clay increases with increasing the applied matric suction. In addition they concluded that in the range of the applied suction $(0-200 \mathrm{kPa})$, the contribution of the suction to the dilatancy seemed to be independent of the specimen type.

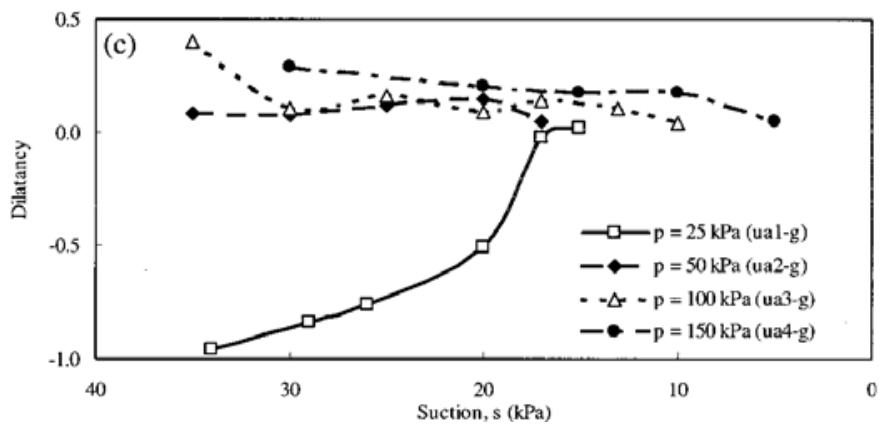

Figure (2.5) Matric suction versus dilatancy (Ng and Chiu, 2003)

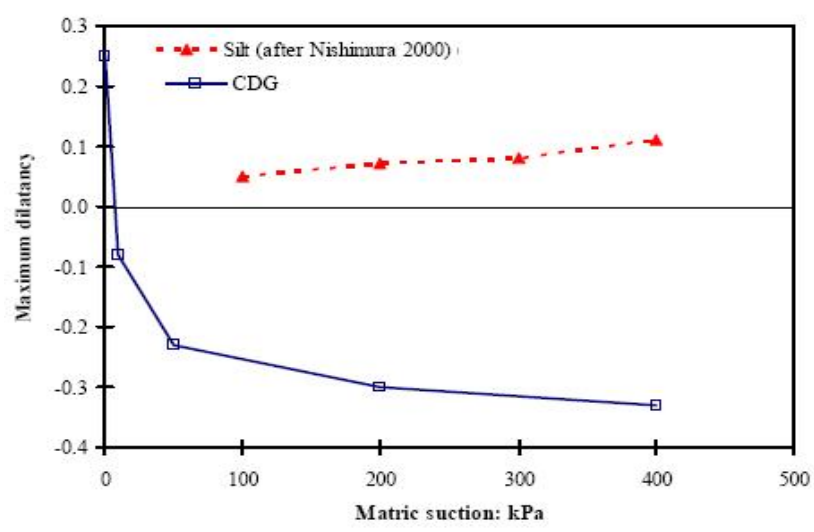

Figure (2.6) Matric suction versus maximum dilatancy (Ng and Zhou, 2005)

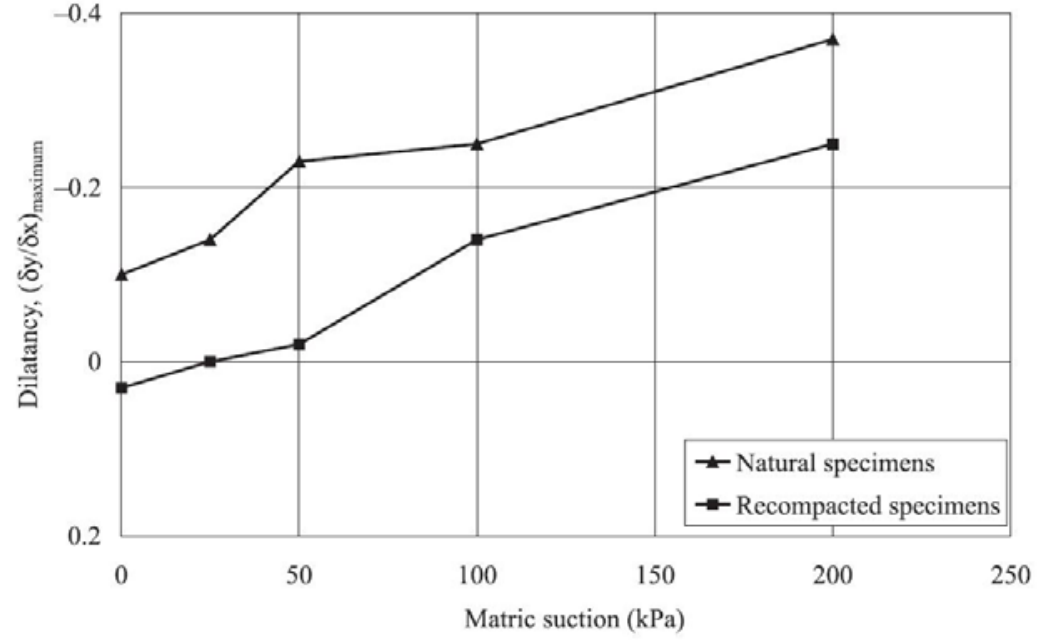

Figure (2.7) Variation of maximum dilatancy with suction for natural and recompacted expansive clay (Zahn and $\mathrm{Ng}, 2006$ ) 


\subsubsection{Laboratory measurement of volume changes in unsaturated soil}

In unsaturated soil testing the methods to measure the volume change of the soil specimen can be categorized as direct and indirect methods.

- The direct methods: (1) The local vertical and radial deformations of the specimen are measured using strain transducers attached to the specimen body. This method is more suitable to the case of relatively small strains. When the sample tends to deform into the barrel shape, the measurement of the change in the diameter of the specimen measured at one or two points may not be representative of the overall volume changes. (2) Noncontacting techniques such as lasers (Romero et al. 1997) and proximity transducers (Hird and Hajj, 1995). These methods allow more accurate measurements of the specimen volume. These techniques require costly and sophisticated installation procedures. (3) Direct air-volume and water-volume measurements can be performed and the soil volumetric changes are deduced by simple addition of the air and water volume changes. Small temperature and atmospheric pressure changes also affect volume measurement and must be taken into account. (4) Image processing (e.g., Gachet et al., 2003; Macari et al., 1997; Rifai et al., 2002; Laloui et al., 2006). As with lasers, direct contact with the specimen is not required, and the soil profile is measured over its entire height (Hoyos et al., 2008).

- The Indirect method: The volume change of the cell fluid is measured and considered to be equal to the volume change of the unsaturated soil specimen. This method is associated with several problems such as the immediate expansion of the cell, plexiglass creep, and possible water leakage. The double-wall cell is used to minimize the possible expansion of the cell. Several fluids were used such as mercury, paraffin, and water.

\subsubsection{Review of double-wall cells}

In Double-wall system, both the inner and outer cells are pressurized by the same pressure during the test. Theoretically, null expansion of the inner cell can be achieved. As a result, the volume change of the inner cell fluid measured during the test will be equal the volume change of the unsaturated soil specimen tested.

Several types of equipment were designed according to the double wall concept. The first double wall cell was presented by Bishop and Donald in 1961. In this doublewall cell the inner cell was opened and mercury was used as a cell fluid in the inner container whereas the outer cell was filled with water. The changes in the level of the mercury surface were observed by the movement of a stainless steel ball floating in the mercury. In double-wall cell with opened inner cell, the soil volume change can be 
deduced from the change the level of the inner cell fluid which can be monitored by a ball floater (Bishop and Donald 1961), a target float (Matyas and Radhakrishna 1968), or a thin layer of silicon oil if mercury is replaced by water (Cui and Delage, 1996). Differential pressure transducer was used to monitor the change in the level of the inner cell fluid (e.g., Rampino et al., 1999; Aversa and Nicotera, 2002; Ng et al., 2002; Cui et al., 2007).

Wheeler (1988) developed a double-wall cell in which the two cells were filled with water. Cui and Delage (1996) presented a cell similar to that presented by Bishop and Donald (1961) where colored water rather than mercury was used as inner cell fluid.

Yin (1998) proposed almost the same system of Donald and Bishop (1961), but with water (instead of the mercury) to fill the open-top cylindrical container, whereas the outer cell was filled with air. Later, Yin (2003) developed a double-wall triaxial cell using de-aired water to fill the inner and outer cell. $\mathrm{Ng}$ et al. (2002) proposed a double-wall cell but with an open-top bottle-shaped inner cylindrical container achieving more accurate reading in the changes of the water surface in the container.

Sivakumar (1993) increased the stiffness of the cell by reinforcing the cells with fiberglass bands. Sivakumar et al. (2002) presented a double-wall cell with an essential difference that the inner cell was made of the high quality glass eradicating the absorption of the water by the acrylic walls of the inner cell. Table (2.1) summarizes the double wall cells. It should be noted here that all proposed double-wall cells are triaxial cells. Figures (2.8) and (2.9) show double-wall systems proposed by Wheeler (1988) and $\mathrm{Ng}$ et al. (2002), respectively.

Table (2.1) Summary of the triaxial double wall cells

\begin{tabular}{ccc}
\hline Reference & Inner cell Fluid (C/O)* & Outer cell fluid \\
\hline Bishop \& Donald (1961) & Mercury (O) & Water \\
Wheeler (1986) & Water (C) & Water \\
Cui \& Delage (1996) & Colored water (O) & Water and air \\
Yin (1998) & Water (O) & Air \\
Geiser et al. (2000) & Water (O) & Water \\
Toyota et al. (2001) & Water, bottled shape (O) & Water and air \\
Sivakumar et al. (2002) & Water (C) & Water \\
Ng et al. (2002 ) & Water, bottled shape (O) & Water and air \\
Aversa \& Nicotera (2002) & Water, bottled shape (O) & Air \\
Leong et al. (2003) & Water (C) & Water
\end{tabular}

* Note: $\mathrm{C}$ and $\mathrm{O}$ refer to close or open inner cell, respectively. 


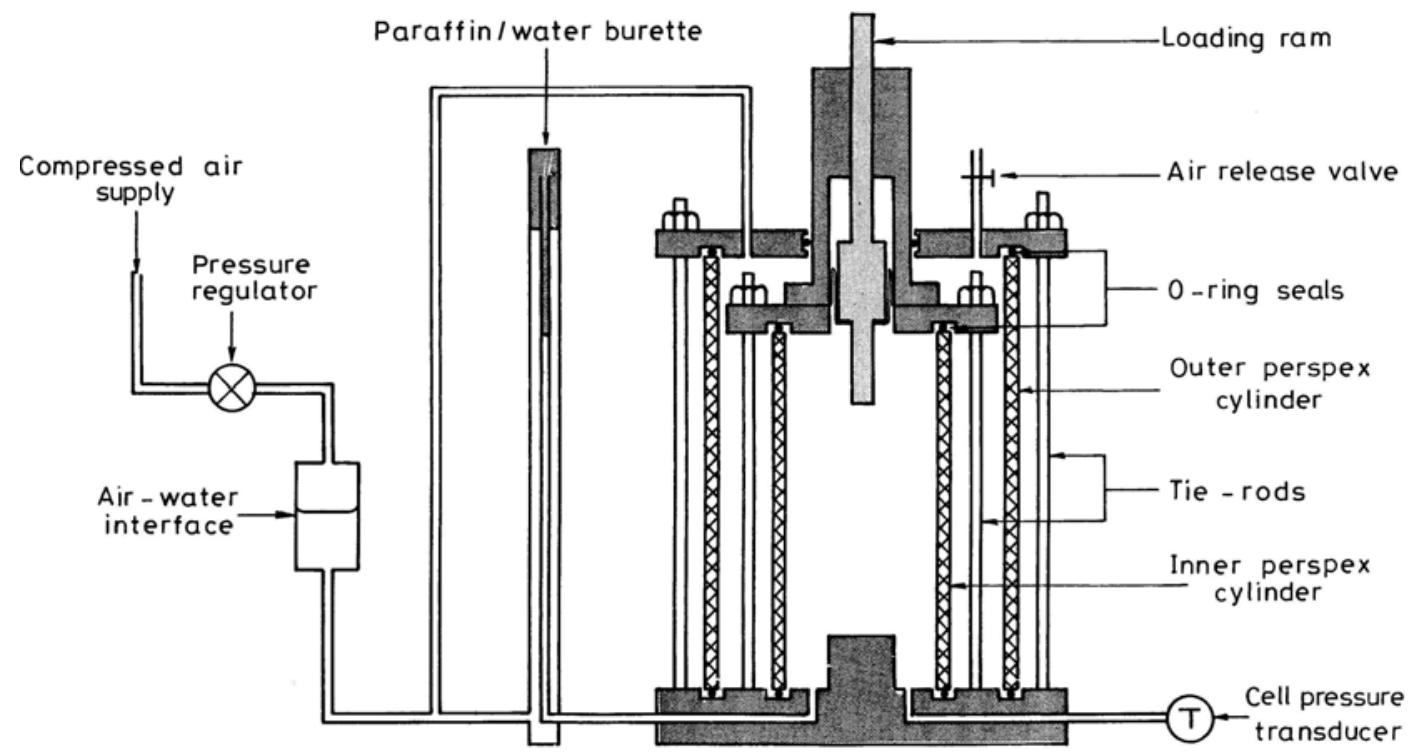

Figure (2.8) Double-wall triaxial cell (Wheeler, 1986)

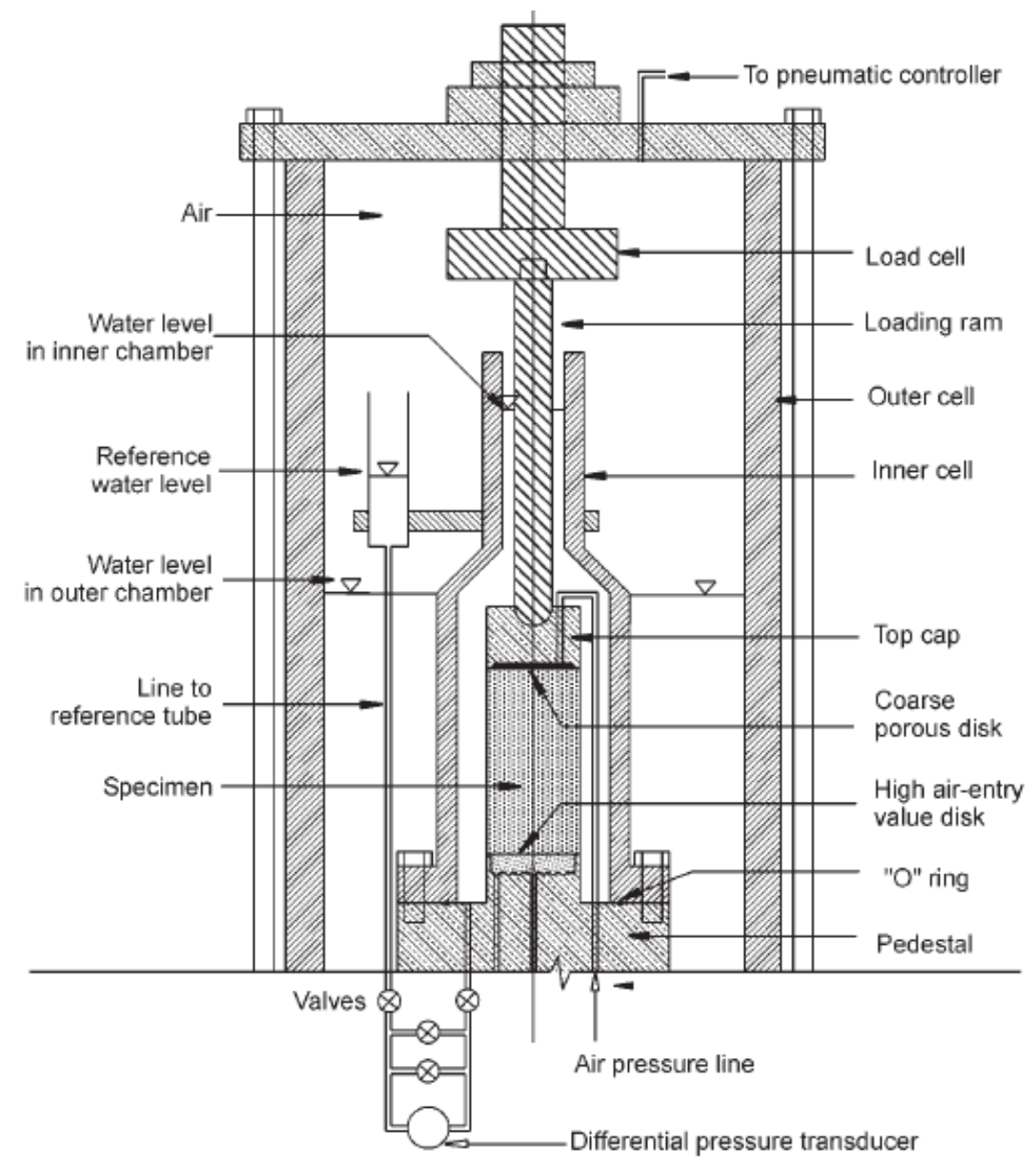

Figure (2.9) Double-wall triaxial cell (Ng et al., 2002) 


\subsection{Plane-strain state}

\subsubsection{Plane-strain concept in geotechnical engineering}

In several geotechnical field problems the deformation conditions and the geometry of the structure itself lead to consider the case as a plane-strain state. In the plane-strain state the deformation of the soil is considered to be, approximately, zero in one direction (i.e., the long dimension of the structure) and the soil is free to deform in the two other directions. Long retaining walls, strip foundations, embankments, and slopes are examples of the plane-strain state. Figures (2.10), (2.11), and (2.12) illustrate the plane-strain problems, stress and strains, and stress path for plan-strain state, respectively.

As shown in Figure (2.12), the plane-strain conditions which is accompanied with the $\varepsilon_{2}=0$, occur at Lode angle of $\theta=15-30^{\circ}$. For triaxial compression triaxial test and triaxial extension test, the lode angle is $0^{\circ}$ and $30^{\circ}$, respectively (Nakai et al., 1986, Nakai, 2007). Figures (2.13) and (2.14) illustrate the failure criterion in deviatoric plane and the stress path for plan-strain and triaxial tests, respectively.

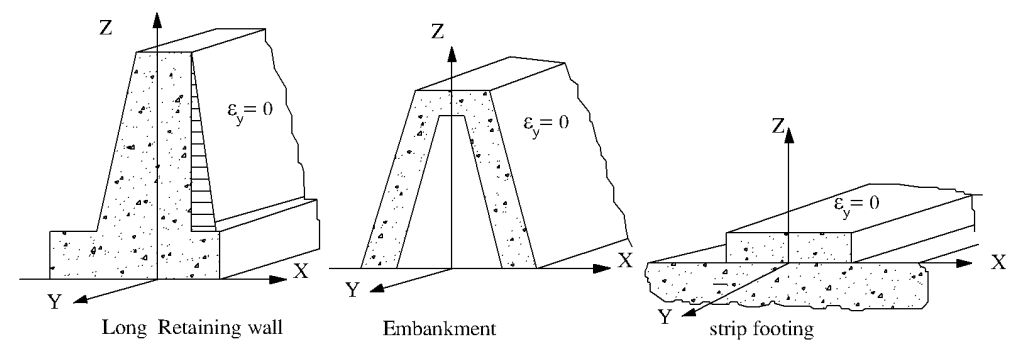

Figure (2.10) Plane-strain problems in geotechnical engineering

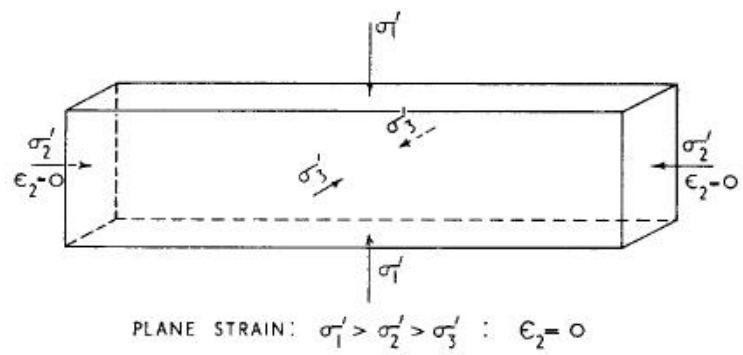

Figure (2.11) Plane-strain state: stresses and strains (Bishop, 1966)
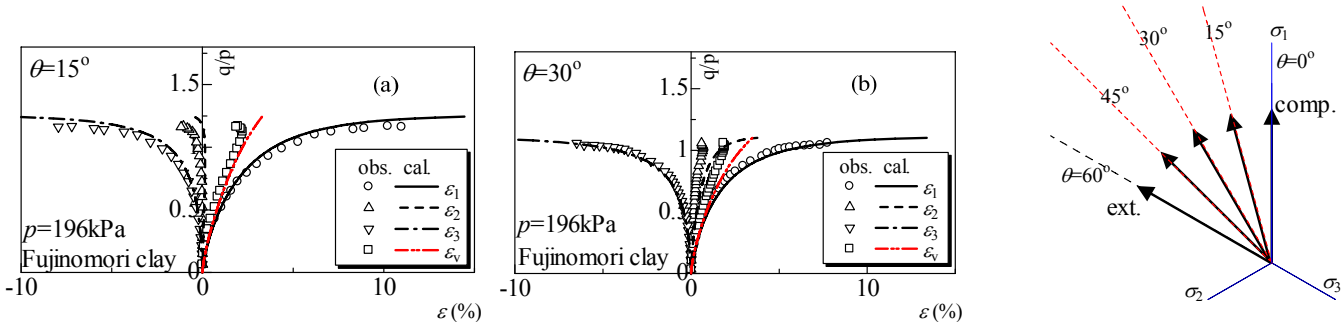

Figure (2.12) Stress path for different values of $\theta$ in true triaxial tests (Nakai, 2007) 


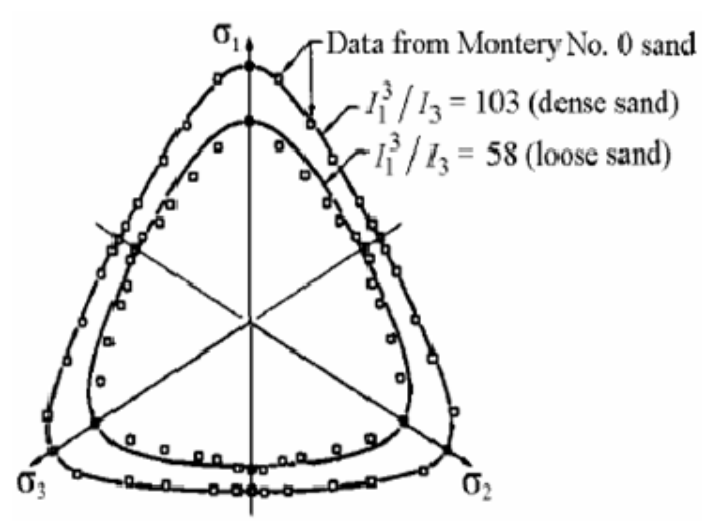

Figure (2.13) Failure criterion in deviatoric plane (Lade and Duncan, 1975)

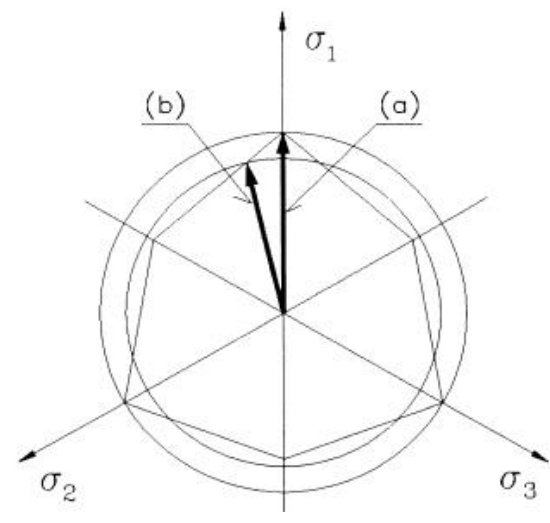

Figure (2.14) Stress path: (a) triaxial; (b) biaxial test (Sterpi, 2000)

In several geotechnical field problems the plane-strain data are more appropriate to applied than that obtained from triaxial test (Lo et al., 2000). In addition to the fact that the state of deformation in several field problems can be approximated closely to planestrain problem, strain localization problems in the field can be better understood by conducting laboratory tests using plane-strain apparatus (Wanatowski, 2005).

In 1961, Conforth reported that the traditional triaxial test may still to be the favorite test in the commercial laboratories of soil mechanics to determine the soil strength parameters. But, in some special areas of soil mechanics practice, a good knowledge of the plane-strain state is required and has several applications (Conforth, 1961).

The measured value of the intermediate stress in the case of plane-strain conditions is of interest. Also, in the applied researches, the conclusion and the design procedures will be more valuable to the profession if the soil parameters (which were used in the calculations) correspond with the actual strain conditions at the failure. Increasing the accuracy of the design will, in practice, reduce the project cost (e.g. construction of the earth dams).

The importance of using the soil strength under plane-strain conditions has been highlighted by several researches in stability analysis (Bishop, 1955; Little and Price, 1958), field measurement of the pore-water pressures (Penman, 1956; conference on Pore Pressure and Suction in Soils 1960), and shear strength and strain localization characteristics measurements (e.g., Cornforth, 1961; Bishop, 1966; Lee, 1970; Green, 1971; Marachi et al., 1981; Park and Tatsuoka, 1994, Sterpi, 2000; Hanna, 2001; Alshibli et al., 2004; Wanatowski, 2005). 
Using the shear strength parameter determined from the axisymmetric triaxial test results will in most cases lead to a conservative design (Ko and Davison, 1973). But in some other cases, the design may not be as conservative as commonly thought. It has been reported that the soils tested in the plane-strain state are highly susceptible to imperfections. This will lead to material instability or bifurcation, where sudden failure can occur much sooner than that observed in the triaxial tests (Lee, 1970; Marachi et al., 1981; and Peters et al., 1988).

Strength and deformation parameters of granular materials in plane-strain tests are different from those measured in triaxial tests. Dense homogeneous sand tested under plane-strain conditions has higher shear strength and smaller strain at failure compared to conventional triaxial test results (Lee, 1970; Marachi et al., 1981). The maximum angle of friction in triaxial test was $\phi_{t r}=41^{\circ}$ whereas for the same sand and the same porosity the angle of friction of $47^{\circ}$ was measured in biaxial test by Vardoulakis (1977).

Several researches (e.g. Cornforth, 1964; Rowe, 1969; Bolton, 1986; Schanz and Vermeer, 1996) have observed that a little or no difference is usually observed between the angle of the internal friction $\left(\phi_{\mathrm{p}}\right)$ in plane-strain and triaxial compression for very loose soils. The same observation is for the angle of internal friction at the critical state $\left(\phi_{\mathrm{cv}}\right)$. This implies that the Mohr-Coulomb hexagon is well suited for very loose soils and for critical state conditions (Georgiadis et al., 2004).

Arthur et al. (1977a) emphasized the importance of Coulomb's model. They stated that even after two hundreds years; the Coulomb's model (Coulomb, 1776) remains a fundamental tool for geotechnical engineers. After the discovery of thin rupture layers in landslides and foundation failures, Coulomb's model was revived and the oldest shearing apparatus (i.e., the shear box) remains useful because it induces a thin rupture layer within the soil specimen.

\subsubsection{Literature review of plane-strain devices}

\subsubsection{General}

In the last forty years several plane-strain devices were presented by research groups. A trial has been done here to review the plane-strain devices used by several research groups.

In the conventional compression triaxial test, the stress state in the specimen shows non-uniform behavior, and the vertical stress values at failure become unreliable. In the direct shear test the specimen has kinematical constraints and the specimen is 
specimen is forced to fail along a predetermined failure plane (Alshibli and Akbas, 2007). Saada and Townsend (1981) stated that in the simple shear devices used by Roscoe (1953) and Stroud (1971) the deformations were inhomogeneous and it was impossible to satisfy kinematical and statical boundary conditions.

In order to improve the testing conditions and increase the accuracy of the measured shear strength parameters, several biaxial devices have been developed. These devices were used mainly in the investigation of the shear strength, deformation characteristics, and shear banding of saturated or dry soils under plane-strain conditions.

The failure patterns of granular materials under plane-strain state are different from the failure patterns that can be observed in the triaxial test. Under plane-strain condition the specimens fail along a well-defined shear plane(s). But in the conventional axisymmetric triaxial compression test, either localized shear plane or bulging diffuse failure modes occurs depending on the confining pressure and the density of the soil specimen (Lee, 1970; Peters et al., 1988).

Peric et al. $(1990,1992)$ found, analytically, that the stress states and combination of stresses are the utmost important for the localization of deformations in homogenous materials. They reported also that the bifurcation instability can not occur in the hardening regime under ideal conventional triaxial compression for dilatant materials, whereas under plane-strain conditions the bifurcation instability can occur at nearly any stage of loading.

The biaxial shearing tests are more complicated to conduct than triaxial tests (Wanatowski and Chu, 2006).These difficulties are mainly related to the need for special mold, membrane, accessories, and the preparation of a prismatic soil specimen. The particular kinematic conditions imposed by the plane-strain apparatus permit the "spontaneous" development of shear bands, which is partially inhibited under axisymmetric (triaxial) conditions (Sterpi, 2000).

Most of the presented devices have some shortcomings. For instance, in the device presented by Topolnicki (1990) it is not possible to observe the formation of the shear bands due to the fact that the cell is completely sealed.

In other devices, the intermediate stress $\left(\sigma_{2}\right)$ can not be measured such as in the devices presented by Lee (1970); Desrues (1984); Drescher et al. (1990); Han and Vardoulakis (1991); and Alshibli et al. (2004). 
In other devices such as that proposed by Hanna (2001) and Conforth (1961), the intermediate stress $\left(\sigma_{2}\right)$ can be measured but it is not possible to observe the shear banding during the test. In the device proposed by Finno et al. $(1996,1997)$ and Wanatowski (2005), these two issues (i.e., the visibility of the shear band and ability of measuring the intermediate stress) were taken into account. Wanatowski (2005) used the measurements of the intermediate stress $\left(\sigma_{2}\right)$ to determine the onset of shear band.

The behavior of fine-grained sand in plane-strain conditions has been studied intensively by several researchers (e.g., Desrues, 1984; Hammad, 1991; Mokni, 1992; Han and Vardoulakis, 1991; Han and Drescher; 1993; and Mochizuki et al., 1993).

The behavior of clay in plane-strain conditions has been studied by several researchers such as Hambly (1972), Drescher et al. (1990), Finno and Rhee (1993), Lo et al. (2000), and Fauziah and Nikraz (2007).

\subsubsection{Literature review of plane-strain devices for saturated and dry soil testing}

An early plane-strain apparatus was designed at Imperial College, London. The details of this apparatus have been presented by Wood (1958). A photograph of the device and the specimen at the end of the test are shown in Figure (2.15). In this planestrain device, the intermediate stress (i.e., $\sigma_{2}$ ) was measured using the null technique similar to that used in measuring the pore-water pressure within soil specimen. Silicon grease was used in-between the membrane and the metal plates. This arrangement reduced the coefficient of friction to the value of 0.02. Later, the Imperial College apparatus was used in subsequent studies (e.g., Conforth, 1961; Wade, 1963; Conforth, 1961, 1964).

Duncan (1966) developed a plane-strain apparatus to test clayey specimens in plane-strain conditions. Later, Lee (1970) used this plane-strain apparatus to test circular and rectangular specimens of Antioch sand.

Hambly (1969) studied the plane-strain behavior of the clay using a biaxial apparatus at the University of Cambridge. Detailed description of the biaxial apparatus was presented by Hambly and Roscoe (1969). Later, Hambly (1972) presented a series of biaxial tests on remolded normally consolidated Kaolin. The biaxial apparatus can accommodate samples in the form of rectangular prisms of up to $13.5 \mathrm{~cm} \times 13.5 \mathrm{~cm} \times 5$ $\mathrm{cm}$ between six rigid platens. 


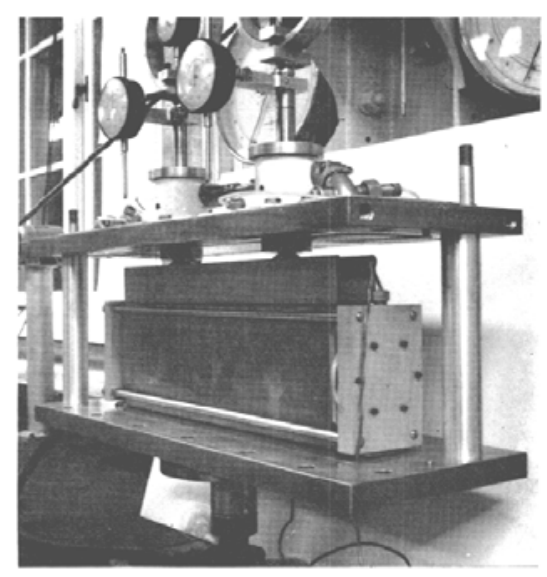

(a)

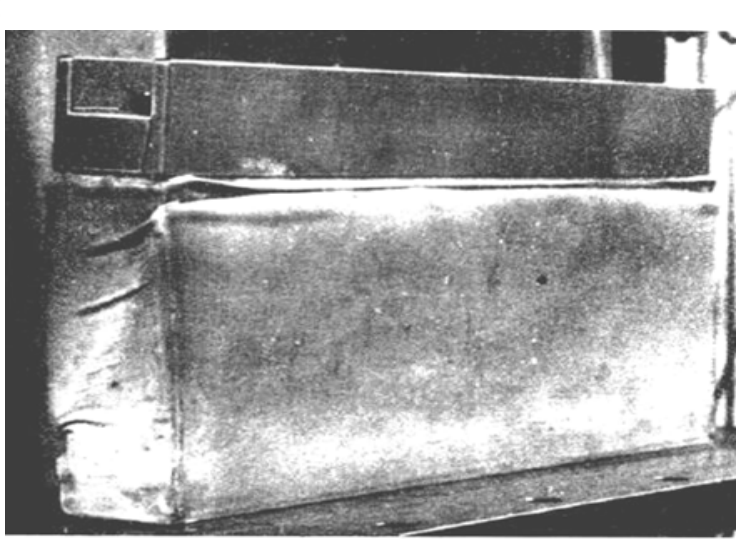

(b)

Figure (2.15) Imperial college plane-strain apparatus: (a) loading system; (b) specimen at the end of the test (specimen is $508 \mathrm{~mm}$ long, $406 \mathrm{~mm}$ high, and $101 \mathrm{~mm}$ thick)

(Wood, 1958; Conforth, 1961)

Barden et al. (1969) used a plane-strain device to study the stress dilatancy behavior in sand. Cubical samples of sand have been tests under plane-strain conditions. In this version of plane-strain device the intermediate stress was not measured. Later in the consequent modifications a load cell was provided to measure the intermediate stress.

Arthur et al. (1977a) presented the results of a series of tests on sand under different experimental conditions. The aim of the work was to define a new failure criterion of granular material. Shear bands orientation was also monitored. In this study three different apparatuses were used in this study: the improved shear apparatus (DSA), Cambridge simple shear apparatus, and London flexible plane-strain apparatus (FPSA).

Vardoulakis (1977) outlined a theoretical and experimental analysis of the spontaneous shear band formation in the biaxial tests on sand specimens. The biaxial apparatus was built depending on some experiences with similar apparatus in the University of Karlsruhe, Germany. Figure (2.16) shows the first biaxial apparatus used by Vardoulakis (1977) and Vardoulakis et al. (1978).

In the tests conducted by Vardoulakis (1978) the dimensions of the sample were: $33 \times 80 \times 140 \mathrm{~mm}$. The deformation was restricted along the long direction of the cross section of the specimen. Vardoulakis and Goldscheider (1981) and Vardoulakis and Graf (1985) modified the original biaxial apparatus by using a submersible load cell. In addition, lateral displacements were measured in two opposite points of the faces of the specimen. Drescher et al. (1990) improved the biaxial apparatus designed by Vardoulakis and Goldscheider (1981) by adding a linear bearing platform allowing the free lateral displacement of the lower part of the specimen. 


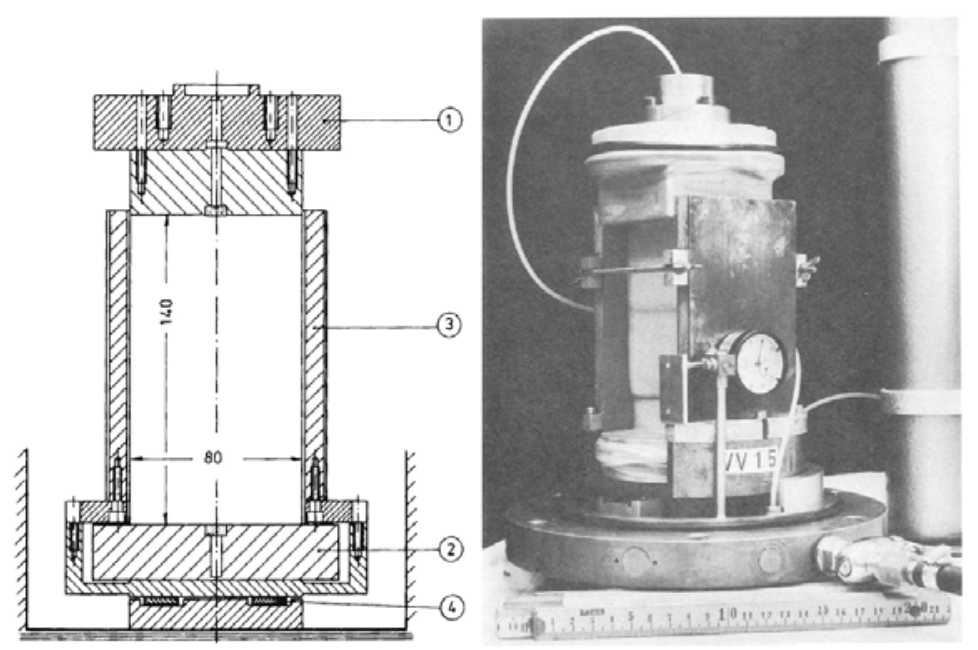

Figure (2.16) Schematic diagram and specimen arrangement of the biaxial apparatus (Vardoulakis, 1977; Vardoulakis et al., 1978)

Han and Vardoulakis (1991) presented the results of drained and undrained biaxial compression tests on saturated sand, focusing on the various soil failure phenomena were observed in the tests. A patterned failure mode was illustrated by X-ray radiographs. In this biaxial apparatus, the load was measured using load cells at the top and the bottom of the specimen.

Marachi et al. (1981) performed a series of plane-strain tests on Monterey sand of different sizes of specimens.

Finno and Rhee (1993) and Viggiani et al. (1993) used a plane-strain device for evaluating the effects of shear banding on the behavior of soft Chicago glacial clays and stiff Vallericca clay, respectively. Harris (1994) used the same plane-strain device in studying the localization in loose granular soils and its effect on the undrained strength. Harris at al. (1995), in order to record a full field planar deformation, modified the device presented by Vardoulakis and Drescher (1988). This device has been also used by Finno et al. $(1996,1997)$.

Finno et al. $(1996,1997)$ presented experimental study on the behavior of loose, fine grained, saturated sand under undrained conditions in a plane-strain apparatus at Northwestern University. This device is similar to that developed by Drescher et al. (1990). Together with the local measurements of the boundary forces and deformations, the stereophotogrammetry is used to track the progressive localization of strains.

It can be said that the plane-strain device presented initially by Vardoulakis in 1977 formed an important basic design of several other subsequent plane-strain devices which were used by Vardoulakis' co-workers or other research groups (e.g., Vardoulakis 
and Graf, 1985; Vardoulakis and Drescher, 1988; Han and Vardoulakis, 1991; Finno and Rhee, 1993; Viggiani et al., 1993, Harris, 1994; Harris at al., 1995; Finno et al., 1996, 1997; Mooney et al., 1997, Sterpi, 2000; Finno and Rechenmacher, 2003).

Oda et al. (1978) investigated the anisotropic shear strength of sand in a planestrain device. The anisotropic parallel alignment of particles effects the shear strength of sand and the changes in the shear strength can be more clearly observed in the planestrain test $\left(\varepsilon_{2}=0\right)$ than in symmetric stress condition. In this plane-strain device, the four rigid platens were polished and lubricated using two greased rubber membrane to provide frictionless sliding surfaces. The specimen was $60 \mathrm{~mm}$ high, $80 \mathrm{~mm}$ long, and $44 \mathrm{~mm}$ wide. The intermediate principle stress $\left(\sigma_{2}\right)$ was controlled by null techniques similar to that used in measuring pore-water pressure (cf. Wood, 1958; Conforth, 1961).

The specimen was prepared by filling the former with the dry sand, soaked very slowly into the water, and was then frozen. The cell pressure $\left(\sigma_{3}\right)$ was applied to hold the specimen while it was allowed to thaw. In the mean time the intermediate stress $\left(\sigma_{2}\right)$ was increased simultaneously with cell pressure and it was about $3 \%$ greater than cell pressure to insure a tight contact between the specimen and the two side platens. Figure (2.17) shows the plane-strain specimen and the preparation method of the specimen with an angle $(\delta)$ in the plane-strain tests.

Freezing method was used in this study and other studies (e.g., Oda et al., 1978) for the following two reasons: firstly, it is difficult with conventional circular crosssection membrane to achieve good contact between the membrane and the inner surface of the mould by vacuuming the space between them. Secondly, preparation of samples with $\delta$ rather than $90^{\circ}$ cannot be made using the normal dry air-pluviation method.

Park and Tatsuoka (1994), using an improved version of the plane-strain apparatus that has been used by Tatsuoka et al. (1986), studied the anisotropic and deformation of six types of sand. In this study relatively large specimens were prepared. The specimen's height was $200 \mathrm{~mm}$, and the cross section of the specimen was $180 \mathrm{x} 80$ $\mathrm{mm}^{2}$. Yoshida et al. $(1993,1995)$ studied the shear banding phenomenon in eight types of sands using this plane-strain apparatus. Specimen's height was $20 \mathrm{~cm}$ and the cross section was $160 \times 80 \mathrm{~mm}^{2}$ ( $80 \mathrm{~mm}$ in the direction of the minor principle stress $\sigma_{3}$ ).

Yasin et al. (1999) used the plane-strain compression (PSC) apparatus presented by Tatsuoka and Park (1994). In the (PSC) apparatus, the boundaries of $\sigma_{1}$ and $\sigma_{2}$ are rigid and lubricated whereas the boundary of $\sigma_{3}$ is flexible. 


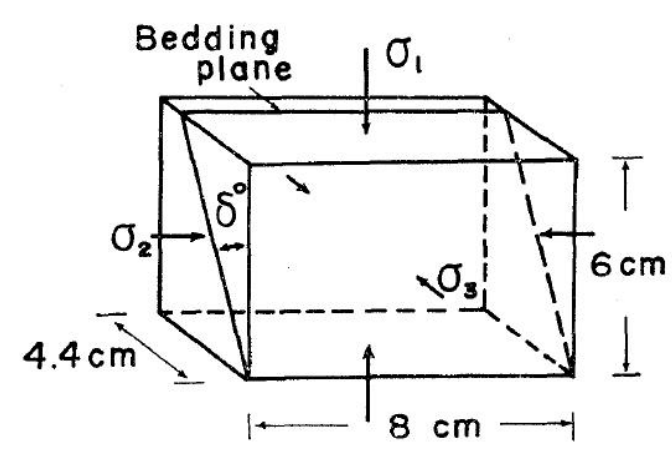

(a)

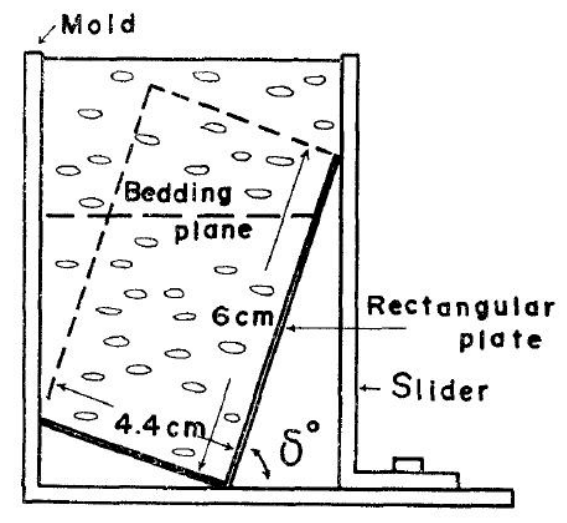

(b)

Figure (2.17) The plane-strain specimen (a) geometry and test conditions; (b) the method adopted to prepare a specimen with a tilting angle $(\delta)$ (Oda et al., 1978)

Masuda et al. (1999) modified the plane-strain apparatus presented by Park and Tatsuoka (1994). The modifications have been done essentially to conduct tests under plane-strain extension, cyclic, and compression conditions. In the plane-strain extension conditions the lateral confining pressure (the major principle stress $\sigma_{1}$ ) is larger than the vertical stress (the minor principle stress $\sigma_{3}$ ), and the intermediate stress $\left(\sigma_{2}\right)$ becomes larger than the vertical stress. This stress state cannot be achieved with conventional plane-strain apparatus, as only compressive stresses can be applied between the specimen and the lateral confining platens. It should be noted here that the plane-strain extension tests have been done previously by Duncan and Seed (1966) using a method similar to that used by Masuda et al. (1999).

Shaw (1980) presented a biaxial apparatus developed originally at the British Rail Technical Center to study the behavior of granular materials under three dimensional stress system. Show and Brown (1988) modified the original biaxial apparatus to study the behavior of granular materials under repeated load. The top and the bottom loading rams were replaced with a fixed platen containing a load cell. This modification was done to impose the plane-strain condition in the vertical direction.

Desrues (1984) presented a new plane-strain apparatus at the laboratory 3S/IMG, Grenoble, France. This biaxial apparatus was improved later in subsequent works (e.g., Hammad, 1991; Mokni, 1992; Tillard, 1992). In the original biaxial apparatus the tests were performed under low confining pressure, using vacuum inside the specimen and atmospheric pressure outside. The tests have been performed on dry specimens of Hostun sand. This device has been significantly improved by Hammad (1991) and Mokni (1992) with respect to the method of applying the cell pressure. In addition, the volume changes system and the pore-water pressure measurement system were also improved allowing 
continuous and more accurate volume change measurements throughout the tests on saturated sand in drained conditions (Hammad, 1991) and undrained conditions (Mokni, 1992). The improved version of Grenoble's biaxial apparatus was used later by Tillard (1992), Mokni and Desrues (1999), and Desrues and Viggiani (2004). Mokni and Desrues (1999) used this biaxial device to test Hostun sand in plane-strain state under undrained conditions. The specimen was 335 x 103 x $35 \mathrm{~mm}$. High slenderness ratio of 3.3 was chosen to allow the free development of shear planes away from the end platens.

It should be noted here that in the Grenoble's biaxial device, the deformation is restricted $\left(\varepsilon_{2}=0\right)$ along the short dimension of the cross section of the specimen. Whereas in the biaxial device used in this and other biaxial devices (e.g., Conforth, 1961; Vardoulakis, 1978; Oda et al., 1978; Park and Ttasuoka, 1994; Sterpi, 2000; Hanna, 2001; Alshibli, 2004) the deformation is restricted along the long dimension of the cross section of the specimen. Just in two other devices (i.e., Lo et al., 2000; and Fauziah and Nikraz, 2007, 2008), the deformation of the specimen was restricted along the small dimension of the cross section of specimen. Certainly, the work done in Grenoble is a comprehensive research and it needs more discussion in detail. However, this is beyond the scope of this thesis. Figure (2.18) shows the plane-strain apparatus developed in Grenoble by Desrues and Hammad (1991).

Allersma (1993) developed a new biaxial apparatus at the Delft University of Technology to investigate the long term behavior of clay under different loading paths. The biaxial apparatus presented by Allersma (1993) has been used later in several researches such as Bizzarri et al. (1995), Bizzarri and Allersma (1998, 2003), and Hayashi and Allersma (2004).

Topolnicki et al. (1990) investigated the stress-strain behavior of saturated, remolded clay in a cubical plane-strain apparatus. Both normally consolidated and overconsolidated samples were investigated. The biaxial apparatus used in this investigation was designed originally by Kuntsche (1982).

Sterpi (2000) investigated the influence of the laboratory testing conditions on the mechanical characterization of sand. Standard triaxial and plane-strain compression tests have been done using a new plane-strain apparatus derived from the original device designed by Vardoulakis and Drescher (1988). This device is capable of measuring the lateral displacements and the intermediate stress. 

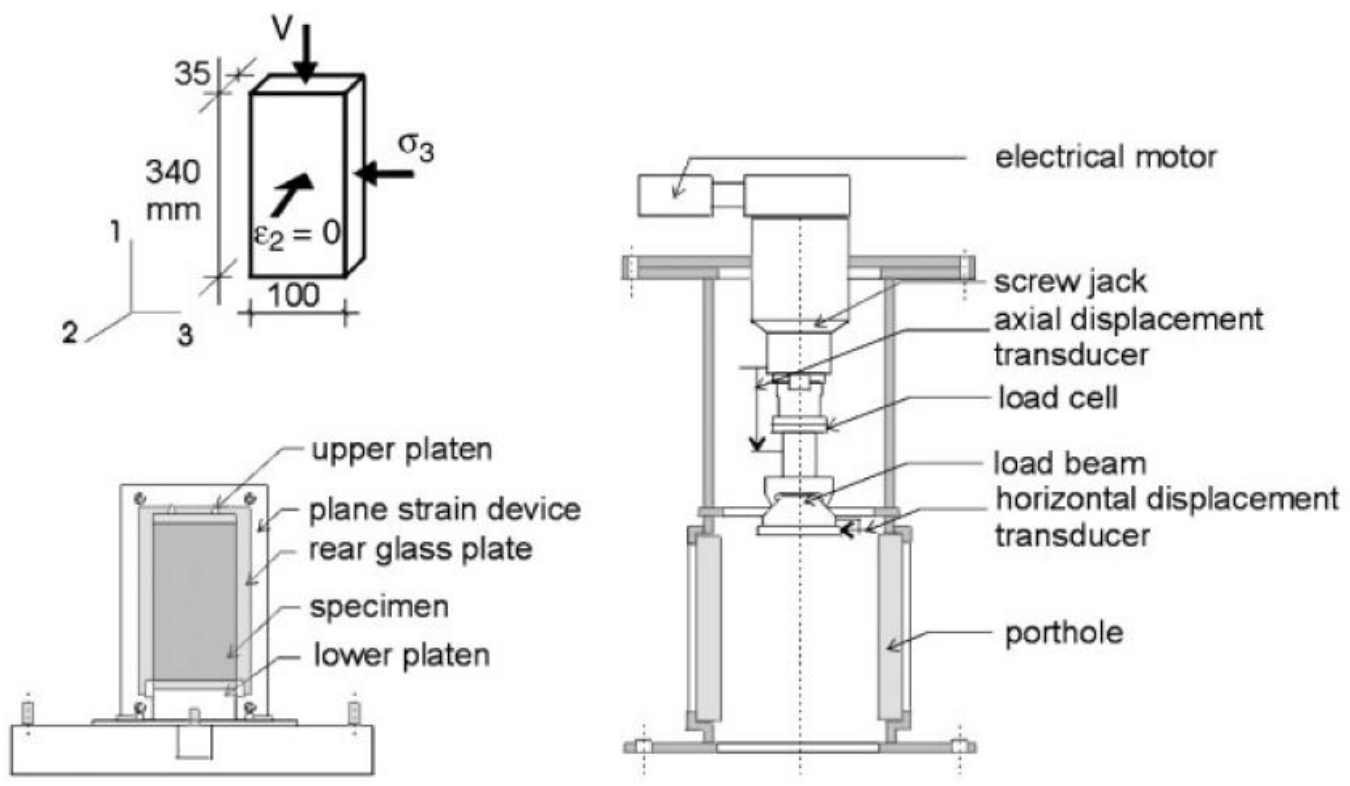

Figure (2.18) The plane-strain apparatus (Desrues and Hammad, 1989)

Lo et al. (2000) developed a biaxial device to study the strain softening and failure characteristics of overconsolidated clay. The tests were performed on remolded kaolin specimens under drained and undrained conditions. Hanna (2001) carried out an experimental investigation of the shear strength of dry sands using triaxial and planestrain apparatus.

Alshibli and Sture (2000) tested three types of sand under plane-strain conditions using a new plane-strain device. The tests were performed to investigate the effect of the confining pressure, density, and grain size on the constitutive and instability behavior of granular material. The deformation of the specimen was recorded using a video camera. In this device, the end platen is restrained against rotation and lateral movements.

Later, Alshibli et al. (2004) presented an improved version of the plane-strain device used previously. The design of the Louisiana plane-strain apparatus (LA-PSA) took into consideration the geometry configuration for optical measurements and instrumentation, tracking of the development of shear band, and the flexibility in altering boundary conditions. The (LA-PSA) is provided with a lateral displacement track assembly to enable free development and propagation of the shear band.

Wanatowski (2005) studied the strain softening and instability of sand under plane-strain conditions using plane-strain apparatus developed at Nanyang Technological University. The test setup in this device is shown in Figure (2.19). The free end technique, described by Rowe and Barden (1964), was used to reduce the boundary 
friction. Using this device, Wanatowski and Chu (2007, 2007a) studied the coefficient of the lateral earth pressure at rest and the static liquefaction of sand under plane-strain state. Table (2.2) presents a summary of plane-strain devices presented by several research groups.

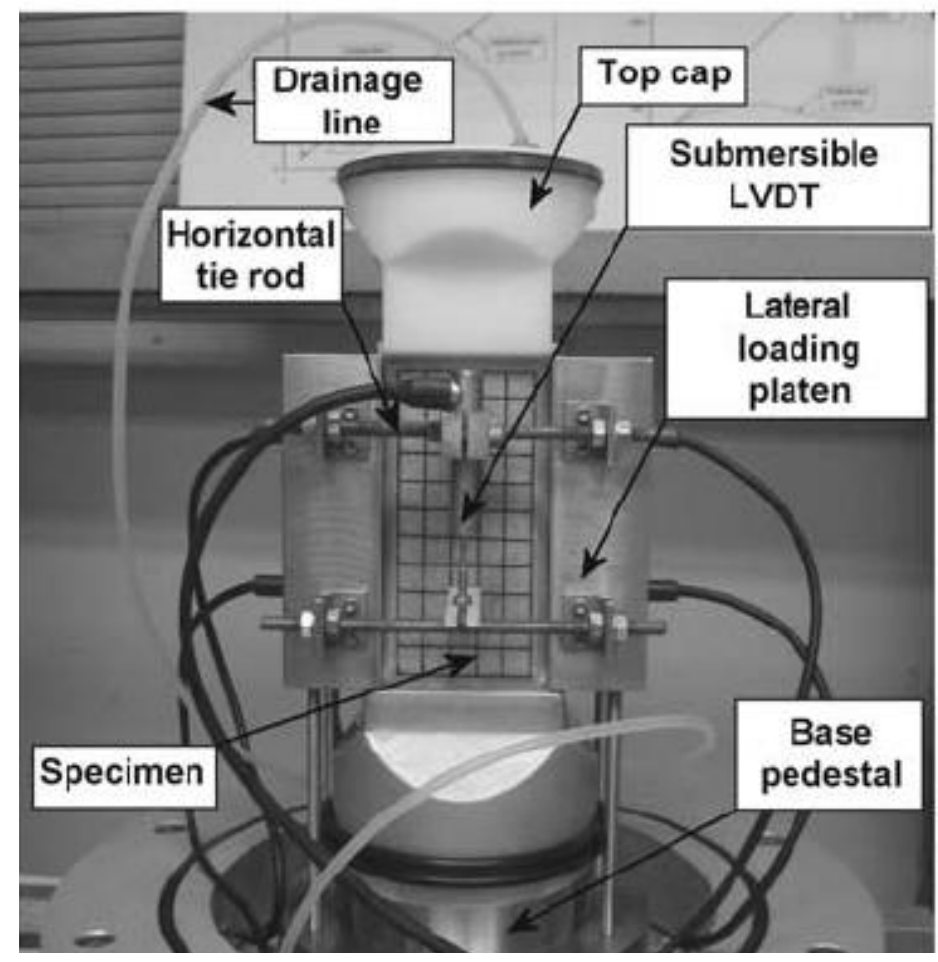

Figure (2.19) The plane-strain apparatus (Wanatowski, 2005) 
Table (2.2) Summary of plane-strain devices

\begin{tabular}{|c|c|c|c|c|c|}
\hline Reference & $\begin{array}{l}\text { Research group, } \\
\text { location }\end{array}$ & $\begin{array}{c}\sigma_{2} \\
\text { Measurement }\end{array}$ & $\begin{array}{l}\text { Specimen }(\mathrm{mm}) \\
\mathrm{H} \times \mathrm{B} \times \mathrm{T}^{\mathrm{a}}\end{array}$ & $\begin{array}{l}\text { Movement of } \\
\text { Bottom end } \\
\text { platen }\end{array}$ & Remarks \\
\hline $\begin{array}{l}\text { Wood (1958) } \\
\text { Conforth (1961) }\end{array}$ & $\begin{array}{l}\text { Imperial college, } \\
\text { London, UK }\end{array}$ & Yes & $102 \times 51 \times 406$ & No & $\begin{array}{l}\text { Null technique was used to } \\
\text { measure } \sigma_{2}\end{array}$ \\
\hline $\begin{array}{l}\text { Leussink and Wittke } \\
\qquad(1963)\end{array}$ & $\begin{array}{l}\text { Uni. of Karlsruhe, } \\
\text { Germany }\end{array}$ & Yes & $600 \times 1000 \times 200$ & No & Large scale model testing \\
\hline $\begin{array}{l}\text { Duncan and Seed (1966) } \\
\text { Lee (1970) }\end{array}$ & $\begin{array}{l}\text { Uni. of California, } \\
\text { Berkely, USA }\end{array}$ & No & $\begin{array}{l}71 \times 71 \times 28 \\
61 \times 71 \times 28 \\
\end{array}$ & No & \\
\hline Campanella and vaid & $\begin{array}{c}\text { Uni. of British } \\
\text { Columbia, Canada }\end{array}$ & Yes & $57 \times 25 \times 100$ & No & \\
\hline Hambly $(1969,1972)$ & Uni. of Cambridge, UK & Yes & $\begin{array}{c}50 \times 70- \\
130 \times 50 \times 70-130 \\
\end{array}$ & No & \\
\hline Arthur et al. (1977) & $\begin{array}{l}\text { Uni. College, London, } \\
\text { UK }\end{array}$ & Yes & $100 \times 100 \times 100$ & - & $\begin{array}{l}\text { Cubic sample, top and } \\
\text { bottom platen are fixed }\end{array}$ \\
\hline Vardoulakis et al. (1978) & $\begin{array}{l}\text { Uni. of Karlsruhe, } \\
\text { Germany }\end{array}$ & No & $140 \times 80 \times 34$ & Yes & $\begin{array}{c}\text { Cell pressure is imposed by } \\
\text { air }\end{array}$ \\
\hline $\begin{array}{l}\text { Desrues (1984) } \\
\text { Hammad (1991) } \\
\text { Mokni (1992) }\end{array}$ & $\begin{array}{c}\text { Laboratorie 3S-IMG, } \\
\text { Grenoble, France }\end{array}$ & No & $\begin{array}{l}100 \times 100 \times 100 \\
340 \times 175 \times 35\end{array}$ & Yes & $\begin{array}{l}\text { White transparent paraffin } \\
\text { oil is used as a cell fluid }\end{array}$ \\
\hline Drescher et al. (1990) & $\begin{array}{l}\text { Uni. of Minnesota, } \\
\text { USA }\end{array}$ & No & $140 \times 40 \times 80$ & Yes & \\
\hline Finno et al. (1997) & $\begin{array}{c}\text { Northwestern Uni., } \\
\text { USA }\end{array}$ & Yes & $140 \times 40 \times 80$ & Yes & $\begin{array}{c}\text { Modification of Drescher et } \\
\text { al. (1990) }\end{array}$ \\
\hline
\end{tabular}


Table (2.2) (Continued)

\begin{tabular}{|c|c|c|c|c|c|}
\hline Reference & Research group, location & $\begin{array}{c}\sigma_{2} \\
\text { Measurement }\end{array}$ & $\begin{array}{l}\text { Specimen }(\mathrm{mm}) \\
\mathrm{H} \times \mathrm{B} \times \mathrm{T}^{\mathrm{a}}\end{array}$ & $\begin{array}{c}\text { Movement of } \\
\text { Bottom end } \\
\text { platen }\end{array}$ & Remarks \\
\hline $\begin{array}{c}\text { Tatsuoka et al. (1986, } \\
\text { 1994) } \\
\text { Yasin et al. (1999) }\end{array}$ & Uni. of Tokyo, Japan & Yes & $\begin{array}{c}105 \times 80 \times 40 \\
140 \times 160 \times 80^{b}\end{array}$ & Yes & $\begin{array}{l}\text { Axial strain measured by } \\
\text { proximity transducers }\end{array}$ \\
\hline Topolonicki et al. (1990) & $\begin{array}{l}\text { Uni. of Karlsruhe, } \\
\text { Germany }\end{array}$ & No & $\begin{array}{l}45-133 \times 45- \\
133 \times 50\end{array}$ & Yes & $\begin{array}{l}\text { Modification of the } \\
\text { apparatus of Hambly (1969) }\end{array}$ \\
\hline Lo et al. (2000) & $\begin{array}{l}\text { National University of } \\
\text { Singapore, Singapore }\end{array}$ & No & $120 \times 40 \times 120$ & No & \\
\hline Sterpi (2000) & $\begin{array}{l}\text { Technical Uni. of Milan, } \\
\text { Italy }\end{array}$ & Yes & $140 \times 40 \times 80$ & Yes & $\begin{array}{l}\text { lateral displacements are } \\
\text { used to observe shear band } \\
\text { onset }\end{array}$ \\
\hline Hanna (2001) & Concordia Uni., Canada & Yes & $75 \times 38 \times 92$ & No & \\
\hline Alshibli et al. (2004) & $\begin{array}{c}\text { Louisiana state Uni., } \\
\text { USA }\end{array}$ & No & $180 \times 120 \times 60$ & Yes & $\begin{array}{c}\text { lateral displacements are } \\
\text { used to observe shear band } \\
\text { onset }\end{array}$ \\
\hline Wanatowski (2005) & $\begin{array}{c}\text { Nanyang } \\
\text { Technological Uni., } \\
\text { Singapore }\end{array}$ & Yes & $180 \times 60 \times 60$ & Yes & $\begin{array}{c}\sigma_{2} \text { measurements are used to } \\
\text { observe shear band onset }\end{array}$ \\
\hline $\begin{array}{l}\text { Nikraz and Fauziaha } \\
(2008)\end{array}$ & $\begin{array}{c}\text { Curtin Uni. of } \\
\text { Technology, Australia }\end{array}$ & No & $72 \times 72 \times 36$ & No & $\begin{array}{l}\text { Capable of Testing } \\
\text { unsaturated clay }\end{array}$ \\
\hline
\end{tabular}

( $\left.{ }^{a}\right)$ The distance between the immovable platen used to impose the plane-strain state.

(b) Apparatus can accommodate a size range. 


\subsubsection{Literature review of plane-strain devices for unsaturated soil testing}

As known to the author, just one device of the proposed devices is capable of testing unsaturated soils. Fauziah and Nikraz (2007, 2007a) studied the behavior of overconsolidated clay under plane-strain condition using a new developed biaxial apparatus. Later, Fauziah and Nikraz (2008) presented tests under plane-strain conditions of unsaturated compacted clay. The biaxial apparatus was equipped with high air-entry value discs at the interface between the unsaturated soil specimen and the pore-water pressure measuring system. The specimen is $72 \mathrm{~mm}$ high and the cross section of the specimen is $72 \times 36 \mathrm{~mm}^{2}$. The specimen is restricted laterally by two rigid Perspex plates $36.7 \mathrm{~mm}$ apart. In this device, the axial load is measured by a submersible load cell. The axial displacements of the specimen are measured by an external transducer (LVDT). Laser sensors were used to monitor the volume change of the soil skeleton. Figure (2.20) shows a photograph of the specimen and a schematic diagram of the biaxial device.

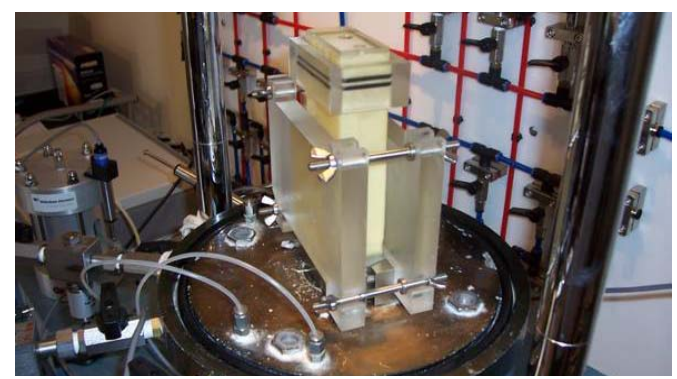

(a)

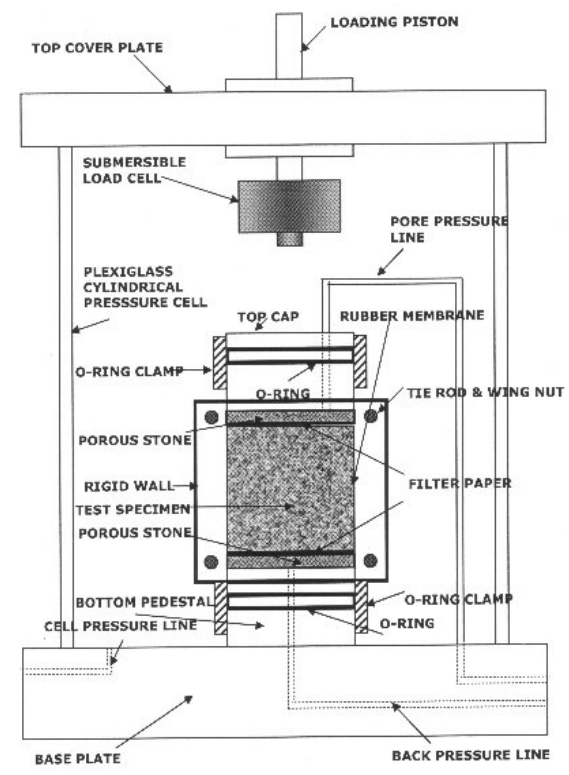

(b)

Figure (2.20) Biaxial device: (a) specimen; (b) schematic diagram (Fauziah and Nikraz, 2008) 


\subsubsection{Literature review of plane-strain results}

Huge amount of plane-strain results are available in the literature. A trial is made here to present some results of plane-strain tests. In the following sections, the results concerning the shear strength and strain localization (shear banding) will be presented.

\subsubsection{Literature review of plane-strain results concerning shear strength}

Conforth (1961) presented a comparison of the failure characteristics of the planestrain and triaxial compression tests in which the cell pressure was kept constant as shown in Figure (2.21). He concluded that the measured drained shear strength under planestrain conditions is always higher than in the triaxial tests, and that the triaxial specimens have a greater positive volume change (dilation) at failure. The volume change curves in the triaxial and plane-strain tests tend to converge at the looser densities. In addition, the axial strain at failure in the triaxial test is almost three times higher than that in planestrain tests for the same density.

Lee (1970) performed a series of plane-strain and triaxial tests on sand in both drained and undrained conditions. He reported that the specimen under plane-strain conditions reaches a higher value of maximum principal stress ratio than that in triaxial compression test. This difference decreases as the density decreases. His results showed that the plane-strain specimens fail at smaller axial strain compared to triaxial test specimens. He concluded that for dense specimens the difference between the plane-strain and triaxial compression tests is the greatest for low confining pressure, and the difference decreases as the confining pressure increases.

The importance of using side walls to attain the plane-strain conditions was also studied by Lee (1970) by testing three specimens, cylindrical, rectangular, and rectangular with side plates. He confirmed the importance of using the side plates to impose the plane-strain conditions. He presented the variations of the initial tangent modulus, E, and Poisson's ratio, $v$, for Antioch sand tested in plane-strain and triaxial tests as shown in Figure (2.22).

The same behavior was observed in a series of plane-strain and conventional triaxial compression tests reported by Marachi et al. (1981). The comparisons between the plane-strain and triaxial tests are shown in Figures (2.23) and (2.24). 

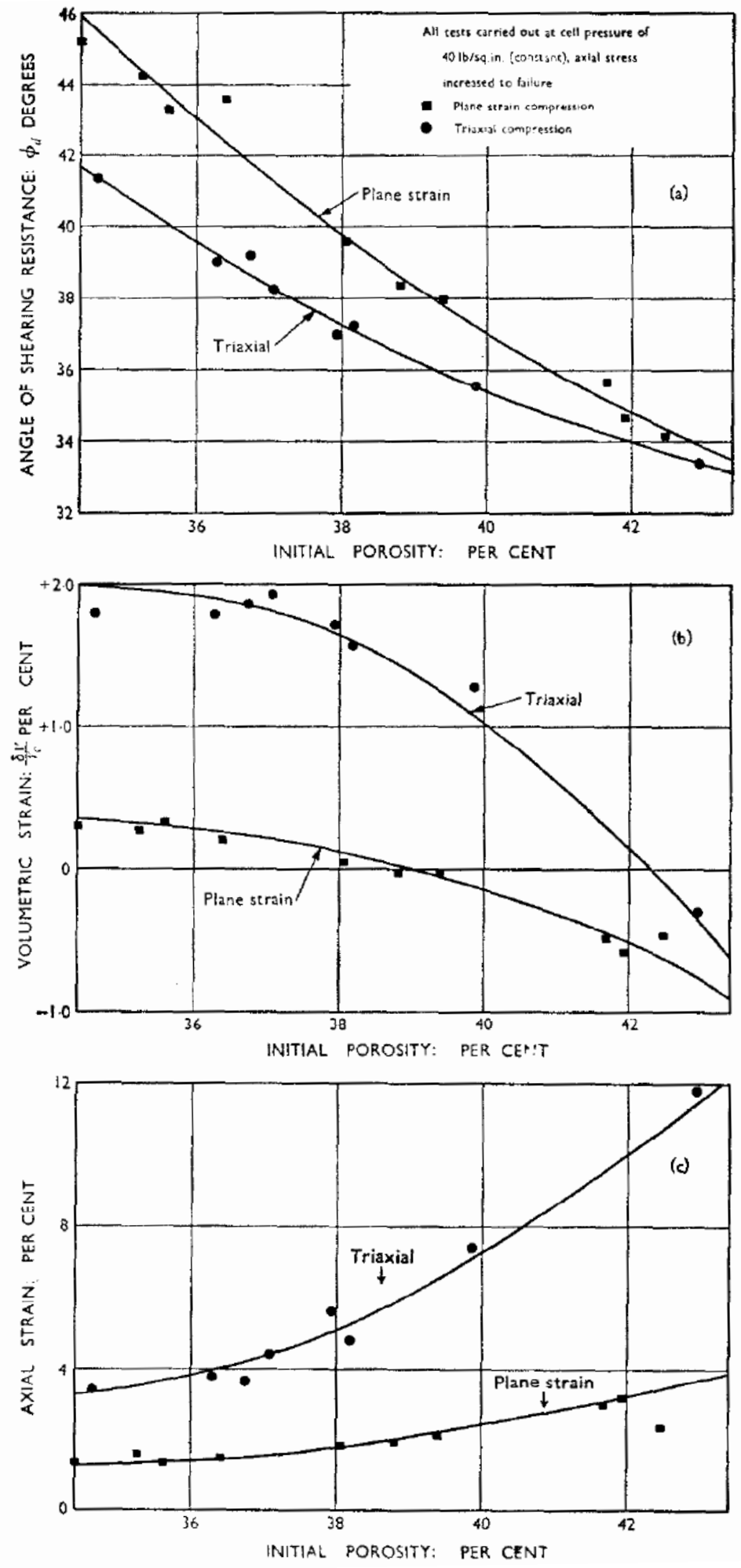

Figure (2.21) Plane-strain versus triaxial failure characteristics (Conforth, 1961) 

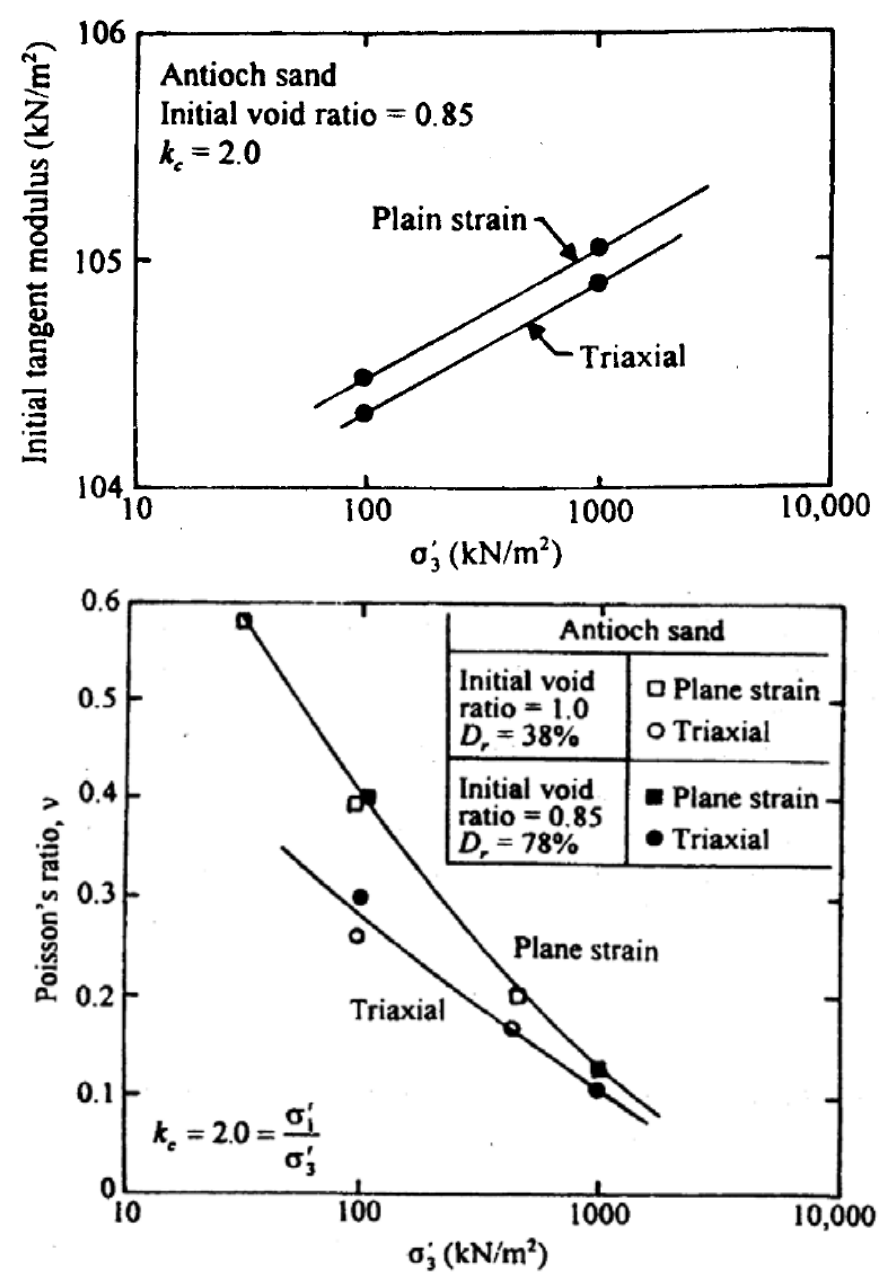

Figure (2.22) Plane-strain versus triaxial: variation of tangent modulus and Poisson's ratio (Lee, 1970)
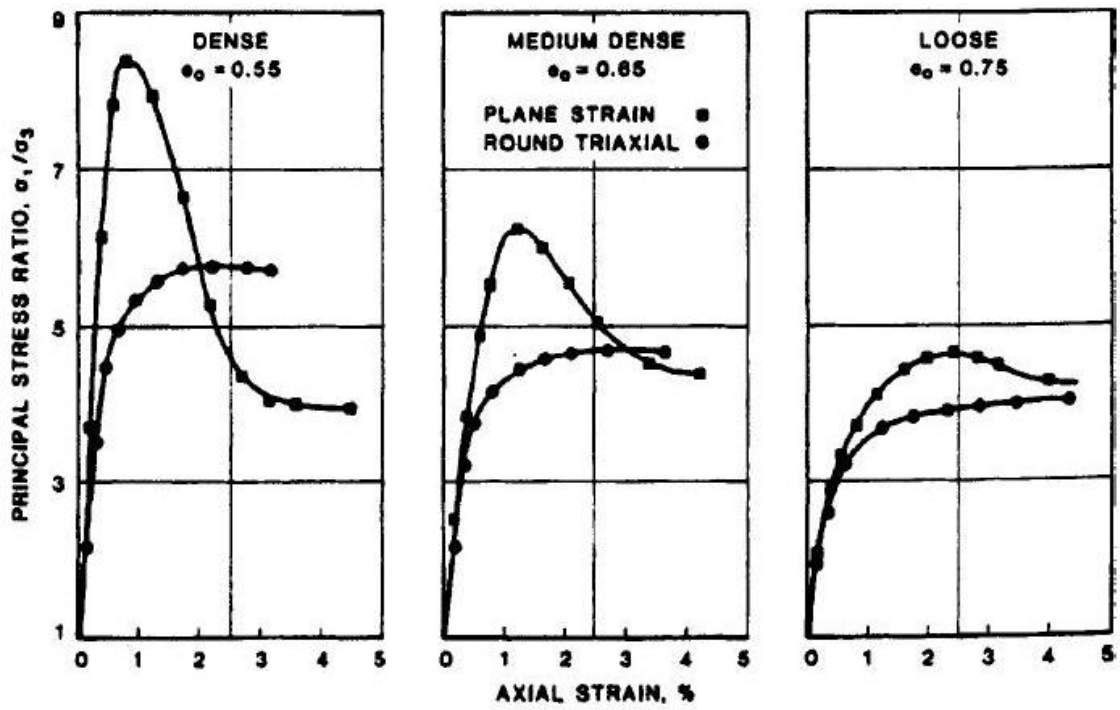

Figure (2.23) Plane-strain test versus triaxial test (Marachi et al., 1981) 

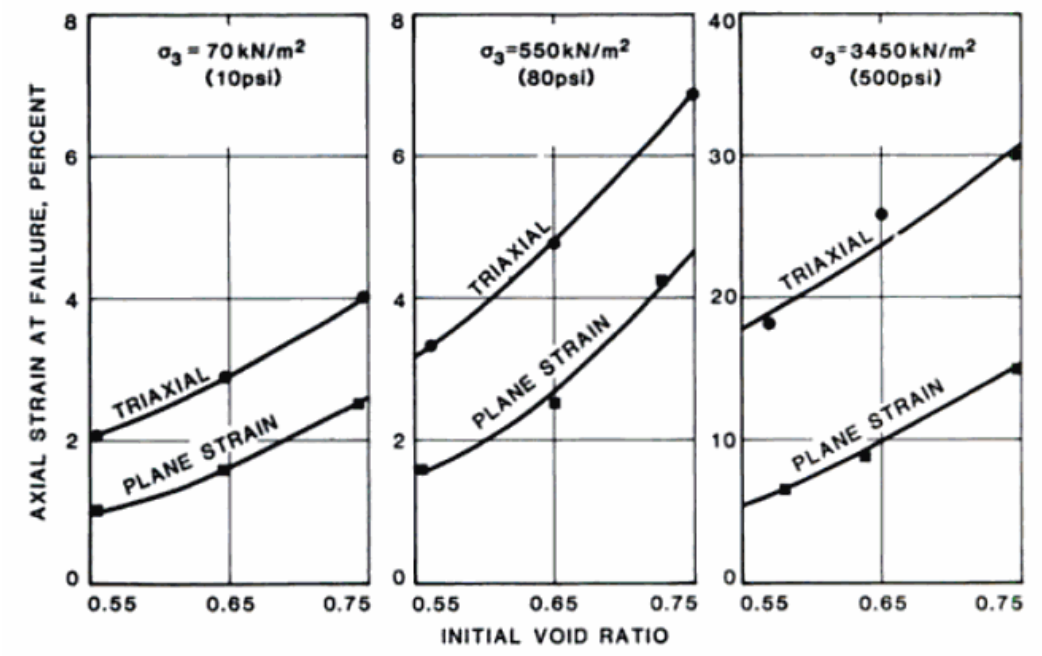

Figure (2.24) Axial strain at failure in biaxial and triaxial tests (Marachi et al., 1981)

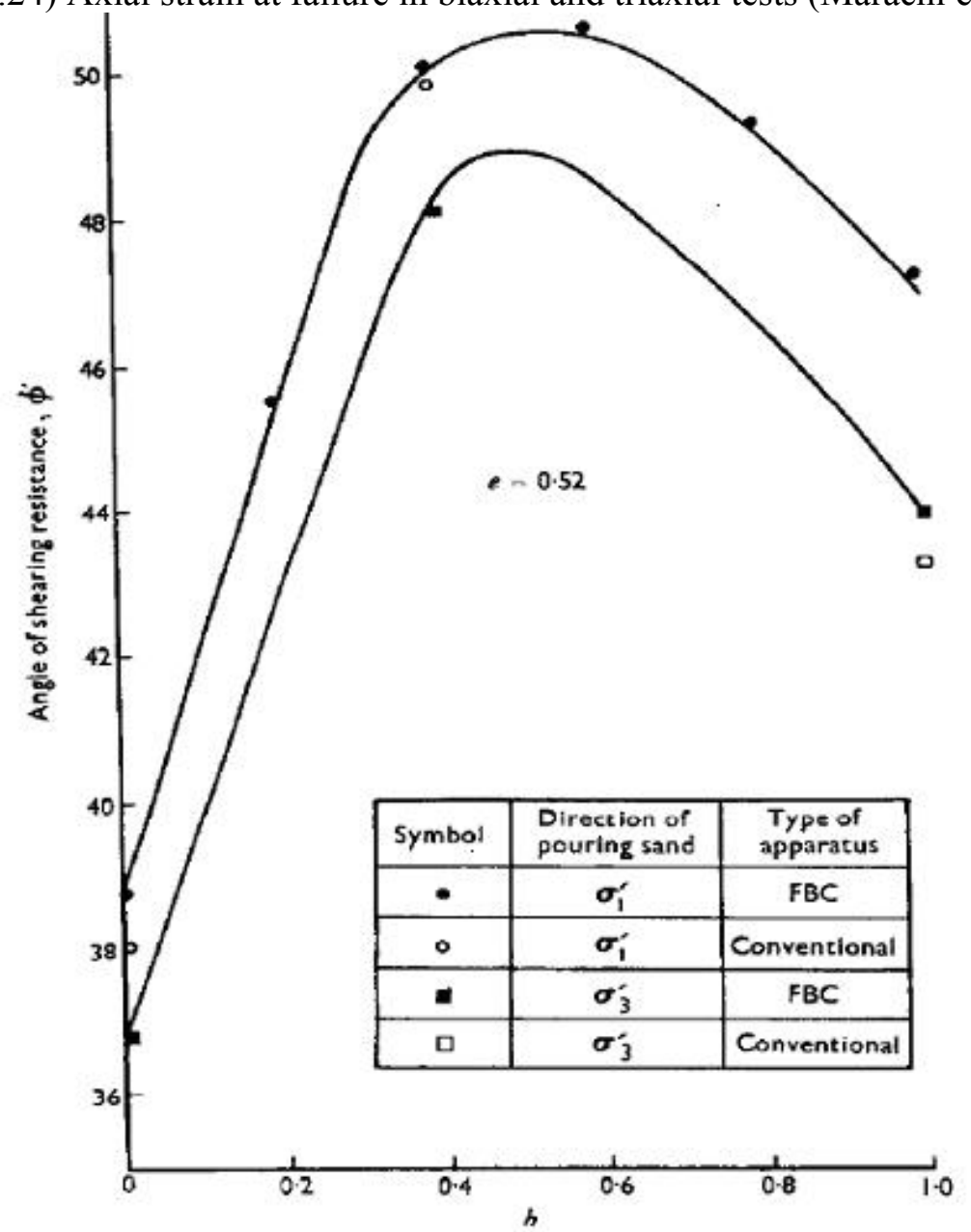

Figure (2.25) Variation of the angle of shearing resistance with the intermediate principle stress for standard Leighton sand for $\sigma_{3}{ }_{3}=42 \mathrm{kN} / \mathrm{m}^{2}$ (Arthur et al., 1977a) 
Figure (2.25) shows the variation of shearing angle with the intermediate principle stress of standard Leighton sand in the flexible biaxial cell (FBC) presented by Arthur et al. (1977a). The effect of the intermediate principle stress $\left(\sigma_{2}{ }_{2}\right)$ is presented using the variable $b$ defined by Bishop (1966). The variable $b$ varies from zero to unity. $b$ is zero in the triaxial compression test and it is one in the triaxial extension test.

$b=\left(\sigma_{2}^{\prime}-\sigma_{3}^{\prime}\right) /\left(\sigma_{1}^{\prime}-\sigma_{3}^{\prime}\right)$

The dependency of the internal angle of friction on the confining pressure in the plane-strain compression tests was studied by Tatsuoka et al. (1986a, 1991). The relationship between the angle of friction with confining pressure of dry Toyoura sand is presented in Figure (2.26).

The anisotropy in sand (effect of bedding angle) under plane-strain conditions was investigated in several researches (e.g., Oda et al., 1978; Tatsouka et al., 1986; Park and Tatsuoka, 1994). Oda et al. (1978) investigated the anisotropy in Toyoura sand in planestrain conditions. They conducted plane-strain tests on Toyoura sand with different angles of bedding (tilting) $(\delta)$. The maximum and minimum deviator stress were measured at $\delta=90^{\circ}$ and $\delta=15^{\circ}$, respectively. In addition, measuring the intermediate principle stress $\left(\sigma_{2}\right)$ showed that the intermediate principle stress gradually increases upon reaching peak point then it decreases as shown in Figure (2.27).

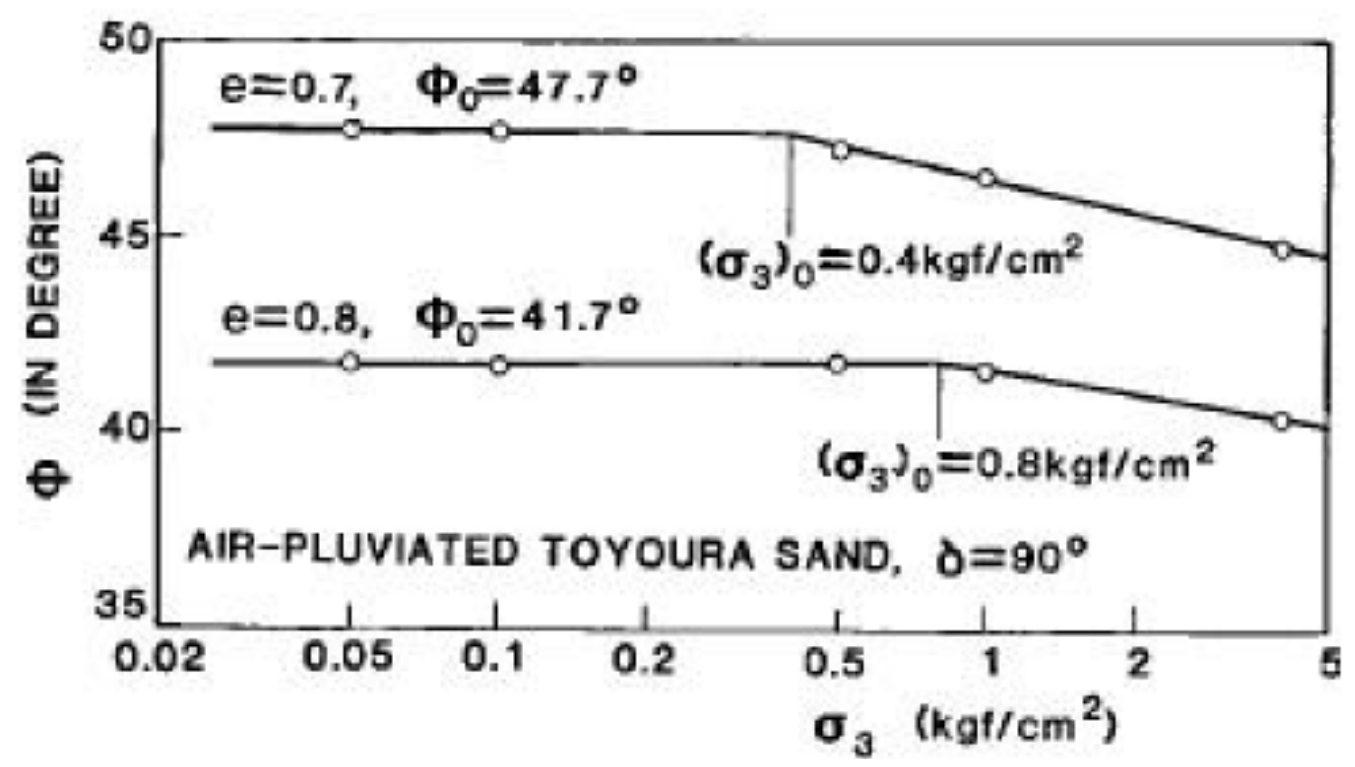

Figure (2.26) The effect of the pressure level on the angle of internal friction of Toyoura sand in plane-strain compression tests (Tatsuoka et al. 1986a, 1991) 


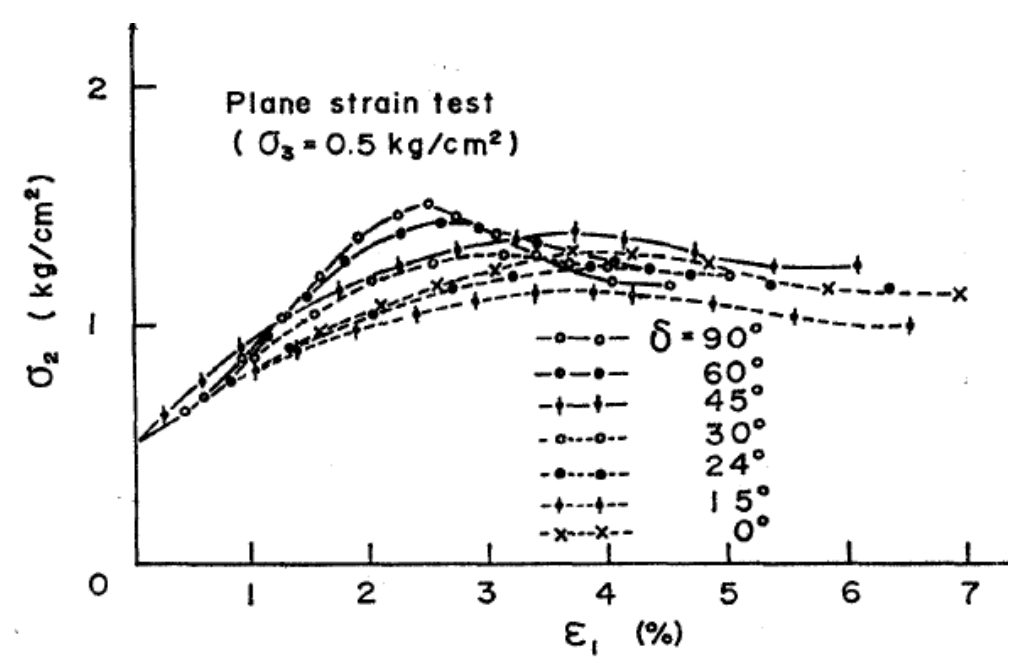

Figure (2.27) The effect of bedding angle $(\delta)$ on the intermediate stress $\left(\sigma_{2}\right)$ (Oda et al., 1978)

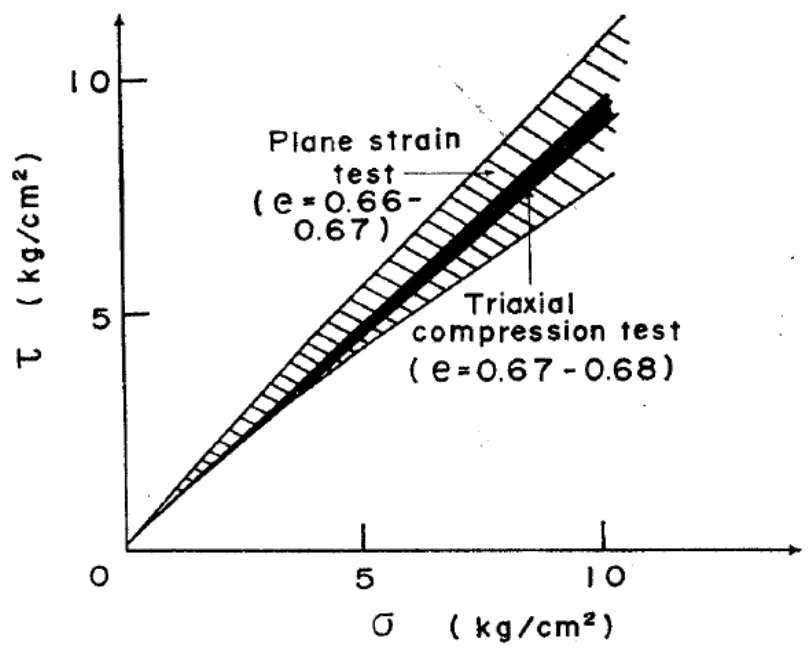

Figure (2.28) Mohr's failure envelops in the plane-strain and triaxial compression tests (Oda et al., 1978)

The hatched and solid areas in Figure (2.28) were determined for two boundary values of the tilting angle. The upper failure line of the hatched area refers plane-strain tests with $\delta=90^{\circ}$, whereas the lower line is for $\delta=24^{\circ}$. The solid area is for the triaxial tests with tilting angle $0^{\circ}$ to $90^{\circ}$. It can be concluded that the shear strength of sand in the plane-strain tests is higher than in the triaxial compression tests in limited range of tilting angle. When the tilting angle $(\delta)$ is in the range $0^{\circ}-30^{\circ}$; the triaxial test may gives higher shear stress than the plane-strain compression test (Oda et al., 1978). 


\subsubsection{Literature review of plane-strain results concerning shear banding}

In addition to investigating the anisotropy effect on the shear strength of sands in plane-strain conditions; the strain localization was also investigated by Prof. Tatsuoka and his co-workers in several works (e.g., Tatsuoka et al., 1986; Tatsuoka et al., 1990; Yoshida et al., 1993; Yoshida and Tatsuoka, 1997). The deformation characteristics of the shear band have an important effect on the mechanism of the failing soil mass such as in bearing capacity problems. The void ratio inside shear band is much higher than the average void ratio. Assuming that the thickness of the shear zone is zero overly simplify the actual behavior of real soils (Tatsuoka, 2000).

Vardoulakis et al. (1978) studied the shear bands in sand as a bifurcation problem and proposed an equilibrium theory of shear bands in sand bodies. The proposed model was verified using the results of plane-strain tests carried out on Karlsruhe sand in various loading types. Two types of loading system were adopted in the study of Vardoulakis et al. (1978). The first with clamped loading piston, the second is with hinged piston as it is illustrated in Figure (2.29). They reported that the horizontal movement started at the peak point, and the shear band is visible on the free faces of the specimen after 0.5-1.0 mm horizontal displacement. Vardoulakis et al. (1978) stated concerning to shear band orientation that laboratory tests are extremely sensitive to the boundary conditions and loose samples are more sensitive than dense ones.

Almost over the last three decades, an extensive program of tests on sand has been carried out in Grenoble. Different types of plane-strain compression tests were performed by changing the materials used (type, size of grains), the mean effective stress, the void ratio, the drainage conditions, the boundary conditions, the rate of loading, and the specimen slenderness.

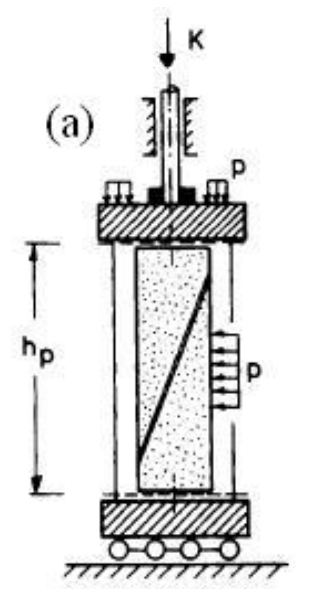

(b)

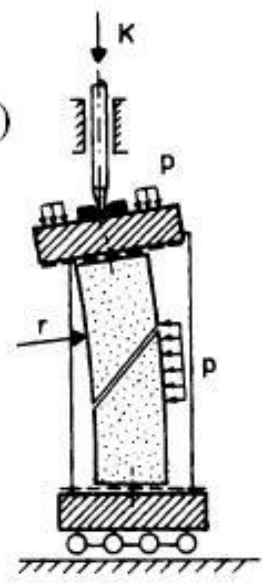

Figure (2.29) Loading cap: (a) clamped; (b) hinged (Vardoulakis et al., 1978) 


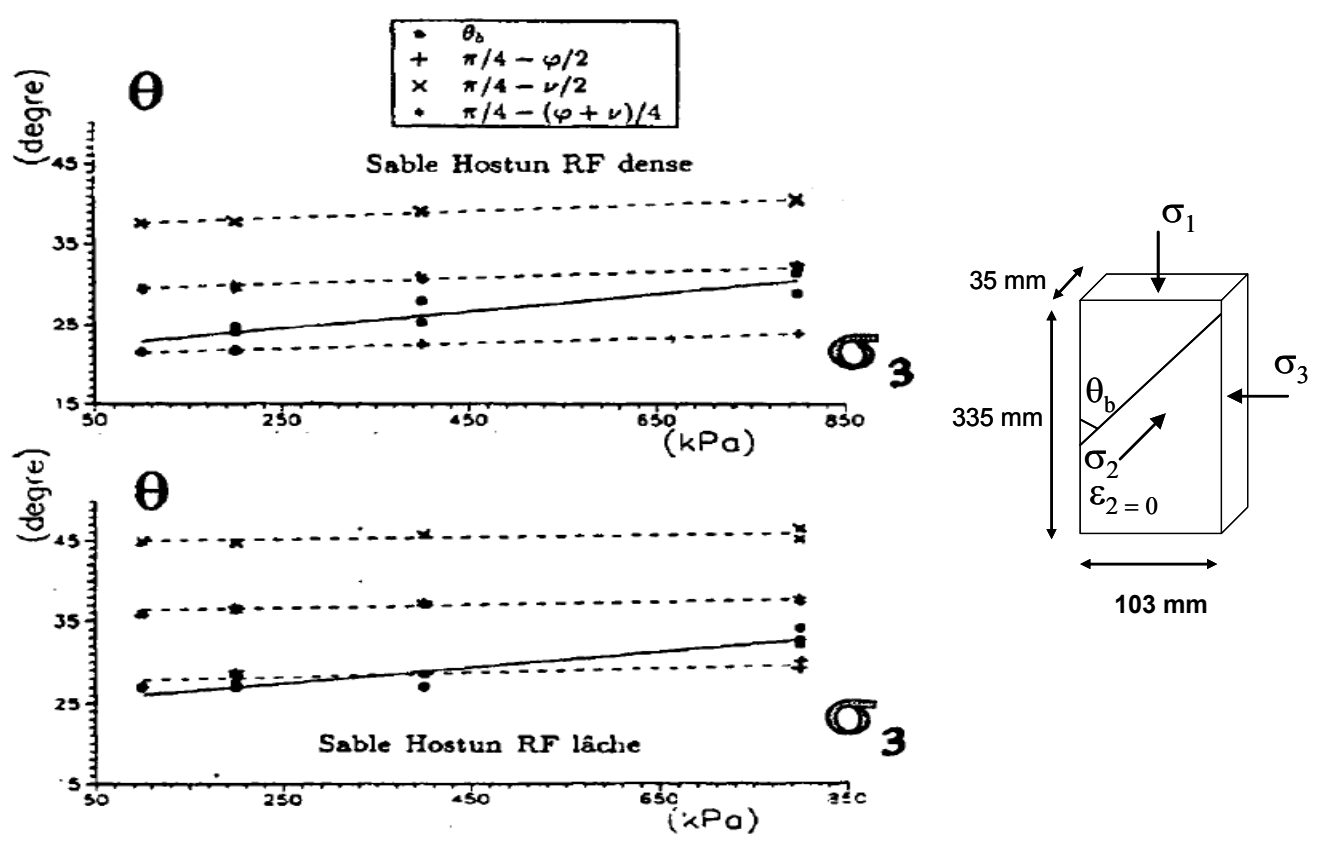

Figure (2.30) Shear band orientation versus confining pressure for dense and loose specimens (Desrues and Hammad, 1989; Hammad, 1991)

Desrues and Viggiani (2004) presented an overview of the experimental results obtained from the drained plane-strain compression tests in Grenoble using sterophotogrammetry. Desrues and Viggiani (2004) stated that a general statement can be made that for given sand that the width of the shear band decreases as the confining pressure and the initial density increases.

Viggiani et al. (2001) reported that there is no relationship between the mean size of the sand and the orientation of the shear band. In addition, it is not possible to relate the shear band orientation to the uniformity of the sand grading. In other word, the microstructure is a key factor and its influence on shear banding can not be simply described using grain size distribution (Desrues and Viggiani, 2004).

Figure (2.30) shows the shear band orientation versus the confining pressure for the dense and loose specimen in plane-strain tests in drained conditions from the tests done in Grenoble. The angles of the shear bands have been measured (in respect to the direction of the major principle stress) from the first available photograph on which the band is visible. Hammad (1991) concluded from the tests performed by changing the mean effective stress and the initial void ratio that dense and loose sand specimens showed shear banding and the orientations of the shear bands depend on the initial void ratio and on the mean effective stress. 
Mokni (1992) in his doctoral work performed plane-strain tests in undrained conditions on Hostun sand, these results have been presented later by Desrues (1995) and Mokni and Desrues (1999). Strain-stress curves for undrained and drained biaxial tests showed some differences between the drained and undrained behavior and the following remarks were obtained: (1) Strain localization occurs in both drained and undrained plane-strain tests. (2) Strain localization in drained tests occurs at axial strain much lower than in undrained test. (3) The effective stress ratio in drained test is higher than in undrained test. (4) The changes in pore-water pressure (in undrained test) and volume changes (in drained test) stop after localization. (5) The friction angle at the start of residual state in drained test is higher than in undrained test.

Finno et al. (1996) studied the strain localization and undrained steady state of sand by testing loose and very loose, fine-grained, saturated sand in a plane-strain apparatus. Steady state of deformation is the state in which the mass is continuously deforming at constant volume, constant normal effective stress, constant shear stress, and constant rate of shear strain as defined by Poulos et al. (1985).

Finno et al. (1996) reported that the angle of shear band inclination (in respect to the direction of the minor principle stress) varies from $55^{\circ}$ to $65^{\circ}$ for all undrained tests performed, whereas the Coulomb orientation $\left(\pi / 4+\phi^{\prime} / 2\right)$ varies from $61^{\circ}$ to $63.5^{\circ}$. Finno et al. (1997) clarified that the orientation angle of the shear band to the vertical increases an average of $3^{\circ}$ as strain progresses in the band and the thickness of the first band varies from 10 to 25 times the mean grain diameter.

Alshibli and Sture (2000) presented the results of series of plane-strain compression tests on three types of sand (fine, F; medium, M; and coarse, C). The measured shear band orientations by Alshibli and Sture (2000) together with other experimental measurements cited in the literature are presented in Figure (2.31). It is clearly shown that the experimentally measured orientation of shear band are scattered. It is difficult to conclude a trend (increasing or decreasing) with the applied confining pressure. The measurements reported by Vardoulakis (1980) are scattered and it can be concluded that for low confining pressures (lower than $100 \mathrm{kPa}$ ) the measured $\theta$ increases with the increasing of the confining pressure. 


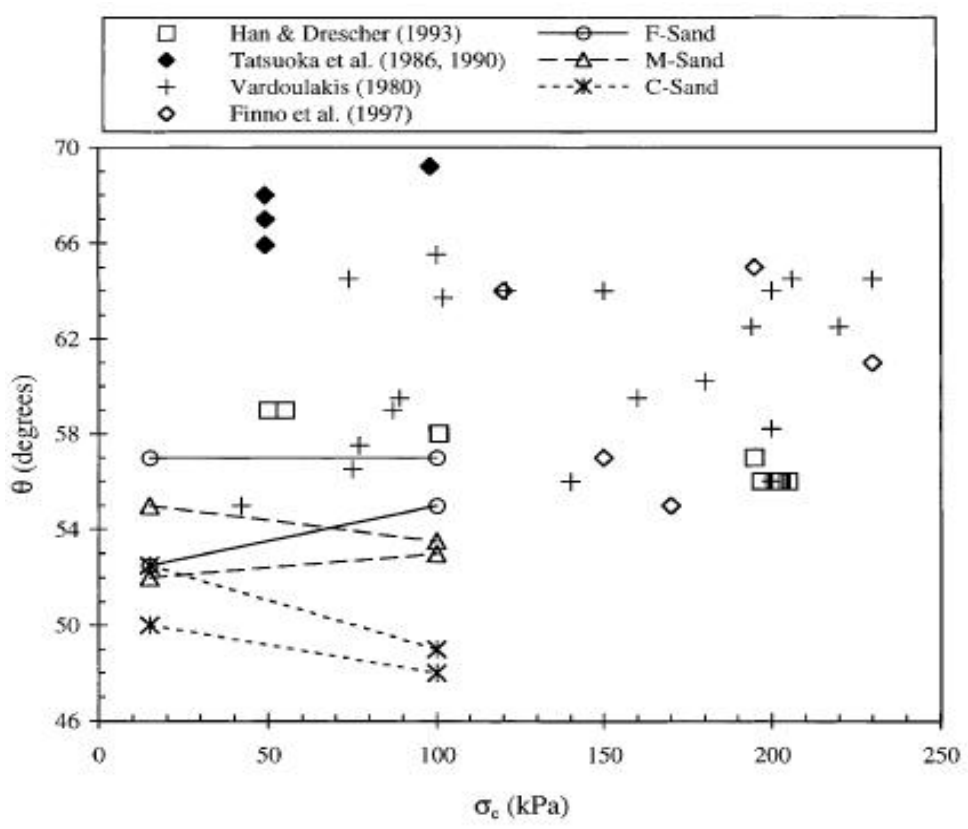

Figure (2.31) Shear band angle versus confining pressure (Alshibli and Sture, 2000)

The results of Alshibli and Sture (2000) showed that (at confining pressure lower than $100 \mathrm{kPa}$ ) $\theta$ increases or does not change for the F-sand. But for the M-sand and $\mathrm{C}$ sand the measured $\theta$ decreases as the confining pressure increases. The onset of the shear band was determined by locating the point in which the readings of the three horizontal LVDTs start to deviate. The orientation of the shear band was measured at the onset of shear band. The inclination of the band changed as the compression proceeds due to the change in the specimen height (Alshibli and Sture, 2000). This coincides with the observations reported by Finno et al. (1996, 1997).

Sterpi (2000) presented the measurement of the lateral displacement of sand specimen tested under plane-strain conditions. The measurements of the lateral displacements of the specimen in different points showed that upon reaching the peak no further displacement were recorded by the transducer mounted at the upper portion of the specimen. Beyond peak condition, the deformation can be considered as a rigid movement between two portions of the sample that slide along the shear band.

Oda and Kazama (1998) reported the observation of extremely large voids in the shear band. They noticed from X-ray photographs of the specimens tested in plane-strain conditions that the shear bands are not exactly straight, but gently curved with variation of the inclination angle with respect to the principal stress direction as it illustrated in Figure (2.32). As reported by Vermeer (1990) the inclination angle of the shear band depends sensitively on some boundary conditions. 


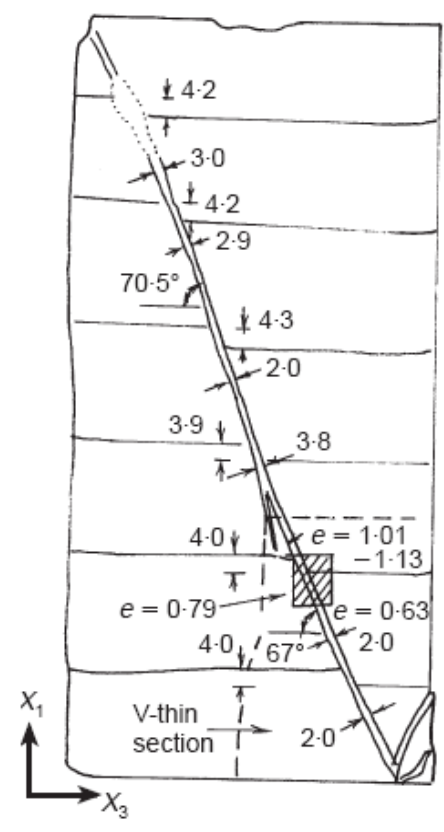

(a)

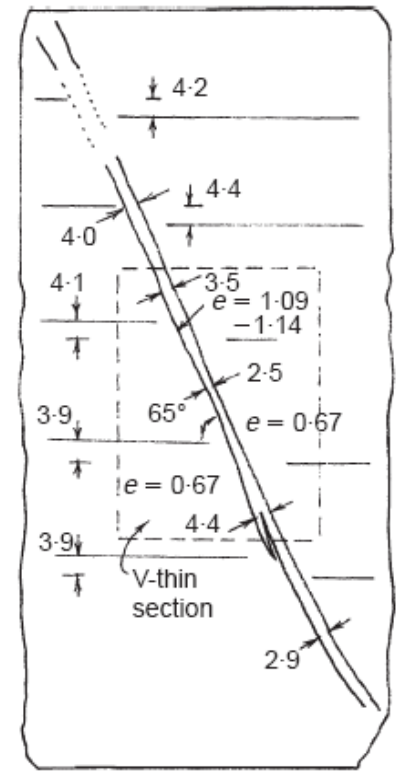

(b)

Figure (2.32) Sketches of the X-ray images (a) Toyoura sand; (b) Ticino sand (Oda and Kazama, 1998).

Mokni (1992) indicated that the thickness of the shear band of Hostun sand tested in plane-strain conditions depends on the mean size of the sand. The experimental observation of Roscoe (1970) showed that the shear band thickness is $20 \mathrm{~d}_{50}$. Batiste et al. (2004), in study on F-75 Ottawa sand in triaxial test, reported the thickness of the shear band in the range $8.33 \mathrm{~d}_{50}$ to $16.68 \mathrm{~d}_{50}$.

Vardoulakis and Graf (1985) used X-ray photographs of shear bands in fine and medium grained sand specimens tested under plane-strain conditions to determine the thickness of shear band. They concluded that the shear band thickness is about 16 times the mean grain diameter; their finding was also supported in the theoretical predictions presented by Muehlhaus and Vardoulakis (1987). Vardoulakis and Aifantis (1991) found that the thickness of the shear band is about $20 \mathrm{~d}_{50}$. 


\subsection{Strain localization in Granular material}

Several theoretical and numerical methods were presented to study the shear bands formation and the strain localization in granular materials. Such as the theory of bifurcation, the Cosserat theory, and strain gradient theories.

The theory of bifurcation was used to investigate the failure modes in frictional and cohesive materials. In the theory of bifurcation, the continuum splits into three regions at the beginning of the strain localization; the localization zone (shear band), and two continua (blocks).

Strain localization has been extensively investigated in the last three decades (e.g., Vardoulakis, 1979, 1980, 1981, 1983; Vardoulakis and Aifantis, 1991; Vardoulakis and Sulem,1995; Mühlhaus and Vardoulakis, 1987; Mühlhaus et al., 2001; Gudehus, 1996; Gudehus and Nübel, 2004; Tejchman and Wu, 1996; Tejchman et al., 1999; Tejchman and Gudehus, 2001; Alshibli and Sture, 1999 , 2000; Oda et al., 1997, 1998, 1999; Saada et al., 1999; Desrues et al., 1989, 1996; Desrues and Mokni,1999; Desrues 1998; Finno et al., 1997; Han and Drescher, 1993; Vermeer, 1982; Voyiadjis and Song, 2002).

The theory of strain localization was firstly proposed by Hadamard (1903) and later developed by, Hill (1962), Mandel (1965), and Rice (1976). This theory was used to predict the orientation of shear bands in different types of materials (Rudnicki and Rice, 1975; Rice and Rudnicki, 1980; Vardoulakis, 1979, 1980, 1981, 1988, 1989; Molenkamp, 1985; Peric 1990). The first international workshop on "Localization of Soils" was held in Karlsruhe, Germany in 1988 (University of Karlsruhe, special issue, 1988) and the second was held in Gdansk, Poland in 1989 (Dembicki et al., eds., 1989). The further developments in both numerical aspects and experimental studies were presented at subsequent international workshops held in Grenoble, France 1993 (Adachi et al., eds., 1998); Gifu, Japan 1997 (Chambon et al., eds., 1994); Perth, Australia 1999 (Muehlhaus et al., eds., 2001); Minnesota, U.S.A. 2002 (Labuz and Drescher, eds., 2003); Chania, Greece 2005 (Nicot et al., eds., 2005).

When soil is sheared, the shear strains usually localize into narrow intensive shearing zones. These shearing zones normally called shear bands and are generally described by their thickness and angle. Shear band is the thin layer of the material in which large shearing deformations occur resulting in localized failure (Lo et al., 2000). 
The shear band in sand is visible and the thickness is about 15 times the particle size, whereas in clay the shear band thickness is invisible and the shear band is viewed as a slip line (Vermeer, 1990).

Papamichos and Vardoulakis (1995) categorized the factors influencing the shear band formation in granular materials as follows: porosity of the medium, stress induced or inherent anisotropy of the medium, grain size and grain shape, and confining pressure.

Regarding grain size effect on shear band orientation, Vermeer (1990) presented a comprehensive analysis in a theoretical study on the effect of grain size. Vardoulakis (1977) and Desrues et al. (1991) have shown in their experimental studies that the angle of shear band inclination decreases with increasing grain size and angularity, whereas the corresponding shear strain increases.

The influence of confining pressure has been studied experimentally by several researchers such as Hammad (1991) using Hostun sand and Han (1991) using Ottawa sand. Han (1991) presented a theoretical analysis depending on flow and deformation theories. The comparison with the experimental findings regarding the effect of the confining pressure on the shear band orientation showed significant differences, this demonstrated also the deficiency of the ordinary flow theory of plasticity.

Wanatowski and Chu (2005) reported that no shear bands were observed in very loose specimens. Concerning to the formation of shear bands in loose sand, the results presented by Wanatowski (2005) agree with the results presented by Han and Vardoulakis (1991), but; it disagree with the results of the current study, the results of Desrues and Hammad (1991), and Mokni (1992). In addition, Finno et al. $(1996,1997)$ reported that the strain localization has developed in loose specimens under both drained and undrained conditions.

The formation of the shear bands under plane-strain conditions is affected by the type of plane-strain device and the boundary conditions as reported by Yasin et al. (1999).

\subsubsection{Angle of shear band inclination}

Two classical solutions for shear band inclination in frictional materials under plane-strain conditions are referred to as Mohr-Coulomb and Roscoe (1970) solutions.

Shear banding was observed very early by Coulomb (1776). In Mohr-Coulomb solution (static solution) the shear band inclination angle $\left(\theta_{\mathrm{c}}\right)$ is calculated as follow: 


$$
\theta_{C}=\left(45^{\circ}+\frac{\phi_{f}}{2}\right)
$$

where $\theta_{\mathrm{c}}$ is the angle of the shear band inclination measured from the direction of minor principal effective stress, and $\phi_{f}$ is the effective angle of internal friction at failure. Only one static constitutive parameter $\left(\phi_{f}\right)$ is contained in Equation (2.6), and no deformation variables or parameters appear (Alshibli and Akbas, 2007). The angle of internal friction for cohesionless soils is defined as:

$$
\sin \varphi_{f}=\left[\frac{\sigma_{1}-\sigma_{3}}{\sigma_{1}+\sigma_{3}}\right]_{\max }
$$

where $\sigma_{1}=$ the major principle stress and $\sigma_{3}=$ the minor principle stress.

Using the centrifuge technique, Roscoe (1970) introduced the dilatancy effect on the angle of shear band inclination. The shear band inclination angle according to this solution is presented as:

$$
\begin{gathered}
\theta_{r}=\left(45^{\circ}+\frac{\psi_{f}}{2}\right) \\
\sin \psi=\frac{\dot{\varepsilon}_{1}^{p}+\dot{\varepsilon}_{3}^{p}}{\dot{\varepsilon}_{1}^{p}-\dot{\varepsilon}_{3}^{p}}
\end{gathered}
$$

where $\psi_{f}$ is the angle of dilation at failure (in plane-strain conditions) and $\varepsilon_{1}$ and $\varepsilon_{3}$ are the major and minor principle strain, respectively. The dot indicates rate of strain, and $\left(^{p}\right)$ indicates to plastic strain.

According to experimental evidence in several researches the difference between the dilatancy angle and the internal friction angle is $<30^{\circ}$ (Bolton, 1986; Vardoulakis and Graf, 1985; and Tatsuoka et al., 1986, 1990). The difference between the dilatancy angle $(\psi)$ and friction angle $(\phi)$ is about 30 degrees; this gives a significant differences in estimating shear band orientation using Coulomb's or Roscoe's solutions. It should be noted that experimental measurement of shear band orientation in several studies give evidence for both Coulomb's solution and Roscoe's solution (Vermeer, 1990).

Arthur et al. (1977) obtained the following empirical equation from experimental observations:

$$
\theta_{a}=\left[45^{\circ}+\frac{1}{4}\left(\varphi_{f}+\psi_{f}\right)\right]
$$

The empirical equation proposed by Arthur et al. (1977) defining the inclination of shear bands was analytically derived by Vardoulakis in 1980. He extended the bifurcation analysis of Hill and Hutchinson (1974) to sands. 
$\theta \approx \frac{\pi}{4}+\frac{\psi}{4}+\frac{\varphi}{4}$

Vermeer (1982) presented an expression for the shear band inclination angle using a compliance approach as follow:

$\tan ^{2} \theta=\frac{2+\sin \phi_{h}+\sin \psi_{h}}{2-\sin \phi_{h}-\sin \psi_{h}}$

where $\theta=$ angle between the minor principle stress direction and the shear band. The subscript $h$ indicates that the angle of internal friction $\left(\phi_{\mathrm{h}}\right)$ and the angle of dilation $\left(\psi_{\mathrm{h}}\right)$ depend on the degree of hardening.

The angles of shear band inclination are sensitive to the boundary conditions, and the loose specimens are more sensitive than the dense ones (Vardoulakis, 1978). The shear band inclination angle for loose saturated sand under both drained and undrained conditions lies between the Coulomb and Arthur solutions as reported by Finno et al. (1997). Coulomb's solution implies non-rotating stress axes; Roscoe's solutions represent co-rotating stress and strain increment axes during failure. Coulomb's inclination means that a thin deforming layer is separating two rigid bodies, and the strain increment and stress are non-coaxial, whereas Roscoe's inclination implies that this thin deforming layer is separating two deforming bodies, but inside the shear band the strain increment and stress are coaxial at peak (Vardoulakis et al., 1987).

Bardet (1991) reported that the disagreement between the predicted and measured shear band inclination angles can be attributed mainly to the experimental errors in evaluating dilatancy angle $(\psi)$ and friction angle $(\phi)$ and delayed localization. In addition, this scattering of results comes from the variability of the dilatancy and friction angles within the sand specimen.

It is of interest to present briefly the concept of the delayed localization as an explanation of the scattering of the experimental results presented by Desrues (1984). Bardet (1991) stated that the shear bands emerged in the strain-hardening regime need additional energy for their development. The shear bands in granular materials do not grow spontaneously as in strain-softening rocks. The emergence of the shear bands is difficult to be observed using conventional methods, but; it needs sophisticated techniques such as those used by Desrues (1984). It can be noticed that shear banding can be noticeable only in advanced stage of loading (Bardet, 1991).

Most researches focused on the measuring or predicting the shear band inclination angle. The measured shear band inclination angles were compared to the classical 
solutions (i.e. Mohr-Coulomb or Roscoe). Fewer studies investigated the thickness of the shear bands; this may be due to the difficulty of experimentally measuring the thickness of the shear band. In addition, classical theories of soil plasticity fail to predict the shear band thickness.

\subsubsection{Thickness of shear band}

Shear band thickness determination methods can be divided mainly into two categories, i.e., theoretical and experimental methods.

Theoretical derivations: in which the flow and deformation theories of plasticity are used. Muehlhaus and Vardoulakis (1987) reported that the thickness of the shear band is about $16 \mathrm{~d}_{50}$. Later, Vardoulakis and Aifantis (1991) using flow rule and the theory of plasticity reported $20 \mathrm{~d}_{50}$ as a thickness of the shear band. Alshibli et al. (2006) using Cosserat theory, predicted the thickness of the shear band. They found it to vary from $10 \mathrm{~d}_{50}$ to $15 \mathrm{~d}_{50}$ depending on specimen density, confining pressure, shape, size of particles, and sphericity.

Experimental observations: X-ray techniques have been used to measure the thickness of the shear band in several researches (Roscoe, 1970; Scarpelli and Wood, 1982; Han and Vardoulakis, 1991; Oda and Kazama, 1998). Other techniques have been used such as Laser techniques (Tatsuoka et al. 1990), Tomography (Mokni, 1992), and stereophotographic techniques (Desrues et al., 1985; Mokni, 1992; Yoshida et al., 1995)

Some studies gave emphasis on the internal measurement techniques to measure the displacements and volume changes in the shear band. Scarpelli and wood (1982) and Han and Vardoulakis (1991) used the X-ray radiographs. The laser techniques have been used by Tatsuoka et al. (1990). Desrues et al. (1985), Mokni (1992), Yoshida et al. (1995), and Finno et al. (1996) used the tomography and the stereophotographic techniques. Finno et al. (1997) measured the local deformation using two methods, stereophotographic (e.g., Moony et al. 1997) and digital image correlation (DIC) techniques.

The experimental measurement of the shear band is very useful for better understanding the localization mechanism in granular materials during shear, and to give additional data that help in calibrating theoretical models to predict shear band thickness (Alshibli and Hassan, 2008).

Theoretical and numerical studies (Vardoulakis and Sulem 1995) and several experimental investigations (Desrues et al., 1996; Finno at al., 1997; Saada et al., 1999; 
Desrues and Viggiani, 2000) have provided important data concerning shear band width, orientation, pattern of formation and evolution. These researches studied the influence of the stress, density, and specimen's geometry (size and slenderness) on the strain localization. There is also experimental evidence showing that the strain localization in granular soils depends on the microstructure. The differences in the localization characteristics of different sands tested under a given state and loading path can not be explained in terms of macroscopic state variables (i.e. void ratio and stress state only).

The macroscopic mechanical behavior of the granular soils depends on the nature and evolution of the antiparticle contacts through which the stresses are transmitted (Allersma, 1987; Calvetti et al., 1997; Dantu, 1967; Oger, 1987). Viggiani et al. (2001) and Desrues and Viggiani (2004) concluded from their experimental work that the influence of the microstructure parameters such as the shape and angularity of grains and the grain size distribution on the shear banding has still to be established; and it is difficult to find a relationship between the orientation of a shear band and the mean particle size or the degree of uniformity of sand in a simple way.

\subsection{Summary}

The literature review presented in chapter 2 shows that strain localization in granular material and unsaturated soil testing are among the most active research area in geotechnical engineering. In addition, this review shows the need for plane-strain device for unsaturated soil testing that most experimental studies using plane-strain devices have been conducted on dry or saturated soil. Therefore, more experimental studies on unsaturated soil under plane-strain conditions are required for better understanding of unsaturated soil behavior. 


\section{CHAPTER 3}

\section{MATERIAL USED AND EXPERIMENTAL PROGRAM}

\subsection{General}

This chapter presents the basic properties of the materials used in this study. In addition, the experimental program adopted in this study is presented here. Two materials were used in this study. In the tests performed in the new double-wall biaxial device and in the bearing capacity tests Hostun sand was used. For the validation's tests of the concept of the stress state variables using the new biaxial device and investigating the effect of the fine content on the soil water characteristic curves, mixtures of Hostun sand and Spergauer kaolin has been used.

\subsection{Basic properties of the materials used}

Hostun Sand is reference sand well known in the researches (Desrues, 1984; Hammad, 1991; Mokni, 1992; Flavigny et al., 1990; Di Prisco and Imposimato, 1996; Tatsuoka et al., 1997; Shahrour and Rezaie, 1997; Schanz, 1998; Foray et al., 1998; Lins and Schanz, 2003; De Genaro et al., 2004; Lancelot et al., 2006; Bouferra et al., 2007). Hostun sand is originally obtained from a place called Hostun in the area of Drome in France. The colour of Hostun sand may vary between the grey-white and rosy-beige. The chemical components consist of high siliceous amount $\left(\mathrm{SiO}_{2}>98 \%\right)$ and the grain shape varies from angular to sub-angular (Amat, 2007).

Hostun Sand is poorly-graded sand with grain sizes range from $0.1 \mathrm{~mm}$ to 1.0 $\mathrm{mm}$ in diameter. It is classified as (SP) in the unified soil classification system (USCS).

The Spergauer kaolin is obtained from Germany and having a liquid limit of $53.4 \%$ and plastic limit of $32.3 \%$ is classified in (USCS) as a $(\mathrm{CH})$.

Investigating the basic properties of the used material included the determination of specific gravity, plastic and liquid limits, grain-size distribution, and compaction characteristics. The tests were performed based on ASTM standard (ASTM, 1995) and DIN standards (DIN, 1987). 
Determination of the specific gravity of the soils have been done according to the DIN standards DIN 18124KP (DIN, 1987). The average specific gravity values were 2.65 and 2.62 for Hostun sand and Spergauer kaolin, respectively.

The grain size distribution for the Spergauer kaolin was investigated using sedimentation method according to DIN 18123-7 (DIN, 1987). Sodium Pyrophosphate was used as dispersing solution during the test. The amount of the clay (i.e., smaller than $0.002 \mathrm{~mm}$ ) as it is shown in Figure (3.1) is 58\%. Whereas for Hostun sand, the conventional sieve analysis method was used. The grain size distribution curves of Hostun sand and Spergauer kaolin are shown in Figure (3.1).

The liquid limit and plastic limit tests of Spergauer kaolin were performed according to DIN 18122 (DIN, 1987). The liquid limit and the plastic limit obtained from the experiments were $53.4 \%$ and $32.3 \%$, respectively.

The standard compaction tests were conducted according to the ASTM standards. Figure (3.2) shows the standard compaction curves for Hostun sand, Spergauer kaolin, and the three mixtures. The basic classification properties of Huston sand and Spergauer kaolin are summarized in Tables (3.1) and (3.2), respectively. The percentages (on a dry mass basis) of the Spergauer kaolin in the mixtures are summarized in Table (3.3).

Table (3.1) Basic properties of Hostun sand

\begin{tabular}{cc}
\hline Property & Value \\
\hline Specific gravity (-) & 2.65 \\
$d_{10}(\mathrm{~mm})$ & 0.21 \\
$d_{30}(\mathrm{~mm})$ & 0.29 \\
$d_{50}(\mathrm{~mm})$ & 0.36 \\
$c_{\mathrm{u}}$ & 1.72 \\
$c_{\mathrm{c}}$ & 1.05 \\
Classification (USCS) & $\mathrm{SP}$ \\
\hline
\end{tabular}

Table (3.2) Basic properties of Spergauer kaolin

\begin{tabular}{cc}
\hline Property & Value \\
\hline Specific gravity (-) & 2.62 \\
Liquid limit (\%) & 53.4 \\
Plastic limit (\%) & 32.3 \\
Plasticity index (\%) & 21.1 \\
Classification (USCS) & $\mathrm{CL}$ \\
\hline
\end{tabular}


Table (3.3) Mixtures used in the study

\begin{tabular}{cccc}
\hline Mixture & A & B & C \\
\hline Spergauer kaolin (\%) & 5 & 10 & 30 \\
Hostun sand (\%) & 95 & 90 & 70 \\
\hline
\end{tabular}

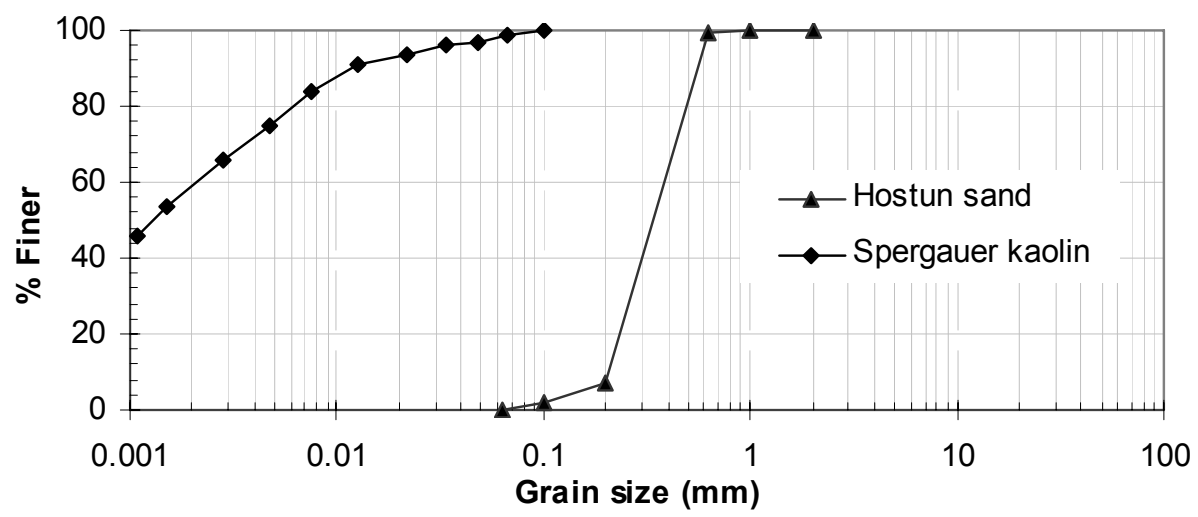

Figure (3.1) Grain size distribution of Hostun sand and Spergauer kaolin

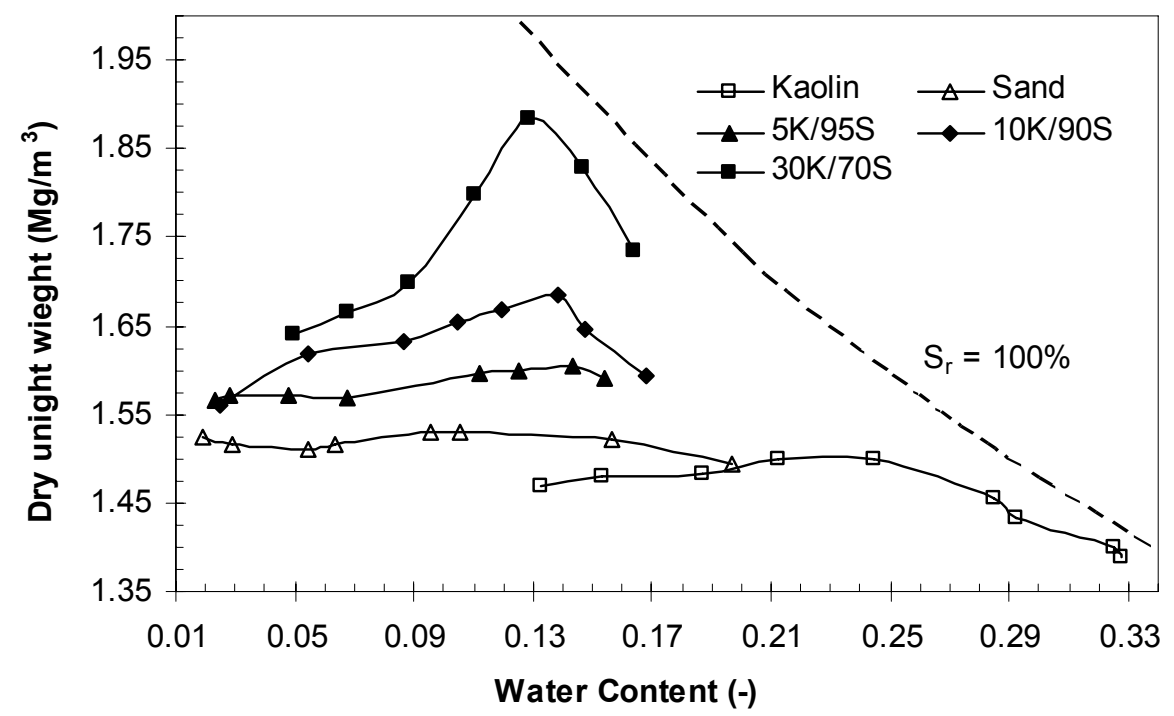

Figure (3.2) Standard proctor compaction curves of the material used

\subsection{Experimental program}

The laboratory program consists of investigating the mechanical behaviour (shear strength and volume change behaviour) for dry, saturated, and unsaturated Hostun sand using the new double-wall biaxial device. Additionally the influence of the applied matric suction on the ultimate bearing capacity of surface strip model footing on unsaturated dense Hostun sand was studied by performing a set of bearing capacity tests on strip footing located on the surface of the sand mass. The effect of the fine content (i.e., kaolin) 
on the parameters of the soil water characteristic curve was investigated by determining the soil water characteristic curves of the sand, kaolin, and three sand-kaolin mixtures.

\subsubsection{Experimental program for biaxial tests}

In all biaxial tests, the specimens after being consolidated were sheared under drained condition. The pore-water and pore-air phases were allowed to drain in/out of the specimen and in the pore pressures were controlled to be constant by mean of air pressure controllers. The specimens were axially compressed by $0.002 \mathrm{~mm} / \mathrm{sec}$ (i.e., strain rate of $1.6 \times 10^{-5} \% / \mathrm{sec}$ ), the low strain rate is vital to ensure the dissipation of induced pore pressures during the compression stage (Fredlund and Rahardjo, 1993).

The testing program of biaxial tests is mainly divided into two main parts:

1. Biaxial drained compression tests on the dry Hostun sand: The influence of the initial void ratio on the behaviour was examined by testing the sand under two different initial conditions (loose specimen $\mathrm{e}_{0}=0.89$ and dense specimen $\mathrm{e}_{0}=0.66$ ).

2. Biaxial drained compression tests on saturated and unsaturated dense sand $\left(\mathrm{e}_{0}=\right.$ 0.66). Three sets of tests were performed, namely B10, B50, and B100. In each set, the net confining pressure $\left(\sigma_{3}-u_{\mathrm{a}}\right)$ was kept constant and the matric suction $\left(u_{\mathrm{a}}-u_{\mathrm{w}}\right)$ was changed to study the effect of the matric suction on the shear strength and volume change behaviour of the unsaturated specimens. The applied matric suction in the consolidation and compression stages was kept constant by controlling the porewater pressure $\left(u_{\mathrm{w}}\right)$ and pore-air pressure $\left(u_{\mathrm{a}}\right)$.

Table (3.4) summarizes the net confining pressures in the tests performed on dry Hostun sand in loose and dense states. Table (3.5) summarizes the stresses (i.e., the net confining pressure and matric suction) in the tests on unsaturated sand.

Table (3.4) Summary of biaxial tests performed on dry sand

\begin{tabular}{cc}
\hline $\begin{array}{c}\text { Dense Hostun sand } \\
\left(\mathrm{e}_{0}=0.66\right)\end{array}$ & $\begin{array}{c}\text { Loose Hostun sand } \\
\left(\mathrm{e}_{0}=0.89\right)\end{array}$ \\
\hline \multicolumn{3}{c}{ Confining pressure $(\mathrm{kPa})$} \\
15 & 50 \\
50 & 100 \\
100 & 150 \\
300 & \\
400 & \\
600 & \\
\hline
\end{tabular}




\subsubsection{Experimental program for bearing capacity tests}

The bearing capacity tests were performed to investigate the effect of the applied matric suction on the ultimate bearing capacity of strip footing on unsaturated Hostun sand. Bearing capacity tests on saturated and unsaturated dense sand $\left(\mathrm{e}_{0}=0.66\right)$ have been performed. Table (3.6) summarizes the bearing capacity tests have been performed in this study on dense sand.

In the bearing capacity tests, the loading speed was chosen to be equal to 0.002 $\mathrm{mm} / \mathrm{sec}$.This is for the sake of compatibility with the biaxial tests and to ensure that no significant changes may occur during the loading stage in the bearing capacity test. In addition, the suction was monitored during the loading stage as mentioned in detail in Chapter 5 .

\subsubsection{Experimental program for determination of SWCCs}

The soil water characteristic curves for Hostun sand, kaolin, and three mixtures, as summarized in Table (3.3), were determined using different devices and techniques as it will be presented in detail in chapter 4.

Table (3.5) Summary of the stresses in biaxial tests on dense unsaturated sand

\begin{tabular}{cccccccc}
\hline Set & $\begin{array}{c}\text { Net confining pressure } \\
\left(\sigma_{3}-u_{\mathrm{a}}\right)(\mathrm{kPa})\end{array}$ & \multicolumn{7}{c}{ Matric suction $\left(u_{\mathrm{a}}-u_{\mathrm{w}}\right)(\mathrm{kPa})$} \\
\hline B10 & 10 & 0 & 2 & 3 & 4 & 8 & 20 \\
B50 & 50 & 0 & 2 & 3 & 4 & 8 & 20 \\
B100 & 100 & 0 & 2 & 3 & 4 & 8 & 20 \\
\hline
\end{tabular}

Table (3.6) Summary of bearing capacity tests on dense unsaturated sand

\begin{tabular}{|c|c|c|c|c|c|c|}
\hline Applied matric suction $(\mathrm{kPa})$ & 0 & 1.5 & 2.1 & 5 & 8 & 20 \\
\hline As prepared condition ( $\mathrm{e}_{0}$, sat. $/$ dry $)$ & 0.66 & 0.66 & 0.66 & 0.66 & 0.66 & 0.66 \\
\hline & /sat. & /sat. & /sat. & /sat. & /sat. & /sat. \\
\hline Loading Speed $(\mathrm{mm} / \mathrm{sec})$ & 0.002 & 0.002 & 0.002 & 0.002 & 0.002 & 0.002 \\
\hline Height of sand in the box (mm) & 350 & 350 & 350 & 350 & 350 & 350 \\
\hline Dimensions of the footing $(\mathrm{mm})$ & \multirow{2}{*}{\multicolumn{6}{|c|}{500,80}} \\
\hline Length, Width & & & & & & \\
\hline \multicolumn{7}{|l|}{ Dimensions of the box (mm) } \\
\hline Length, Width, Height & \multicolumn{6}{|c|}{$1000,505,500$} \\
\hline
\end{tabular}




\subsection{Summary}

The basic properties of the materials used in this study were presented. Hostun sand and Spergauer kaolin have been used in this study. Huston sand has a mean grain size $\mathrm{d}_{50}=0.36 \mathrm{~mm}$ and specific gravity of 2.65. Spergauer kaolin has liquid and plastic limits of $53.4 \%$ and $32.3 \%$ respectively. Three sand-kaolin mixture were used in this study in the determination of soil water characteristic curves (SWCCs) (i.e., A: 5\% kaolin, B: 10\% kaolin, and C: 30\% kaolin). In addition, the experimental programs of the tests carried out in this study were presented. 


\section{CHAPTER 4}

\section{EXPERIMENTAL TECHNIQUES AND PROCEDURES}

\subsection{General}

This chapter presents the experimental techniques and procedures adopted in this study. The new double-wall biaxial device is described in detail. Sample preparation, testing procedure, and the required calibrations of the system components are presented. In additions, the devices and techniques used in determination of water soil characteristic curves (SWCCs) and in bearing capacity tests are presented as well.

\subsection{The new double-wall biaxial device}

The new device consists of two cells (i.e., the outer and inner cell), base platen and top cap equipped with porous and ceramic discs. The required connections and valves are provided to facilitate the application of the inner and outer cell pressures, pore-air pressure, and pore-water pressure. All data, such as volume changes, applied load, and vertical displacement, are collected by a data logger connected to a computer.

In the new system, the inner cell (in which the specimen is mounted) is placed inside another cell (double-wall system). Figure (4.1) shows the principle of the doublewall cell. As shown in the figure, the cell pressure is applied equally inside and outside the inner cell.

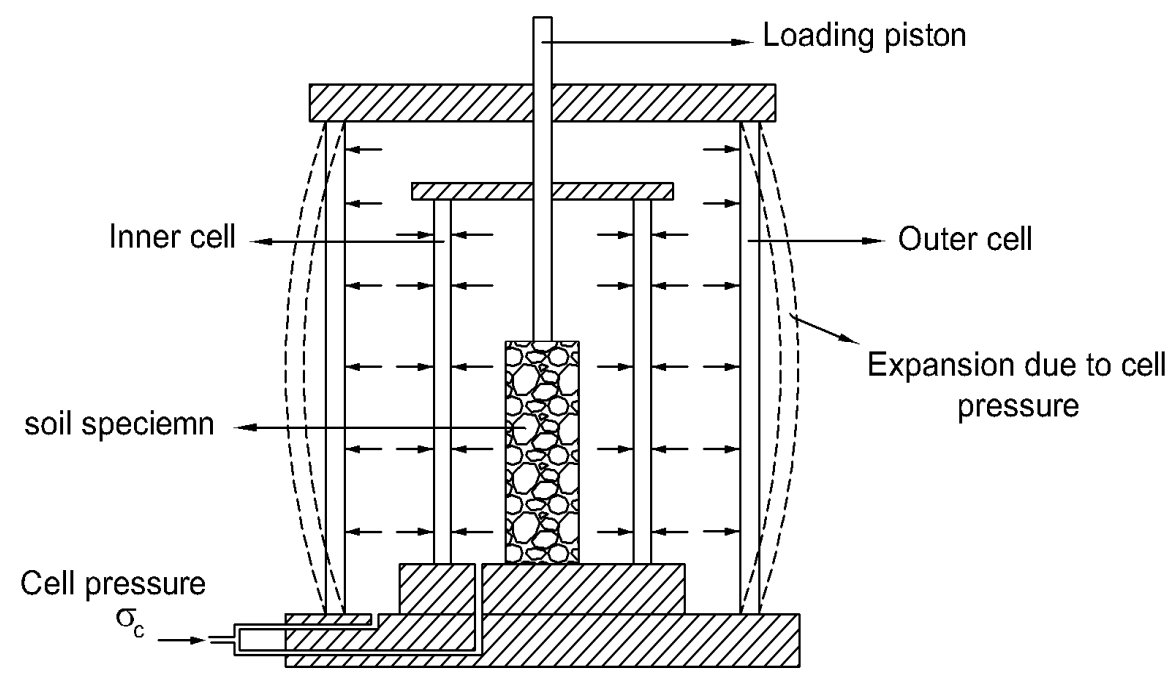

Figure (4.1) The concept of double-wall cell 


\subsubsection{Sample description}

The rectangular (prismatic) soil specimen is $120 \mathrm{~mm}$ high, 100 wide, and $40 \mathrm{~mm}$ thick. The deformation is restricted $\left(\varepsilon_{2}=0\right)$ along the long dimension of the cross section by two immovable side steel platens (i.e., the specimen has a constant wide of $100 \mathrm{~mm}$ ). Figure (4.2) shows the geometry of the specimen and deformation conditions. The slenderness ratio is defined as the ratio of the height of the specimen to the dimension in which the specimen is free to deform. In this study, the slenderness ratio is $120 / 40=3$. The high slenderness ratio was chosen to allow free formation of shear band without reflecting on the end platens. Desrues (1995) observed for specimens with slenderness ratio of 2 that the shear band reflected to the end platen, or deviated towards the corner.

\subsubsection{The inner and outer cells}

As mentioned in section 4.2, the inner cell is totally enclosed within the outer cell. Deaired water is used to fill both cells. The cells are made of high quality acrylic. The outer cell is reinforced with steel bands (rings) to sustain confining pressures up to 1000 $\mathrm{kPa}$. No metal or fibreglass reinforcing rings were provided to the wall of the inner cell. Figures (4.3) and (4.4) show a detailed schematic diagram and a photograph of the double-wall biaxial device used in this study, respectively. The top cap of the inner cell is equipped with four plugs for air bleeding. Two of these plugs are connected to the top cap of the inner cell. These connections facilitate filling and emptying the inner and outer cells. Table (4.1) summarizes the dimensions of the inner and outer cells.

Figure (4.5) shows a photograph of the base of the cell in which the controlling valves, the side platen, and ball bearing are shown. In Figure (4.5), PAP and PWP refer to the pore-air and pore-water pressures, respectively.

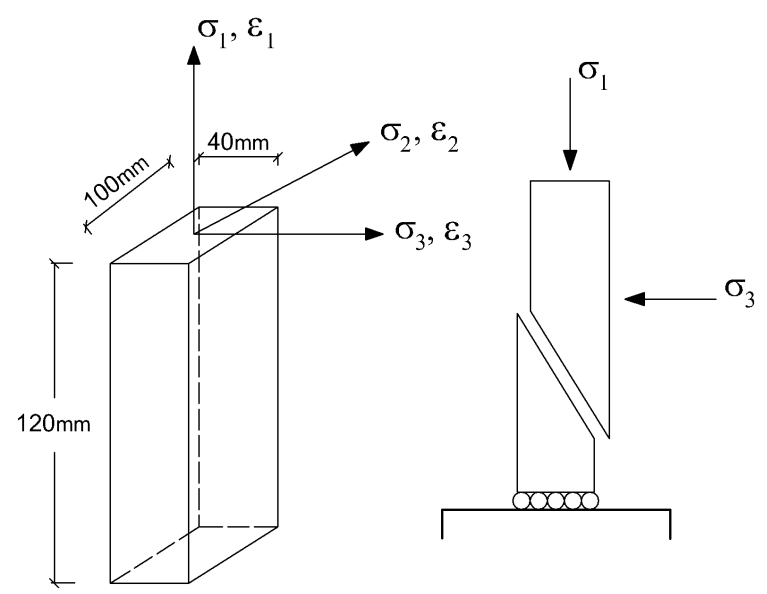

Figure (4.2) Geometry of the specimen and stress and strain conditions 


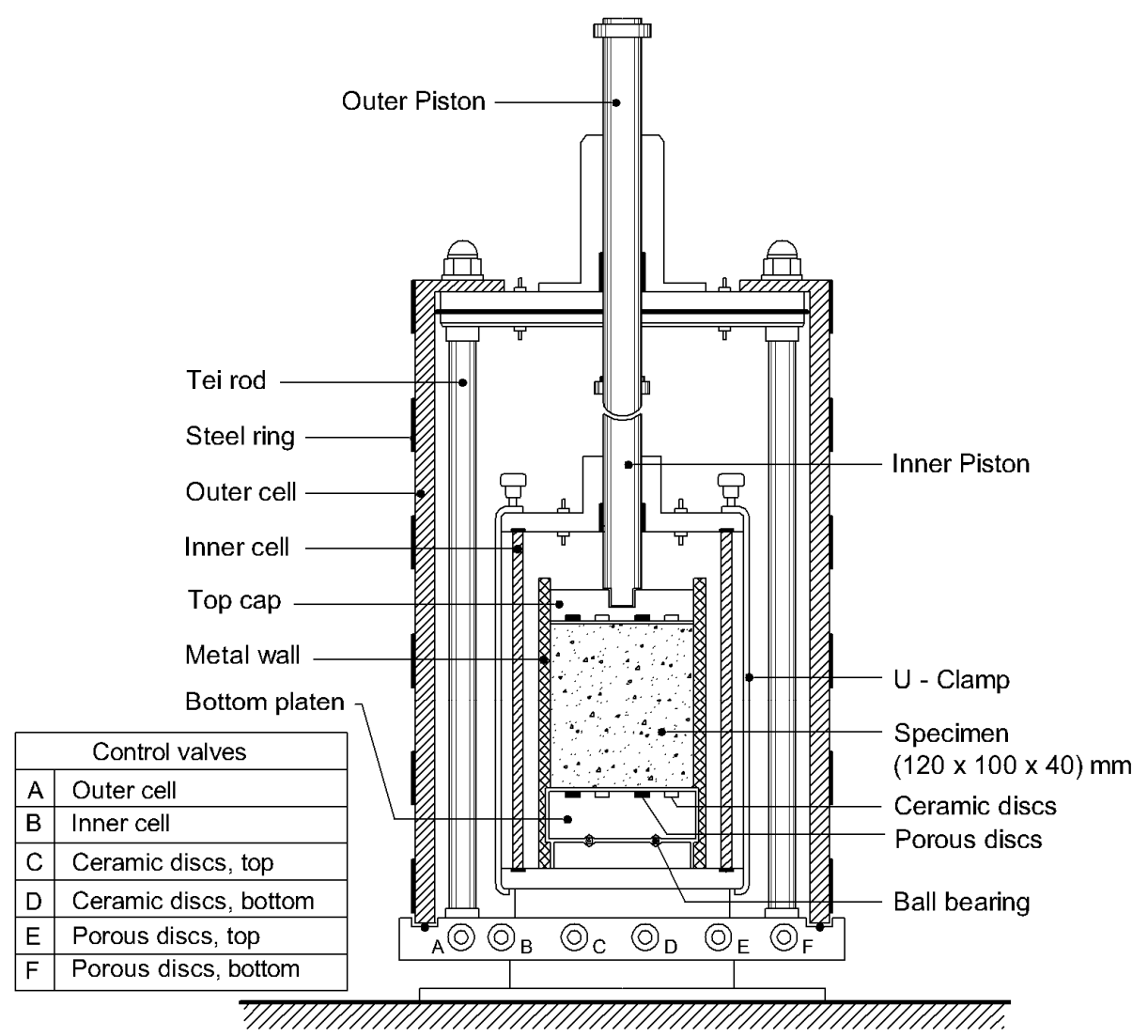

Figure (4.3) Double-wall biaxial cell (schematic diagram)

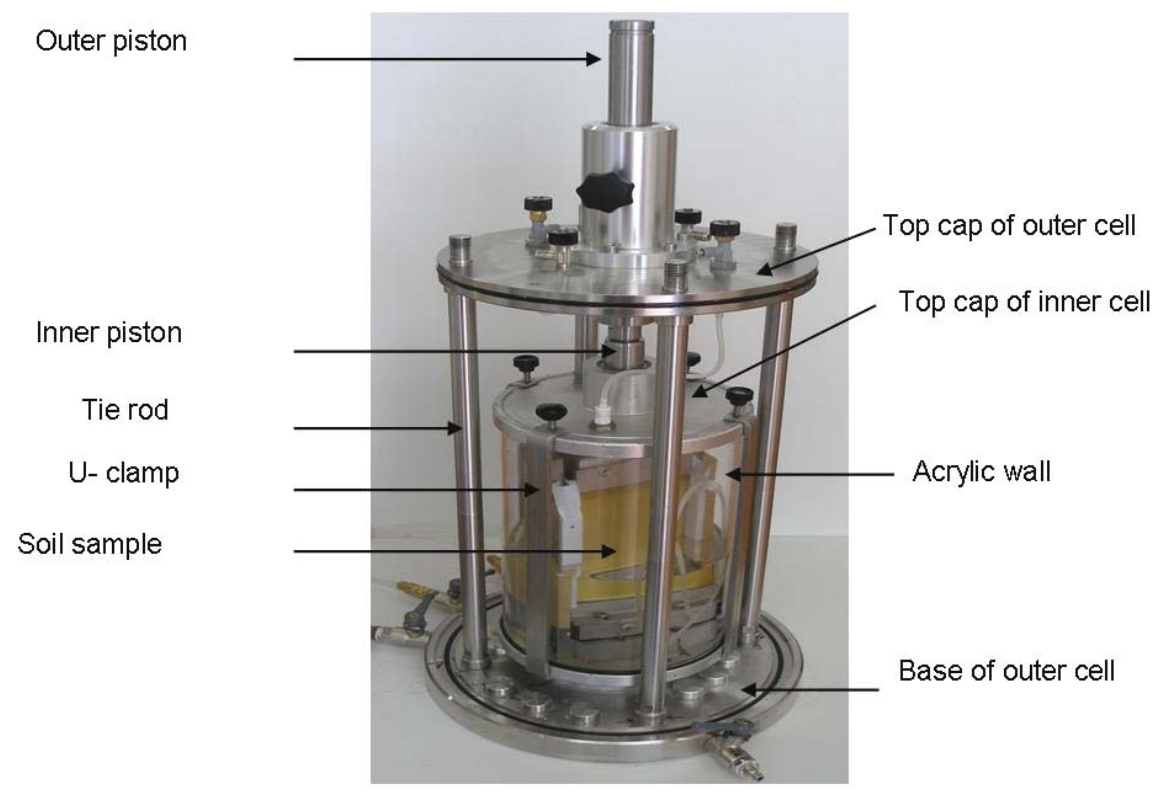

Figure (4.4) Photograph of the double-wall biaxial device (outer wall is not shown) 
Table (4.1) The dimensions of the inner and outer cells

\begin{tabular}{lcc}
\hline & Inner cell & Outer cell \\
\hline Diameter $(\mathrm{mm})$ & 175 & 270 \\
Height $(\mathrm{mm})$ & 270 & 470 \\
Thickness of the acrylic wall $(\mathrm{mm})$ & 5 & 8 \\
\hline
\end{tabular}

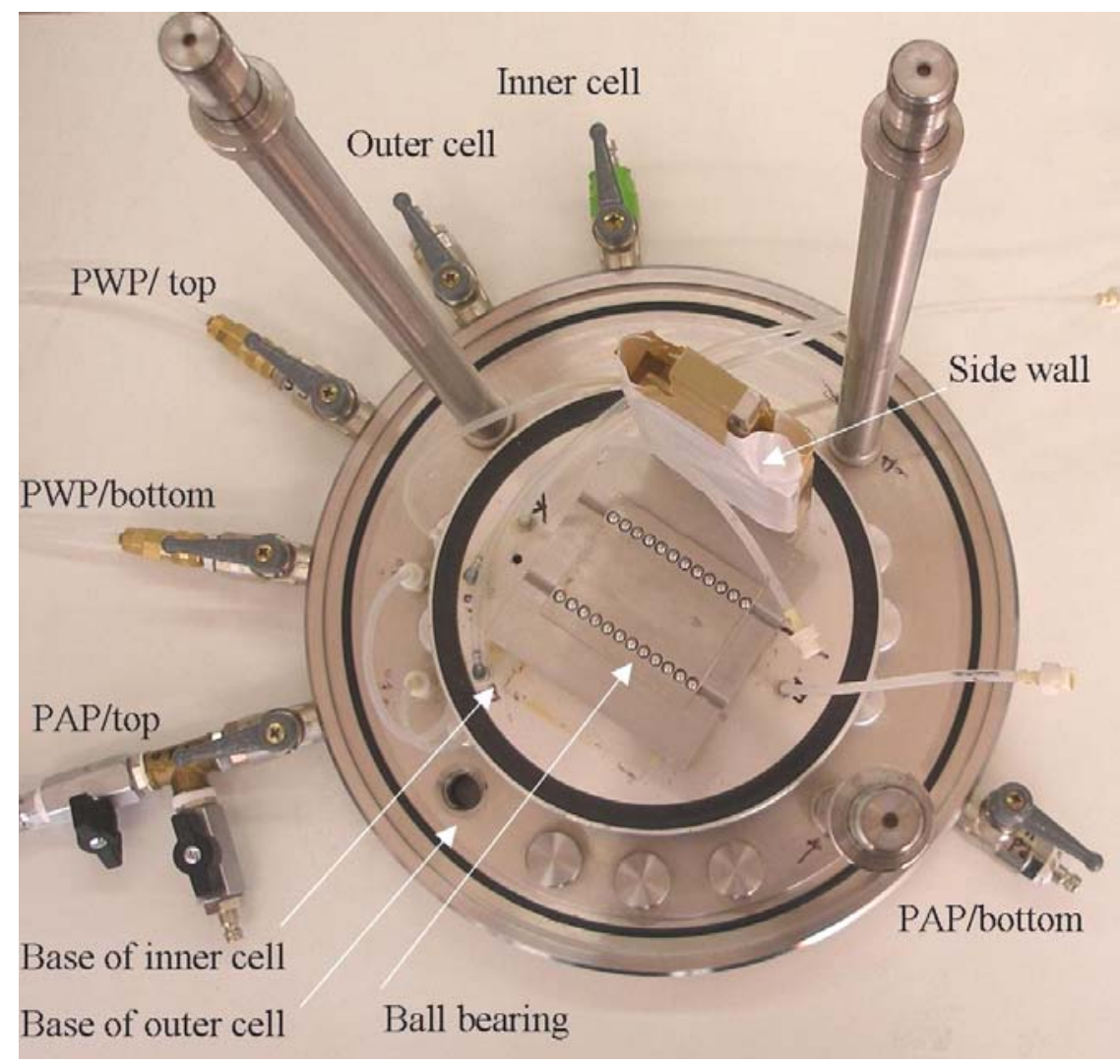

Figure (4.5) The base of the cell and the controlling valves
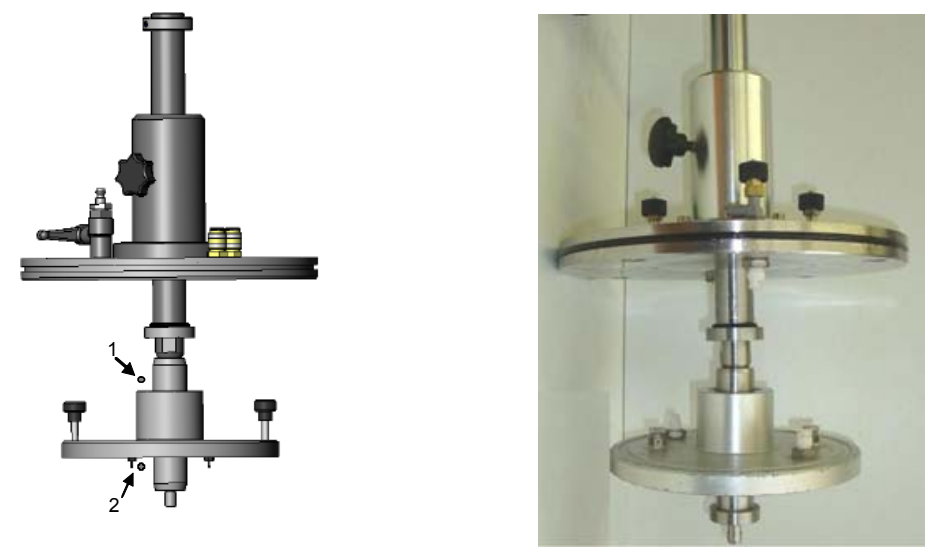

Figure (4.6) The outer and inner pistons 
The outer and inner pistons are $30 \mathrm{~mm}$ in diameter. The outer piston penetrates the top cap of the outer cell, and the inner piston penetrates the top cap of the inner cell. Due to the fact that the cell pressure is the same inside and outside the inner cell, there is no hydraulic gradient between point 1 and point 2 , and no leakage can occur between the shaft and the inner loading piston as shown in Figure (4.6). This will avoid errors in volume change measurements caused by water leakage.

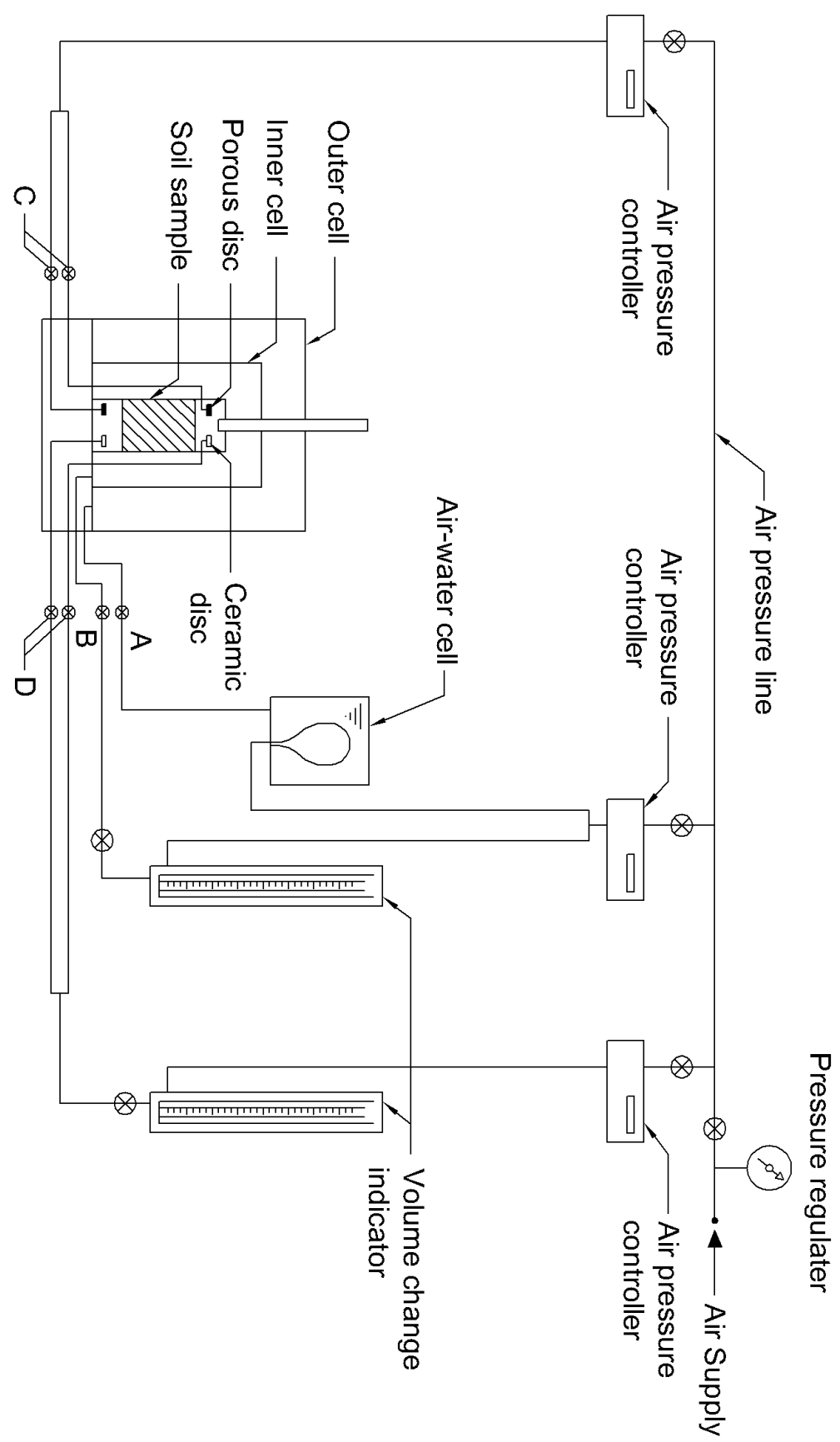

Figure (4.7) Layout of the double-wall biaxial system 
For the outer cell, where the volume change is not of interest, the pressure was applied using air-water cell. Twin-burette volume change indicators were used to measure the volume change of the pore-water phase and the overall volume change of the specimen. Figure (4.7) shows the layout of the double-wall biaxial system.

Figure (4.8) shows a photograph of the cell seated in the loading frame with the two volume change indicators connected to the cell. The loading frame is capable of applying static and dynamic forces to the specimen. In addition, the loading frame is quipped with a hydraulic pump which facilitates the application of the confining pressure statically and dynamically. The loading frame has two load cells with different capacities (i.e., $5 \mathrm{kN}$ and $40 \mathrm{kN}$ ).

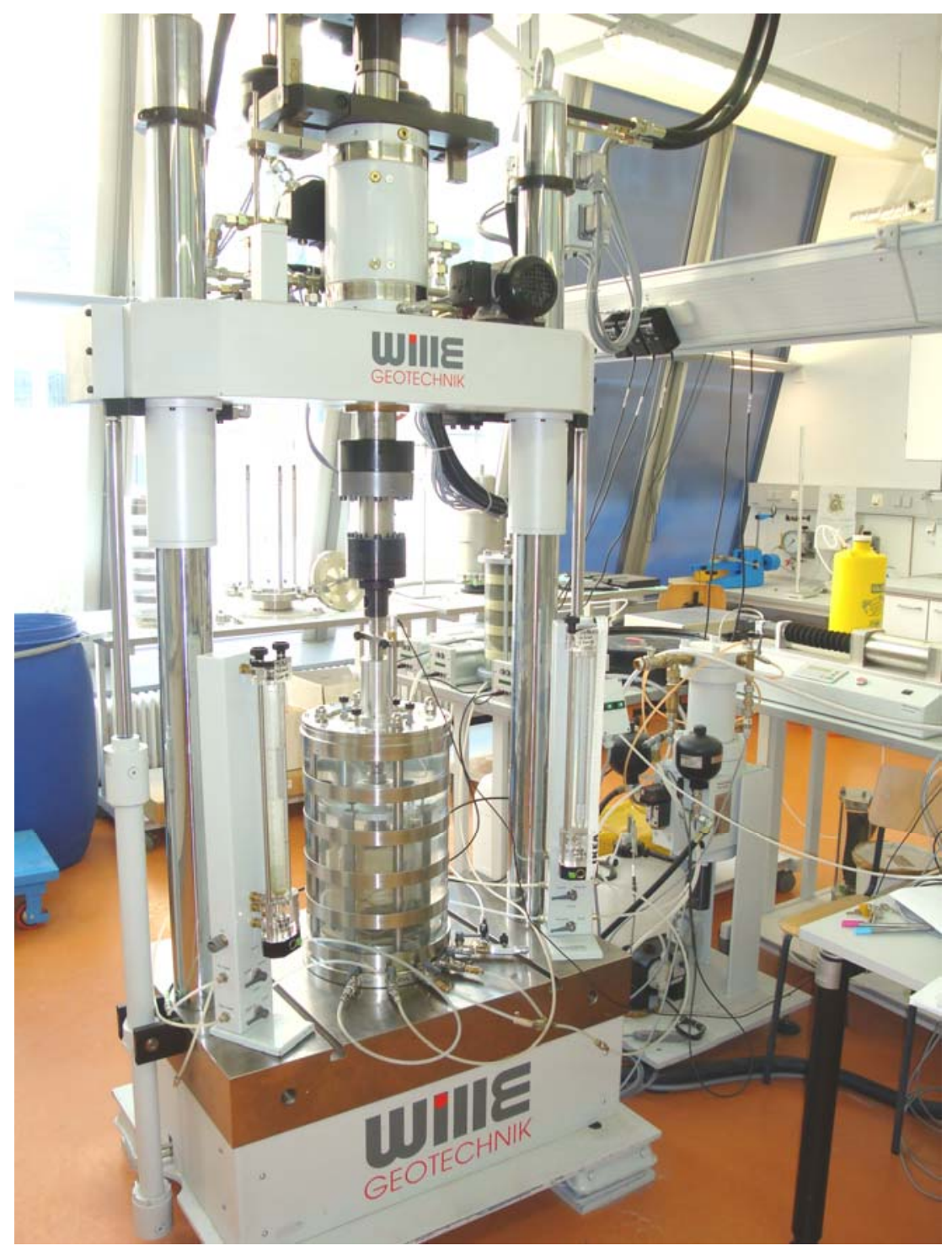

Figure (4.8) Biaxial test set up: the cell is seated in loading frame 


\subsubsection{The top cap and bottom platen}

Both top cap and bottom platen are equipped with two porous discs and two ceramic discs. The ceramic discs are used to apply pore-water pressure $\left(u_{\mathrm{w}}\right)$ whereas the porous discs are used to apply pore-air pressure $\left(u_{\mathrm{a}}\right)$ within the soil specimen. The ceramic discs and the porous discs are fixed to special metal plate. The ceramic discs are glued to the metal plates using an epoxy resin on its periphery. A tight seal between the ceramic disc and metal plate ensures that air will not leak into the water compartment under the ceramic disc. The metal plates are fixed with six screws to the base platen and top cap. To isolate the pore-water phase from the pore-air phase, four O-rings are used inbetween the metal plate and the base.

The ceramic discs and porous discs are $15 \mathrm{~mm}$ in diameter and $5 \mathrm{~mm}$ in thickness. The air-entry value of the ceramic discs used in this study is $100 \mathrm{kPa}$. The metal plates can be simply replaced with other plates provided with ceramic discs with higher air-entry value, enabling the application of higher values of matric suction and thus testing unsaturated soil in a wide range of matric suction. Figures (4.9), (4.10), and (4.11) show photographs of the exploded and assembled top cap and bottom platen.

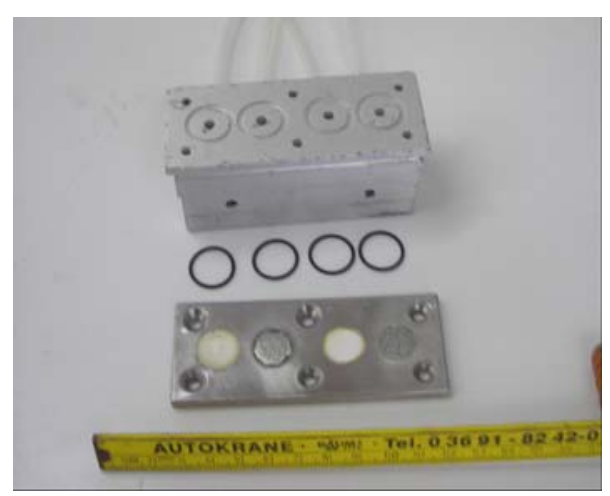

Figure (4.9) Top cap

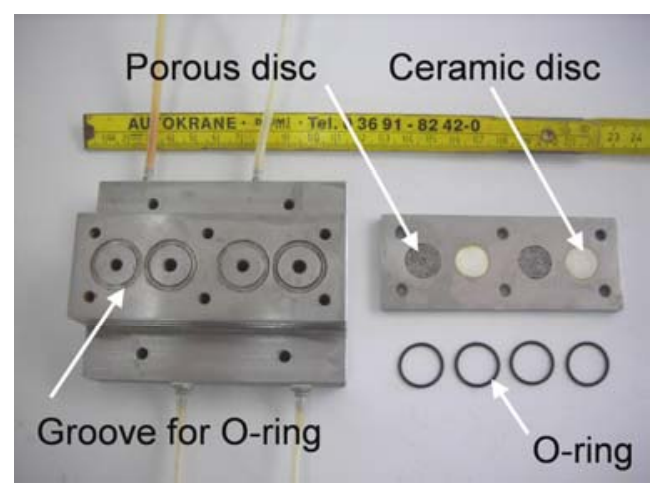

Figure (4.10) Bottom platen

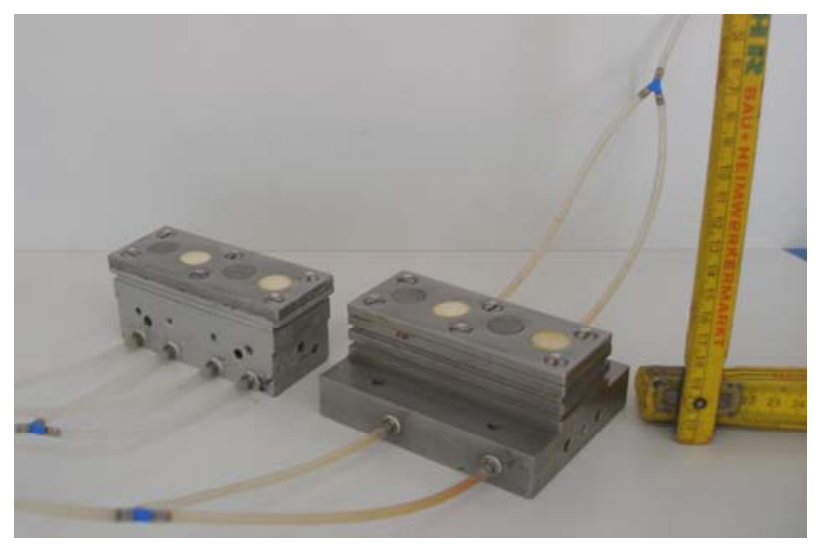

Figure (4.11) Assembled top cap and bottom platen 
Care should be taken while assembling the top cap and the bottom platen. The best way to install the metal plates onto the bottom platen or to the top cap is to assemble it under water. This will ensure that there is no air trapped in-between the metal plate and the base. Detailed description of assembling the top cap and bottom platen is presented in section 4.3.1.

An important feature of the new device is that both the pore-water pressure $\left(u_{\mathrm{w}}\right)$ and pore-air pressure $\left(u_{\mathrm{a}}\right)$ can be independently controlled at the top and bottom of the specimen. Therefore, a suction gradient can be applied enabling investigation of soil characteristics such as permeability and compressibility under suction gradient as illustrated in Figure (4.12). Detailed plan view and cross sections of the top cap and bottom platen are shown in Figures (4.13) and (4.14), respectively.

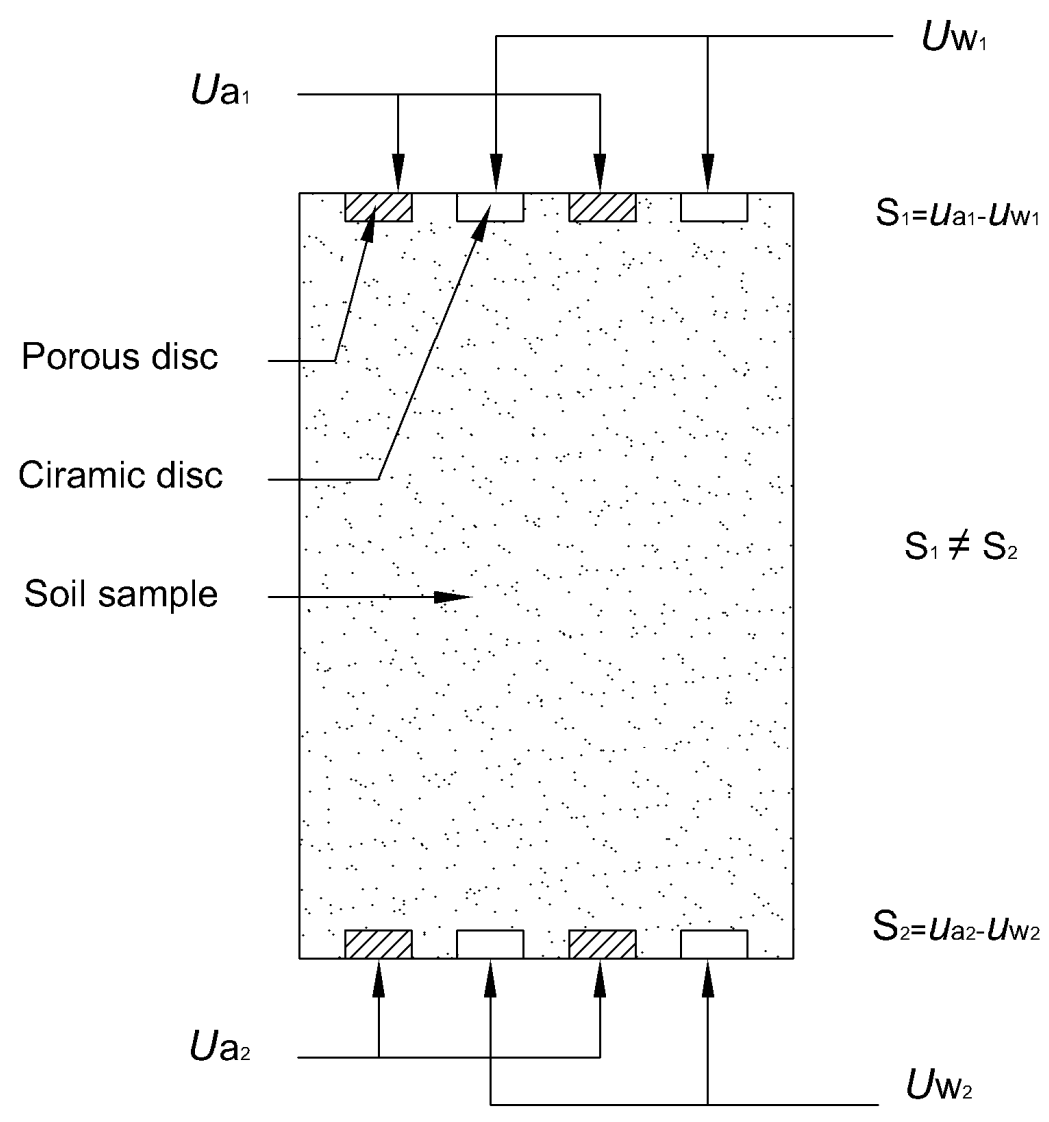

Figure (4.12) Suction gradient in soil specimen 

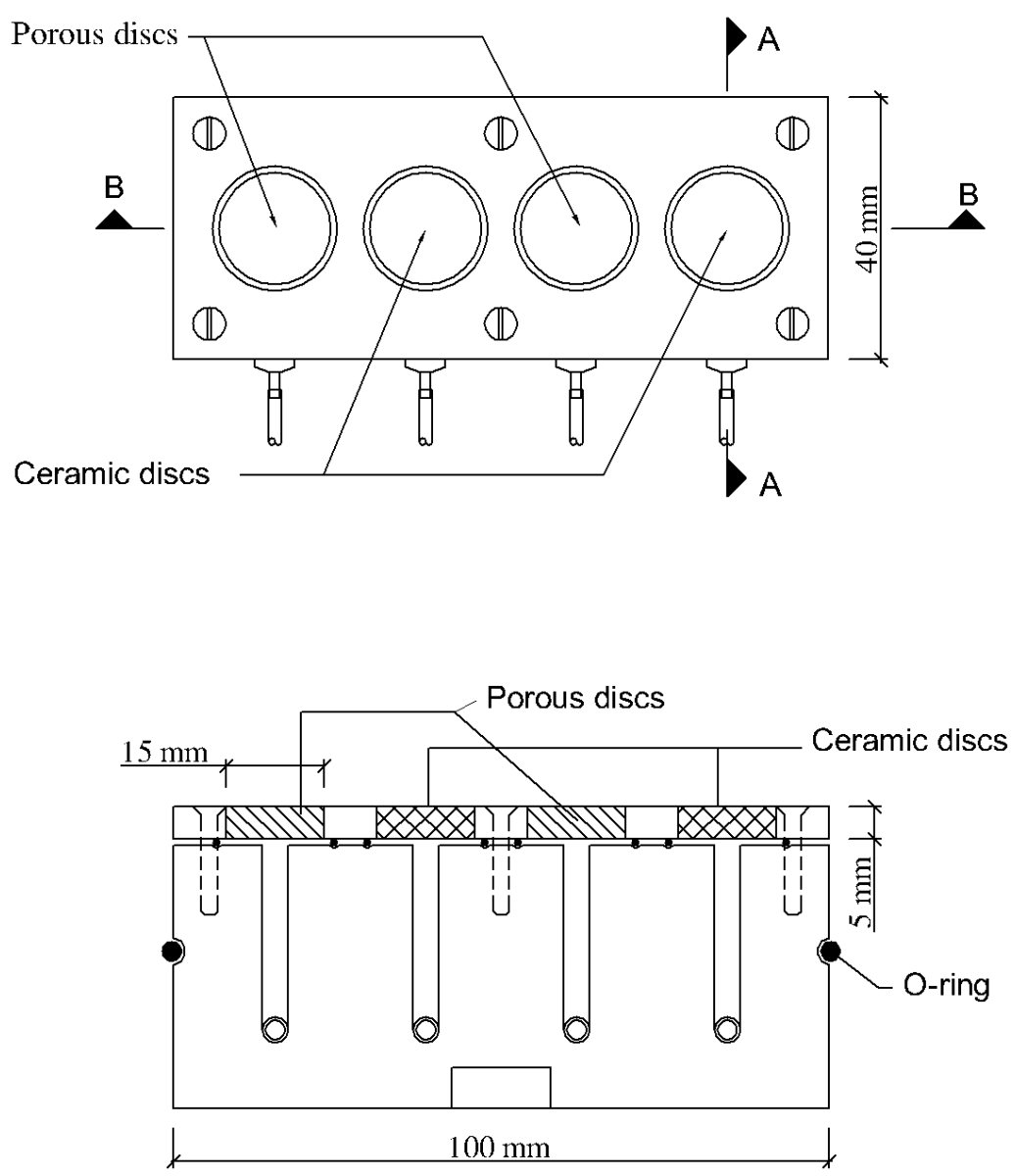

Sec B-B

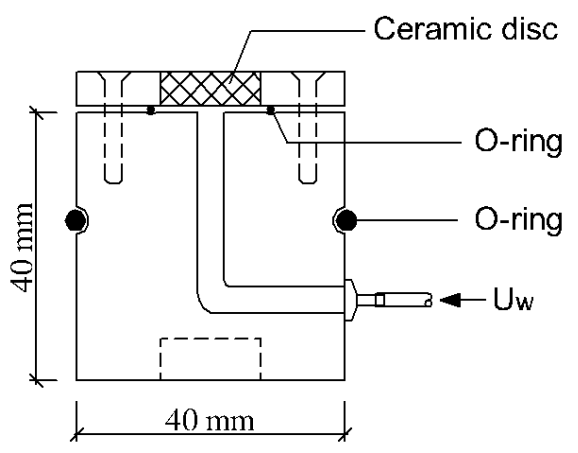

$\operatorname{Sec} A-A$

Figure (4.13) Plan view and cross section in the top cap 

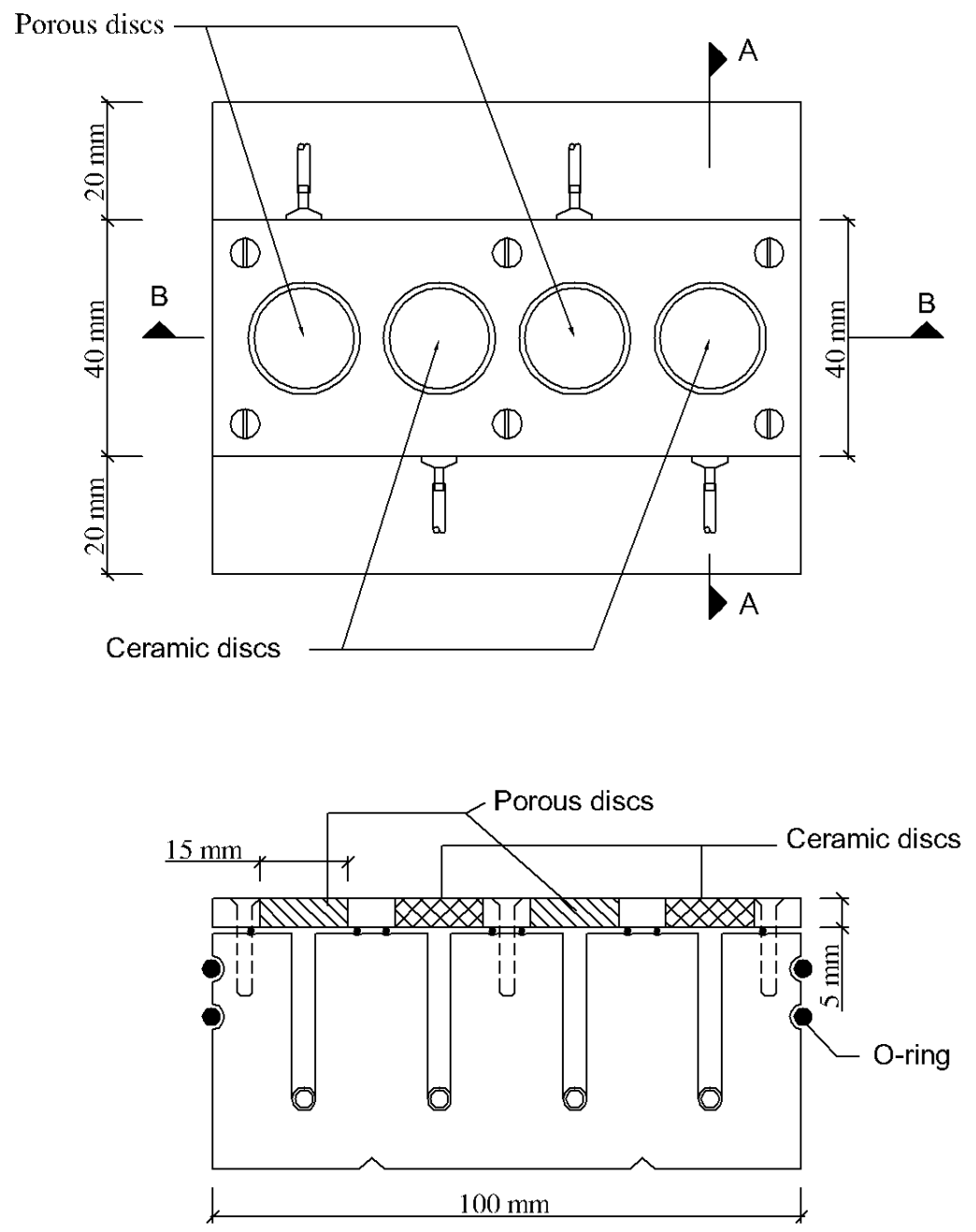

Sec B-B

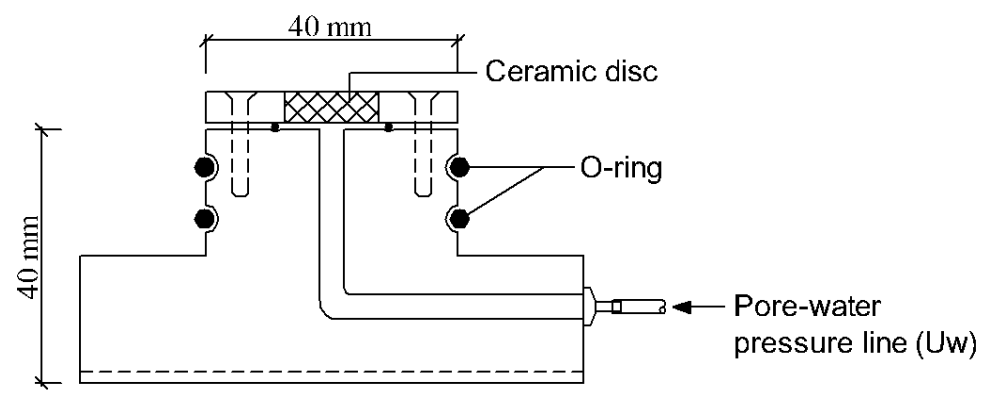

Sec A-A

Figure (4.14) Plan view and cross section in the bottom platen 


\subsubsection{The side platens and ball bearings}

The results presented by Lee (1970) confirmed the importance of using the side platens to attain the plane-strain conditions.

The plane-strain condition is imposed using two immovable stainless steel walls. The walls are $15 \mathrm{~mm}$ thick and $101 \mathrm{~mm}$ apart. Teflon sheets $0.25 \mathrm{~mm}$ in thickness were used to reduce the friction between the membrane and the metal side wall. Teflon sheets and silicon grease was used by Wanatowski (2005). Silicon grease was used in several biaxial devices to reduce the side friction (Tatsuoka et al., 1986; Yoshida et al., 1994).

Unrestrained end platen is of great importance in plane-strain tests. Kinematically, constrained end platens tend to curve the shear band unnaturally (Oda and Kazama, 1998).

To reduce the friction between the soil sample and the bottom end platen (i.e., end restraint), ball bearings with a slid are provided at the base of the sample. This anti friction system allows the translation of the lower portion (block) of the specimen relative to the top portion after the onset of the localization (i.e., shear band). In the new biaxial device, the end bottom platen can be fixed allowing performing compression biaxial tests with different end restrain conditions (i.e., fixed or free bottom end).

Several techniques were used to reduce end restrain effect in the biaxial devices proposed by different research groups. For example, a thin membrane greased with silicon oil was used by Oda and Kazama (1998) and Wanatowski (2005). Pillow block bearings were used by Alshibli et al. (2004). Figure (4.15) shows the two immovable side platens (walls) and ball bearing used in this study. 

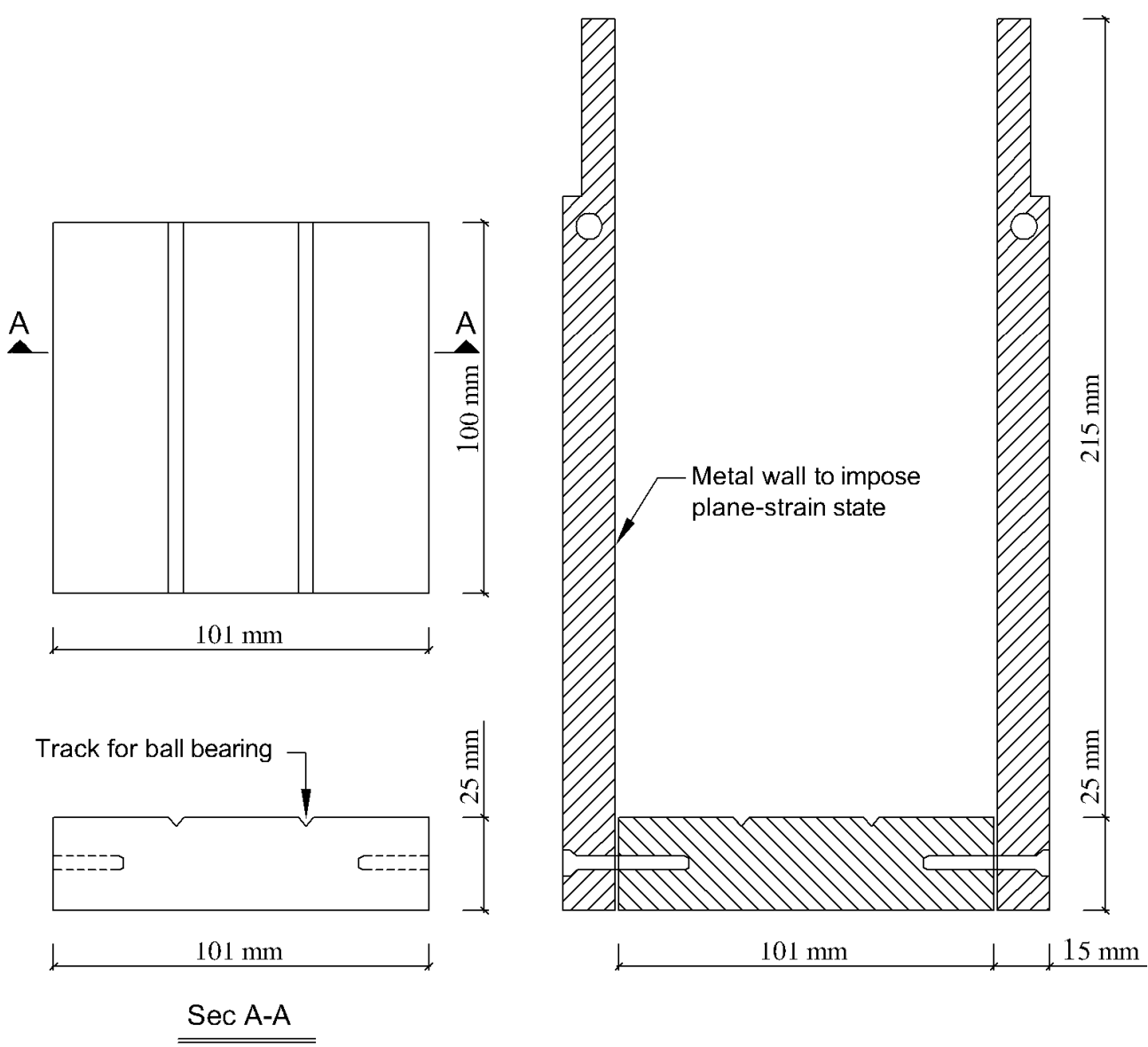

(a)

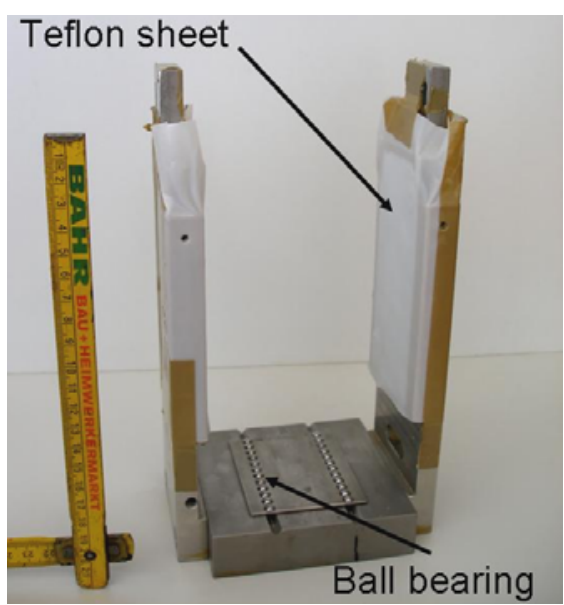

(b)

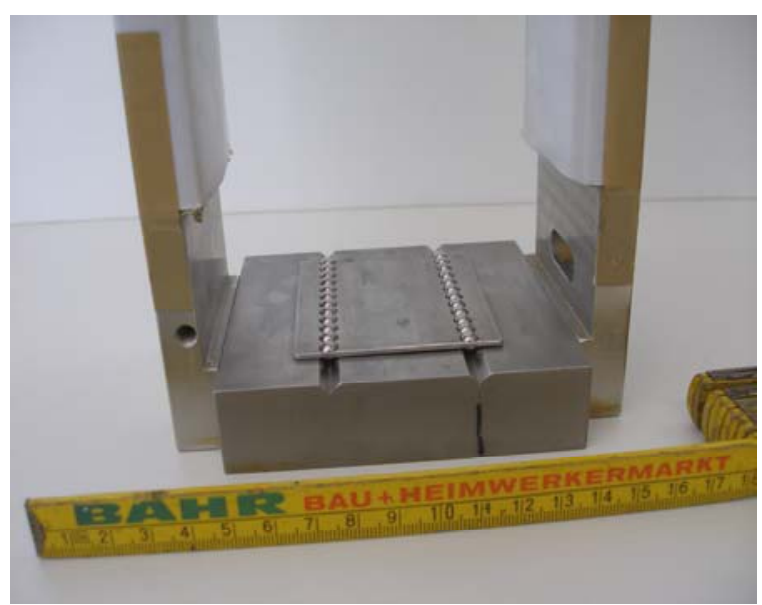

(c)

Figure (4.15) Side platens: (a) plane view and cross section; (b) photograph of the side platens covered with Teflon sheets; and (c) close view of the ball bearing 


\subsubsection{The split mould and membrane}

In order to prepare the rectangular (prismatic) specimen, a special two-part split mould was designed and manufactured. The mould is made of aluminum and equipped with special $5 \mathrm{~mm}$ thick porous stone on its inner surface to facilitate the application of vacuum in between the mould and membrane during the preparation of the sample. The vacuum is applied to align the latex membrane along the inner walls of the mould. Figure (4.16) shows the split mold used in this study.

In the present study the membrane is rectangular in cross section and it is made of high quality latex. The membrane is $0.4 \mathrm{~mm}$ thick and $200 \mathrm{~mm}$ high. Figure (4.17) shows the prismatic-shape membrane before it is cut to the desired height of the specimen. Due to the special shape of the specimen and membrane, the O-rings with their circular shape can not tighten the membrane against the top cap and bottom platen. Therefore, four metal plates were designed and manufactured to be fixed at the periphery of the top cap and base platen to tighten the membrane. Figure (4.18) shows the metal plates fixed partially onto the bottom platen of the specimen.

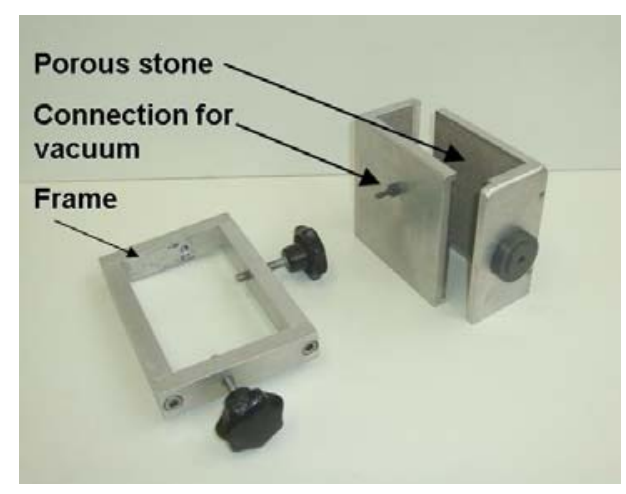

(a)

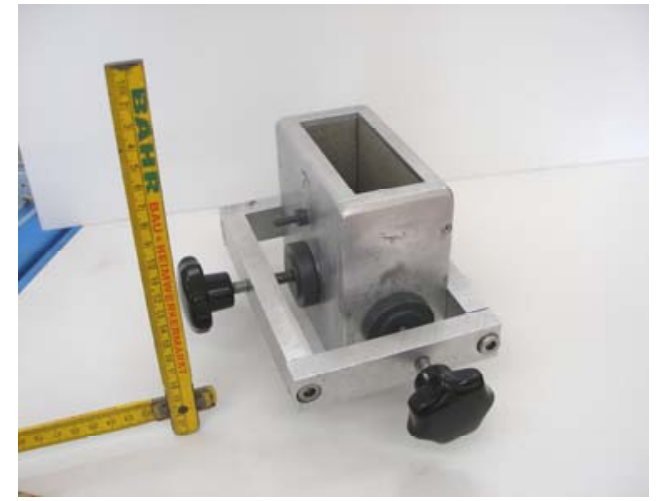

(b)

Figure (4.16) The split mould: (a) before assemblage; (b) full assemblage of the mould

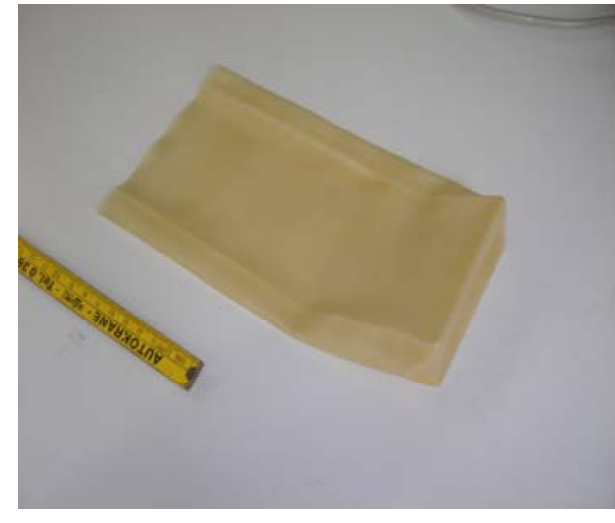

Figure (4.17) The prismatic membrane

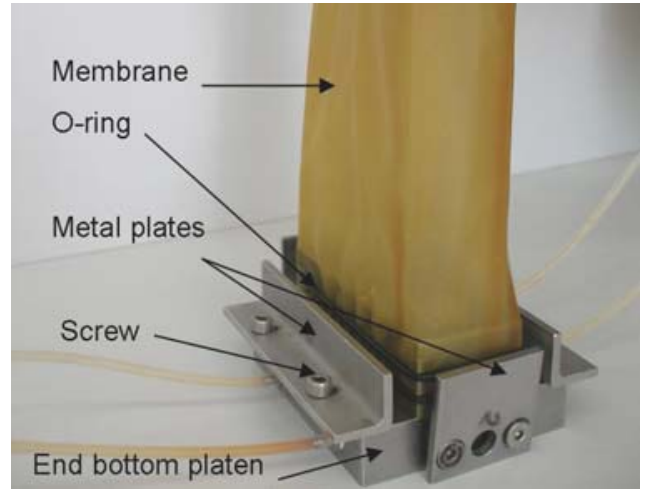

Figure ( 4.18) Metal plates at the bottom platen of the specimen 


\subsubsection{System calibrations}

To enable the new double-wall biaxial device to be used accurately in unsaturated soil testing, it was calibrated for the apparent volume change due to the application of cell pressure. In addition, loading ram displacement during the shearing stage should be considered. System components such as air pressure controllers and volume change indicator were carefully calibrated.

\subsubsection{Air pressure controller}

The air pressure controllers were used to apply and control the confining pressure in the inner and outer cell, pore-air pressure, and pore-water pressure. The accuracy of the applied pressure is of great importance specially when testing the soil under low confining pressures or low matric suctions.

The air pressure controllers were calibrated in two ranges of air pressure. The first range is from $0-10 \mathrm{kPa}$, and the second range is from $10-600 \mathrm{kPa}$. The calibration of the air pressure controllers for low pressure was conducted by connecting the air pressure controller to U-shape tube filled with water and open to atmosphere at the other end. Test setup is illustrated in Figure (4.19). Upon applying the air pressure $\left(\sigma_{a}\right)$, the water level will change in the tube. The applied air pressure is balanced by the weight of the water of the height $h_{i}$. The equilibrium condition can be expressed by the following equation:

$$
\sigma_{a}=h_{i} \cdot \gamma_{w}
$$

where $\sigma_{\mathrm{a}}$ is the applied air pressure, $\mathrm{h}_{\mathrm{i}}$ the difference in water level, and $\gamma_{\mathrm{w}}$ is the unit weight of water. Figure (4.20a) show the relationship between the applied air pressure $\left(\sigma_{i}\right)$ and the pressure calculated from the height of water column $\left(h_{i \cdot} \cdot \gamma\right)$. The calibration of the air pressure controllers under high pressures up to $600 \mathrm{kPa}$ was performed by connecting the air pressure controller to a precise pressure gauge. The relationships between the reading of the air pressure controller and the reading of the pressure gauge for the three air pressure controllers are presented in Figures (4.20b, c, and d). 


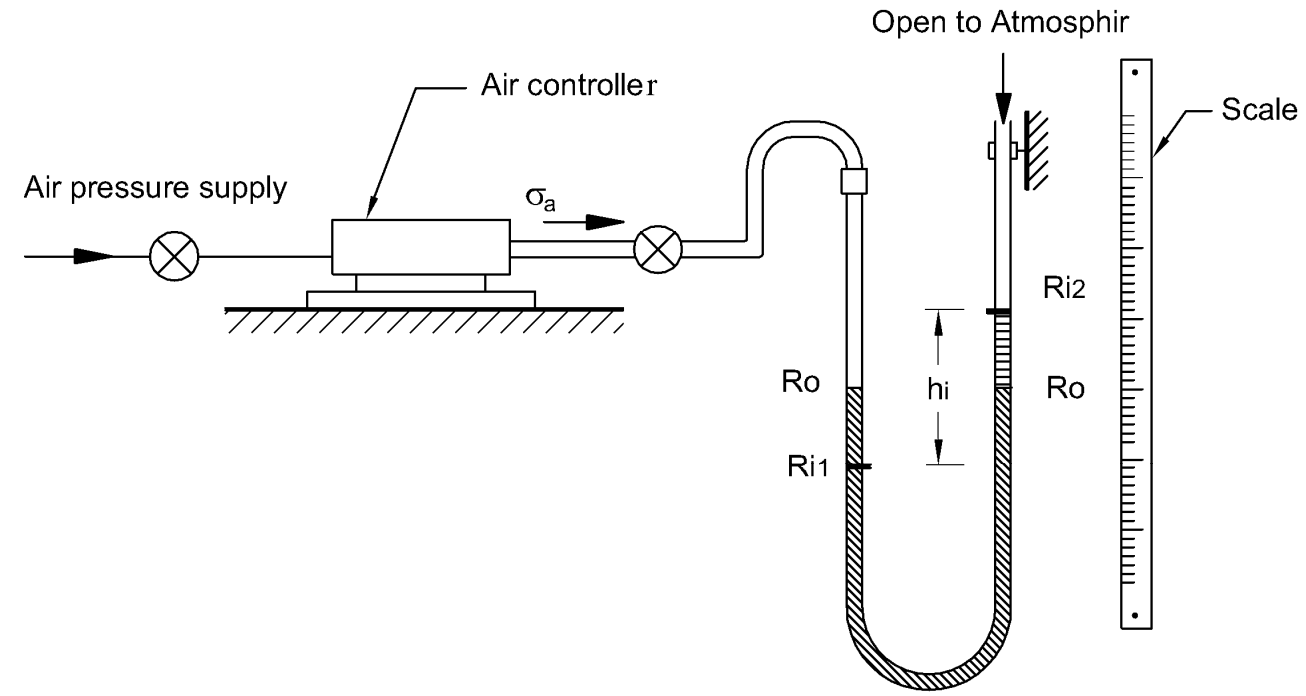

Figure (4.19) Calibration of the air pressure controller for low pressures

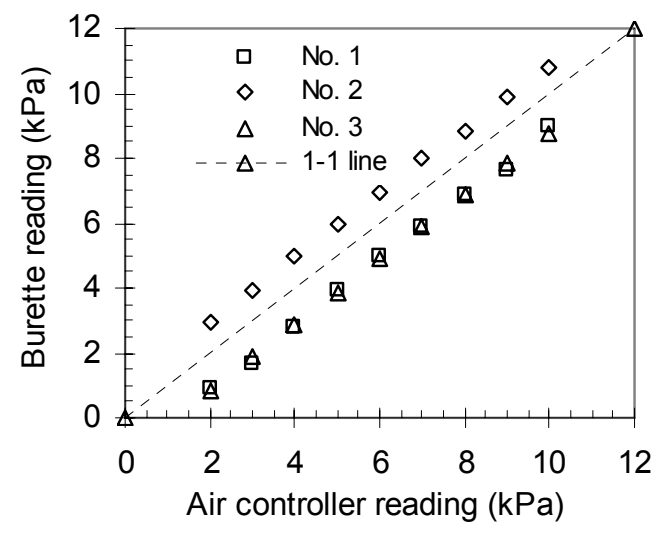

(a)

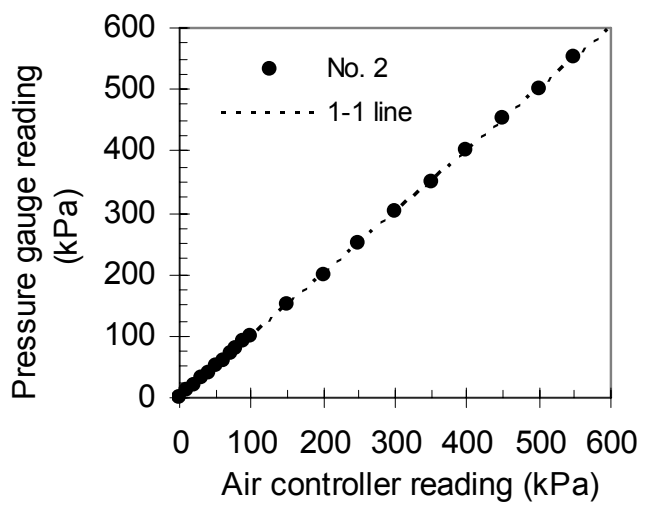

(c)

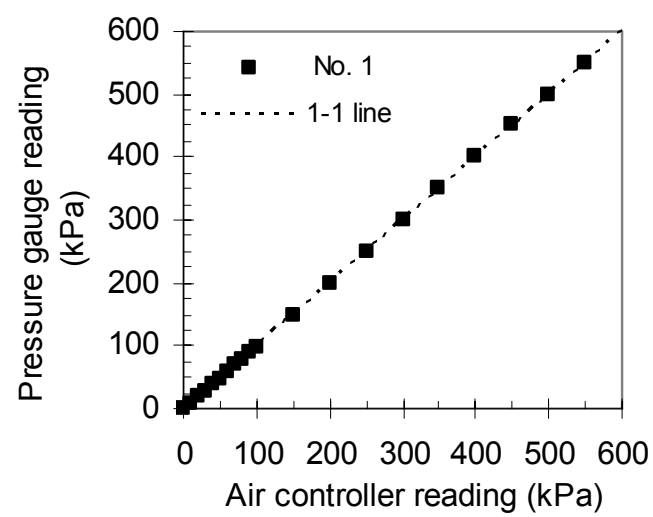

(b)

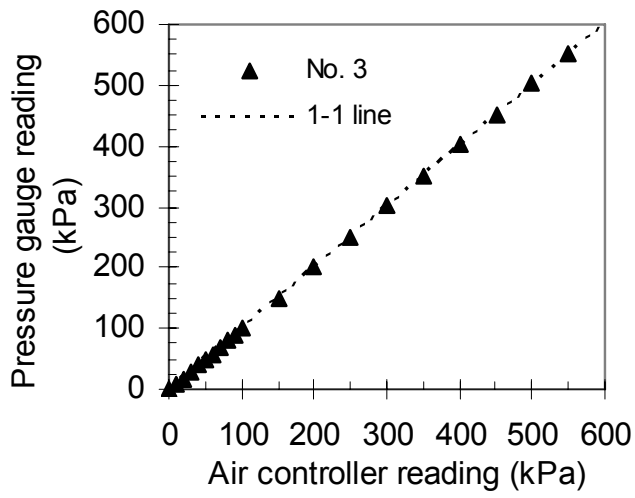

(d)

Figure (4.20) Calibration of air pressure controllers: (a) calibration for low pressures; (b, c, and d) calibration for high pressures 


\subsubsection{Calibration of volume change indicator}

Twin-burette volume change indicator was used to measure the volume changes. The calibration of this device was conducted by filling the burette stepwise with deaired water and recording the corresponding electrical reading of the data logger connected to the volume change indicator as shown in Figure (4.21). The calibration was conducted also in case of emptying the burette. The relationship between the electrical reading, $R_{e}$ $(\mu \mathrm{v})$, and the burette reading, $\mathrm{R}_{\mathrm{b}}(\mathrm{ml})$, is shown in Figure (4.22). The calibration best fitting line has the following equation:

$$
R_{e}=-0.0483 R_{b}+6.32
$$

where $R_{e}$ is the electrical reading of data logger $(\mu v)$ and $R_{b}$ is burette reading $(\mathrm{ml})$.

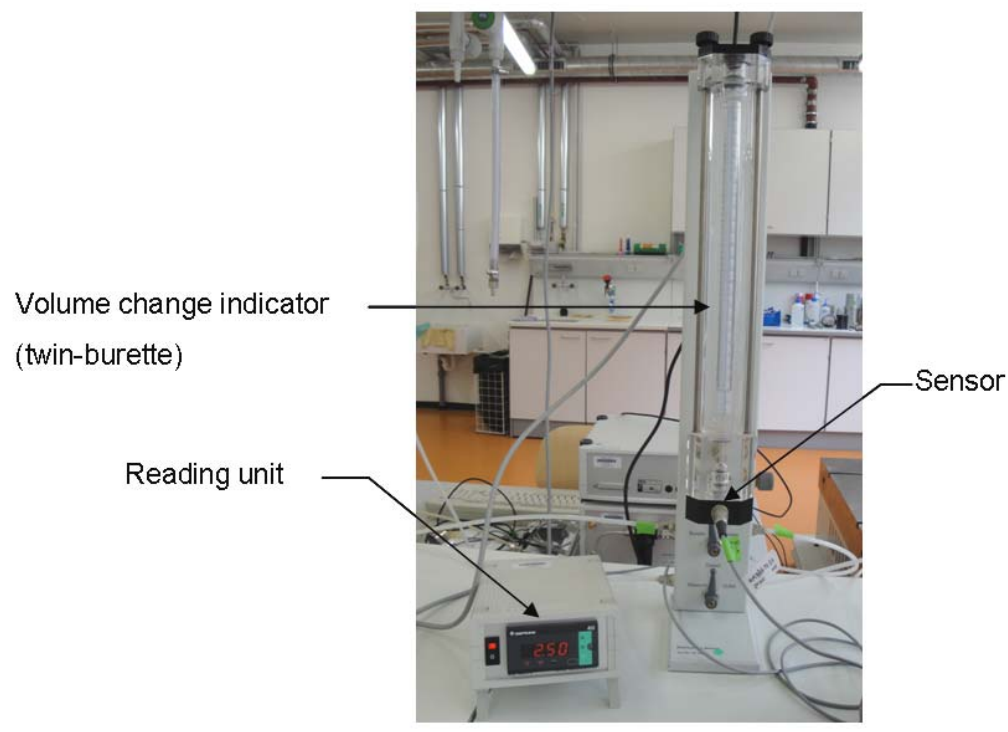

Figure (4.21) Photograph of volume change indicator and the reading unit

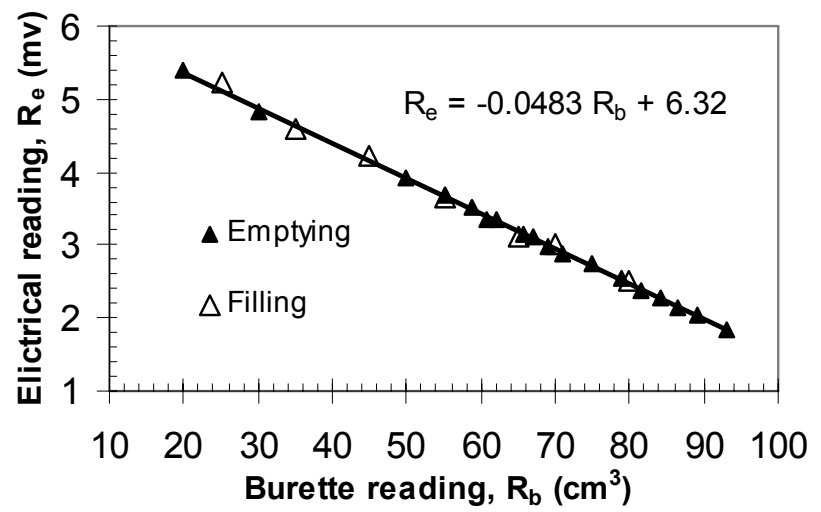

Figure (4.22) Calibration of the volume change indicator 


\subsubsection{Permeability of ceramic discs}

Ceramic discs were used to apply the pore-water pressure within unsaturated soil specimen. To ensure that the ceramic discs are not cracked and it works properly, the permeability of the ceramic discs was determined. The permeability of ceramic discs was determined by the following procedures:

1- The metal plates in which the ceramic discs are cemented (see figure (4.10)) were immersed in deaired water for 24 hours, then the metal plates were mounted in the outer cell. The cell was filled with deaired water and cell pressure of $200 \mathrm{kPa}$ was applied. The metal plates were left 24 hours under the cell pressure to ensure the fully saturation conditions of the ceramic discs. After this, the ceramic discs were installed (under water) on the top cap and bottom platen. Water was allowed to flow through the ceramic discs from a burette under small pressure of 20-30 $\mathrm{kPa}$.

2- The metal plates were installed and fixed to the bottom platen and top cap. The assemblage of the top cap and bottom platen has been performed completely under water to ensure the continuity of the water phase in the water pressure line.

3- Pressure gradient across the ceramic discs was applied by mean of a burette. The volume of the water flowing through the ceramic discs and the elapsed time were measured and recorded.

Two methods were adopted to apply water pressure through the ceramic discs. For low water pressures (i.e., up to $50 \mathrm{kPa}$ ), the water pressure was applied through the water pressure line below the ceramic discs. This procedure was performed to avoid the cracks in the ceramic discs due to the high uplift pressures. Experience showed that thin ceramic discs may crack easily. Uplift pressure of $70 \mathrm{kPa}$ on a $3.2 \mathrm{~mm}$ thick ceramic disc can produce cracks in the disc (Fredlund, 1973). The cracks may not be visible to the naked eye, but are evident during an air-entry or permeability test on the disc (Fredlund and Rahardjo, 1993).

For higher pressure the assembled top cap and bottom platen were mounted in the outer cell. The outer cell was filled with deaired water and cell pressure was applied producing a gradient across the ceramic disc. The volume of water flowing through the ceramic discs is measured using volume change indicator. Figures (4.23) and (4.24) show the test set up in the permeability tests of the ceramic discs for low water pressure and high water pressure, respectively. In Figures (4.25a) and (4.25b), the volume of water flowed through the ceramic discs is plotted against the elapsed time for the top cap and bottom platen, respectively. The straight line indicates a steady-state flow through the 
ceramic discs. The relationship of the hydraulic conductivity versus the applied water pressure is plotted in Figure (4.25c). The results of permeability tests of the ceramic discs show that the average hydraulic conductivity of the ceramic discs is $k_{a v}=2 \times 10^{-8} \mathrm{~m} / \mathrm{sec}$. The average measured values of the hydraulic conductivity of ceramic discs used in this study are close to that reported in the literatures.

Fredlund and Rahardjo (1993) reported a hydraulic conductivity of $8.6 \times 10^{-8}$ $\mathrm{m} / \mathrm{sec}$ for 1 bar (100 kPa) air-entry value ceramic disc. According to Blight (1966), for ceramic disc with $152 \mathrm{kPa}$ air-entry value, the hydraulic conductivity is $2.1 \times 10^{-9} \mathrm{~m} / \mathrm{sec}$. The measured values of the hydraulic conductivity shows that the ceramic discs have no cracks and the discs can be used to apply matric suction within the soil specimen.

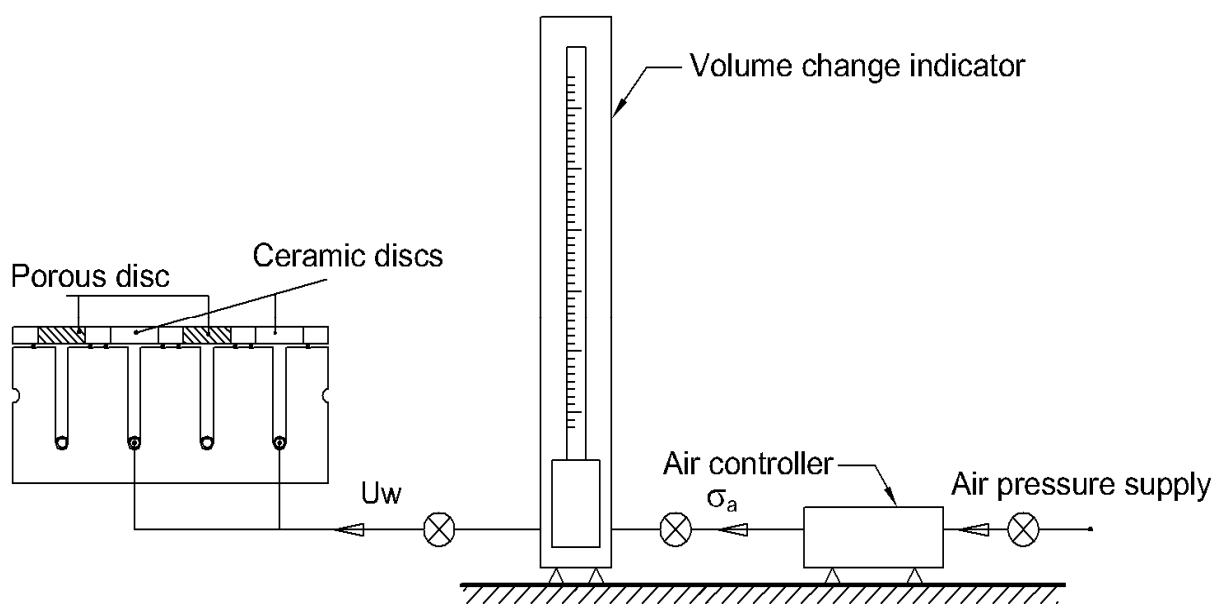

Figure (4.23) Setup of permeability test of ceramic discs under low water pressure

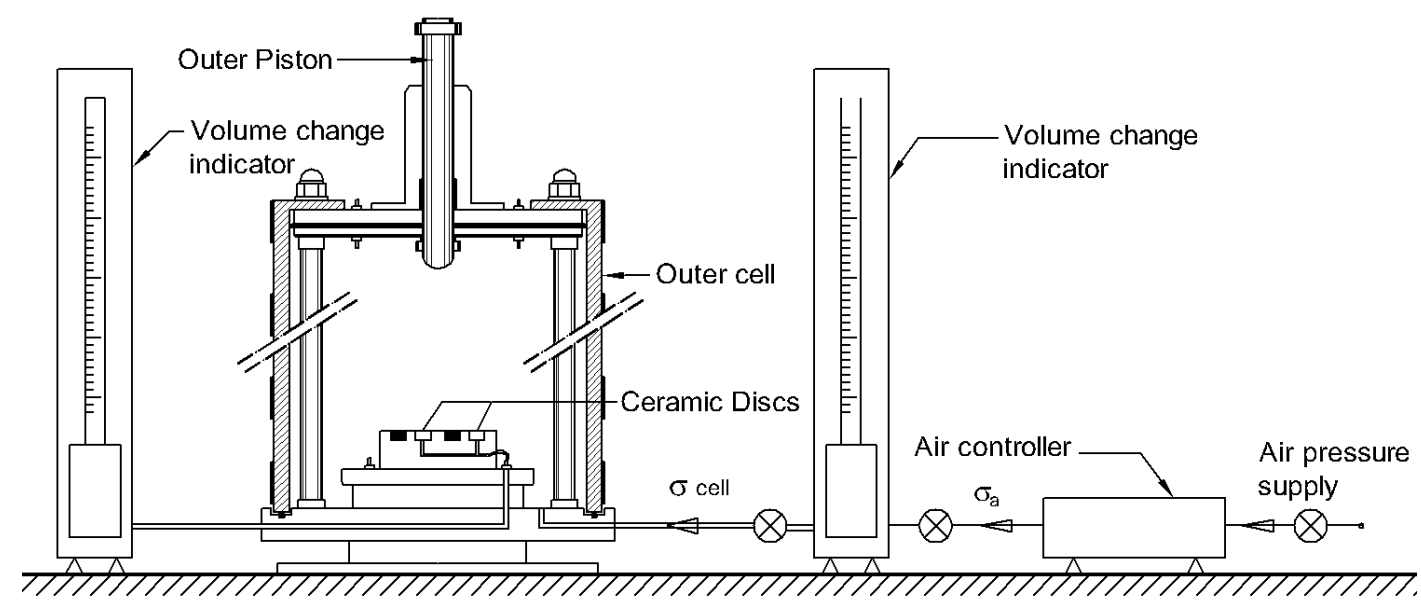

Figure (4.24) Setup of permeability test of ceramic discs under high water pressure 


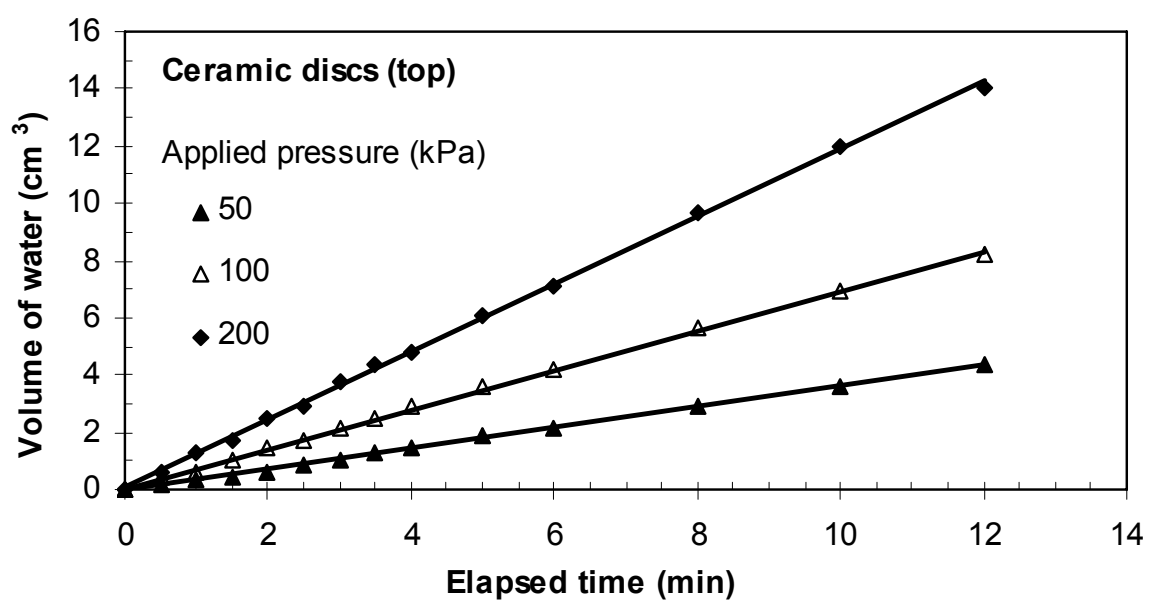

(a)

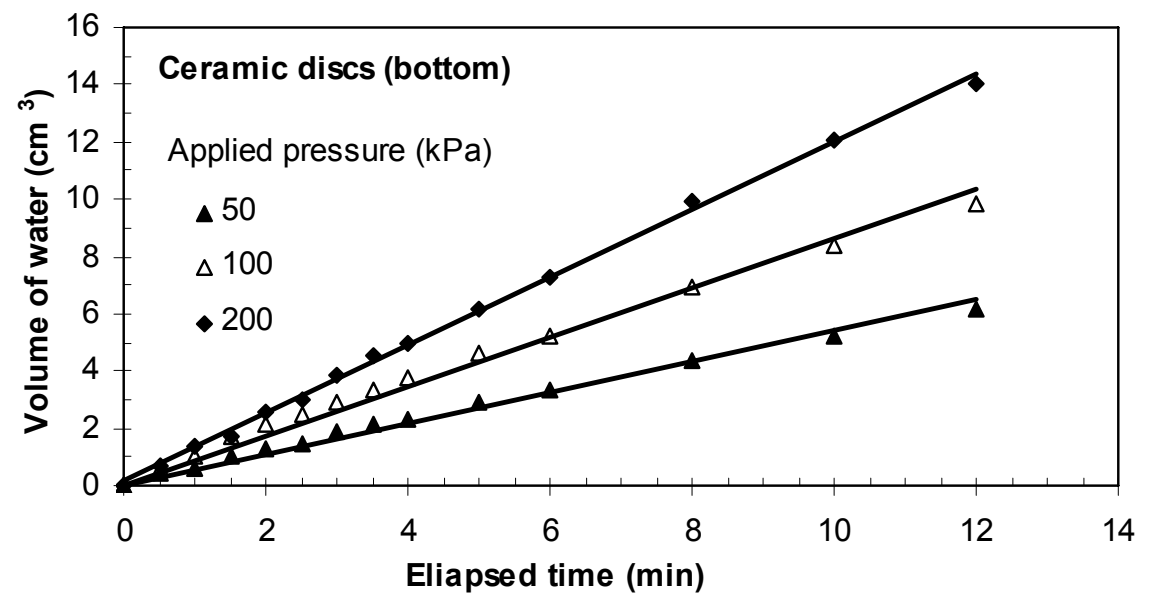

(b)

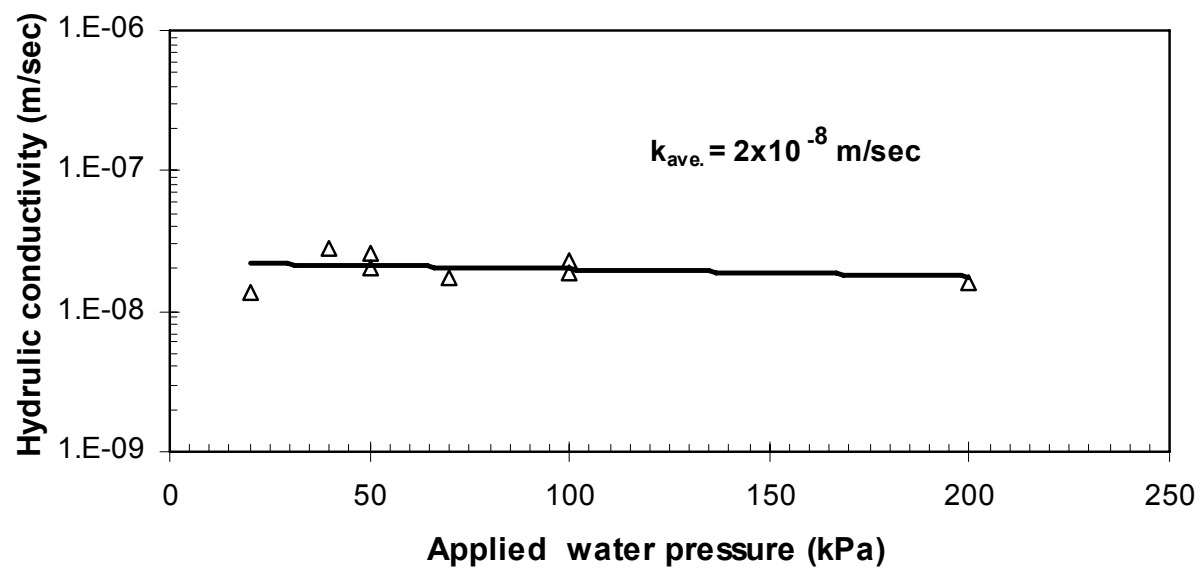

(c)

Figure (4.25) Permeability of the ceramic discs: (a) steady state flow through the ceramic discs at the top cap; (b) at the bottom platen; and (c) hydraulic conductivity versus applied water pressure 


\subsubsection{Inner cell expansion due to the application of cell pressure}

Theoretically, no volume change is expected to occur in the double-wall cell system, but; volume changes may occur in the inner cell due to several factors:

1. The time delay in pressure application to the inner and outer cells and the hysteretic properties of acrylic (Sivakumar, 1993).

2. The slackness of the tubes, connections, and valves in the system.

3. Temperature effect: fluctuations in a wide range can result in considerable error in the measurement volume changes (Agus et al., 2003; Sivakumar, 2002; Ng, 2002).

4. The absorption of water by the acrylic wall of the inner cell. Wheeler (1986) tried to prevent the absorption of water by coating the wall of the inner cell with a waterproofing spray or polyurethane varnish, or even by trying to replace water with another cell fluid that would not be absorbed by the acrylic wall. All theses trail and measures failed to prevent the absorption by the wall of the inner cell.

5. The compression of the wall of the inner cell due to the applied pressure onto both side of the wall.

6. The compression of the water within the inner cell: in the double wall cell proposed by Wheeler (1986), it was found that the compressibility of water account for about one third of the total volume changes of the inner cell. The compression of the water can be calculated using the following equation:

$$
\Delta V_{w}=C_{w} . V_{o} . \Delta \sigma
$$

where:

$\Delta V_{\mathrm{w}}$ is the volume change of water $\left(\mathrm{cm}^{3}\right)$

$V_{\mathrm{o}}$ is the volume of water $\left(\mathrm{cm}^{3}\right)$

$\Delta \sigma$ is the change in applied pressure $(\mathrm{kPa})$

$\mathrm{C}_{\mathrm{w}}$ is the compressibility factor of water, $\mathrm{C}_{\mathrm{w}}=4.58 \times 10^{-7}(1 / \mathrm{kPa})$.

The overall volume change of the inner cell due to the application of the cell pressure was determined using a dummy metal sample. The two cells were filled with deaired water and the cell pressure was applied stepwise. The immediate volume change was recorded. The calibration curve is presented in the Figure (4.26). The calibration of the inner cell was carried out in a wide range of the confining pressure (i.e., 0 - $600 \mathrm{kPa}$ ). The compression of the water of the inner cell due to the applied pressure is also shown in Figure (4.26).

The hysteresis of the system was examined by performing the loading and unloading paths. The cell pressure was increased stepwise from 0 to $600 \mathrm{kPa}$, and then it 
was reduced to zero stepwise following the same loading path. Figure (4.26) shows good repeatability of the overall volume change of the inner cell during the loading and unloading processes. As shown in the figure, the non-linearity occurred in calibration curve can be due to the slackness in the valves and tube fittings in the first increments of cell pressure.

\subsubsection{Calibration of the inner cell using a saturated soil specimen}

The reliability of the system was checked by testing a saturated sample in isotropic consolidation test. For a saturated sample, the volume change of the specimen during the test (i.e., total volume change) is equal to the volume of water drained out from the specimen.

A saturated Hostun sand specimen was prepared with initial void ratio $\mathrm{e}_{0}=0.72$. The cell pressure was applied simultaneously to the outer and inner cell. The volume change of the saturated specimen was measured using two methods, namely $\mathrm{A}$ and B. In method A, the double wall cell technique was used (i.e., by measuring the volume changes of the fluid of the inner cell). In method $B$, the volume of water expelled out from the specimen was measured using a burette with accuracy of $0.1 \mathrm{~cm}^{3}$. Figure (4.27) shows the volume changes measured by the two methods versus the applied confining pressure. The measurements showed good agreement between the volume changes measured by method A and B.

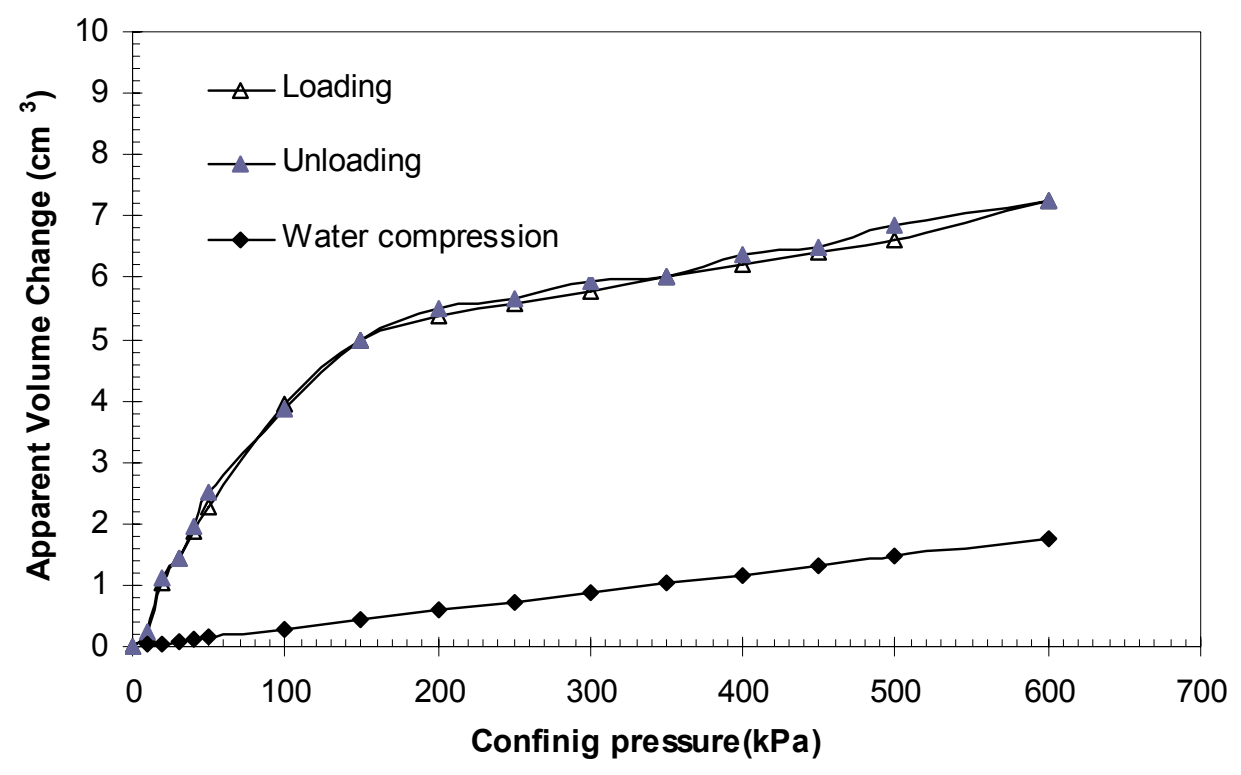

Figure (4.26) Calibration of the inner cell due to the application of cell pressure 


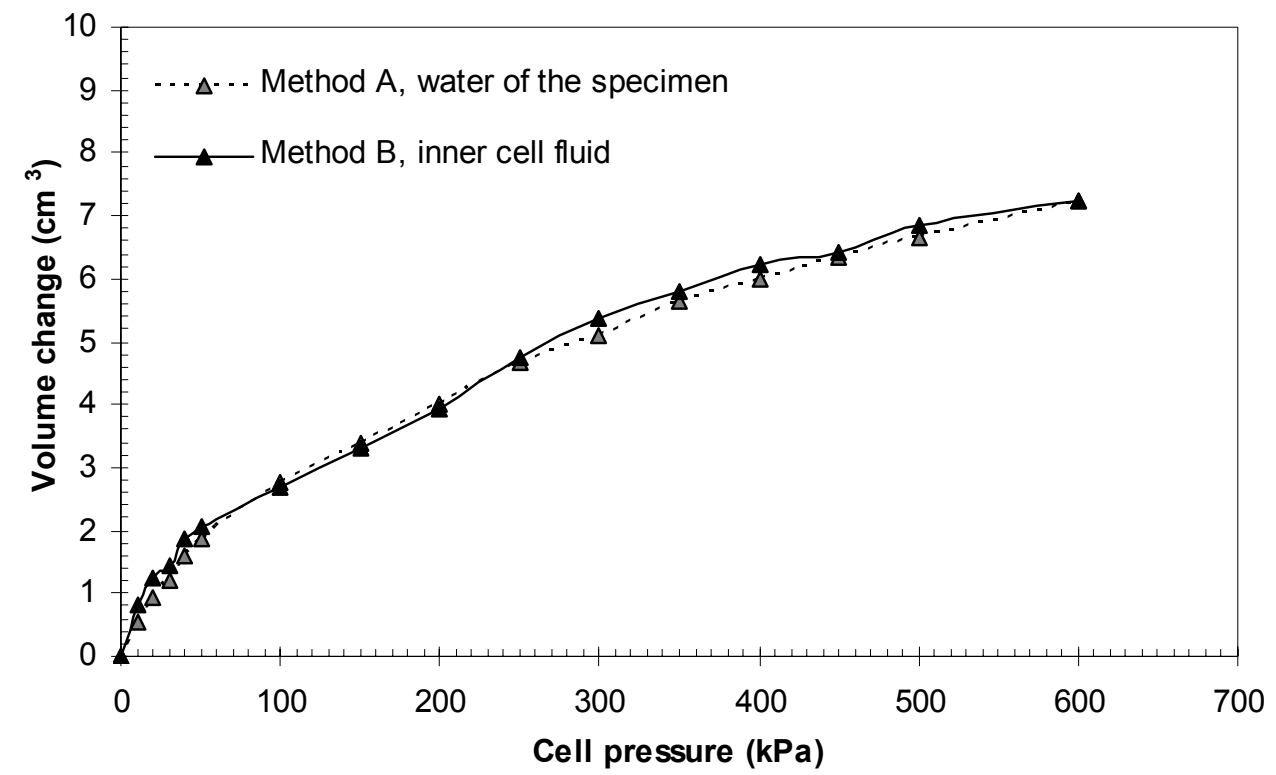

Figure(4.27) Volume changes of saturated sample measured by two methods: A and B

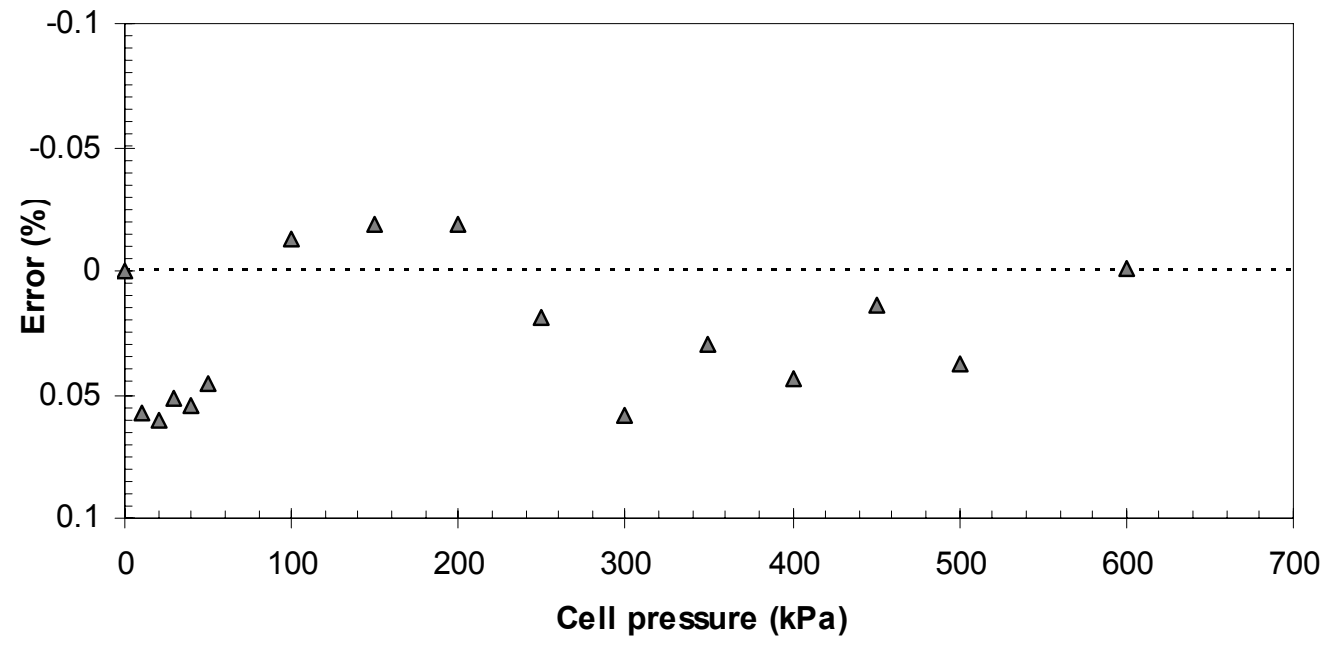

Figure (4.28) Error in the volume change of saturated soil sample measured by two methods (A and $\mathrm{B}$ ) versus confining pressure

Figure (4.28) shows the error shows error in the volume change measurements of saturated soil sample using methods A and B. The figure shows that the maximum error in volume change measurements between method $\mathrm{A}$ and $\mathrm{B}$ is about $0.07 \%$. This value of error in volume change measurements is an acceptable value in unsaturated soil testing as reported by Geiser et al. (2000). 


\subsubsection{Verification of the concept of stress state variables using the new double-wall biaxial device}

Two null tests were conducted on an equalized soil sample under specific stress state. The test is termed null, because the expected result is to measure no volume changes due to the change in the values of the individual pressures (Fredlund and Rahardjo, 1993). But, it is difficult to measure zero volume change over a long period of time, so it is expected to measure a slight volume changes due to several factors such as imperfect testing procedure, air diffusion through the ceramic disc, water loss of the specimen through the evaporation or diffusion, and secondary consolidation (Fredlund and Morgenstern, 1977).

Null tests were performed on Hostun sand-kaolin mixture. The mixture consists of $10 \%$ kaolin and $90 \%$ sand. The specimen has an initial void ratio of 0.56 , coefficient of uniformity of 1.95 , and $\mathrm{d}_{50}$ of $0.35 \mathrm{~mm}$. The specimen was compacted in the special mold and saturated using back pressure method. The back pressure value at the end of saturation stage was $60 \mathrm{kPa}$ and cell pressure was $70 \mathrm{kPa}$.

The axis translation technique (ATT) was used to create the matric suction within the soil specimen. The specimen was equalized under: confining (cell) pressure $\left(\sigma_{\text {cell }}\right)$ of $80 \mathrm{kPa}$, pore-air pressure $\left(u_{\mathrm{a}}\right)$ of $70 \mathrm{kPa}$, and pore-water pressure $\left(u_{w}\right)$ of $60 \mathrm{kPa}$. Thus, the net confining pressure $\left(\sigma-u_{\mathrm{a}}\right)=10 \mathrm{kPa}$ and the matric suction $\left(u_{\mathrm{a}}-u_{\mathrm{w}}\right)=10 \mathrm{kPa}$.

Upon attaining the equilibrium, i.e., when no volume changes were observed, the individual pressures were changed with the same increment so that the stress state variables (i.e., the net confining pressure and the matric suction) were kept constant and equal to their initial values. Pore-air pressure was applied through the porous discs, whereas pore-water pressure was applied through the ceramic discs with air-entry value of $100 \mathrm{kPa}$. Both pore-water and pore-air pressures were applied at the top and bottom of the specimen. Table (4.2) summarizes the pressure applied and the corresponding stress state variables used in the tests.

Table (4.2) Pressures applied (kPa) in the null-tests

\begin{tabular}{lccccc}
\hline & $\sigma_{\text {cell }}$ & $u_{a}$ & $u_{w}$ & $\left(\sigma-u_{a}\right)$ & $\left(u_{a}-u_{w}\right)$ \\
\hline Null test 1 & 100 & 90 & 80 & 10 & 10 \\
Null test 2 & 250 & 240 & 230 & 10 & 10 \\
\hline
\end{tabular}


Figures (4.29) and (4.30) show the total volume changes and the water volume changes measured in a period of two days in null test No.1 and No.2, respectively. The overall volume changes measured in the tests can be attributed to the creep of the system, water absorption by acrylic wall of the cell, and diffusion of water and air through the latex membrane. The membrane is not completely impervious to water (Head, 1986).

To investigate the effect of the possible creep of the inner cell, two creep tests without samples were conducted at constant cell pressure (i.e., 100 and $250 \mathrm{kPa}$ ) and the volume changes of the inner cell were recorded for two days. The overall volume changes due to the creep of the cell are also shown in Figures (4.29) and (4.30).

The volume changes due to the creep of the inner cell were subtracted from the apparent volume changes. By considering the net volume changes of the soil specimens, it can be noticed that the volume of the specimens remains almost constant in the period of two days.

The water volume changes which were measured as water leaving the specimen during the test can be attributed to the diffusion of air to the water phase of the specimen (Fredlund and Morgenstern 1977).

To evaluate the accuracy of the volume change measurement, the corrected volumetric strain $\varepsilon_{v}$ can be given as:

$$
\varepsilon_{v}=\varepsilon_{v m} \pm \beta
$$

where $\varepsilon_{\mathrm{v}}$ is the corrected volumetric strain, $\varepsilon_{\mathrm{vm}}$ is the measured volume change, and $\beta$ is the absolute error. The value of $\beta=0.1 \%$ was proposed by Geiser et al. (2000) as an accepted absolute error in measuring the volumetric strain in triaxial tests on unsaturated soils (Leong et al. 2003). In the null tests carried out using the new double-wall biaxial device, the maximum measured volumetric strain, $\varepsilon_{\mathrm{v}}$, was $0.07 \%$. 


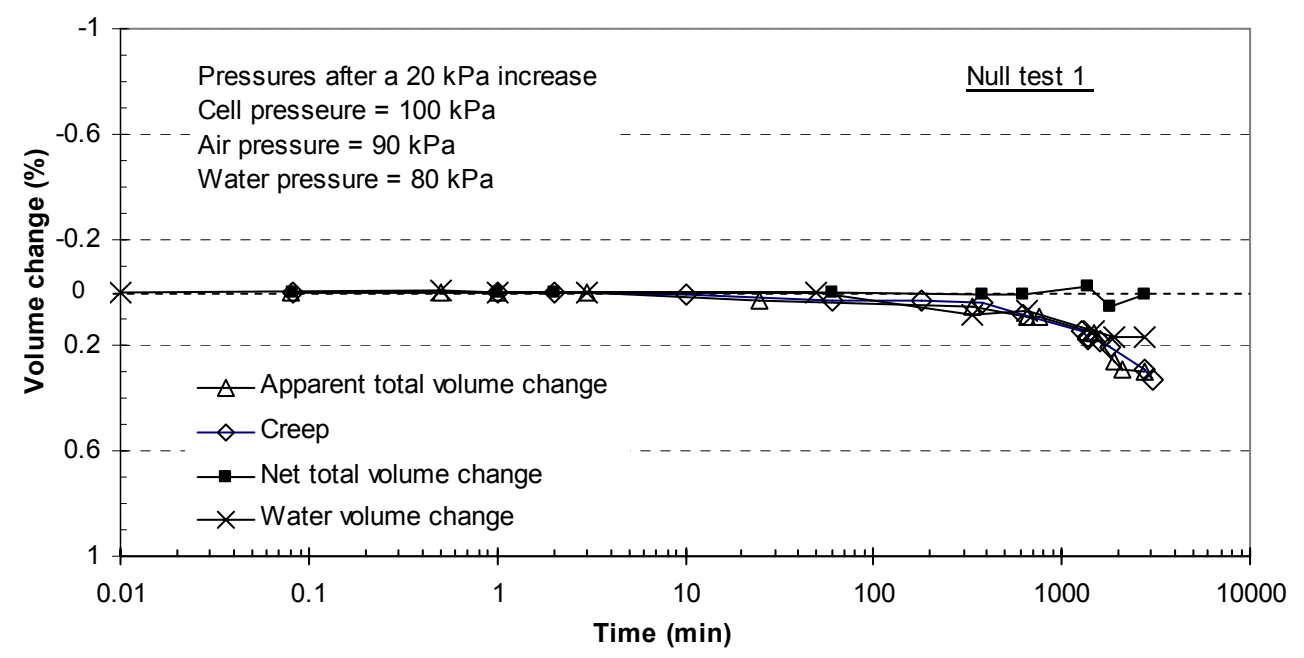

Figure (4.29) Volume change versus elapsed time in Null test No. 1

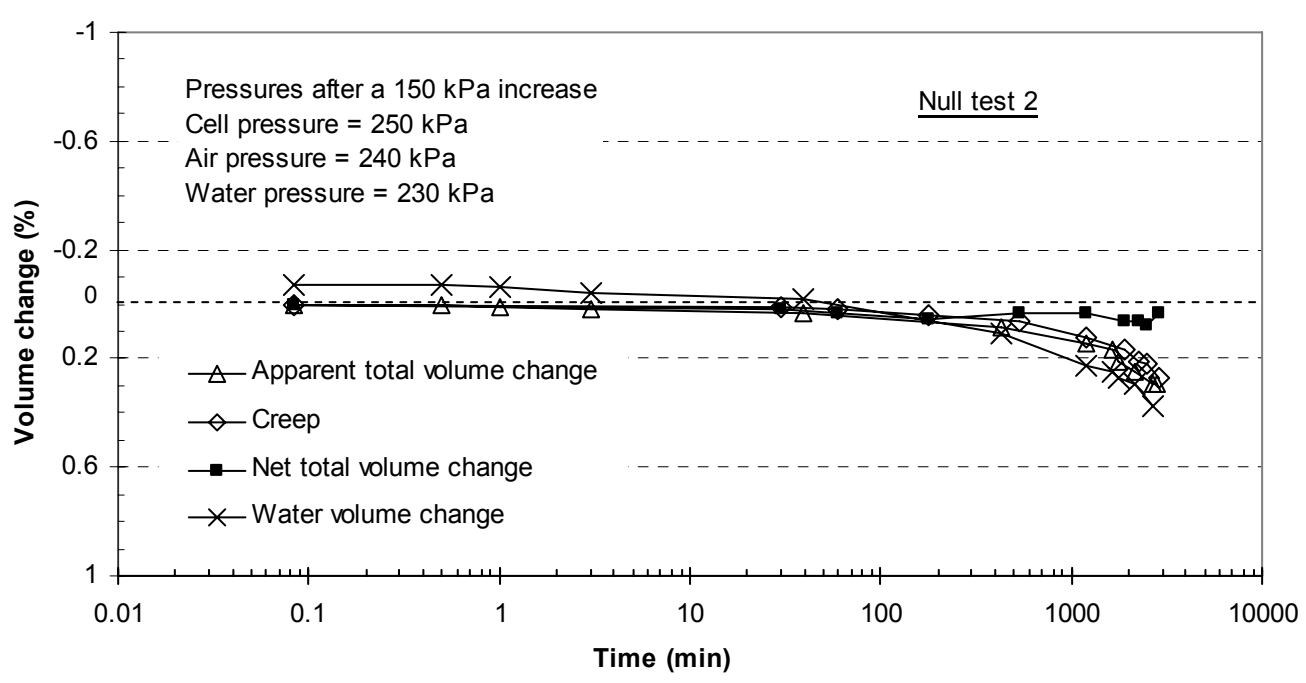

Figure (4.30) Volume change versus elapsed time in Null test No. 2

\subsection{Sample preparation and procedures used}

\subsubsection{Flushing pore-water pressure lines and assembling the top and base platens}

First of all, the ceramic discs were saturated as mention previously. Saturation of the ceramic discs was performed in order to achieve the continuity between the porewater and the water in the compartment beneath the ceramic discs and to prevent the air to pass through the ceramic discs. While assembling the metal plates, in which the ceramic and porous discs are provided, it is important to ensure that no air is trapped in between the metal plates and the top cap and bottom platen. 
In addition, all tubes and tabs of the pore-water pressure lines should be fully saturated. To achieve this, the following flushing procedure was adopted:

- The top cap and the base platen were connected to the base of the cell and immersed in water.

- Water pressure was applied through the volume change indicator (valve $\mathrm{A}$ is opened and valve B is closed). Water is allowed to flow from the twin-burette volume change indicator through the tubes and the base of the cell. Any air bubbles can be detected in the water reservoir where the top cap and bottom platen are immersed. Finally the water pressure was reduced to zero, and valve A was closed.

- Vacuum of $30 \mathrm{kPa}$ was applied (valve A is closed and valve B is opened) and the water flows in the reverse direction from the water reservoir through the tubes, the base of the cell, and volume change indicator. The flow of water will release any trapped air in the valves, connections, and tubes. Air bubbles can be observed in the burette in the volume change indicator. The vacuum was released and the pressure was applied again

- The above procedures (pressurizing and vacuuming processes) were repeated several times (five to six times) after which no air bubbles were observed in the entire system. Figure (4.31) shows the test setup for flushing of the pore-water pressure lines.

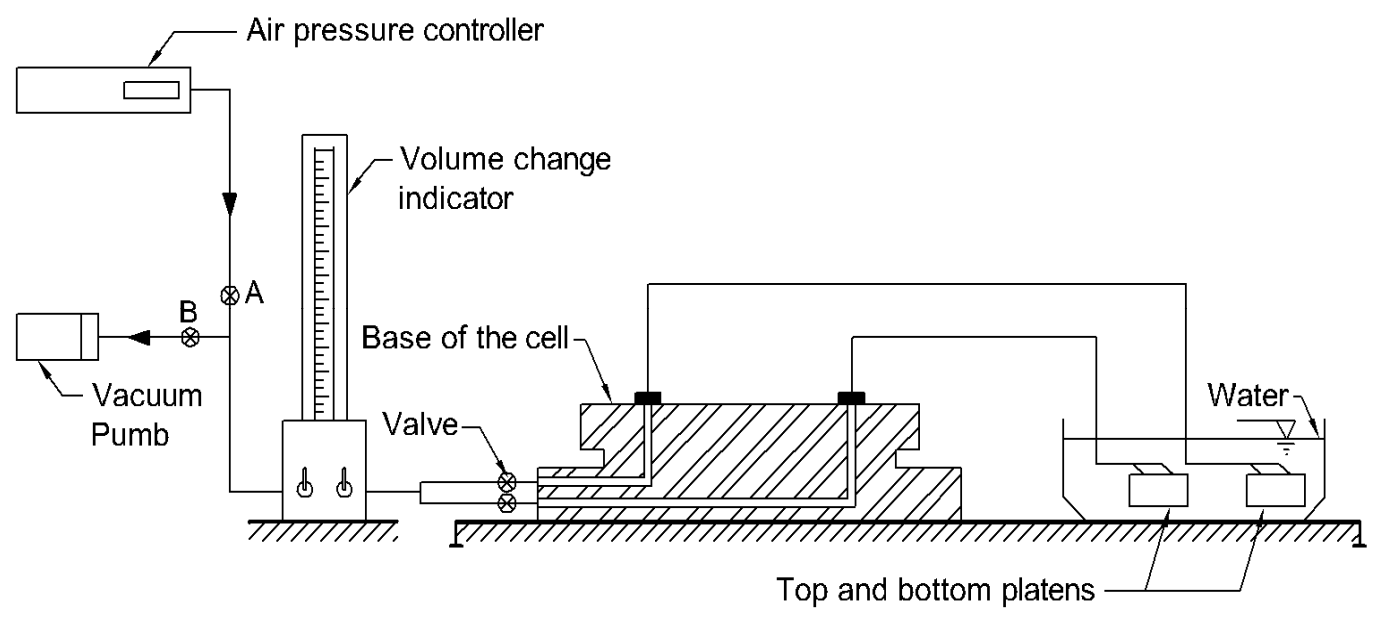

Figure (4.31) Flushing procedure adopted in saturating water pressure lines 


\subsubsection{Sample preparation}

Two preparation methods were adopted. The pluviation was used to prepare dry sand specimens. For the preparation of saturated sand specimens, the water sedimentation method was used.

\subsubsection{Dry sample preparation}

The desired mass of the sand was oven dried and then cooled in a desiccator to room temperature just before sample preparation. The $0.4 \mathrm{~mm}$ latex membrane was cut to the desired length and installed on the end bottom platen (the end bottom platen was already assembled and connected to the base of the cell) and two O-rings were installed as shown in Figure (4.32a). Four metal plates were used to tighten the membrane (Figure (4.32b)). The prismatic shape mould was mounted on these metal plates, and the membrane was stretched around its top. Vacuum of $30 \mathrm{kPa}$ was applied to align the membrane along the inner surface of the mould. Upon applying the vacuum, the membrane stretches and takes the right shape (Figure (4.33a)).

After installing the membrane, the sand was pluviated into the mould. The sand was compacted layer by layer to reach the desired density. A filter paper was used in the bottom and at the top of the specimen. After completion of the sand placement, the top cap (which was already assembled and connected to the base of the cell) was mounted on the specimen and the membrane was carefully pulled over the top cap and secured to it with O-ring and four metal plates as shown in Figure (4.33b).

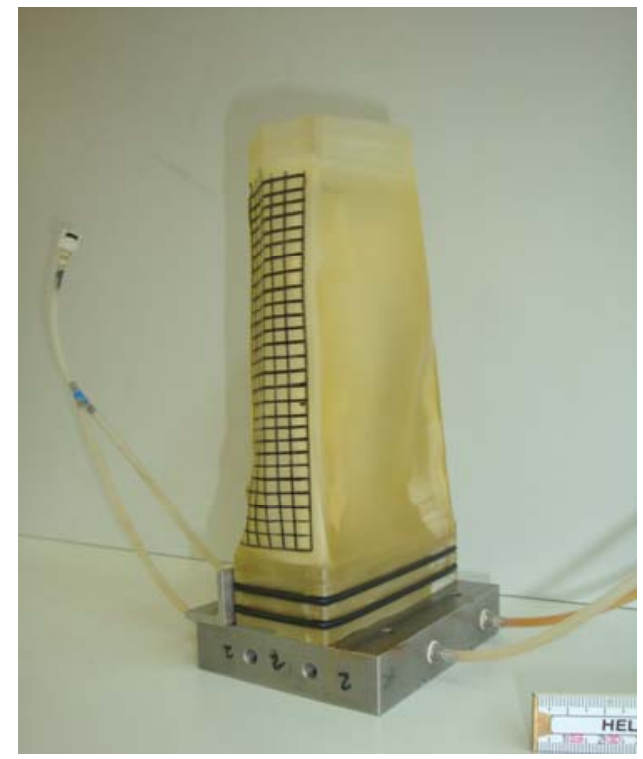

(a)

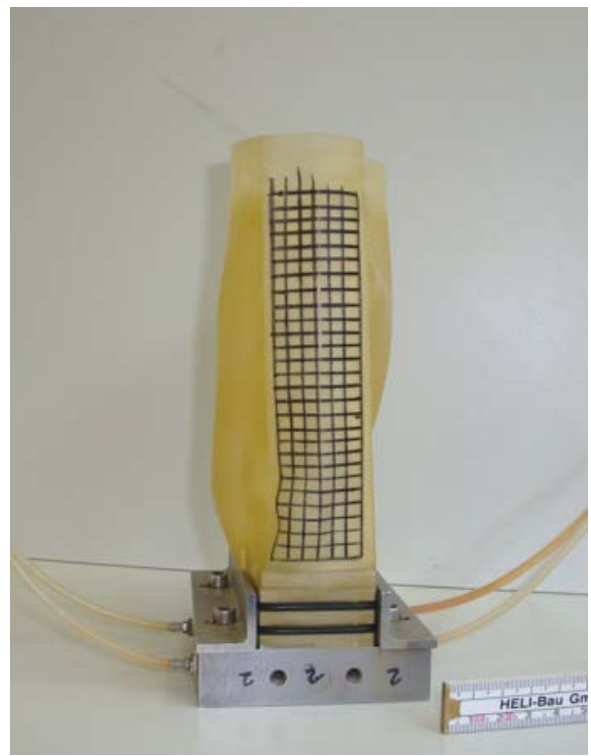

(b)

Figure (4.32) Installing the membrane and the metal plates 


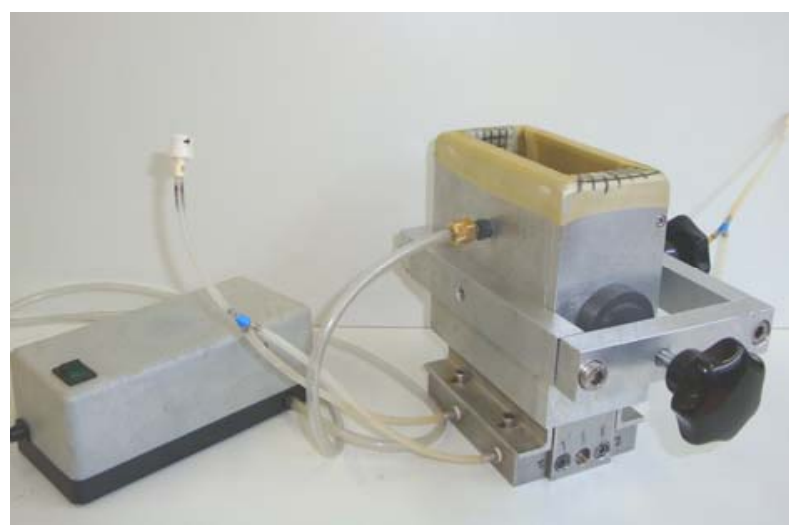

(a)

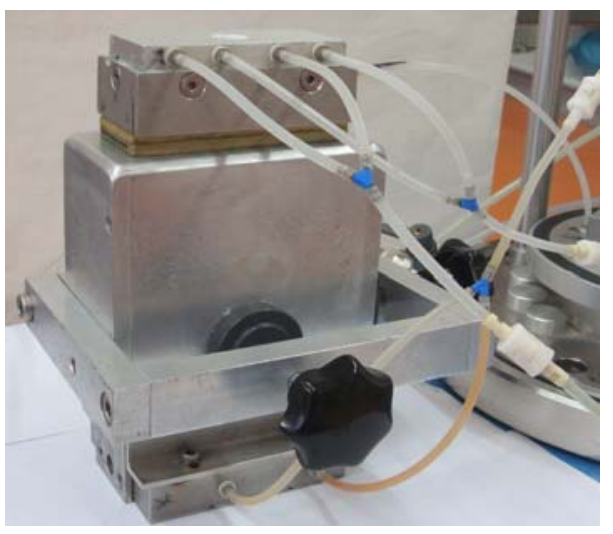

(b)

Figure (4.33) The membrane and the mould: (a) the membrane stretched in the mould;

(b) the membrane is sealed around the top cap

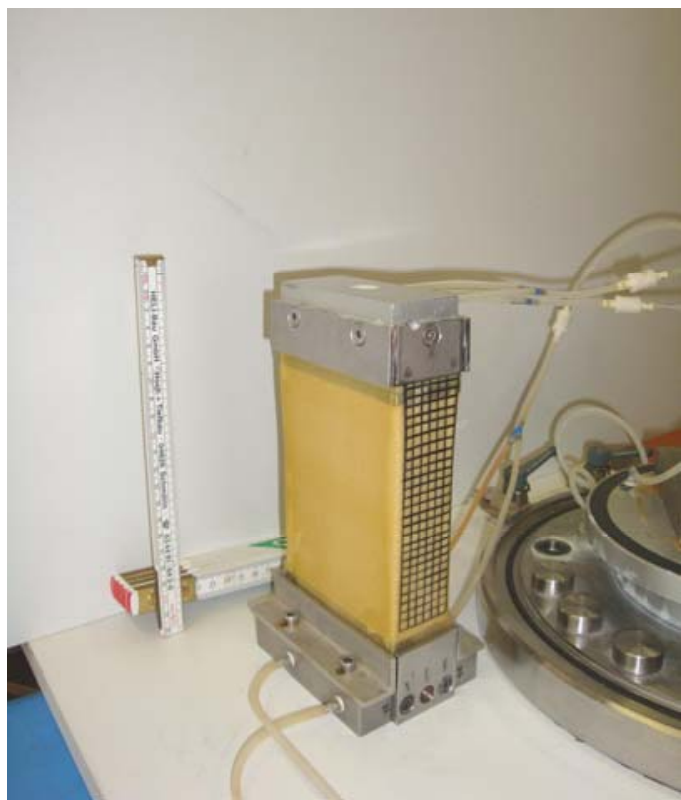

(a)

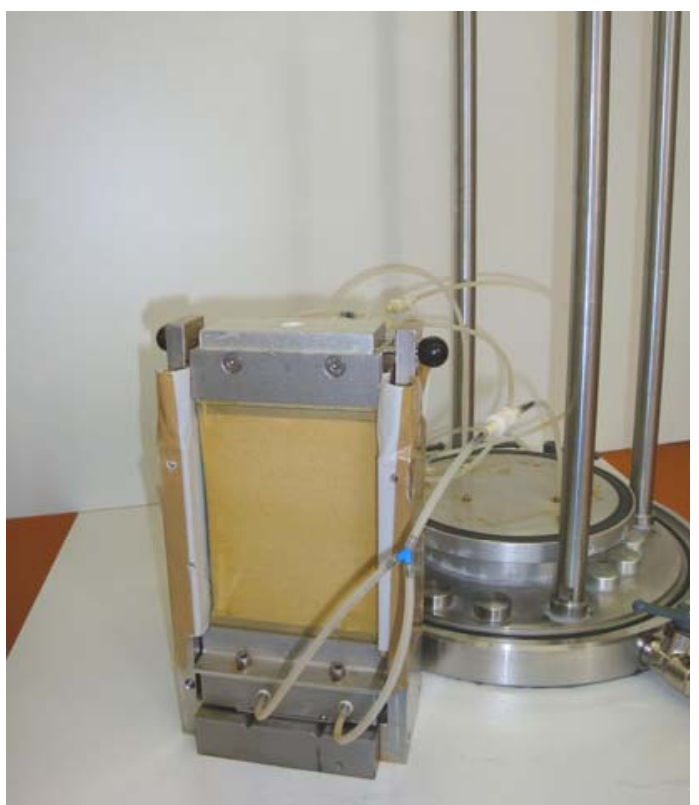

(b)

Figure (4.34) Typical specimen: (a) the specimen under vacuum; (b) the specimen between the two side walls

Before dismantling the mould, a low vacuum of approximately $20 \mathrm{kPa}$ was applied to the base of the sample. The vacuum was applied through the porous discs lines. Figure (4.34a) shows the sand specimen connected to the base of the cell after the split mould was removed and the vacuum was applied with all valves are closed. The sample was mounted on the pedestal on the ball bearing sled and the two stainless steel walls were installed and fixed. Two guide rods were used at the top of the walls together with the top cap of the specimen to ensure the verticality of the soil sample and to avoid any load eccentricity as shown in Figure (4.34b). 


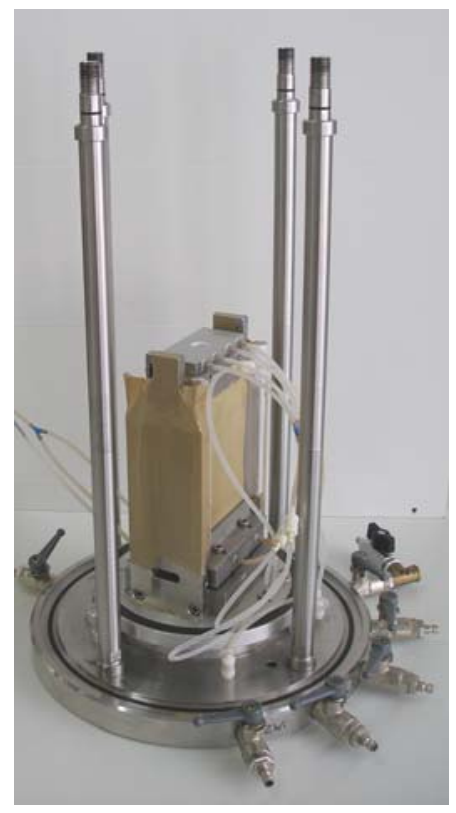

(a)

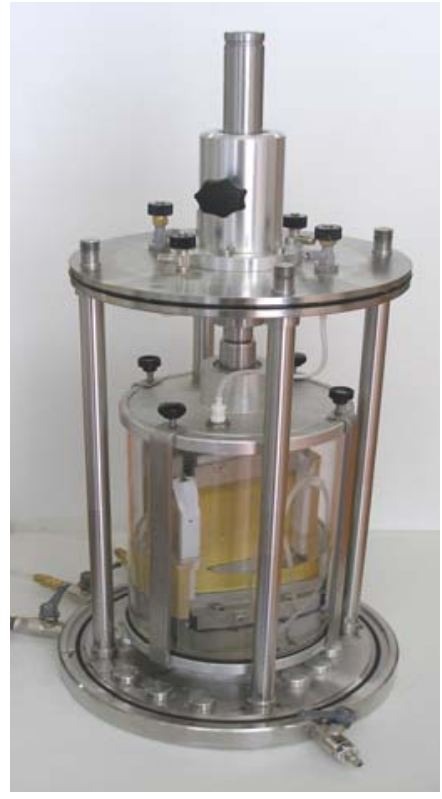

(b)

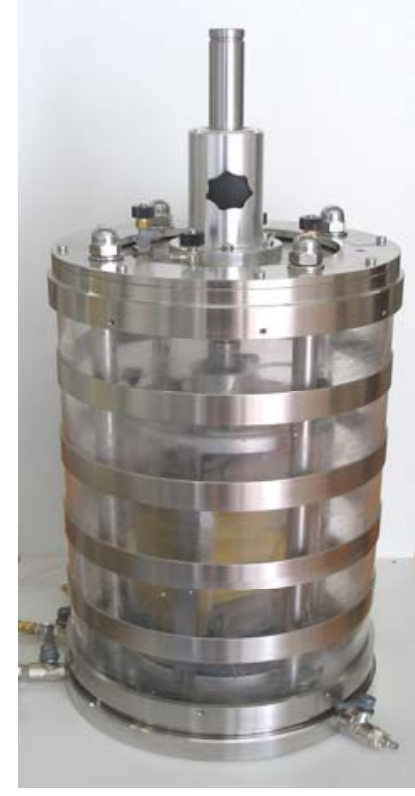

(c)

Figure (4.35) The installation of the inner and outer cell

After the whole block (i.e., specimen, pedestal, and side walls) was mounted on the base of the inner cell (Figure (4.35a)), the top cap of the inner cell and outer cell were installed with the required connections and tubes. The inner piston was pushed into the top cap. The outer piston was pushed to come into contact with the inner piston. Upon attaining good contact condition between the outer and inner pistons, the outer loading piston was fixed and the clampers of the inner cell were fixed and tightened using screws on the top cap of the inner cell as shown in Figure (4.35b). The wall of the outer cell was installed and finally both cells were filled with fresh de-aired water (Figure (4.35c)).

\subsubsection{Saturated sample preparation}

The preparation of saturated samples was almost identical to that adopted for dry samples except in the first stage where the sand should be compacted in the mould. To prepare the initially saturated sample, the membrane was filled with fresh de-aired water, and the sand was pluviated into the membrane. Two holes of $1.5 \mathrm{~cm}$ in diameter were made in the filter paper to ensure good contact between the soil sample and the ceramic discs (i.e., to ensure the continuity of the water phase thought the sample and the water compartment under the ceramic discs). In addition, to hold the specimen temporarily after dismantling the mould and instead of the vacuum in case of dry sample, a low value of negative water pressure (suction) of about $10 \mathrm{kPa}$ was applied to the specimen by lowering down a burette connected to the base of the specimen. 


\subsubsection{Test procedure}

Upon completing the preparation of the sample, the inner and outer cell were filled with fresh de-aired water and pressurized to the desired confining pressure. After consolidation, shearing was carried out under drained conditions.

\subsubsection{Test procedure for dry specimens}

After the initially dry soil was prepared, the inner and outer cells were pressurized to the same confining pressure. The confining pressure in the inner cell was applied through the volume change indicator. For the outer cell (where the volume change is not of interest) the cell pressure was applied through conventional air-water cell. One air pressure controller was used to apply the pressure to both the burette volume change indicator and the air-water cell to eliminate any possible changes in the applied confining pressure in both the inner and outer cells. The overall volume change of the specimen was measured using the burette volume change indicator connected to the inner cell. The accuracy of the volume change indicator used is $0.1 \mathrm{~cm}^{3}$.

After consolidation, the specimen is sheared by compression under drained conditions by pushing the outer loading piston with a loading rate of $0.002 \mathrm{~mm} / \mathrm{sec}$ (i.e., strain rate of $\left.1.6 \times 10^{-5} \% / \mathrm{sec}\right)$. The strain rate, which changes slightly during the shearing process due to the change in the height of the specimen, is calculated as $v / h o$ where $v$ is the loading speed $(\mathrm{mm} / \mathrm{sec})$, and ho is the initial height of the specimen $(\mathrm{mm})$. Fredlund and Rahardjo (1993) reported that strain rates in the range of $8.3 \times 10^{-6}$ to $1.3 \times 10^{-4} \% / \mathrm{sec}$ were used in drained tests on unsaturated silt and clay in several researches.

The axial strain was measured using $50 \mathrm{~mm}$ range external Linear Variable Differential Transducer (LVDT) mounted on the outer piston. The applied load was measured using one of two external load cells. For low confining pressures up to $100 \mathrm{kPa}$ the load cell with a maximum capacity of $5 \mathrm{kN}$ was used. For higher confining pressure, the $40 \mathrm{kN}$ load cell was used. The loading was continued until axial strain of $10-11 \%$ was achieved. Table (4.3) summarises accuracy of load cells and linear variable differential transducer. Figure (4.36) shows the load cells mounted on loading piston.

Table (4.3) Summary of accuracy of load cells and LVDT

$\begin{array}{ccc}\text { Transducer type } & \text { Capacity (range) } & \text { Accuracy } \\ \text { Load cell-A } & 40 \mathrm{kN} & 0.02 \mathrm{kN} \\ \text { Load cell-B } & 5 \mathrm{kN} & 0.002 \mathrm{kN} \\ \text { External LVDT } & 50 \mathrm{~mm} & 0.1 \mathrm{~mm}\end{array}$




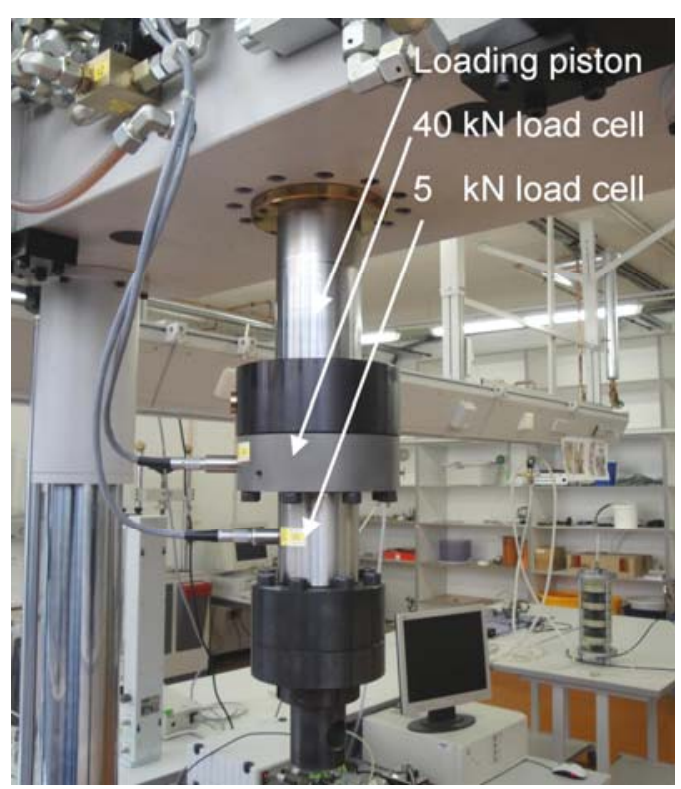

Figure (4.36) Loading piston with two load cells

At the end of the test, the confining pressure was released and both cells were emptied and dismantled. Before releasing the confining pressure, a low vacuum of $30 \mathrm{kPa}$ was applied within the specimen to prevent specimens' collapse and to allow the measuring of the shear band characteristics.

\subsubsection{Test procedure for unsaturated specimens}

After the saturated sample was prepared, the cell pressure in the inner and outer cells, pore-air pressure, and pore-water pressure were applied. The axis translation technique (ATT) proposed by Hilf (1956) was used to apply the predetermined suction. Both the pore-air and pore-water pressures were translated into a positive range of pressure. The pore-air pressure was applied through the porous discs using an air pressure controller with an accuracy of $1 \mathrm{kPa}$. The pore-water pressure was applied through the ceramic discs using burette volume change indicator connected to an air pressure controller.

The specimen was consolidated under the combination of these three pressures (i.e., cell, pore-air, and pore-water pressures). Thus, the stress state variables affecting on the sample during the test are the matric suction (the difference between the pore-air pressure and pore-water pressure $\left(u_{a}-u_{w}\right)$ and the net confining pressure (the cell pressure minus the pore-air pressure $\left(\sigma_{\text {cell }}-u_{a}\right)$.

The overall volume change of the specimen was recorded using burette volume change indicator connected to the inner cell and the volume changes on pore-water phase 
of the specimen was measured using the burette volume change indicator connected to the ceramic discs. The accuracy of the volume change indicator is $0.1 \mathrm{~cm}^{3}$. The equilibrium was considered to be achieved when no volume changes were observed in pore-water volume.

Upon attaining the equilibrium, the soil specimen was sheared by compression under drained conditions for both pore-water and pore-air phases. The specimen was sheared by at loading rate of $0.002 \mathrm{~mm} / \mathrm{sec}$. Drained shear strength tests on unsaturated soils should be performed at slow strain rate in order to ensure the dissipation of the generated pore-water pressure (i.e., no change in the matric suction during the shearing stage) (Fredlund and Rahardjo, 1993).

\subsection{Repeatability in test results}

Repeatability of the test results is an important and essential factor in experimental investigations. The repeatability of the test results in the new double-wall biaxial device was examined by testing three identical samples (i.e., the same void ratio, the same water content, and the same preparation procedure).

Figure (4.37) presents the results of three biaxial compression tests on dry dense specimens. The specimens had the same initial void ratio, $\mathrm{e}_{0}=0.66$, and were sheared at loading speed of $0.002 \mathrm{~mm} / \mathrm{sec}$ under confining pressure of $300 \mathrm{kPa}$. The experimental results of the tests on specimens B1, B2, and B3 show that the stress-strain behaviour of the three specimens is almost identical.

Figure (4.38) shows the mobilized angle of dilatancy versus shear strain for the three tests. Summary of the results of the three tests (B1, B2, and B3) is presented in Table (4.4). The values imply a good agreement in the three tests between the measured angle of internal friction, angle of dilatancy, angle of shear band inclination, and stress ratio at failure.

Table (4.4) Results of three validation biaxial tests: B1, B2, and B3

\begin{tabular}{lccc}
\hline & $\mathrm{B} 1$ & $\mathrm{~B} 2$ & $\mathrm{~B} 3$ \\
\hline Confining pressure, $\sigma_{3}(\mathrm{kPa})$ & 300 & 300 & 300 \\
Maximum angle of friction, $\phi_{\max }(\mathrm{Deg})$ & 44.30 & 44.32 & 44.47 \\
Maximum Angle of dilatancy, $\psi_{\max }(\mathrm{Deg})$ & 13.74 & 13.45 & 13.68 \\
Angles of shear band inclination, $\theta_{\mathrm{m}}(\mathrm{Deg})$ & 59.8 & 58.1 & 58.8 \\
Stress ratio at failure, $\sigma_{1} / \sigma_{3}(-)$ & 5.63 & 5.64 & 5.68 \\
Axial strain at failure $(-)$ & 5.43 & 5.69 & 5.52 \\
\hline
\end{tabular}




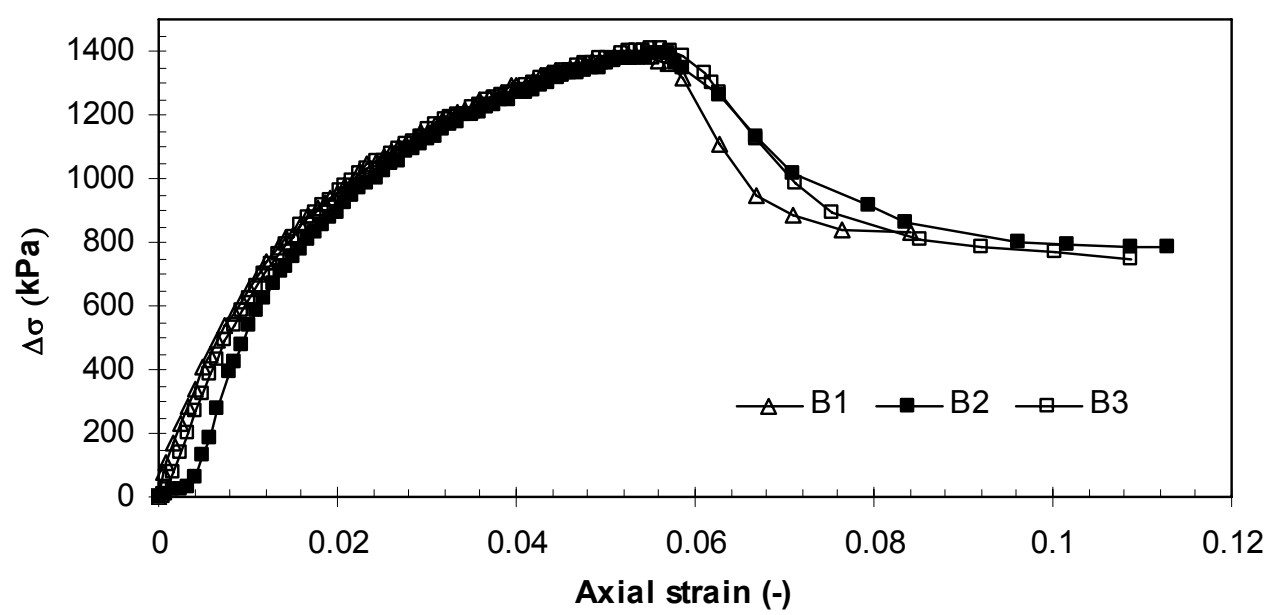

(a)

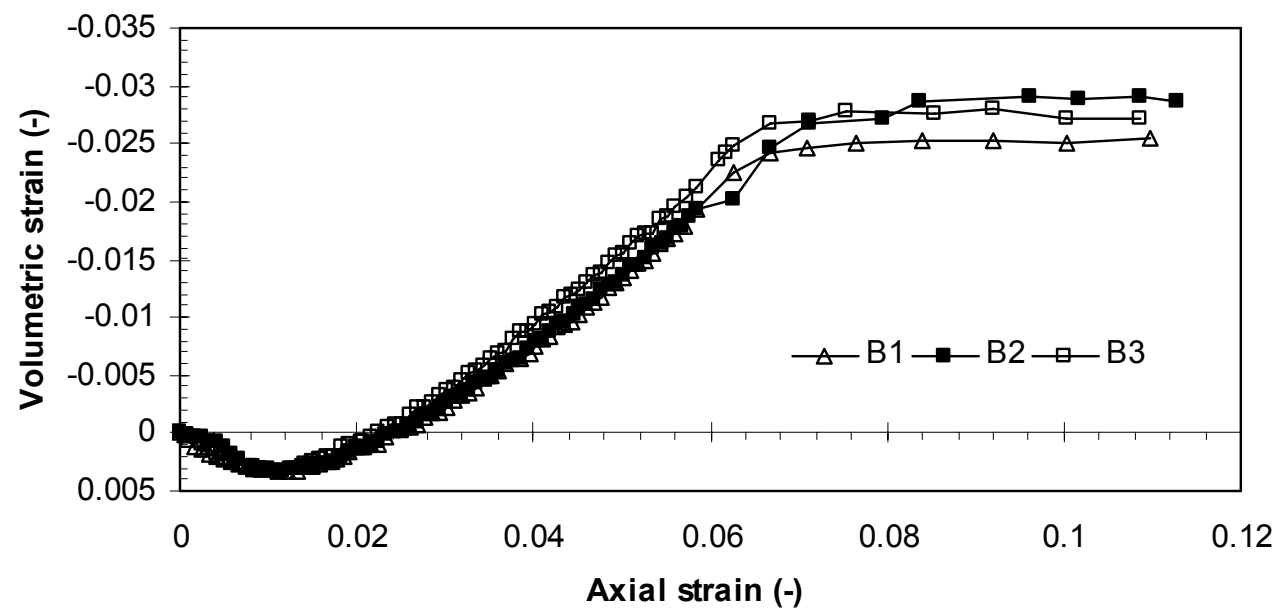

(b)

Figure (4.37) Stress-strain curves in three drained biaxial compression tests (B1,B2, and B3) on dense dry sand specimens under cell pressure of $300 \mathrm{kPa}\left(\mathrm{e}_{0}=0.66\right)$ : (a) axial strain versus deviator stress; (b) axial strain versus volumetric strain

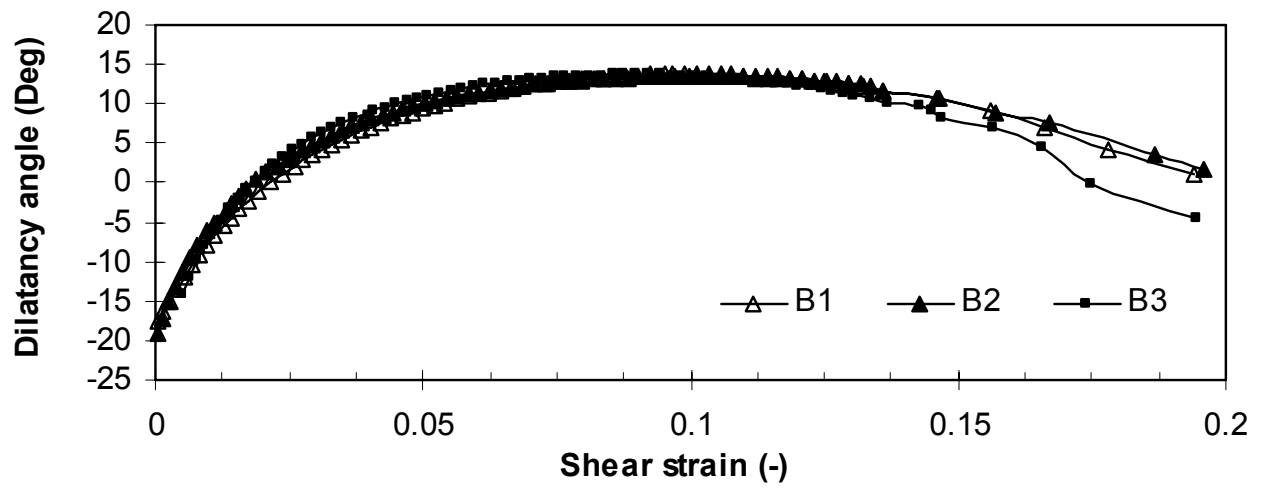

Figure (4.38) Mobilized angle of dilatancy versus shear strain in tests B1, B2, and B3 


\subsection{Techniques and procedures used for SWCC tests}

The laboratory program includes the determination of the drying (drainage) and wetting (imbibition) paths of pure Hostun sand, sand-kaolin mixtures A, B, and C, and pure kaolin. The soil water characteristic curves for the tested soils were determined using different techniques depending on the range of suction applied.

Two techniques (i.e., axis translation technique (ATT) and vapour equilibrium technique (VET)) were used to determine the relationship between the suction and the degree of saturation of the tested soil. In axis translation technique, two equipments were used. For suction range of $0-100 \mathrm{kPa}$, the modified pressure plate apparatus (MPP) (Lins et al., 2009) was used, whereas for the suction range of 100-1000 $\mathrm{kPa}$, pressure plate device was used. For higher suction values (i.e., suction $>3000 \mathrm{kPa}$ up to $100000 \mathrm{kPa}$ ), the vapour equilibrium technique was used. The following sections give an overview of the testing devices and methods adopted for the application of suction ranging from 0 to $100000 \mathrm{kPa}$.

\subsubsection{Sample preparation}

Soil water characteristic curves were investigated by performing drying and wetting paths for the pure Hostun sand $\left(\mathrm{e}_{0}=0.66\right)$, pure Spergauer kaolin $w_{\text {opt }}=22.8 \%$, $\left.\gamma_{d, \max }=1.51 \mathrm{Mg} / \mathrm{m}^{3}\right)$ and three sand-kaolin mixtures: A (95\% sand, 5\% kaolin with $w_{\text {opt }}=$ $\left.14.29 \%, \gamma_{d, \max }=1.6 \mathrm{Mg} / \mathrm{m}^{3}\right), \mathrm{B}\left(90 \%\right.$ sand, $10 \%$ kaolin with $w_{\text {opt }}=13.8 \%, \gamma_{d, \max }=1.68$ $\left.\mathrm{Mg} / \mathrm{m}^{3}\right)$, and C (70\% sand, $30 \%$ kaolin with $\left.w_{\text {opt }}=13 \%, \gamma_{d, \max }=1.88 \mathrm{Mg} / \mathrm{m}^{3}\right)$.

Soil specimens were prepared at the optimal water content and stored in doubled plastic bag for 24 hours to allow equalization of water content. The specimens were statically compacted to reach the desired density based on the standard Proctor curves. After preparation, the specimens were saturated before the suction has been applied stepwise. Water is allowed to flow out or/in the specimen depending on the suction path tested. The next step of suction was not applied until the equilibrium has been achieved (i.e., by achieving a constant mass of the specimen). 


\subsubsection{Pressure plate extractor}

The pressure plate extractor is a well known testing device for determination of the relationship between the degree of saturation, volumetric water content, or gravimetric water content and suction in a soil (ASTM C1699-09). In this study the pressure plate extractor (Soil moisture Equipment Corp.) has been used to apply suction values between 50-1000 $\mathrm{kPa}$ using different ceramic discs with different air-entry values depending on the suction applied (100 kPa disc, $500 \mathrm{kPa}$ disc, and $1500 \mathrm{kPa}$ disc). The axis-translation technique (ATT) (Hilf, 1956) is used for the application of suction to the specimen. During the testing procedure, flushing of the water below the ceramic disc has been carefully carried out periodically to avoid presence of air in the system. Figure (4.39) shows a photograph of the pressure plate extractor used. Schematic diagram of this device is also shown in Figure (4.40).

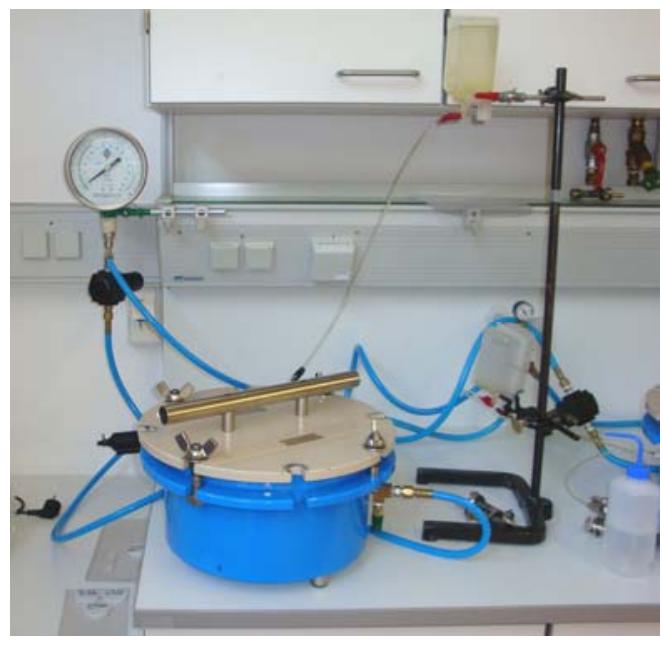

Figure (4.39) Photograph of the pressure plate

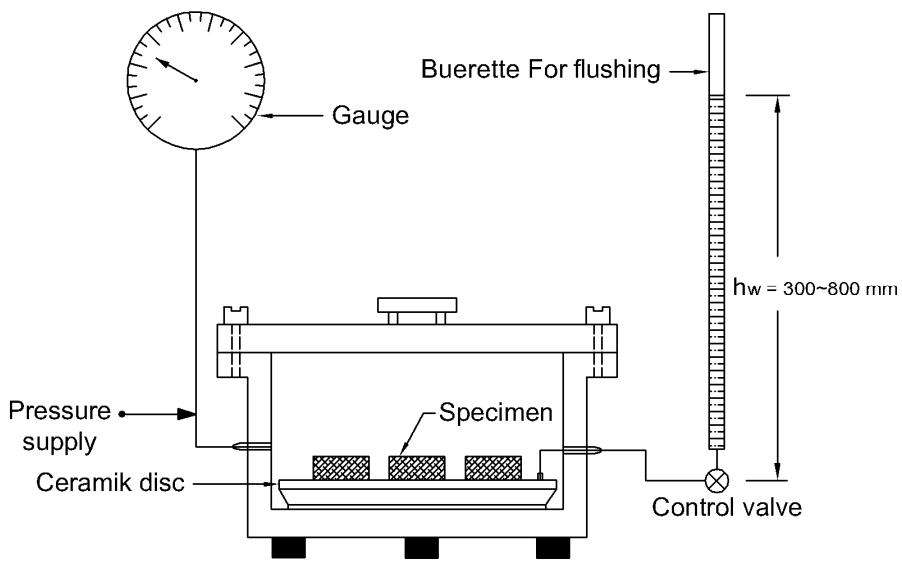

Figure (4.40) Schematic sketch of the pressure plate device 


\subsubsection{Modified pressure plate (MPP)}

The modified pressure plate apparatus enables the determination of the soil-water characteristic curve for both drying and wetting paths (phenomena of hysteresis). The modified pressure plate apparatus was used for applying suction values in the range $0-100$ $\mathrm{kPa}$.

The experimental set up consists of a burette, a scale, an air-pressure system, and the cell itself. The apparatus has a metal ring $70 \mathrm{~mm}$ in diameter and $20 \mathrm{~mm}$ high. A coarse porous stone is placed on the top of the soil specimen. Ceramic disc is placed at the bottom of the specimen. The ceramic disc used in this study has an air-entry value of $100 \mathrm{kPa}$. Therefore suctions smaller then $100 \mathrm{kPa}$ can be applied to the specimens when using the modified pressure plate. The cell is equipped with a minimized water reservoir below the ceramic disc. A burette with a capacity of $25 \mathrm{~cm}^{3}$ and a least count of $0.05 \mathrm{~cm}^{3}$ is connected to this water reservoir. Water inflow and outflow is measured by mean of the burette. Air pressure can be applied at the top of the specimen through a coarse porous stone. The changes in the height of the specimen are measured by a dial gauge mounted on the loading piston. A detailed cross section of the modified pressure plate apparatus is given in Figure (4.41).

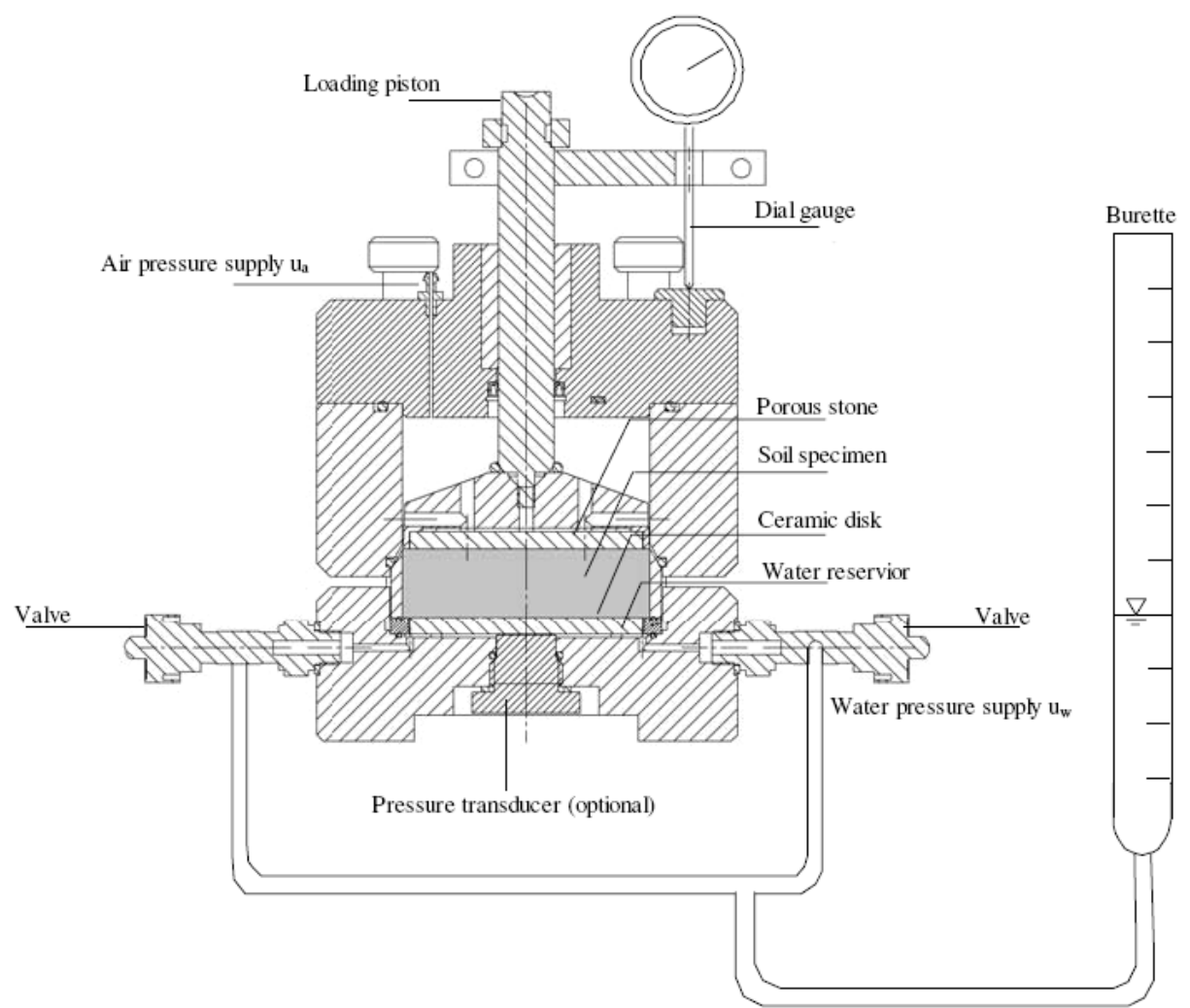

Figure (4.41) Cross section of the modified pressure plate (MPP) (Lins et al., 2009) 
Granular materials show a relatively small range of suctions over which the soil becomes unsaturated. A low air-entry value is a characteristic for this type of materials. The cell uses two methods for application of matric suction on the specimen: Hanging water column technique (Haines, 1930), and Axis-Translation Technique (Hilf, 1956).

The use of the hanging water column technique allows the application of low suction values. By lowering the burette connected to the water reservoir bellow the ceramic disc, suctions up to $5.0 \mathrm{kPa}$ (i.e., $50 \mathrm{~cm}$ water height) in steps of $0.1 \mathrm{kPa}$ can be applied to the specimen. The burette with an accuracy of $0.05 \mathrm{~cm}^{3}$ enables the precise measurements of water inflow and outflow.

For suctions higher than $5 \mathrm{kPa}$, the axis translation technique is used and the air pressure is applied through the control valves at the top of the cell. A photograph of the modified cell and the test setup are shown in the Figure (4.42).

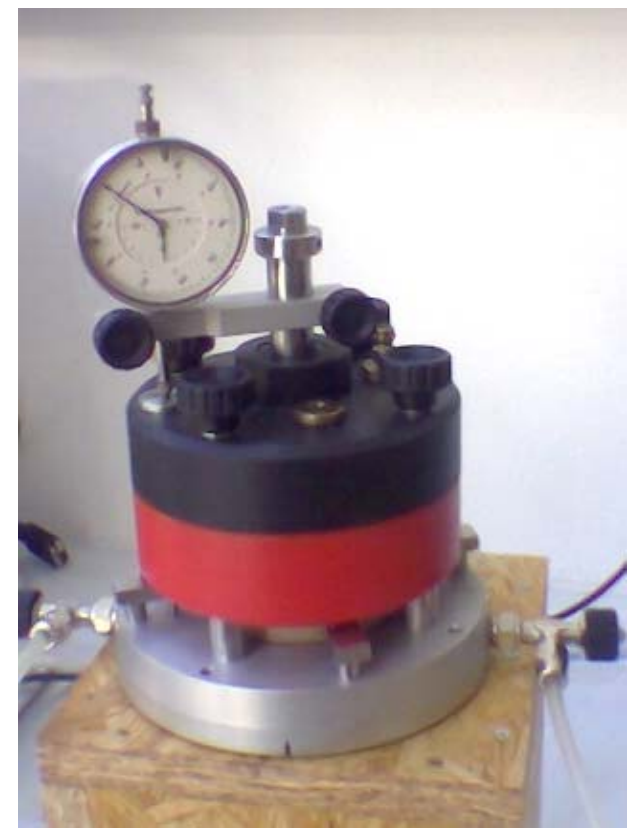

(a)

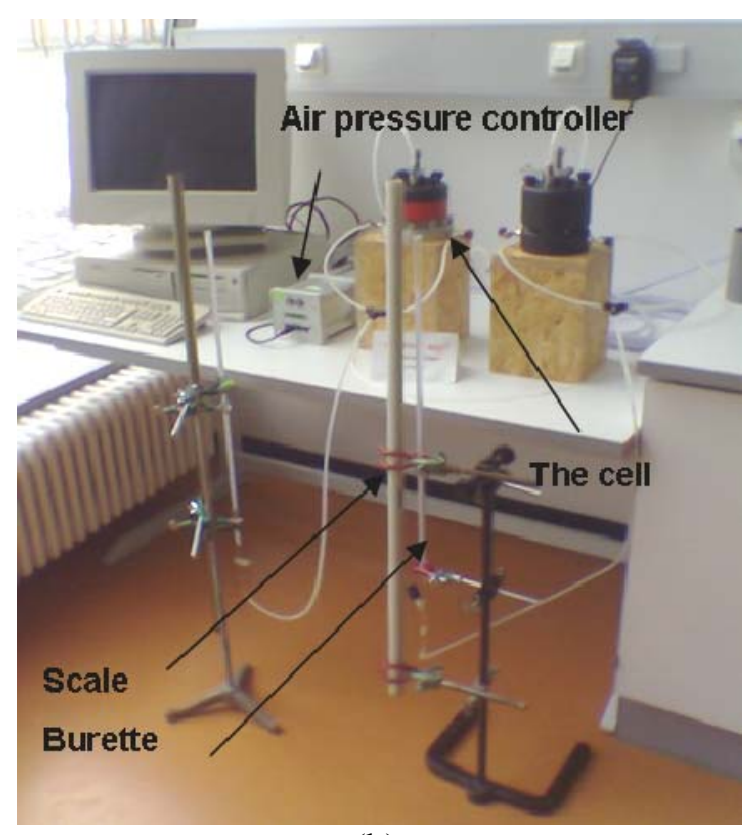

(b)

Figure (4.42) Modified pressure plate: (a) a photograph of the cell; (b) test setup 


\subsubsection{Vapour equilibrium technique (VET)}

The vapour equilibrium technique (VET) has been used in several researches for controlling total suction during unsaturated oedometer and triaxial tests (e.g., Cuisioner and Masrouri, 2002; Lloret et al., 2003; Blatz and Graham, 2003) and for the determination of soil-water characteristic curve of expansive soils (Croney et al., 1952; Agus et al., 2001; Blatz et al., 2003; Schanz et al., 2004).

Generally, the VET can be used to control almost the whole range of total suction. But, the use of VET for applying total suction less than $2000 \mathrm{kPa}$ suffers from inaccuracies since this technique is extremely sensitive to temperature gradient between the salt solution, the vapour space, and the soil specimen (Agus and Schanz, 2003). If the temperature fluctuation can be maintained as high as $0.5^{\circ} \mathrm{C}$, the VET can be used to apply and control the suction higher than $1000 \mathrm{kPa}$ (Arifin, 2008).

The vapour equilibrium technique using salt solutions (VET) was used for inducing suction values higher than $3000 \mathrm{kPa}$ and up to $100000 \mathrm{kPa}$. The tests using vapour equilibrium technique were performed at constant temperature room, in which the temperature was controlled to be constant at $20^{\circ} \mathrm{C} \pm 0.5^{\circ} \mathrm{C}$.

Several salt solutions were used to induce total suction to the specimen by changing the relative humidity of the vapour space in the desiccator. The suction to be applied using $\mathrm{NaCl}$ solutions was calculated according to the equation given by Lang (1967) and the data reported by Pitzer and Pelper (1984). The relative humidity of the vapour above the salt solution was verified using the chilled-mirror hygrometer technique. The chilledmirror hygrometer used in this study was a water activity meter type 3TE produced by Decagon Devices Inc. (Figure (4.43)).

Figure (4.44) shows the vapour equilibrium techniques. Large and small desiccators were used. The use of small desiccator can avoid the effects of the differences in initial suction of the specimens since only one specimen was placed in the desiccator (Arifin, 2008). 


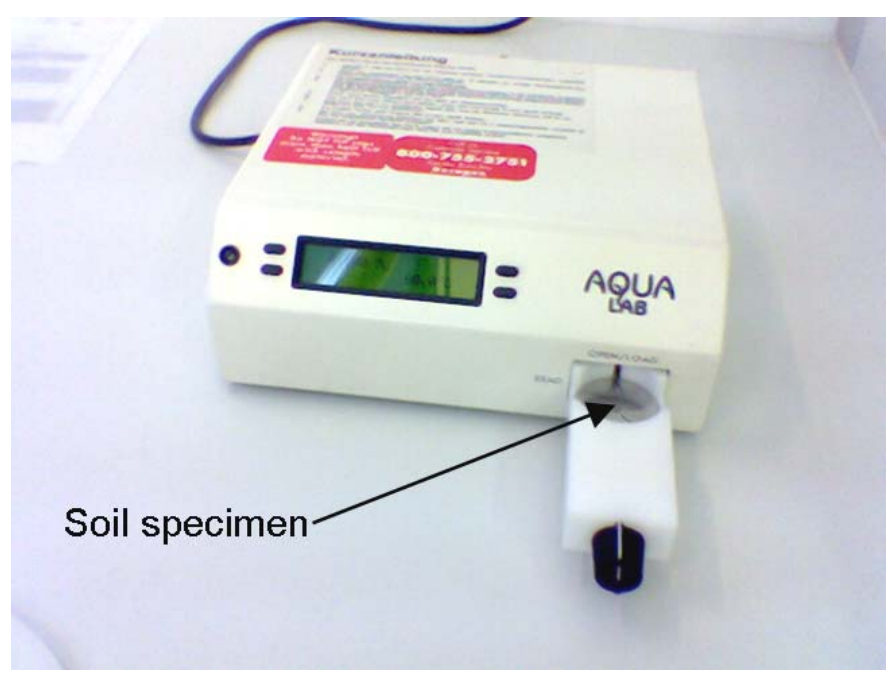

Figure (4.43) Photograph of chilled-mirror hygrometer device
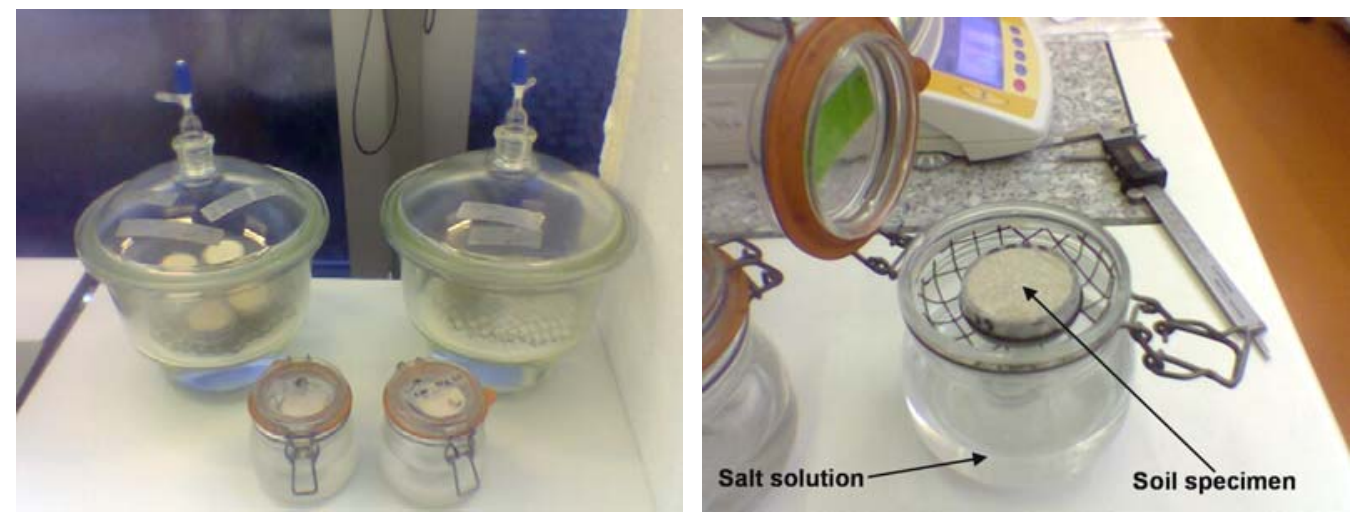

(a)

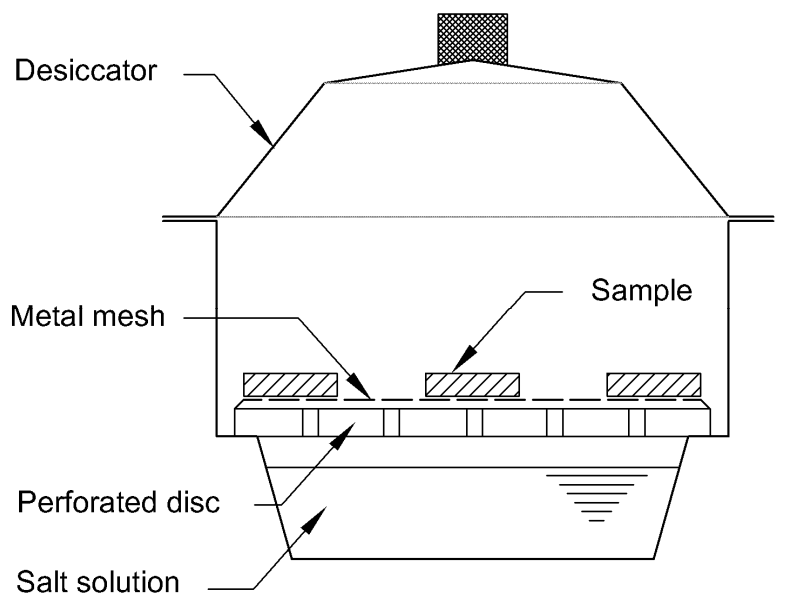

(b)

Figure (4.44) Vapour equilibrium technique: (a) photograph of the desiccators used; (b) schematic diagram of vapour equilibrium technique 


\subsection{Techniques and procedures used in bearing capacity tests}

Bearing capacity tests were performed to investigate the effect of suction on the ultimate bearing capacity of a model strip footing on unsaturated Hostun sand. A specially designed box was used to conduct the bearing capacity tests.

\subsubsection{Sand box}

As it is illustrated in Figure (4.45), the box is $1000 \mathrm{~mm}$ long, $500 \mathrm{~mm}$ high, and $500 \mathrm{~mm}$ wide. The box consists of an outer frame made of wood and an inner tank made of plexiglass. The thickness of the plexiglass wall is $10 \mathrm{~mm}$. The outer wood frame was constructed in order to attain the plane-strain conditions (i.e., to prevent the lateral deformation during loading stage). Care was taken to ensure, as much as possible, complete contact conditions between the plexiglass wall and the wooden frame.

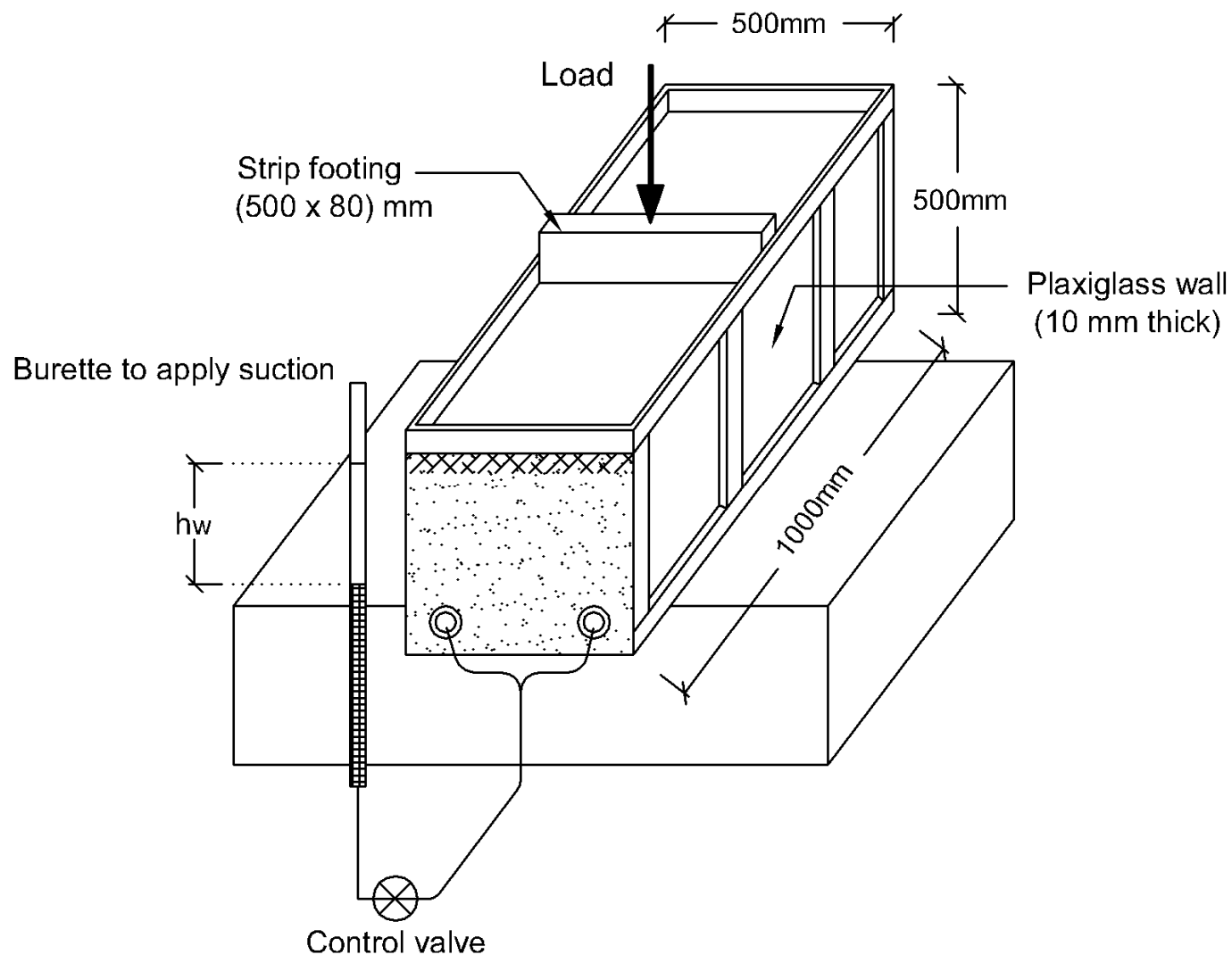

Figure (4.45) Schematic diagram of the bearing capacity test 


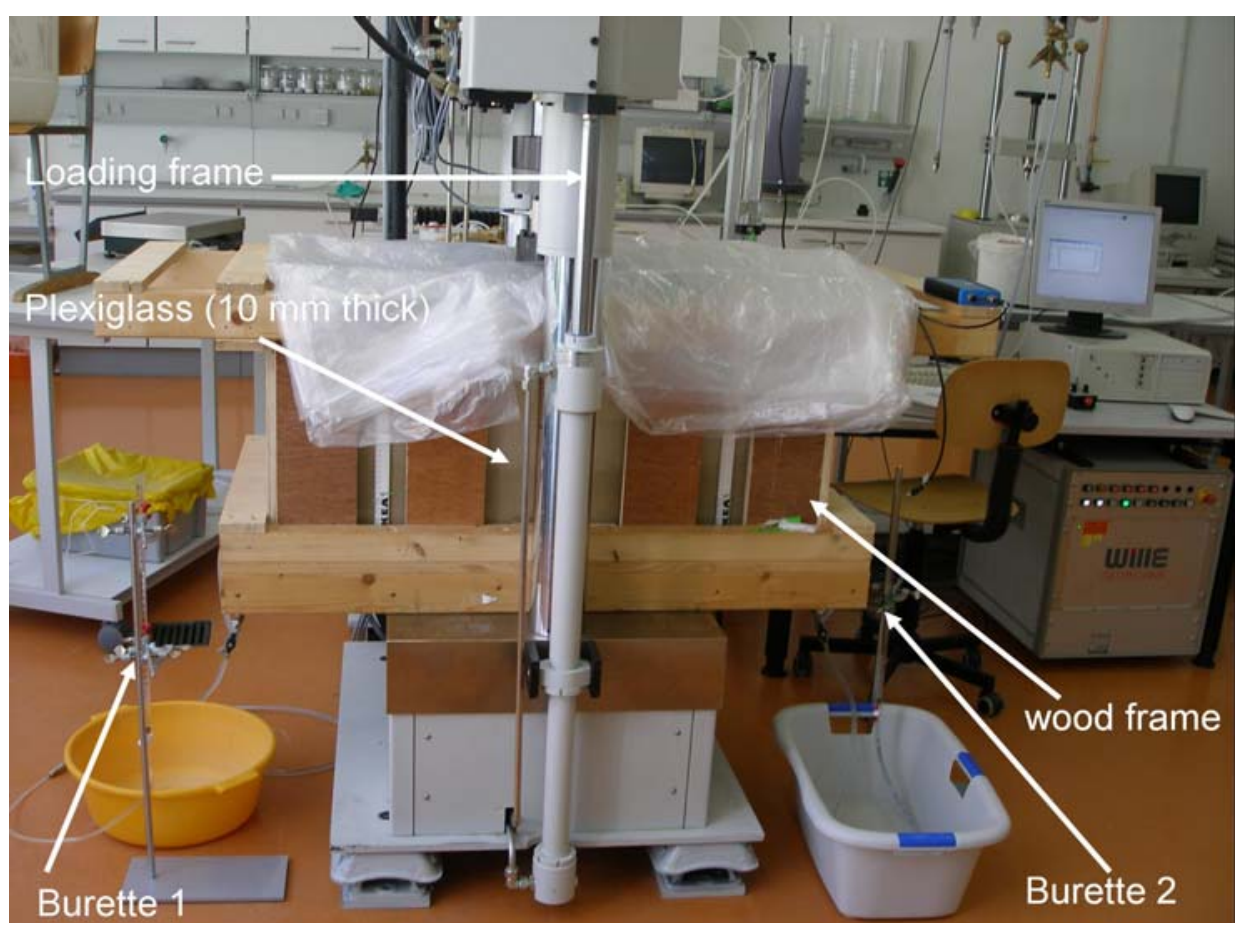

Figure (4.46) Bearing capacity test

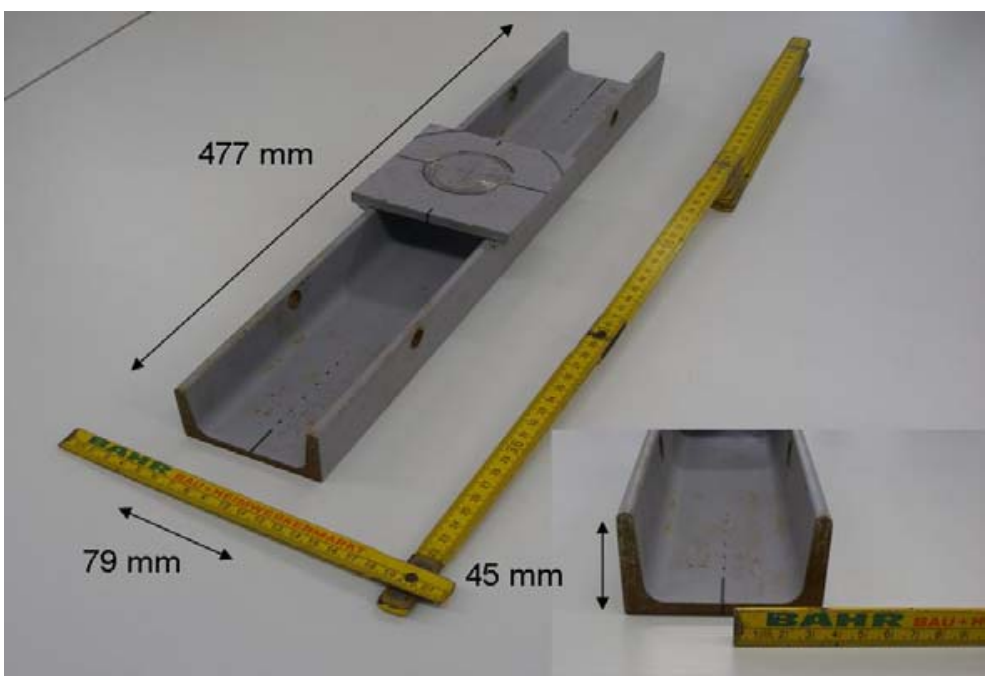

Figure (4.47) Photograph of the model strip footing

In order to apply the matric suction to the soil mass, two holes were made in each side wall of the box. These four holes were equipped with special fine metal mesh to allow the water but not the sand from flowing. The predetermined value of suction can be applied to the sand mass by hanging water column technique. Two burettes were used one in each side as illustrated in Figure (4.46). 
The applied matric suction was monitored using two tensiometer sensors at a depth of 10 and $100 \mathrm{~mm}$ from the soil surface. The model strip footing used in this study is $477 \mathrm{~mm}$ long. The cross section of the model strip footing is U-shape $49 \mathrm{~mm}$ wide and $45 \mathrm{~mm}$ high. Figures (4.47) and (4.48) show photographs of the model footing and the tensiometer used, respectively.

The dimensions of the box were considered such that failure conditions due to loading will occur within the box and will not intersect the side walls as it is illustrated in Figure (4.49). The calculations using Rankin's analysis (Förster, 1998) show that the failure zone extends to a total length of about $260 \mathrm{~mm}$ and the maximum depth to 100 $\mathrm{mm}$. The box was designed such that the box dimensions are greater than the calculated values of the failure zone (i.e., $1000 \mathrm{~mm}$ in length, $500 \mathrm{~mm}$ in width, and $500 \mathrm{~mm}$ in height).

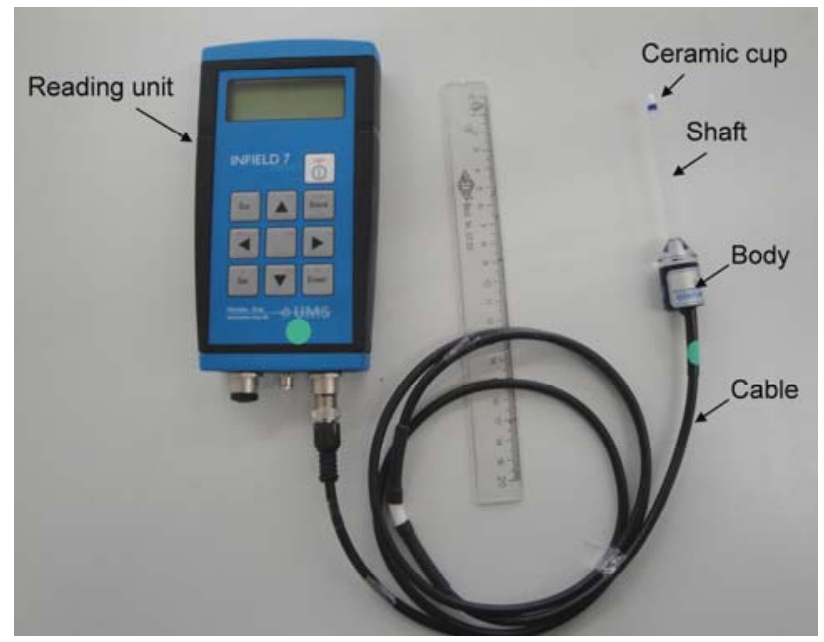

Figure (4.48) Photograph of the tensiometer (type T5) and the reading unit

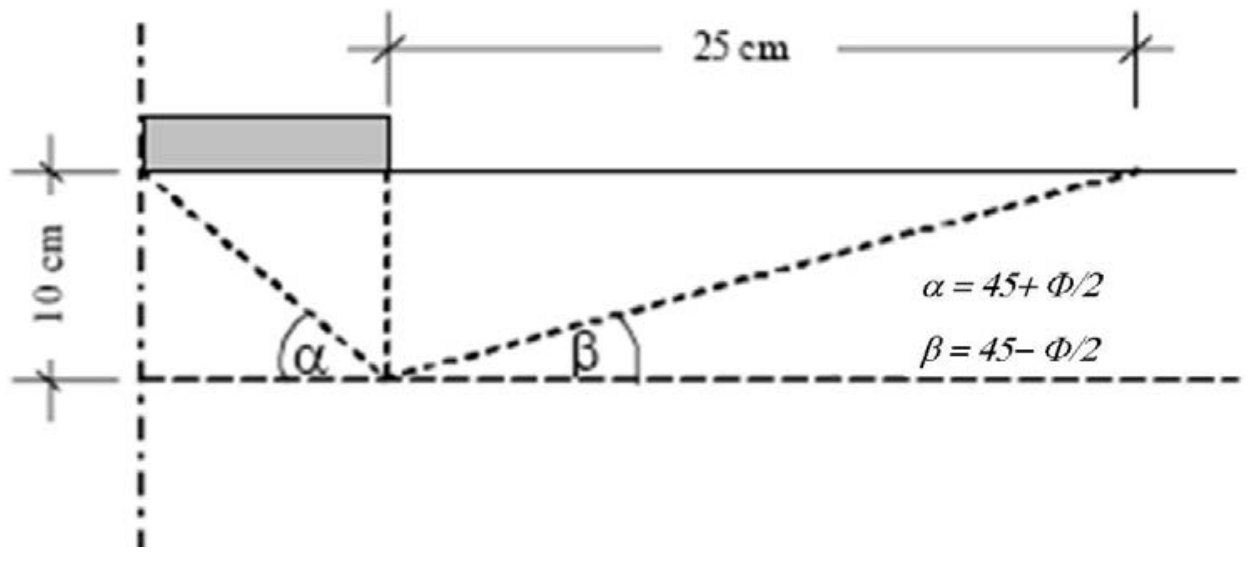

Figure (4.49) Failure mechanism below the model strip footing 


\subsubsection{Sample preparation and testing procedure}

The sample was prepared by pluviation of the sand into the box. The box was placed in the loading frame and the box was filled with water. The sand was pluviated and compacted layer by layer. The height of the sand in all tests was $350 \mathrm{~mm}$. the sand was compacted on 7 layers each is $50 \mathrm{~mm}$ height. The required dry mass of sand for each layer was determined to achieve the target density. The height of each layer was controlled using a scale mounted on the side walls. After completing the preparation of the saturated sample, the suction was applied by lowering the two burettes to the predetermined height.

Upon reaching the equilibrium (i.e., no water flow out of the sand mass) the model footing was loaded. It should be noted here that during the application of suction (equalization stage) and loading stage, the box was completely covered with a plastic sheets to prevent the evaporation of the water. Loading speed of $0.002 \mathrm{~mm} / \mathrm{s}$ was adopted in bearing capacity tests which is the same loading rate used in biaxial tests. The loading continued until reaching a settlement of 30-35 mm. The applied load was measured using a load cell with a capacity of $40 \mathrm{kN}$ and accuracy of $0.05 \%$ of the applied load. The footing settlements (i.e., the displacement of the loading piston) were measured with a resolution equal to $0.001 \mathrm{~mm}$. All experimental data were collected using a data logging system. Test setup and the location of the tensiometers are shown in Figure (4.50).

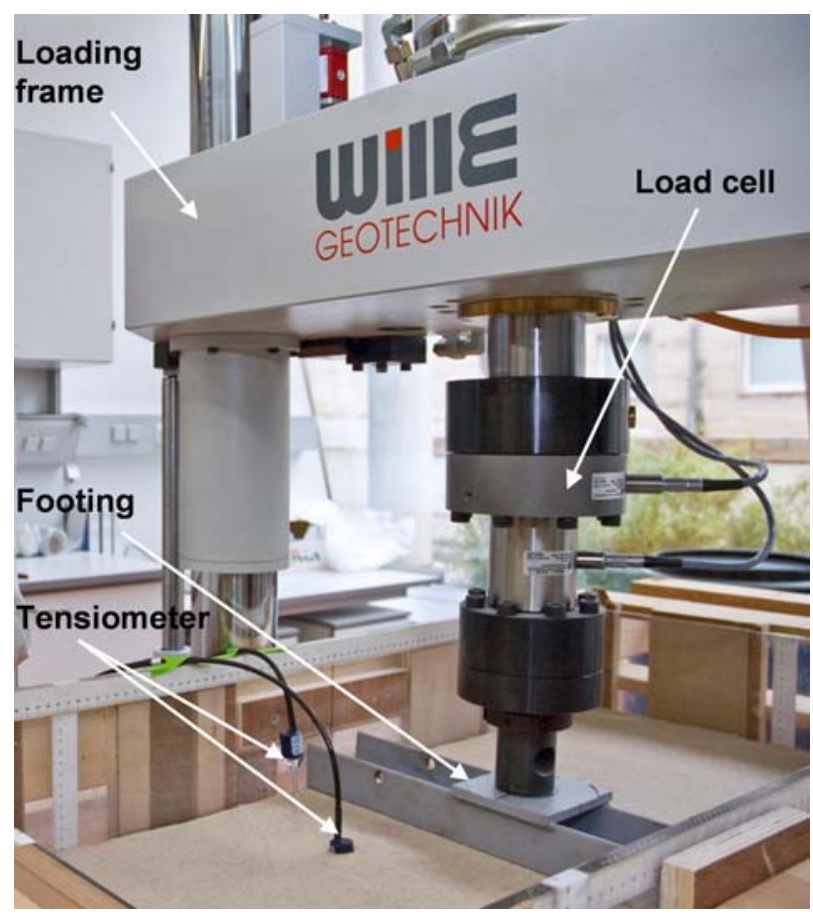

Figure (4.50) Bearing capacity test: the location of the tensiometers 


\subsection{Summary}

A new double-wall biaxial device has been described in this chapter. The new developed device enables testing dry, saturated, and unsaturated soils in plane-strain conditions. The main feature of the new device is that the volume change of unsaturated soil specimen can be measured precisely using double-wall cell concept. Matric suction can be applied and controlled. Suction gradient can be applied within the unsaturated soil specimen. In addition, using the new device, the shear strength and shear banding in soils under different end restrain conditions (i.e., free end/fixed end) can be studied. The required calibrations were presented. The concept of the stress state variables was validated using the new device. It has been shown in this chapter that the new system shows a good repeatability of the test results. The new biaxial device was calibrated and proved to be a reliable device for unsaturated soil testing.

Additionally, the techniques used in biaxial tests, bearing capacity tests, and soil water characteristic curves tests were presented in detail. 


\section{CHAPTER 5}

\section{EXPERIMENTAL RESULTS}

\section{$5.1 \quad$ General}

This chapter presents the results of the biaxial tests on Hostun sand (dry, saturated, and unsaturated conditions) performed using the new double-wall biaxial device. In addition, the results of the bearing capacity tests of model strip footing on saturated and unsaturated Hostun sand are presented. The results of the tests of the soil water characteristic curves of sand-kaolin mixtures are also presented in this chapter.

\subsection{Biaxial tests results}

In the following sections the results of biaxial tests on dry, saturated, and unsaturated sand will be presented. A satisfactory analysis of these results was performed by applying the following equations and relations. The major axial strain, $\varepsilon_{1}$, volumetric strain, $\varepsilon_{\mathrm{v}}$, and shear strain, $\gamma$, are calculated using the following equations:

$$
\begin{gathered}
\varepsilon_{1}=\frac{\Delta h}{h_{0}} \\
\varepsilon_{v}=\frac{\Delta v}{v_{0}}
\end{gathered}
$$

$\gamma=\varepsilon_{1}-\varepsilon_{3}$

where $h_{\mathrm{o}}=$ initial height of the specimen, $\Delta \mathrm{h}=$ change in height of the specimen, $v_{0}=$ initial volume of the specimen, $\Delta \mathrm{v}=$ change in volume of the specimen, and $\varepsilon_{1}$ and $\varepsilon_{3}$ are the major and minor principal strain, respectively. The deviator stress, $\Delta \sigma$, and the major principle effective stress, $\sigma^{\prime}{ }_{1}$, are calculated as follows:

$$
\begin{aligned}
& \Delta \sigma=\frac{p_{c}}{A_{c}} \\
& \sigma_{1}=\sigma_{3}+\Delta \sigma
\end{aligned}
$$

In case of unsaturated sand, the major principle stress was calculated as follow:

$$
\sigma_{1}=\left(\sigma_{3}-u_{a}\right)+\Delta \sigma
$$

where $\sigma_{3}=$ cell pressure, $P_{\mathrm{c}}=$ corrected axial force, $A_{\mathrm{c}}=$ corrected cross section of the specimen, $u_{\mathrm{a}}=$ pore-air pressure. 


\subsubsection{Results for loose and dense dry Huston sand}

Figure (5.1) shows a typical results of the biaxial compression test on dense dry Hostun sand specimen with initial void ratio $\mathrm{e}_{0}=0.66$ and confining pressure $\sigma_{3}=15$ $\mathrm{kPa}$. Figure (5.1a) shows the deviator stress $\left(\Delta \sigma=\sigma_{1}-\sigma_{3}\right)$ versus the axial strain $\left(\varepsilon_{1}\right)$ and Figure $(5.1 \mathrm{~b})$ shows the volumetric strain $\left(\varepsilon_{\mathrm{v}}\right)$ versus the axial strain $\left(\varepsilon_{1}\right)$.

Figure (5.1) shows that, the deviator stress increases by increasing the axial strain until the maximum value is reached (i.e., peak point). Beyond this point, softening happens and the shear strength decreases until reaching a constant value. Figures (5.2) and (5.3) show the experimental results of the biaxial tests under several confining pressures for the dense and loose Hostun sand, respectively. Figures (5.2) and (5.3) show that the maximum deviator stress, $\left(\sigma_{1}-\sigma_{3}\right)_{\max }$ increases with increasing the confining pressure $\left(\sigma_{3}\right)$, whereas the tendency of specimens to dilate during shearing decreases by increasing the confining pressure.

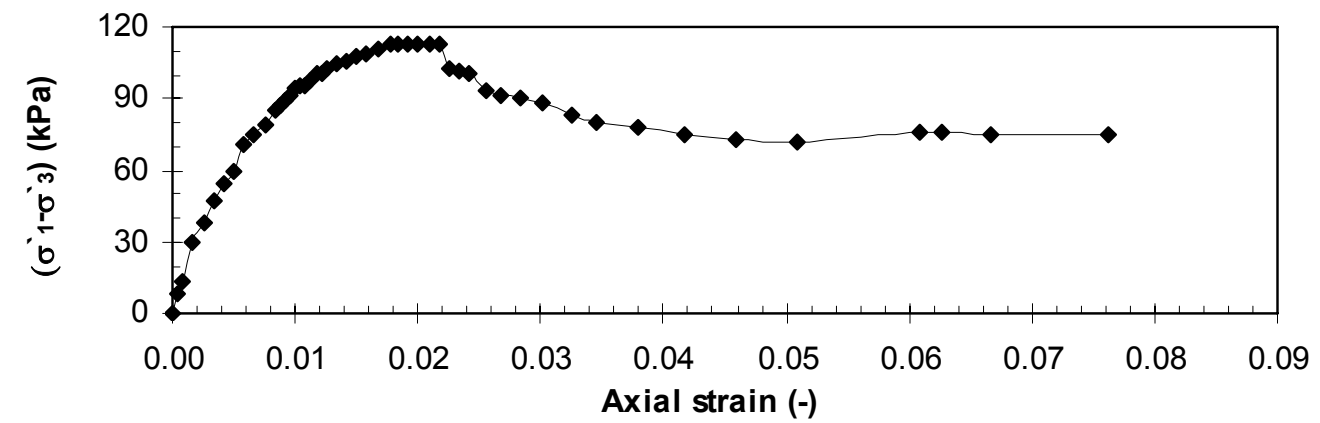

(a)

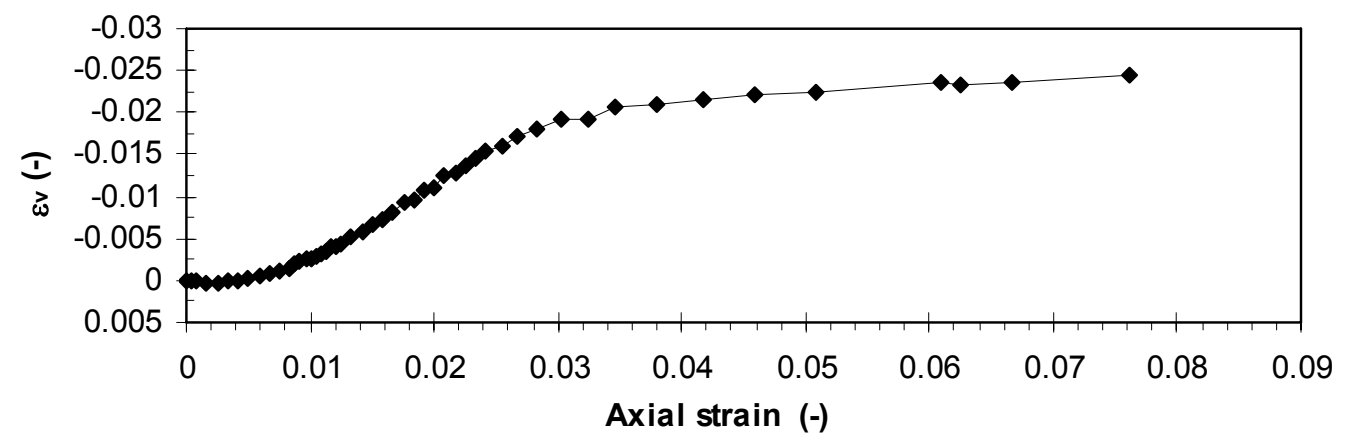

(b)

Figure (5.1) Experimental results of biaxial test on dense dry specimen: (a) axial strain versus deviator stress; (b) axial strain versus volumetric strain $\left(\sigma_{3}=15 \mathrm{kPa}\right)$ 


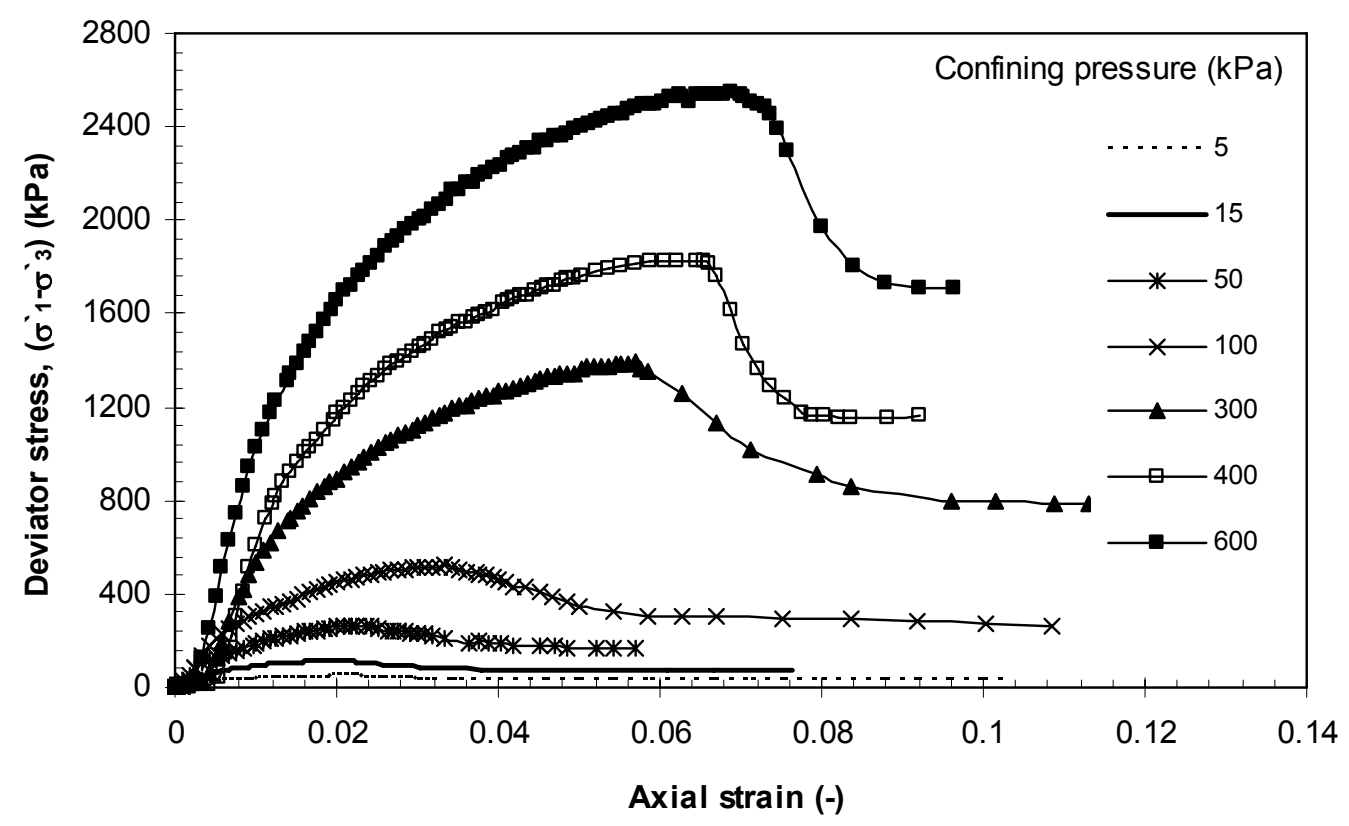

(a)

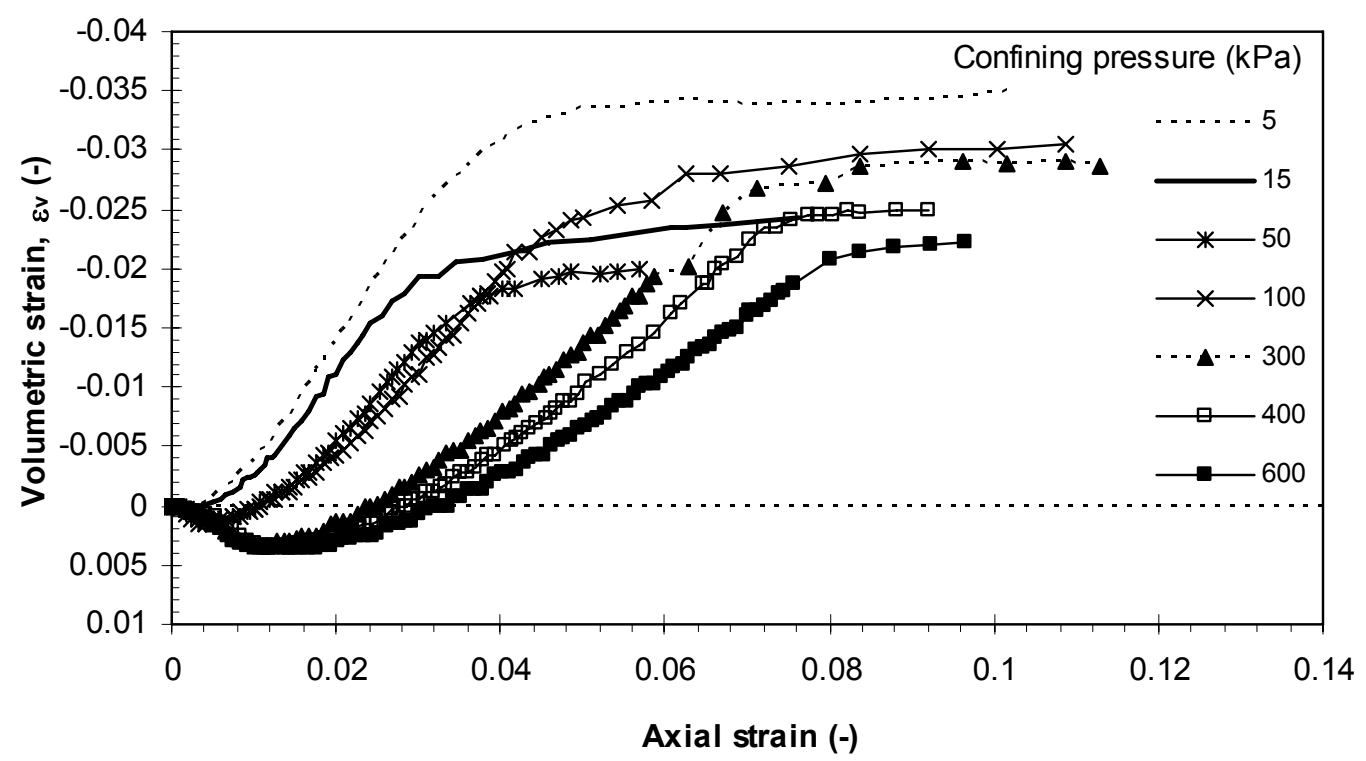

(b)

Figure (5.2) Experimental results of the tests on dense sand specimens: (a) deviator stress versus axial strain; (b) volumetric strain versus axial strain 


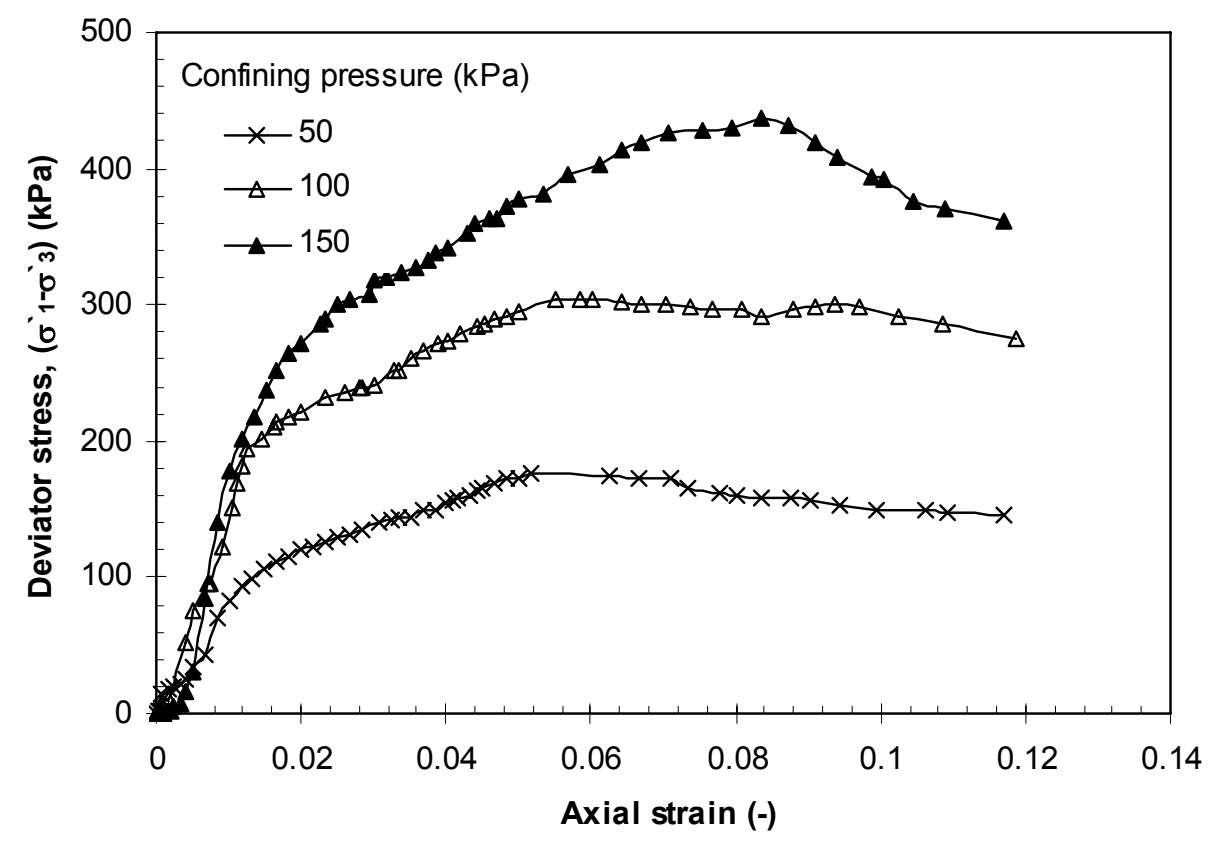

(a)

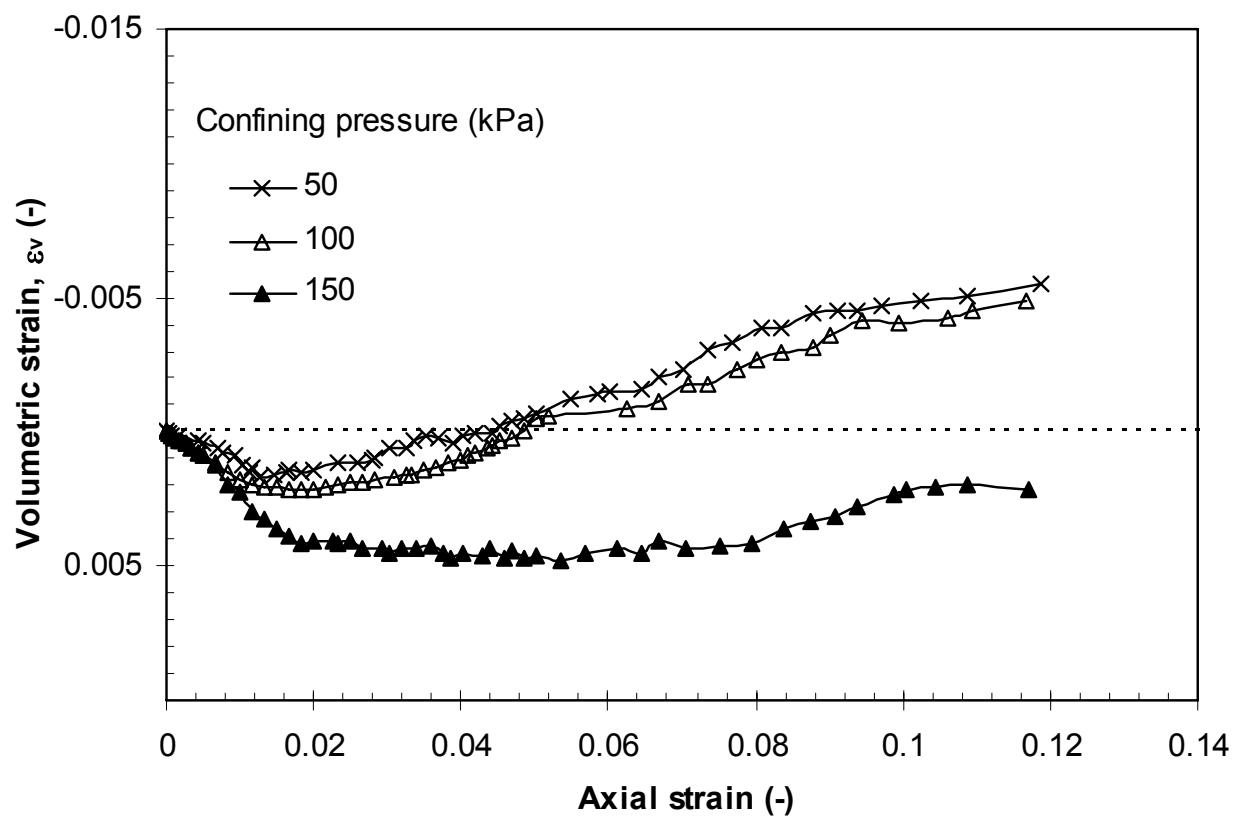

(b)

Figure (5.3) Experimental results of the tests on loose sand specimens: (a) deviator stress versus axial strain; (b) volumetric strain versus axial strain 
The effective stress paths for the dense and loose specimens are shown in Figure (5.4). The stress paths were drown in ( $\left.\mathrm{p}^{\prime}-\mathrm{q}^{\prime}\right)$ plane using the following definition of stresses (MIT stress system (Bardet, 1997)):

$\mathrm{p}^{\prime}=\left(\sigma^{\prime}{ }_{1}+\sigma^{\prime}{ }_{3}\right) / 2$

$q^{\prime}=\left(\sigma^{\prime}{ }_{1}-\sigma^{\prime}{ }_{3}\right) / 2$

where $\sigma_{1}{ }_{1}$ is the major principle effective stress and $\sigma_{3}{ }_{3}$ is the minor principle effective stress.

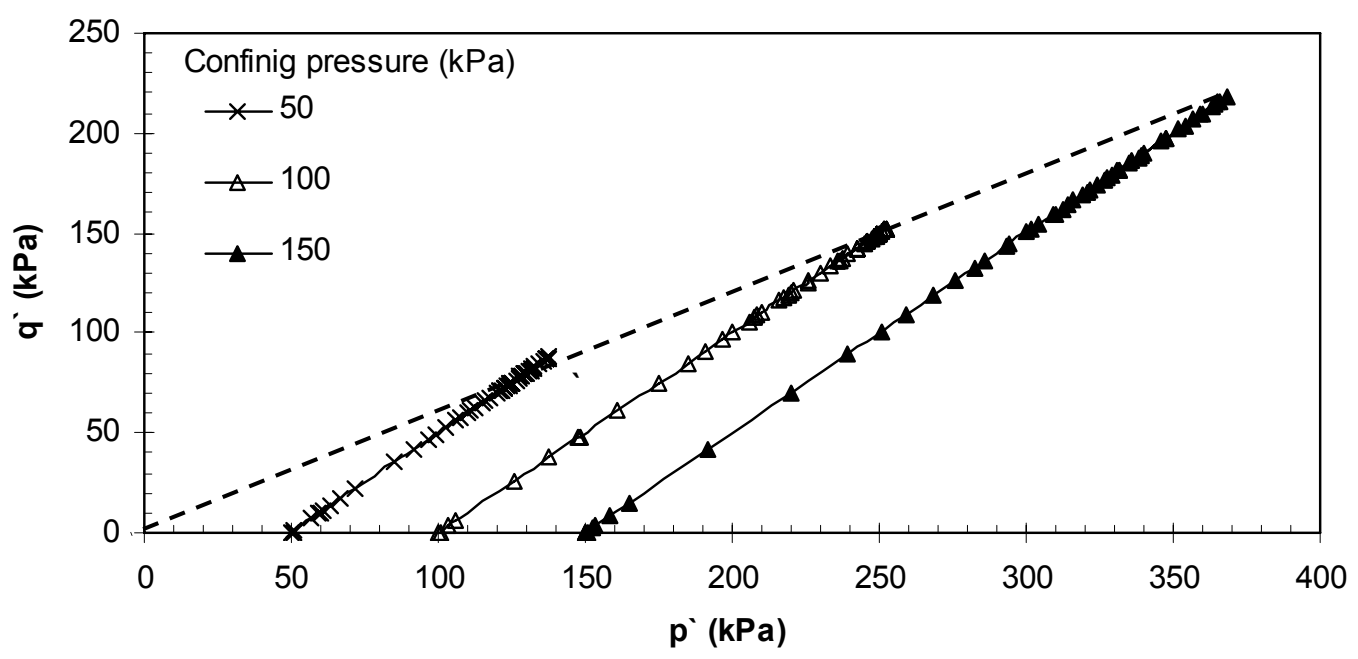

(a)

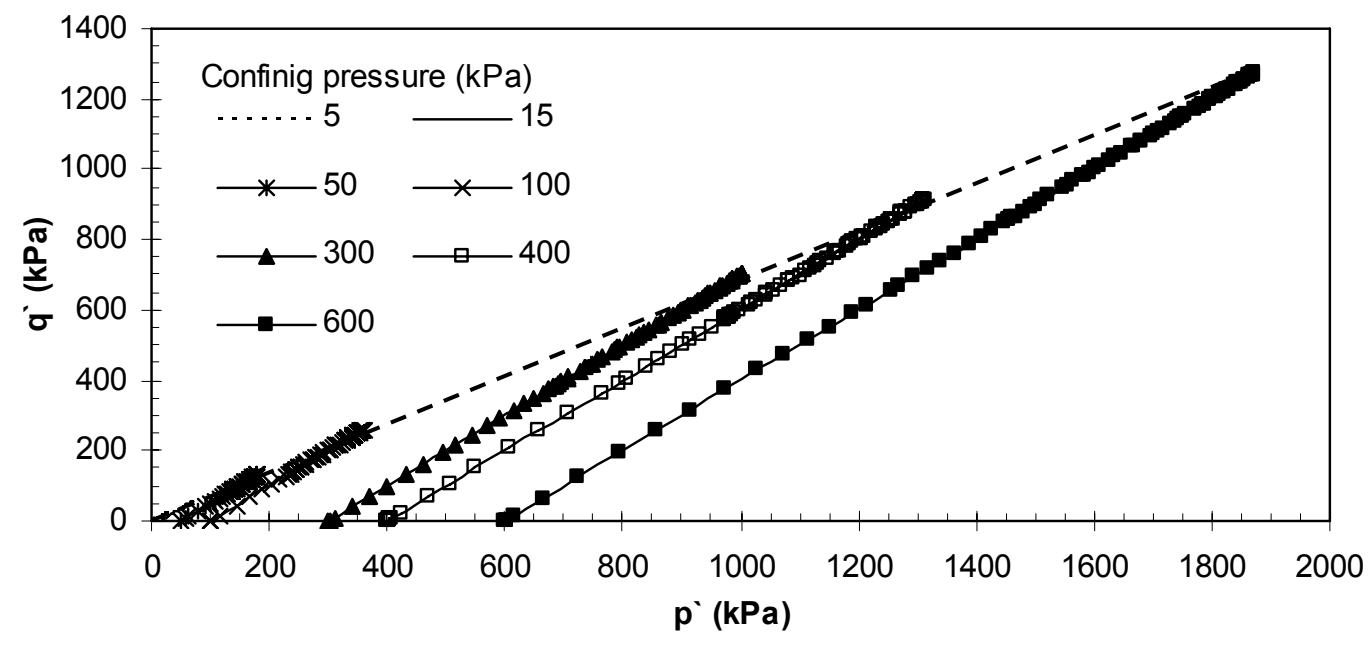

(b)

Figure (5.4) Stress paths in biaxial tests: (a) loose sand; (b) dense sand 
Shear band inclination angles were measured at the end of the test (i.e., residual state) in respect to the direction of the minor principle stress as illustrated in Figure (5.5). Figure (5.6) shows the relationship between the angle of shear band inclination and confining pressure for the dense and loose dry Hostun sand.

In the current version of biaxial device, the shear bands can not be observed in the plane of the intermediate stress $\left(\sigma_{2}\right)$ because the platens used to impose the plane-strain conditions are made of stainless steel. The shear bands were observed on the free faces of the specimen (i.e. on the plane of the minor principle stress, $\sigma_{3}$ ).

In this research, the failure mechanism was well documented and observed from the photographs of the specimen after the test. Figures (5.7), (5.8), and (5.9) show photographs of the specimens at the end of the test in $\sigma_{2}$ and $\sigma_{3}$ planes for specimens tested under confining pressures of 5,50 , and $300 \mathrm{kPa}$, respectively. The displacement of the bottom platen is also shown in the figures. The measured displacements of the lower platen at the end of the tests were in the range of $3-4 \mathrm{~mm}$. It should be noted here that in all the tests in the current study the bottom platen was free to move laterally from the beginning until the end of the test.

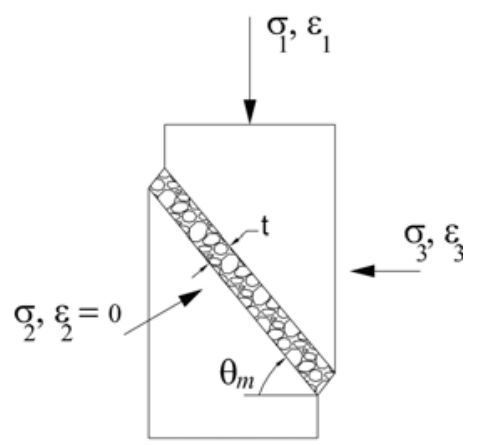

Figure (5.5) Shear band characteristics

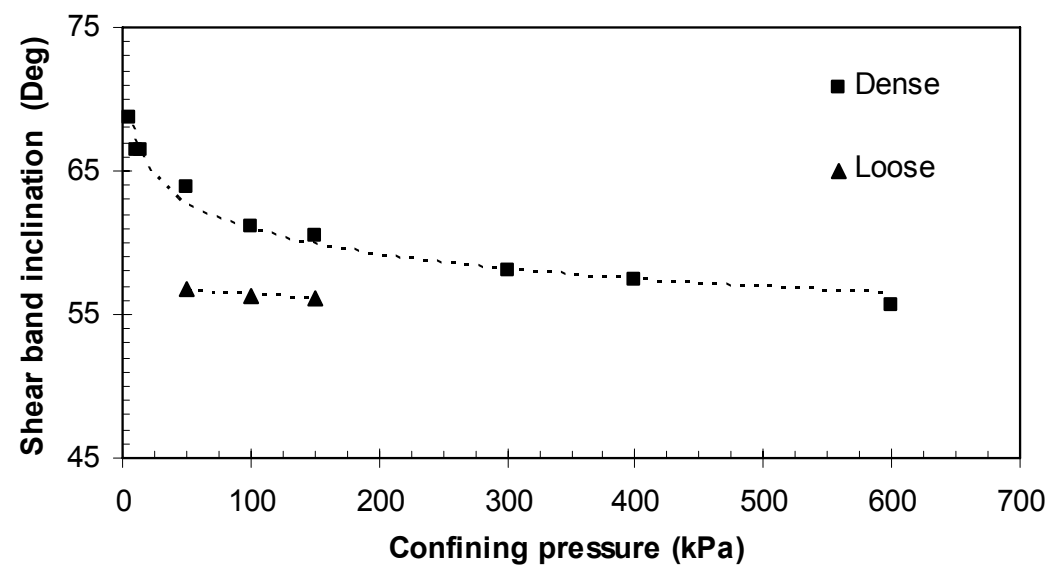

Figure (5.6) Angle of shear band inclination versus confining pressure of dense and loose Hostun sand 


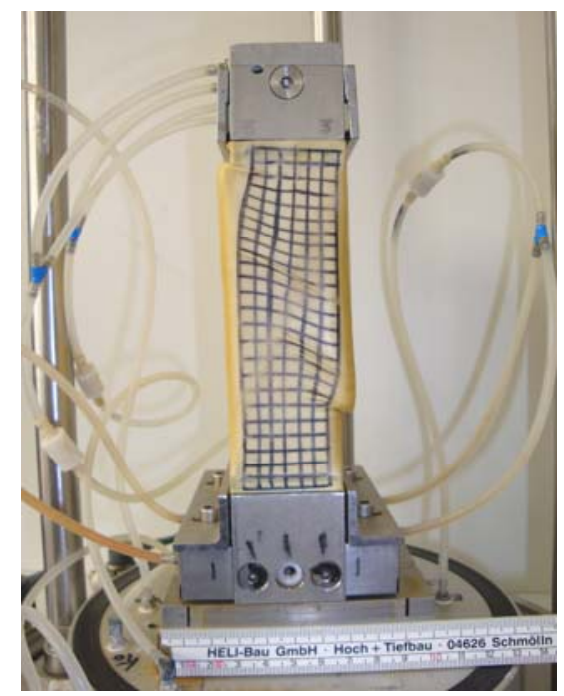

(a)

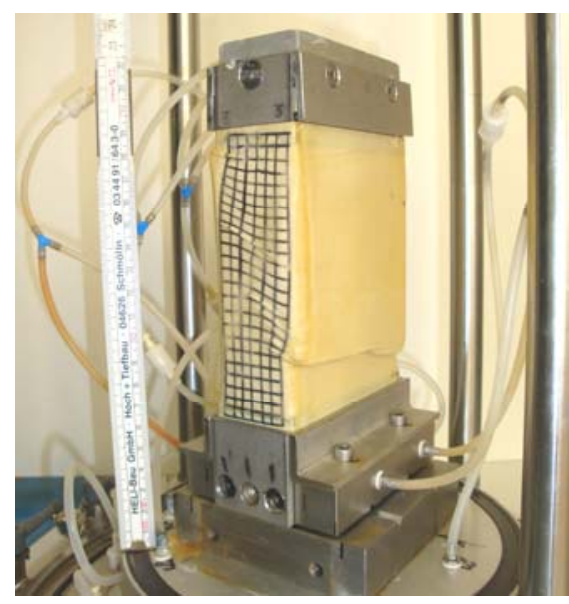

(b)

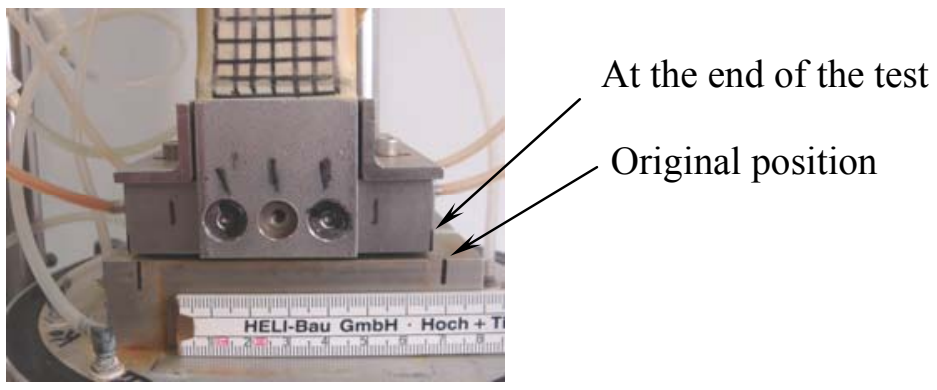

(c)

Figure (5.7) Specimen at the end of the test, $\sigma_{3}=5 \mathrm{kPa}, \mathrm{e}_{0}=0.66$ : (a) shear band in $\sigma_{2}$-plane; (b) shear band in $\sigma_{3}$-plane; (c) displacement of the bottom platen 


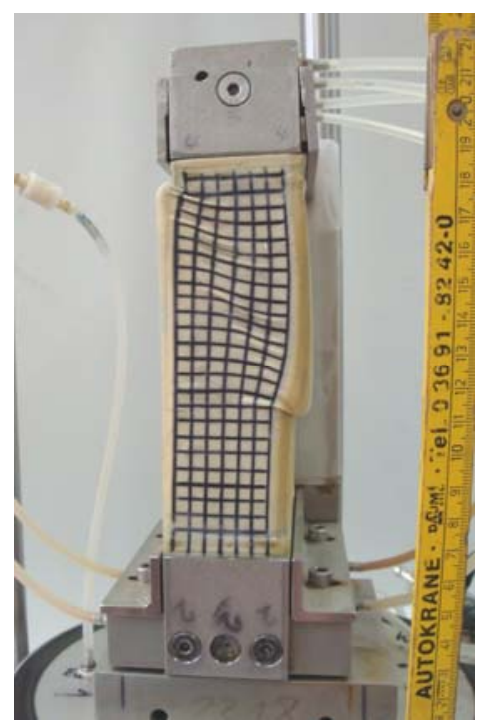

(a)

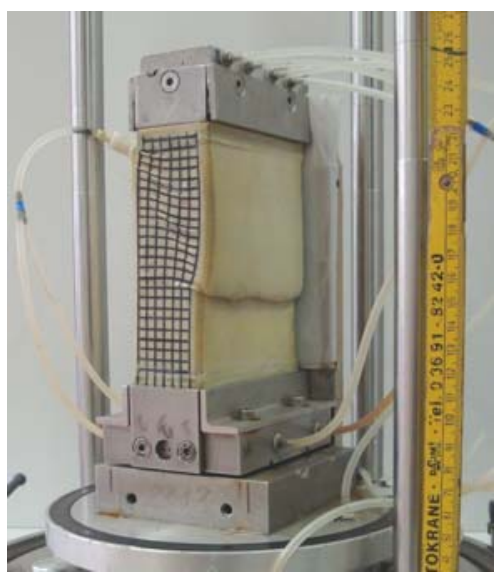

(b)

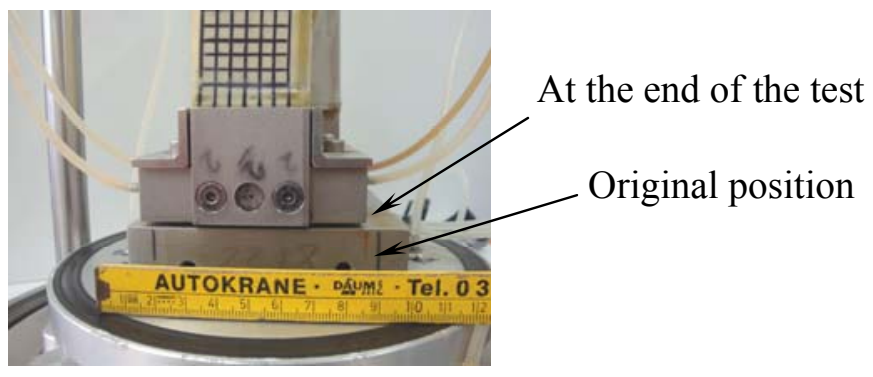

(c)

Figure (5.8) Specimen at the end of the test, $\sigma_{3}=50 \mathrm{kPa}, \mathrm{e}_{0}=0.66$ : (a) shear band in $\sigma_{2}$-plane; (b) shear band in $\sigma_{3}$-plane; (c) displacement of the bottom platen 


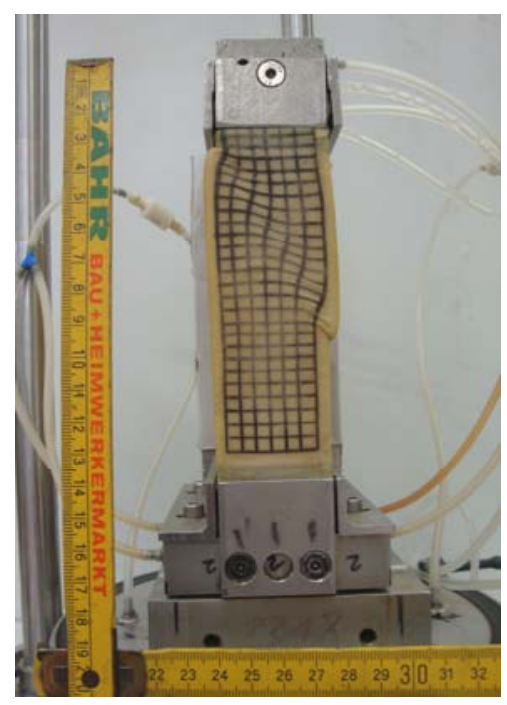

(a)

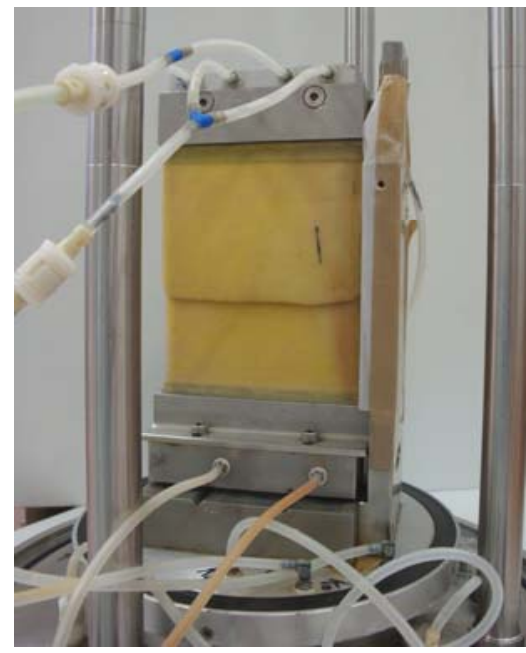

(b)

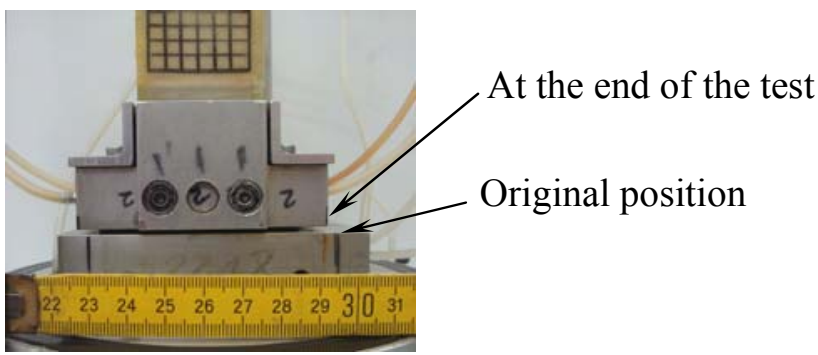

(c)

Figure (5.9) Specimen at the end of the test, $\sigma_{3}=300 \mathrm{kPa}, \mathrm{e}_{0}=0.66$ : (a) shear band in $\sigma_{2}$-plane; (b) shear band in $\sigma_{3}$-plane; (c) displacement of the bottom platen 
In most of the tests, the shear bands were symmetric (i.e., both faces of the specimen show the same angle of inclination.). If difference was observed, the angles of shear band inclination were measured at both faces of the specimen and the average was considered. The same phenomenon (i.e., different angles of shear band in each side face) was observed by Vardoulakis et al. (1978). The shear band observed on the free face of the specimen was horizontal.

In some tests, the shear band was not exactly straight rather it was almost semicurved and two angles of inclination were possibly observed on one side face of the specimen as shown in Figure (5.10). In this case, a fitting line was drawn and an average inclination was determined. This phenomenon was also observed in the biaxial tests (e.g., Vardoulakis and Graf, 1985; Oda and Kazama, 1998; Oda and Iwashita, 1999, 2000).

The measurements of the shear band thickness at the end of the tests showed an average thickness of 5-7 mm. Figure (5.11) shows the shear band with a noticeable thickness formed for a dense sand specimen sheared under confining pressure of $100 \mathrm{kPa}$. The thickness of the shear bands in the specimens were simply determined be naked eye using a scale. Disadvantage of using this method is that no difference in the thickness of the shear band was noticed for the specimens sheared under different confining pressures in the range of 5 to $600 \mathrm{kPa}$.

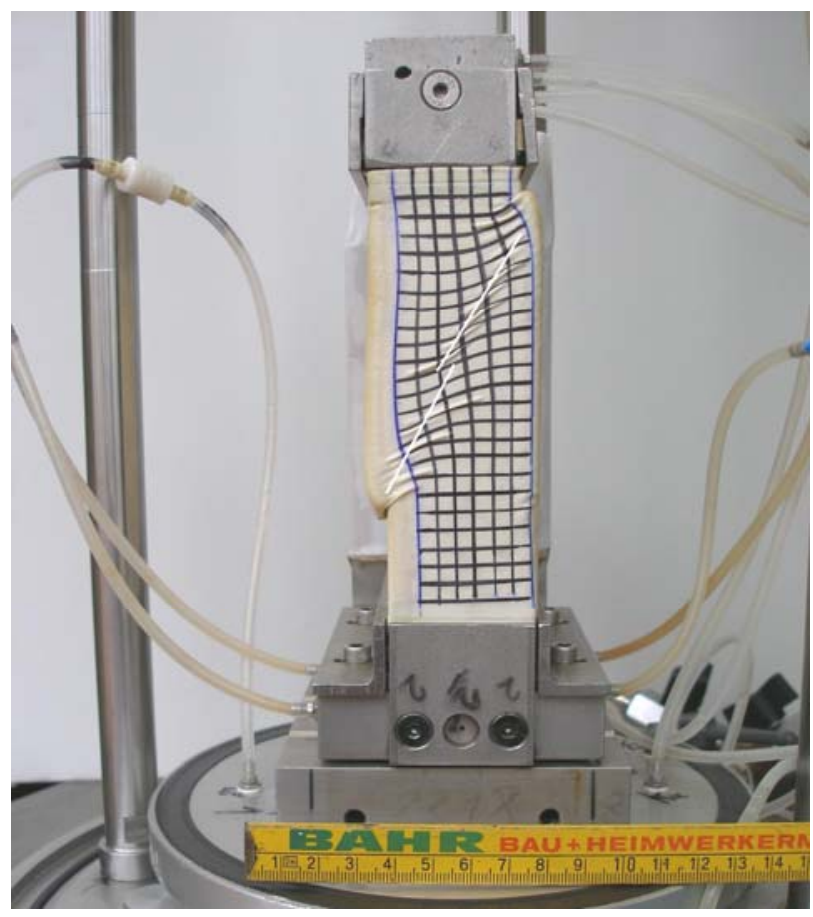

Figure (5.10) Shear band with two inclinations on the $\sigma_{2}$ plane 


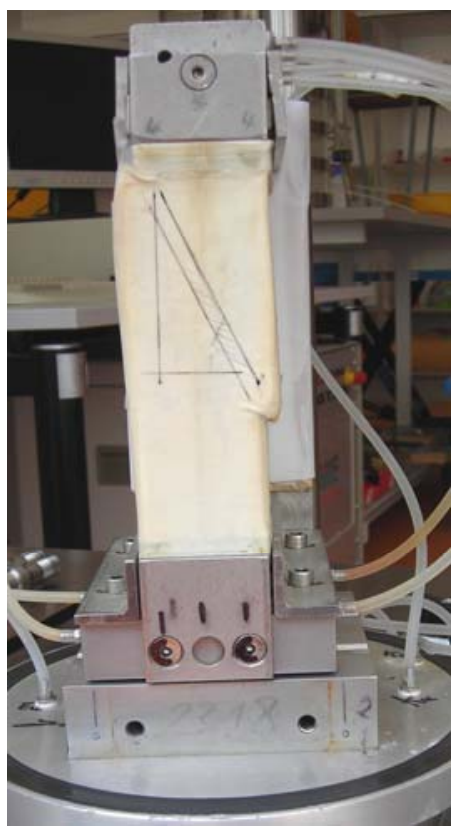

(a)

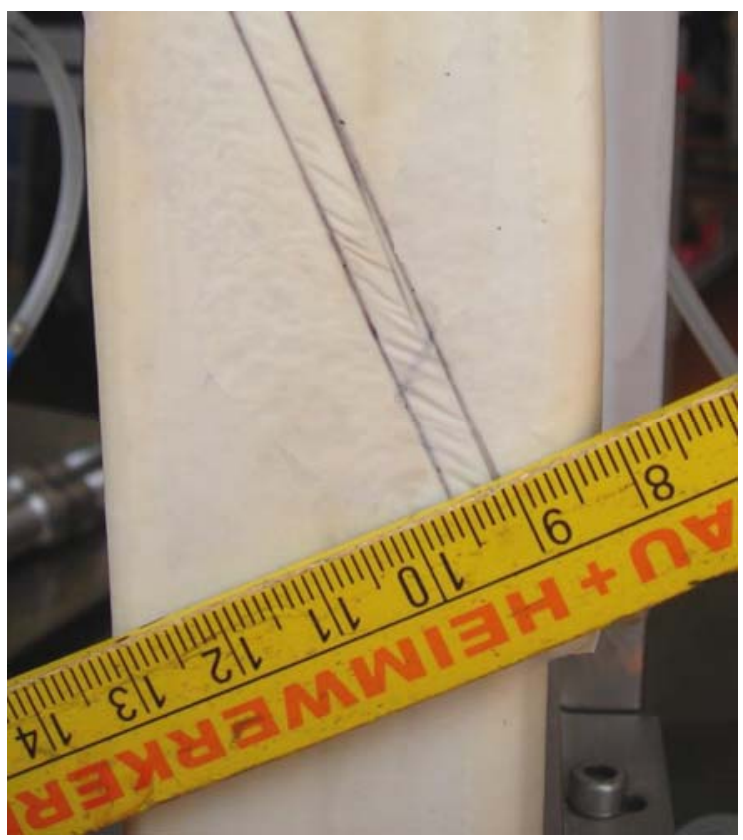

(b)

Figure (5.11) Noticeable thickness of the shear band at the end of biaxial test on dry dense specimen tested under confining pressure of $100 \mathrm{kPa}$ : (a) shear band in $\sigma_{2}$-plane;

(b) zoom up of the shear band

The thickness of the shear band is not constant. No shear band is like a rectangular plate with constant thickness, but in a wavy form. The shape and position of the shear band change slightly from section to section. In addition, the thickness of the shear band changes during the shear displacement (Oda and Iwashita, 1999).

The deformation of the membrane at the end of the test makes the border of the shear band unclear. Measuring shear band thickness at the end of the test using a scale may not be completely accurate due to the deformation of the membrane which gives an error in estimating the shear band thickness. Oda and Kazama (1998) reported the difficulty in measuring the shear band thickness; they stated that it is sometimes thought that the shear band can bee seen through the convoluted membrane. Overestimation of the shear band thickness can be happen even X-ray photographs are used (Oda and Kazama, 1998).

Alshibli and Sture (1999) used two independent digital imaging analysis techniques to measure shear band thickness of a fine-grained sand specimen tested under plane strain loading conditions. They reported that the localized deformations of granular materials can be easily and accurately monitored and measured using surface digitization of the latex membrane. In addition they ensured that the shear band thickness 
measurements obtained from membrane surface digitization and epoxy impregnation techniques are very close.

Mokni and Desrues (1999) conducted a testing program to get sure that the membrane will not affect the behaviour of the specimens and the onset of localization. As a result of their study, it was concluded that using latex membrane with a thickness equal to mean grain size $\left(d_{50}\right)$ with silicon grease will effectively reduce the friction between the specimen and the side platens (walls). Mokni and Desrues (1999) reported to the importance of measuring the shear band thickness at the onset of the shear band that in this stage the distortion of the latex membrane is still negligible.

When the soil is sheared along a single-plane, in both triaxial and biaxial tests; the membrane will be stretched as illustrated in Figure (5.12). In reality, the membrane stretching is less than that indicated by the idealized condition in Figure (5.12) and its effect is usually neglected (Head, 1986).

Desrues and Hammad (1989) reported that some increment of the shear strength occurs after the peak and this can be due to the reaction of the membrane at the shear band plane. The reaction of the membrane decreases as the confining pressure increases and becomes relatively less important at high confining pressures.

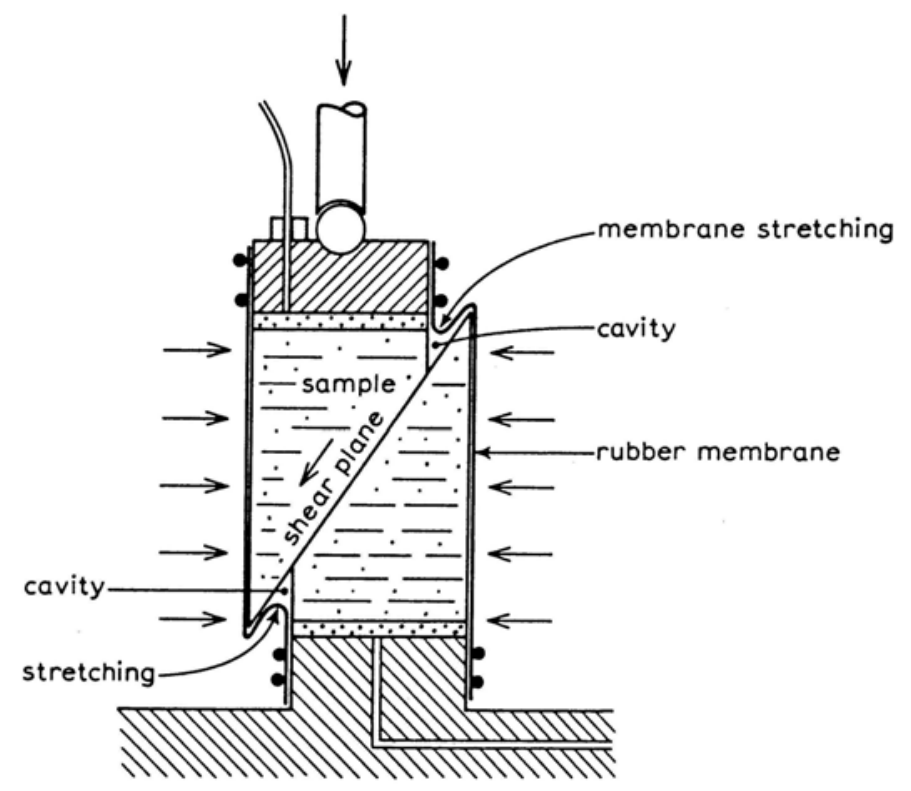

Figure (5.12) Stretching of membrane due to a single-plane slip (Head, 1986) 


\subsubsection{Results of unsaturated dense Hostun sand}

Figures (5.13), (5.14), and (5.15) show the experimental results of the biaxial tests on saturated and unsaturated dense sand specimens. As mentioned in Chapter 3, three set of tests have been done (i.e., B10, B50, and B100). In each set, the net confining pressure $\left(\sigma_{3}-u_{\mathrm{a}}\right)$ was kept constant and several values of matric suction $\left(u_{\mathrm{a}}-u_{\mathrm{w}}\right)=0,2,3,4,8,20$ $\mathrm{kPa}$ were applied and kept constant during the tests. Figures (5.11), (5.12), and (5.13) present the stress-strain curves for the set B10, B50, and B100, respectively.

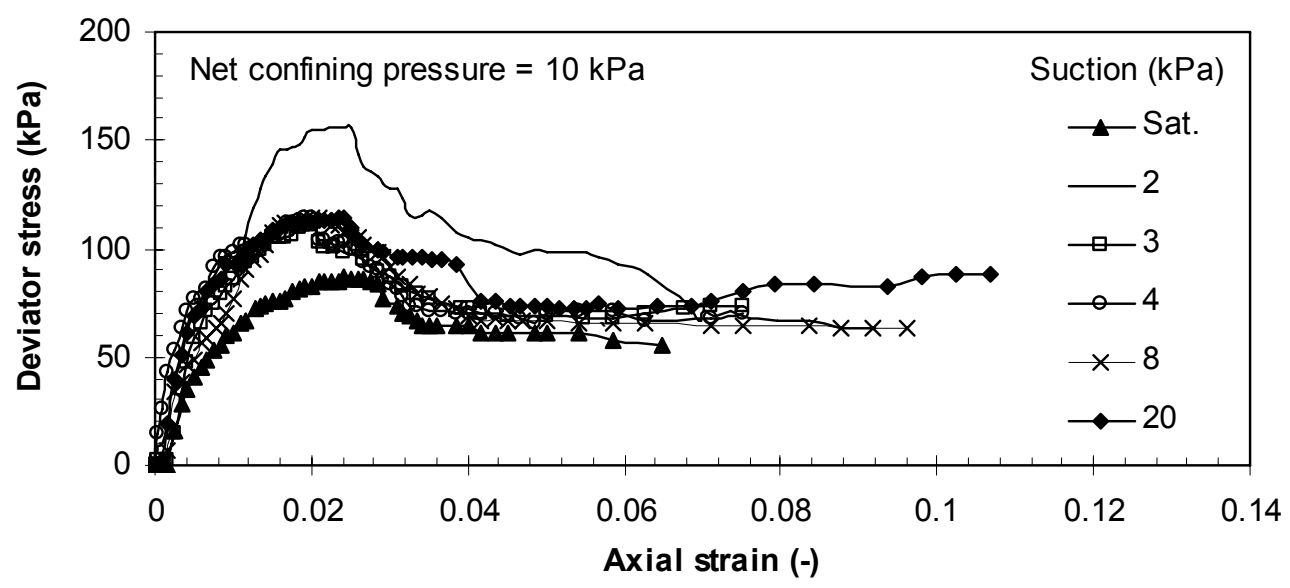

(a)

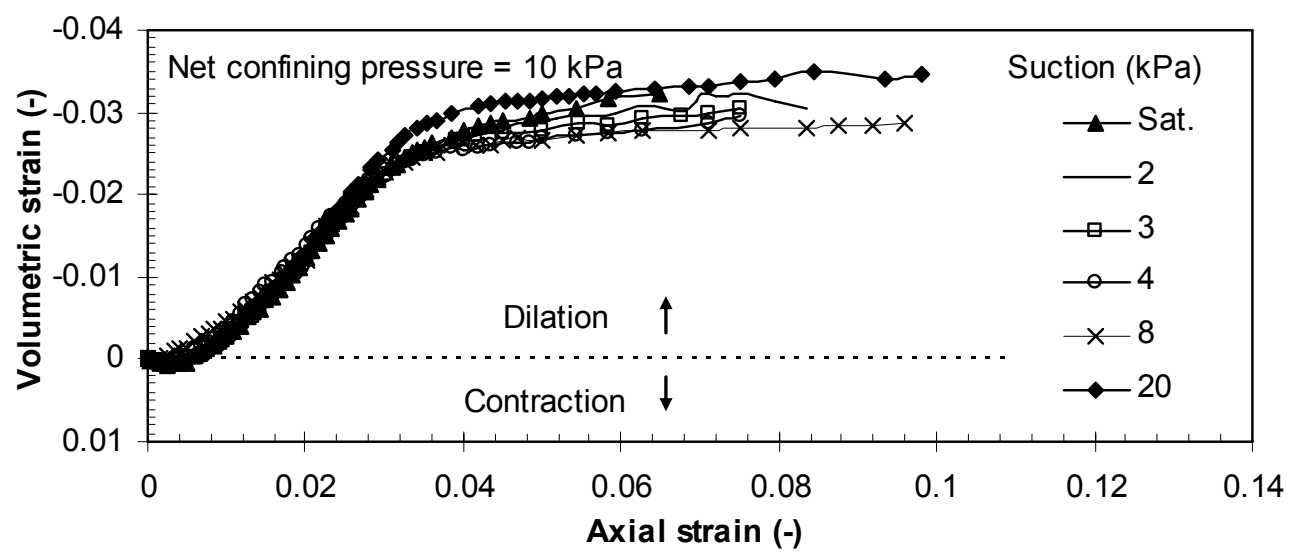

(b)

Figure (5.13) Stress-strain curves for set B10, $\left(\sigma_{3}-u_{a}\right)=10 \mathrm{kPa}$ : (a) axial straindeviator stress; (b) axial strain-volumetric strain 


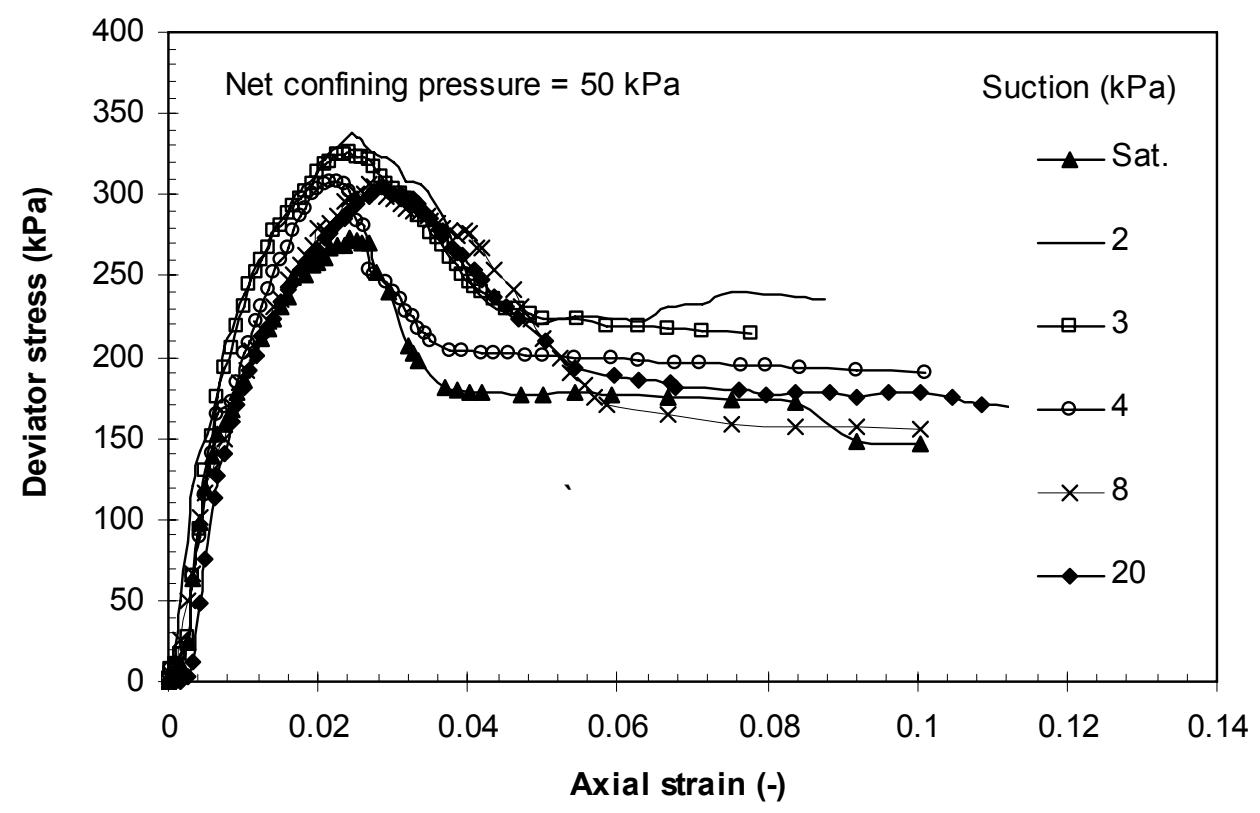

(a)

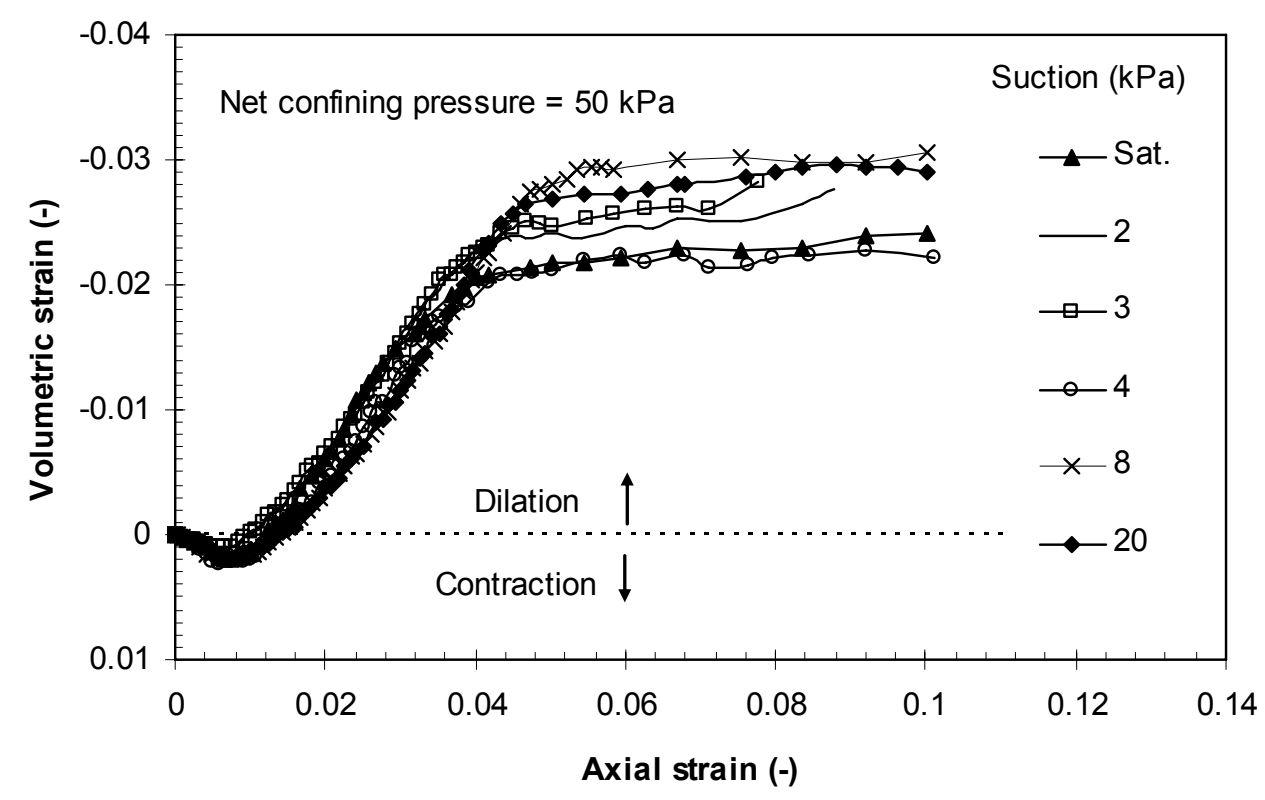

(b)

Figure (5.14) Stress-strain curves for set B50, $\left(\sigma_{3}-u_{a}\right)=50 \mathrm{kPa}$ : (a) axial straindeviator stress; (b) axial strain-volumetric strain 


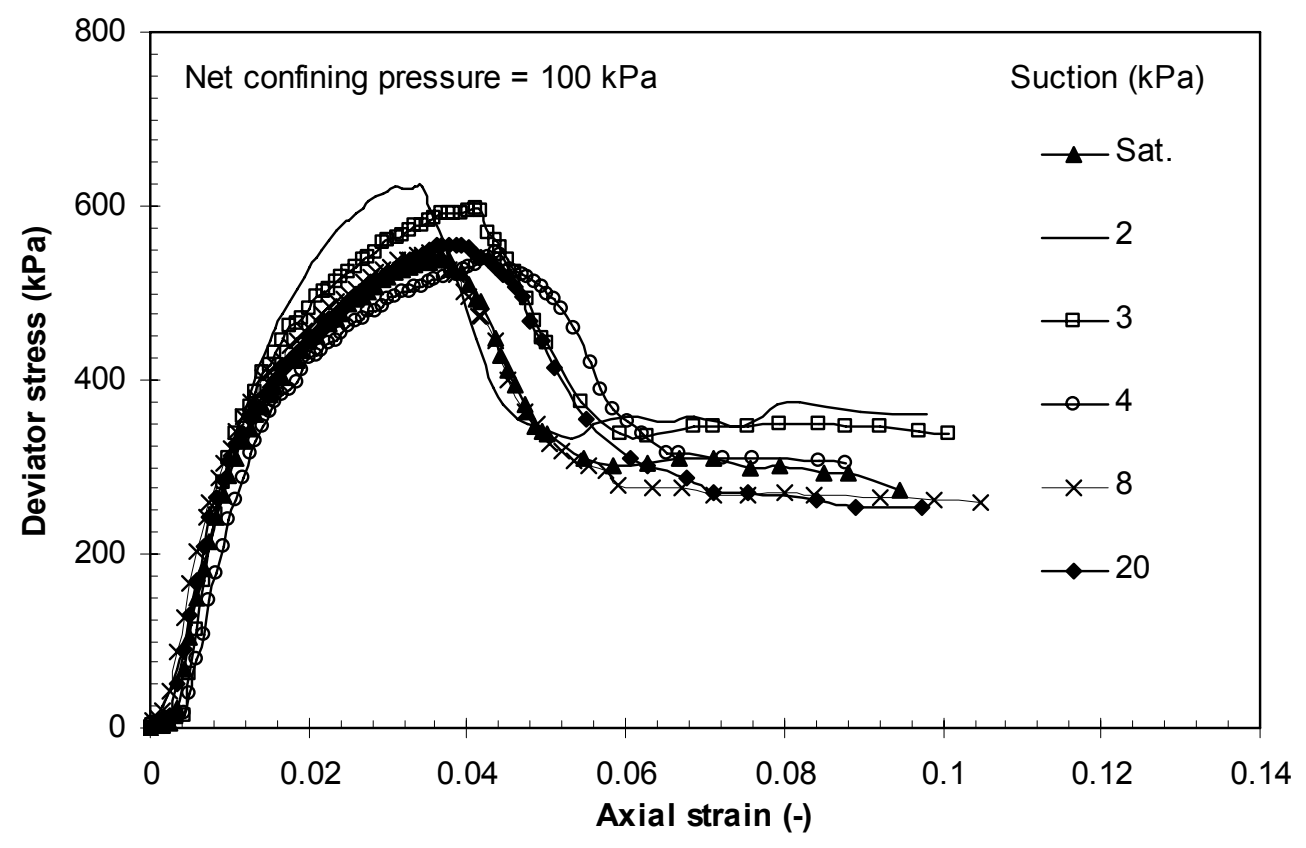

(a)

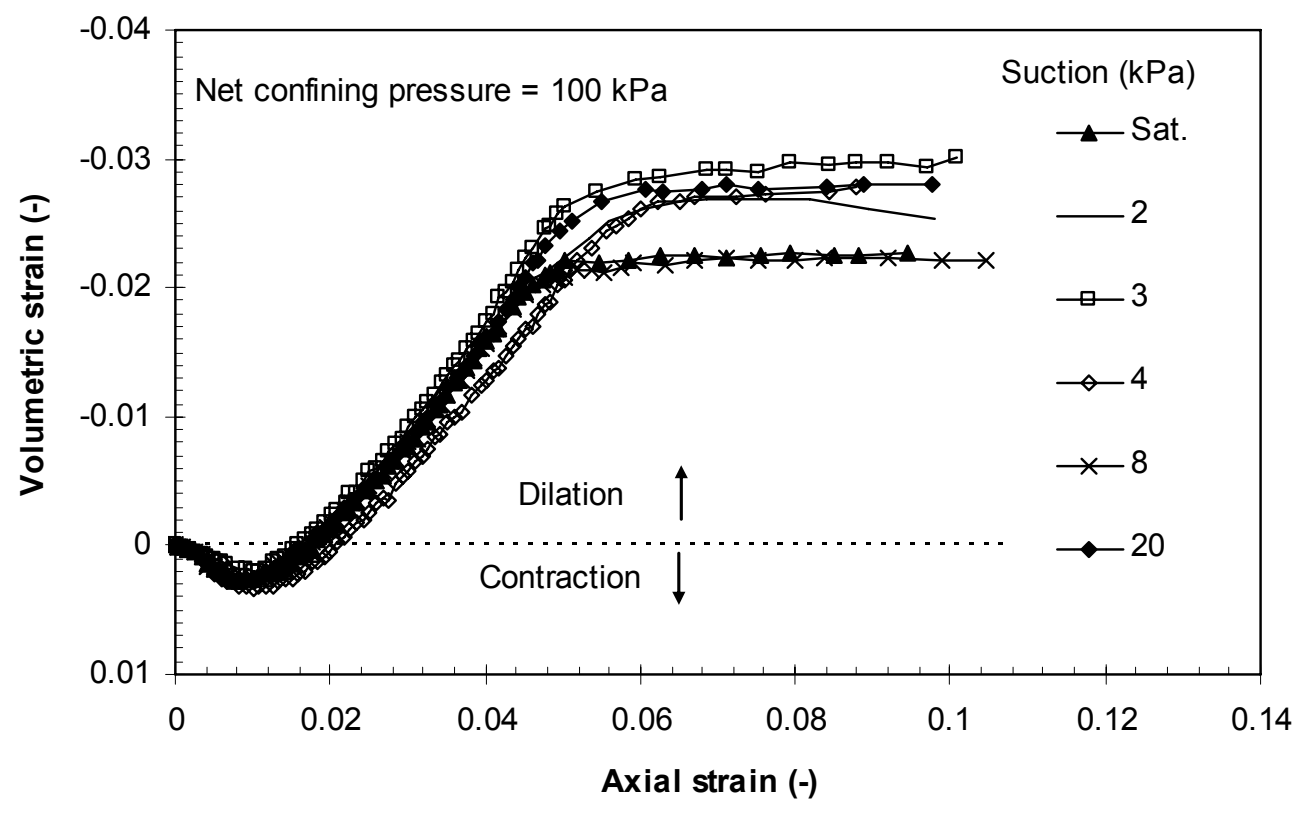

(b)

Figure (5.15) Stress-strain curves for set B100, $\left(\sigma_{3}-u_{a}\right)=100 \mathrm{kPa}$ : (a) axial straindeviator stress; (b) axial strain-volumetric strain 
Figure (5.16) shows the measured angles of shear band inclination, $\theta_{\mathrm{m}}$, for unsaturated Hostun sand tested under different values of net confining pressure and matric suction. As it is shown in Figure (5.16), change in matric suction has almost no significant effect on the angles of shear band inclination when the net confining pressure was kept constant in each set of tests. The figure shows that shear band inclination decreases by increasing net confining pressure. It can be concluded that the angle of the shear band inclination is mainly affected by the net confining pressure $\left(\sigma_{3}-u_{a}\right)$.

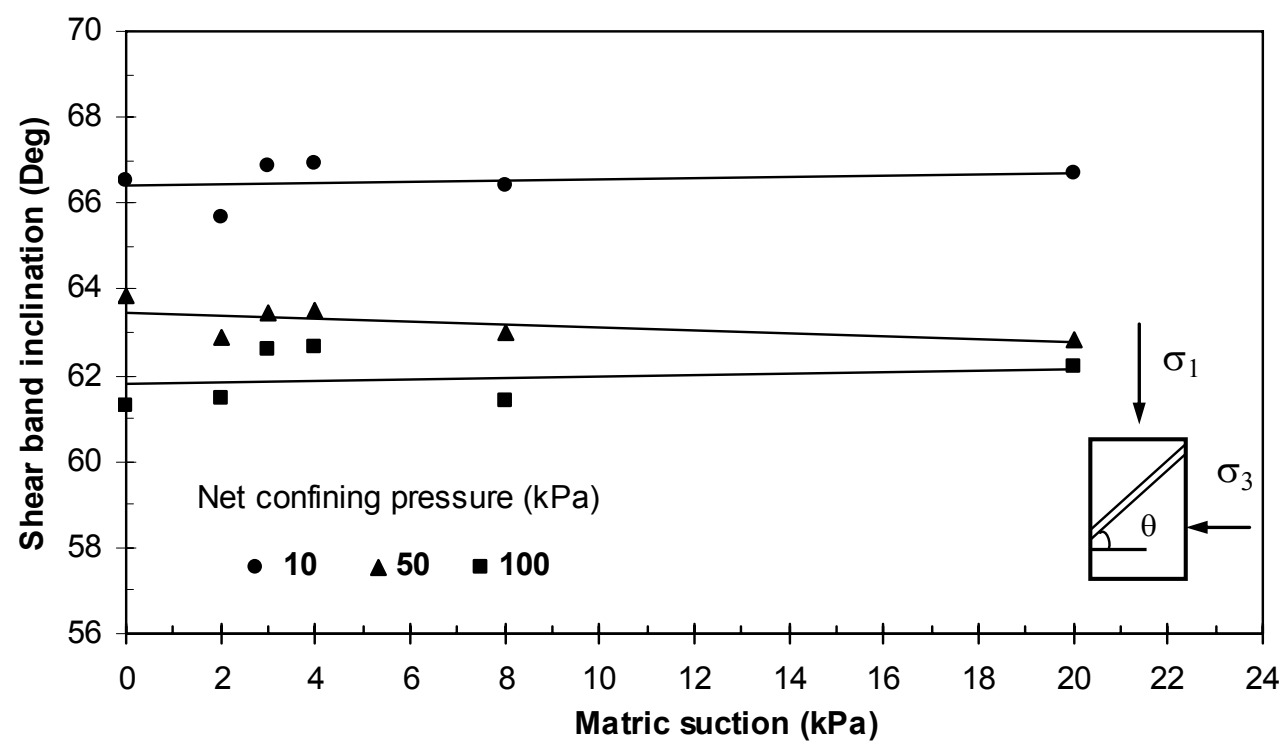

Figure (5.16) Matric suction versus the angle of shear band inclination of unsaturated dense Hostun sand specimens 


\subsection{Results of bearing capacity tests of model strip footing on unsaturated Hostun sand}

Figure (5.17) shows the relationship between the settlement of the model strip footing and the applied load for the saturated and unsaturated dense Hostun sand. The applied matric suction was monitored during the equalization and loading stages using two tensiometers. The first was located at the surface of the sand mass (depth $=10 \mathrm{~mm}$ ) and the second tensiometer was at $80 \mathrm{~mm}$ depth as illustrated in Figure (5.18).

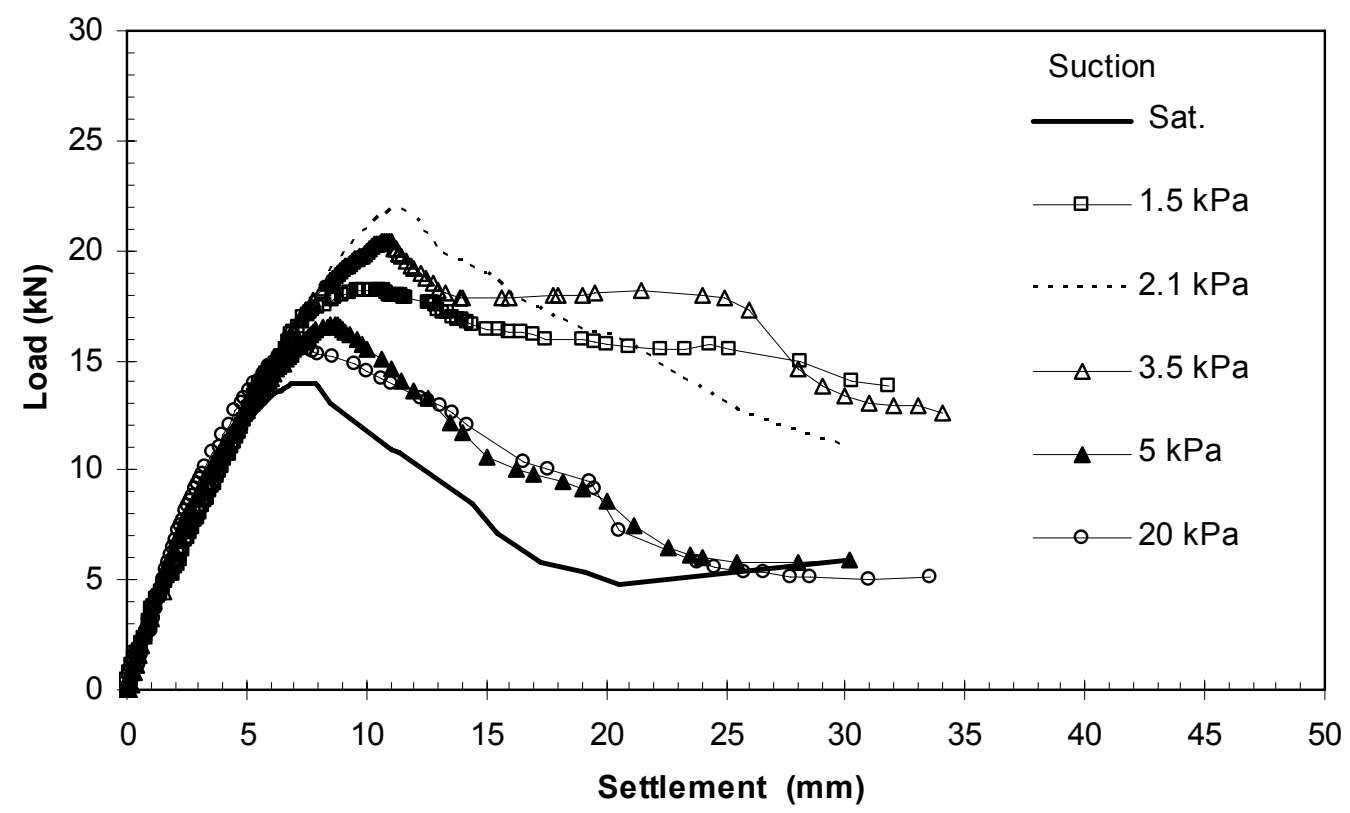

Figure (5.17) Load-settlement relationship of model strip footing on Hostun sand

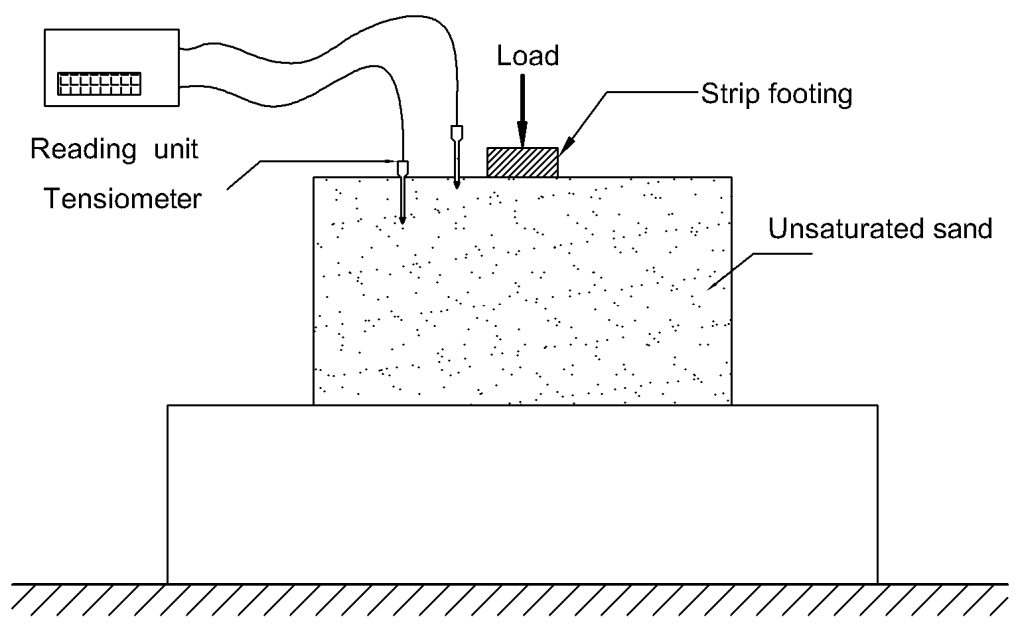

Figure (5.18) Location of the tensiometers in bearing capacity test 
Figure (5.19) shows an example of the changes in matric suction (at two depths: land $8 \mathrm{~cm}$ ) during the loading stage of a bearing capacity test of the model strip footing on unsaturated Hostun sand (matric suction of $2 \mathrm{kPa}$ ). It can be noticed that the matric suction was almost constant during the loading stage. This can be attributed to two reasons, firstly the low strain rate have been used (loading speed $=0.002 \mathrm{~mm} / \mathrm{sec}$ ), the second is that sand mass was covered during the tests using a plastic cover preventing as much as possible the evaporation of the water from the sand mass. The water content of the sand specimens taken from different depths was determined at the end of the test; and the suction at $d=B$ (where B is the width of the strip footing) was considered in studying the effect of the matric suction on the bearing capacity of the model strip footing. Figure (5.20) shows the suction profiles under the strip footing in the tests.

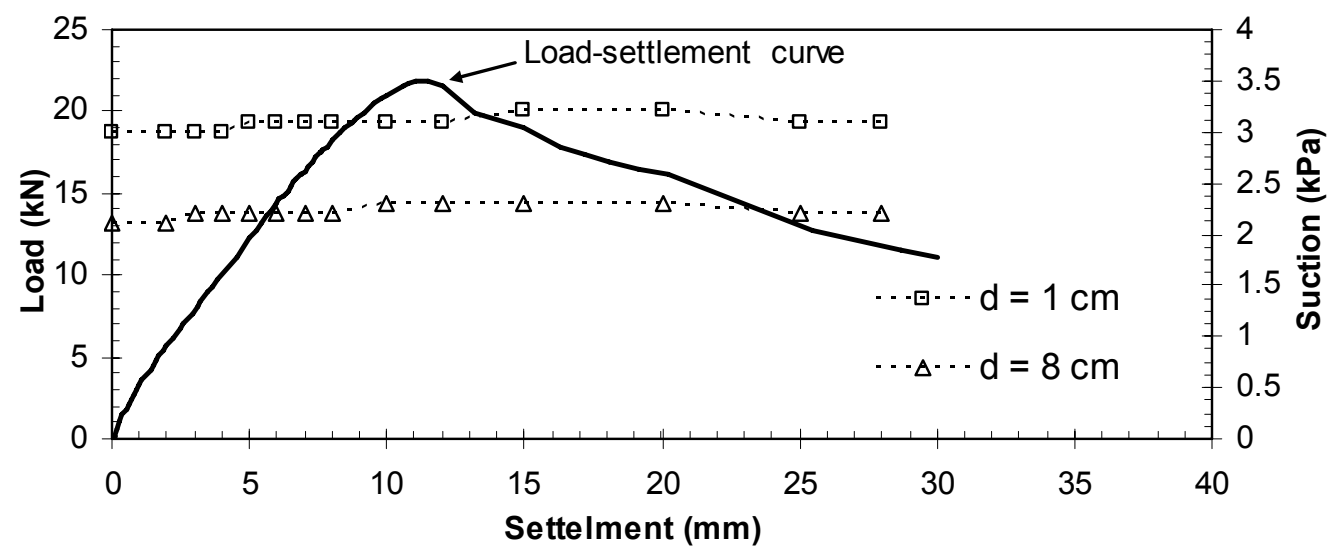

Figure (5.19) The changes in the applied matric suction during the bearing capacity test of strip footing on dense unsaturated Hostun sand $\left(\mathrm{e}_{0}=0.66\right.$, Suction $\left.=2.1 \mathrm{kPa}\right)$

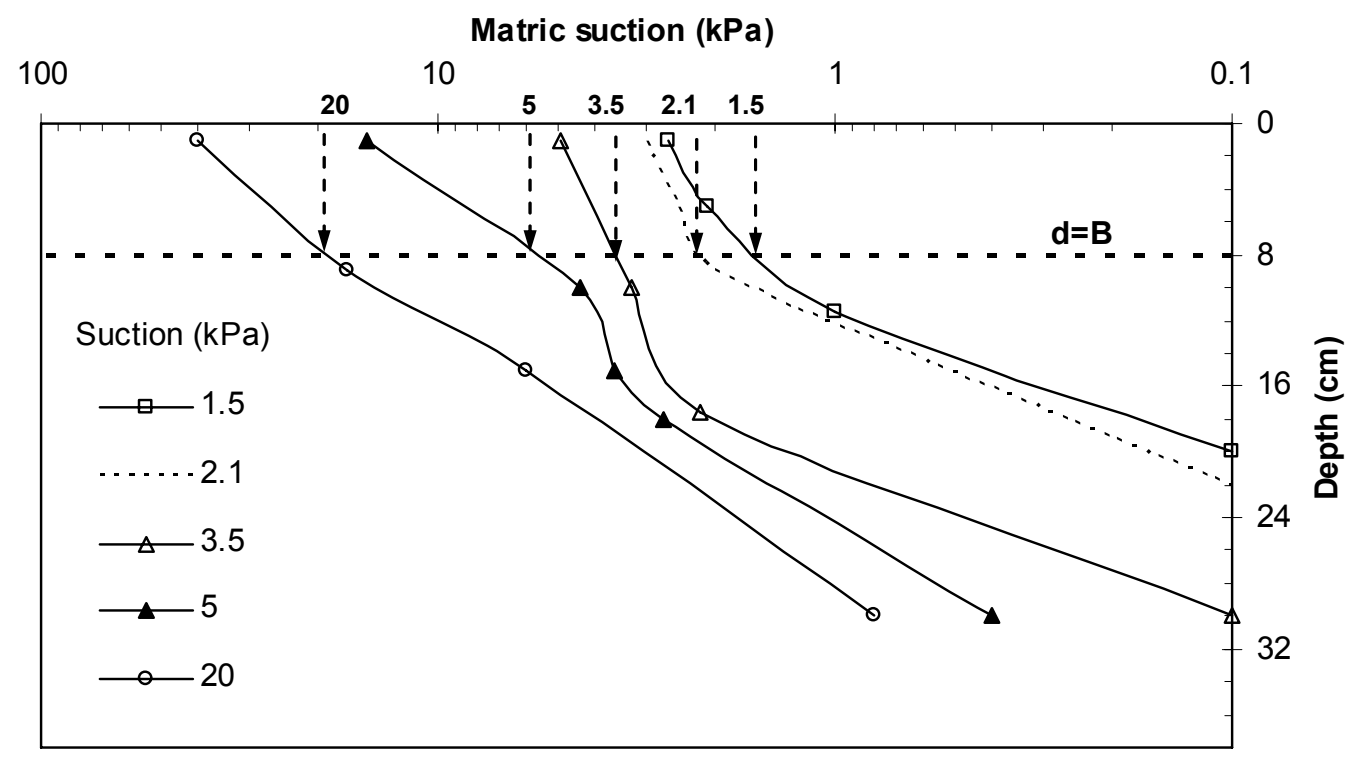

Figure (5.20) Suction profiles under the strip footing in the bearing capacity tests 


\subsection{Soil water characteristic curves (SWCCs)}

Soil water characteristic curves were investigated by performing drying and wetting paths for the pure Hostun sand $\left(\mathrm{e}_{0}=0.66\right)$, pure Spergauer kaolin $w_{\text {opt }}=22.80 \%$, $\left.\gamma_{d, \max }=1.51 \mathrm{Mg} / \mathrm{m}^{3}\right)$, and the three mixtures A (95\% sand, 5\% kaolin with $w_{\text {opt }}=14.29 \%$, $\left.\gamma_{d, \max }=1.60 \mathrm{Mg} / \mathrm{m}^{3}\right), \mathrm{B}\left(90 \%\right.$ sand, $10 \%$ kaolin with $\left.w_{\text {opt }}=13.80 \%, \gamma_{d, \max }=1.68 \mathrm{Mg} / \mathrm{m}^{3}\right)$, and C (70\% sand, $30 \%$ kaolin with $\left.w_{\text {opt }}=13.00 \%, \gamma_{d, \max }=1.88 \mathrm{Mg} / \mathrm{m}^{3}\right)$.

The changes of mass of the specimens by time are given in Figure (5.21) and Figure (5.22). Figure (5.21) is for the experiments performed in the pressure plate extractor at suction of 20 and $400 \mathrm{kPa}$ and Figure (5.22) is for experiments performed using vapour equilibrium technique at suction of 3000 and $30000 \mathrm{kPa}$. Figure (5.23) shows the SWCCs for the pure Hostun sand, pure Spergauer kaolin, and mixtures A, B, and $\mathrm{C}$.

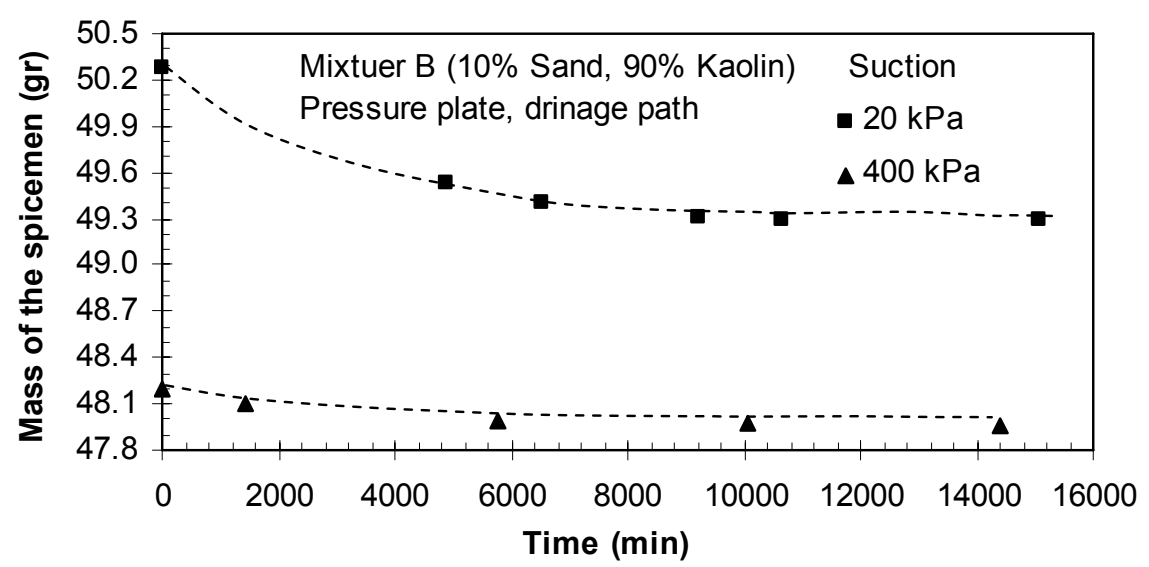

Figure (5.21) Measured mass of mixture B specimen due to applied suction during drainage path in the pressure plate extractor

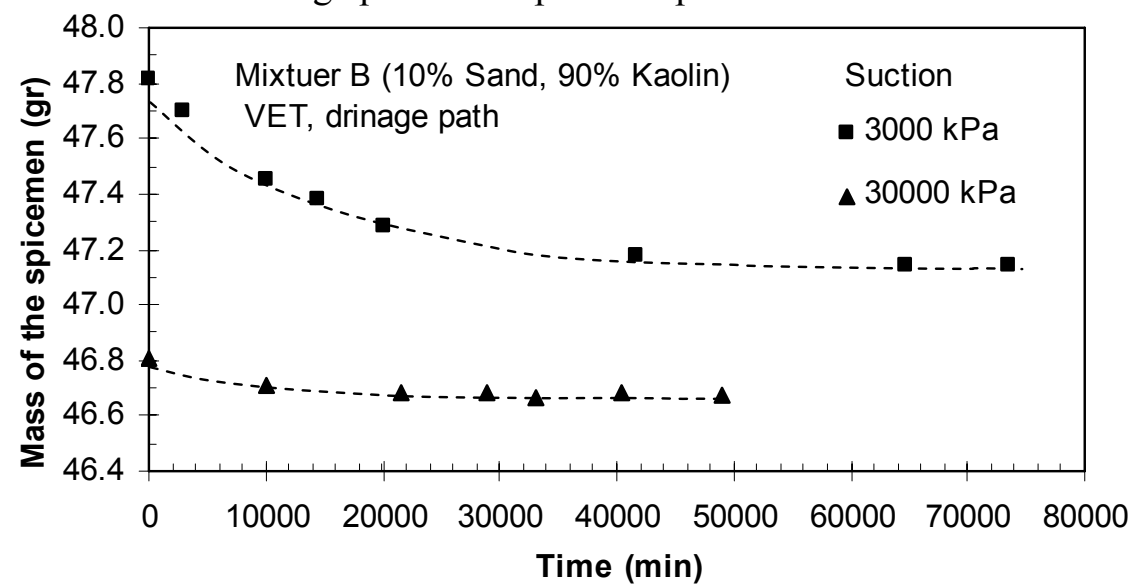

Figure (5.22) Measured mass of mixture B specimen due to applied suction during drainage path using vapour equilibrium technique 


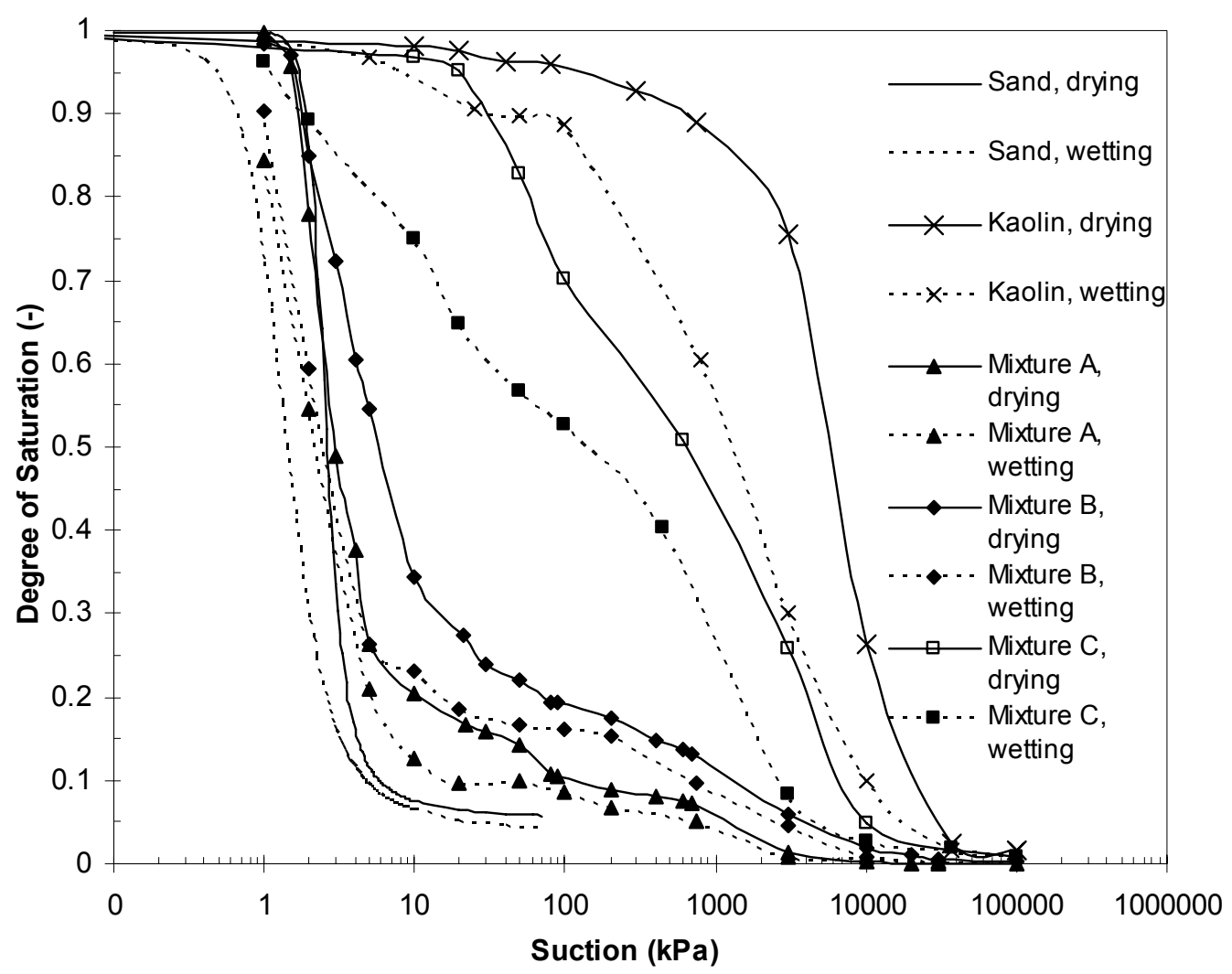

Figure (5.23) SWCCs (drying \& wetting) of the materials used 


\section{CHAPTER 6}

\section{ANALYSIS AND DISCUSSION}

\subsection{General}

In this chapter, the discussion of the experimental results of the tests performed using the new double-wall biaxial device is presented. The discussion brought out in this chapter includes comparison of the results of this study with other results from the literature (e.g., Desrues and Hammad, 1989; Han and Vardoulakis, 1991; Alshibli and Sture, 2000; Wanatowski, 2005). Emphasis is given to compare the results of the present study with the results obtained in Grenoble, France by Prof. Desrues and his co-workers in the last three decades.

Comparisons between the measured and predicted shear strength calculated using two approaches proposed by Vanapalli et al. (1996) and by Khallili and Khabbaz (1998) are presented as well. The measured ultimate bearing capacity of unsaturated Hostun sand is compared to the predicted one calculated using the approaches proposed by Vanapalli and Mohamed (2007). The results of SWCCs tests are also discussed and the effect of the fine content on the characteristics of soil water characteristic curves is clarified.

\subsection{Discussion of the biaxial tests' results on dry Hostun sand}

Discussion of results of biaxial tests on the dense and loose dry specimens will be presented in two sections. The first section discusses the results relevant to stress-strain behaviour. (i.e., angle of internal friction, angle of dilatancy, elasticity modulus). The second section will focus on the results relevant to shear banding (i.e., shear band inclination angle and the thickness of the shear band).

\subsubsection{Stress-strain behaviour of dry Hostun sand}

In this chapter, the results of the dense and the loose Hostun sand are referred to as (D) and (L), respectively. Whereas the Grenoble's biaxial results of dense and loose Hostun sand are referred as (GD) and (GL), respectively. In addition, some triaxial results obtained in Grenoble on dense Hostun sand are referred as (GTD). Figure (6.1) shows the effect of the applied confining pressure on the maximum angle of friction $\left(\phi_{\mathrm{p}}\right)$. The results of biaxial and triaxial tests on Hostun sand obtained in Grenoble are also shown in 
the figure. The highest values of $\phi_{\mathrm{p}}$ were measured under the lowest confining pressures. By increasing the confining pressure the maximum friction angle decreases. The friction angles measured for dense Hostun sand specimens are $55.8^{\circ}$ and $42.8^{\circ}$ for confining pressures of $5 \mathrm{kPa}$ and $600 \mathrm{kPa}$, respectively. The angle of friction at peak $\left(\phi_{\mathrm{p}}\right)$ was calculated using the following equation:

$$
\sin \phi_{p}=\left(\sigma_{1}^{\prime}-\sigma_{3}{ }^{\prime}\right)_{p} /\left(\sigma_{1}{ }_{1}+\sigma_{3}{ }_{3}\right)_{p}
$$

where $\sigma_{1}{ }_{1}$ is the major principle effective stress at peak; $\sigma_{3}^{{ }_{3}}$ is the minor principle effective stress at peak. Figure (6.1) shows that the maximum angle of friction in planestrain conditions is higher than that deduced from the triaxial test. This agrees with the observations in other researches (e.g., Conforth, 1961; Lee, 1970; Marachi et al., 1981; Hanna, 2001). The present results agree well with the results obtained in Grenoble on Hostun sand specimens tested in a biaxial device.

Similar changes of friction angle with pressure were also observed in triaxial tests. Example is given in Figure (6.2) where the results of triaxial tests on two types of sands presented by Kutter et al. (1988) show that the friction angle varies about $15^{\circ}$ by changing the confining pressure in the range of 50-1500 $\mathrm{kPa}$.

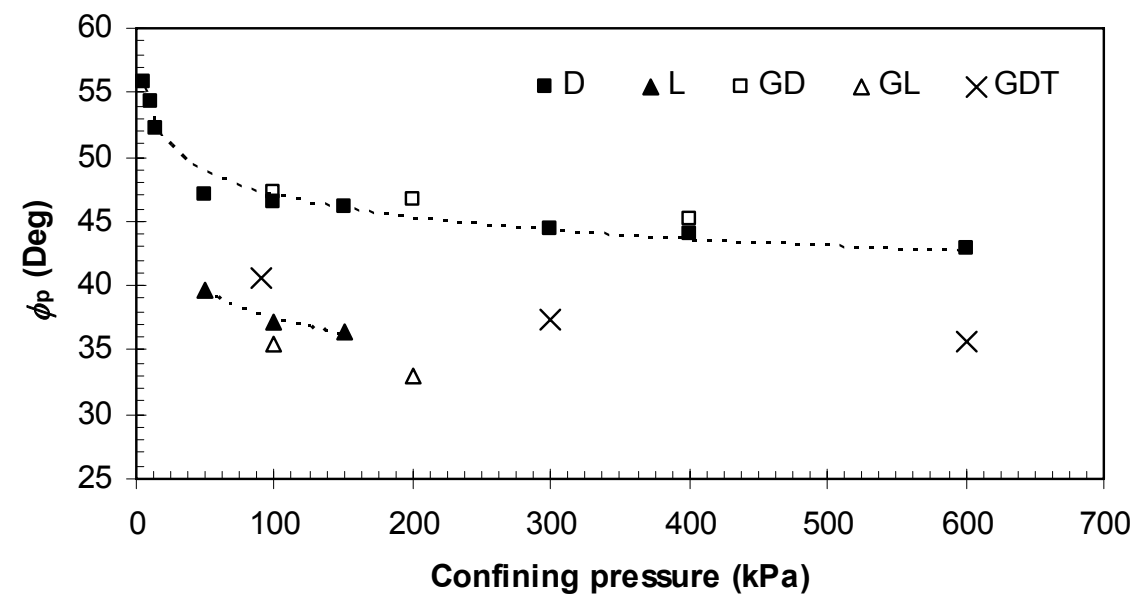

Figure (6.1) Angle of internal friction at peak versus confining pressure

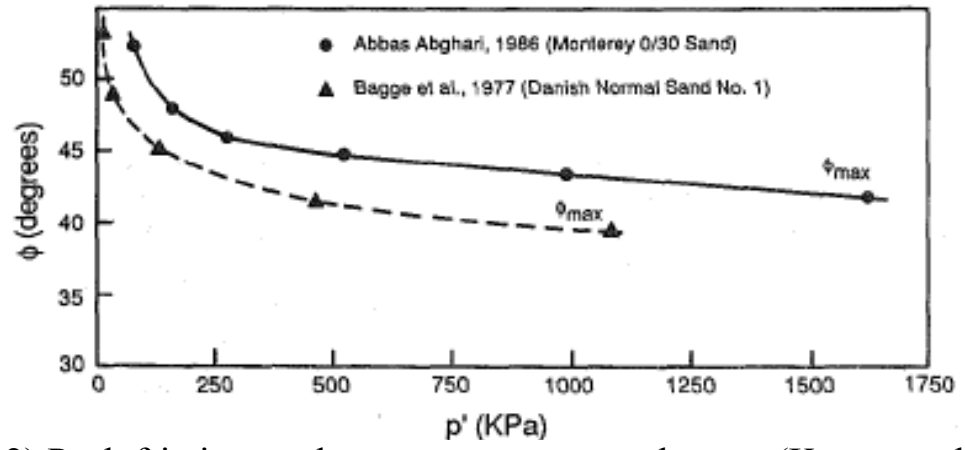

Figure (6.2) Peak friction angle versus mean normal stress (Kutter et al., 1988) 
The internal angle of friction is not constant for a given soil, even the void ratio is constant, but rather changes greatly depending on the following factors: the confining pressure, principle stress direction with respect to the bedding plane (anisotropy), and the intermediate principle stress (Oda and Iwashita, 1999). It is important to obtain c and $\phi$ from test data in the pressure range which will be felt in the soil (Kutter et al., 1988).

By straining the specimen, the dilatancy angle increases until it reaches a maximum value. Beyond this maximum value, and by continuing loading the specimen, the dilatancy angle decreases and reaches constant low value at the end of loading (i.e., in constant volume conditions). The mobilized angle of dilatancy versus the axial strain in biaxial test on dry Hostun sand under confining pressure of $15 \mathrm{kPa}$ is shown in Figure (6.3). The angle of dilatancy was calculated using the following equation:

$\dot{n} \forall=\dot{t}, /$

where $\gamma$ is the shear strain $\left(\gamma=\varepsilon_{1}-\varepsilon_{3}\right) ; \varepsilon_{0}$ is the volumetric strain (in axisymmetric conditions: $\varepsilon_{v}=\varepsilon_{1}+\varepsilon_{2}+\varepsilon_{3}$, in plane-strain condition: $\left.\varepsilon_{v}=\varepsilon_{1}+\varepsilon_{3}\right)$.

Figure (6.4) shows the relationship between the maximum angle of dilatancy and the confining pressure in the present study. In addition, the results of biaxial and triaxial tests on Hostun sand obtained in Grenoble are also plotted in the figure. The figure shows that the maximum angle of dilatancy is clearly affected by the confining pressure. It can be seen that the dilatation's tendency of the soil decreases by increasing the confining pressure. The maximum angle of dilatancy is measured at the lowest confining pressure. The dilatancy angles measured for dense Hostun sand specimens are $20.6^{\circ}$ and $11.1^{\circ}$ for confining pressures of $5 \mathrm{kPa}$ and $600 \mathrm{kPa}$, respectively.

Figure (6.4) shows good agreement between the results of the present study and the biaxial results obtained in Grenoble. Small differences were noticed between the dilatancy angles in plane-strain (biaxial) conditions and that in axisymmetric conditions (triaxial). Table (6.1) summarizes the maximum angles of friction and dilatancy for the dense and loose Hostun sand in a wide range of confining pressures (5-600 kPa).

The dilatancy angle may be considered independent of testing conditions. Schanz and Vermeer (1996) reported a dilatancy angle of $13.3-14.0^{\circ}$ for dense Hostun sand specimen tested in triaxial test under confining pressure of $300 \mathrm{kPa}$. In the present study, dense Hostun sand specimen tested under the same confining pressure shows a dilatancy angle of $13.3-13.8^{\circ}$. This is also supported by the data presented by Bolton (1986). 


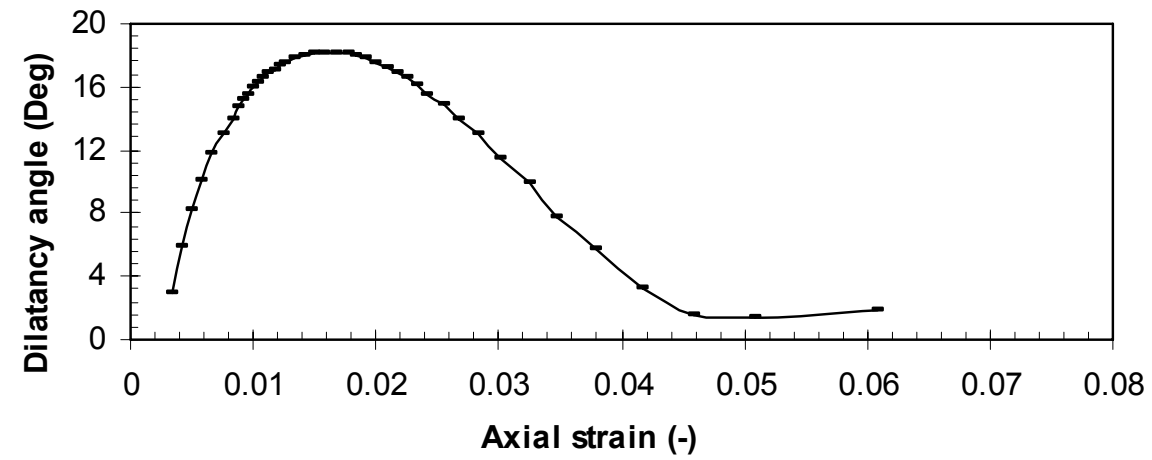

Figure (6.3) Mobilized angle of dilatancy versus axial strain $\left(\sigma_{3}=15 \mathrm{kPa}\right)$

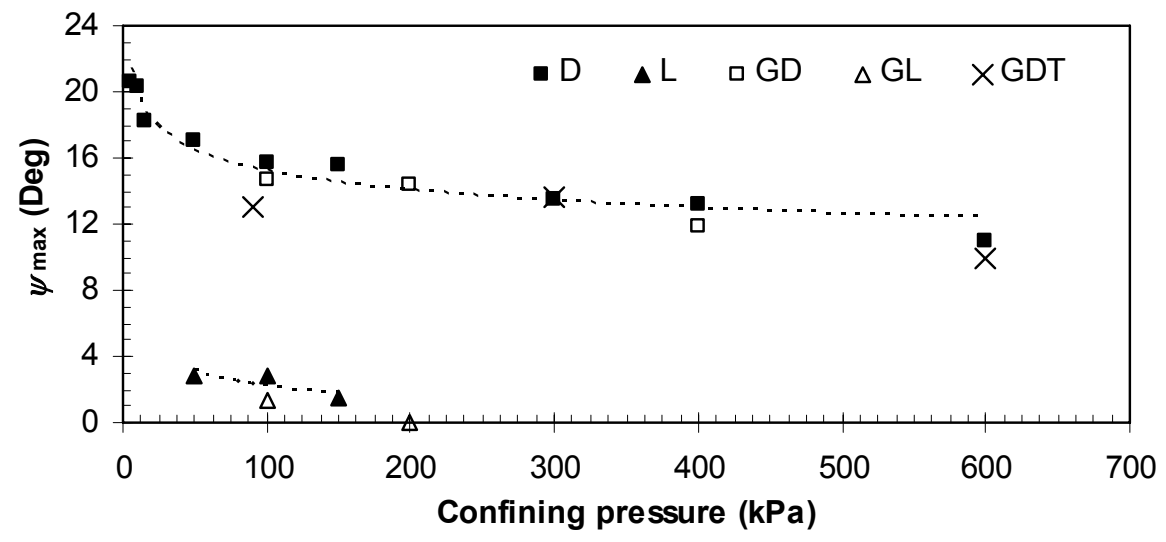

Figure (6.4) Maximum angle of dilatancy versus confining pressure (the result of this study and data from Grenoble)

Table (6.1) Summary of the maximum angles of friction and dilatancy for the dense and loose Hostun sand

\begin{tabular}{lll}
\hline & Dense sand & Loose sand \\
\hline Confining pressure, $\sigma_{3}(\mathrm{kPa})$ & $5-600$ & $50-150$ \\
Maximum angle of friction, $\phi_{\max }(\mathrm{Deg})$ & $55.8-42.8$ & $39.6-36.4$ \\
Maximum Angle of dilatancy, $\psi_{\max }(\mathrm{Deg})$ & $20.6-11.1$ & $2.8-1.4$ \\
\hline
\end{tabular}

Schanz and Vermeer (1996) presented an equation to calculate the mobilized angle of dilatancy in plane-strain conditions as follow:

$$
\sin \psi_{m}=\frac{\sin \phi_{m}{ }^{p s}-\sin \phi_{c v}{ }^{p s}}{1-\sin \phi_{m}{ }^{p s} \sin \phi_{c v}{ }^{p s}}
$$

where $\psi_{\mathrm{m}}$ is the mobilized angle of dilatancy, $\phi_{\mathrm{m}}$ is the mobilized angle of friction, and $\phi_{\mathrm{cv}}$ is the constant volume angle of friction. 
The subscript $(\mathrm{m})$ indicates the dependency of the angle of dilatancy on the level of the applied strain. The superscript $\left({ }^{p s}\right)$ was used to denote that the angle of friction should be determined under plane-strain conditions.

Figure (6.5) exemplary presents the changes in the mobilized angle of dilatancy, $\left(\psi_{\mathrm{m}}\right)$ calculated using Equations (6.2) and (6.3) versus shear strain in biaxial compression test on dry Hostun sand specimen tested under confining pressure of $100 \mathrm{kPa}$. The figure shows that, for this confining pressure (i.e., $100 \mathrm{kPa}$ ), the mobilised angle of dilatancy calculated by the equation proposed by Schanz and Vermeer (1996) is lower than that obtained by the general definition.

The comparison between the maximum angle of dilatancy (for dense and loose sand) calculated using both Equations (6.2) and (6.3) versus the confining pressure is presented in Figure (6.6). The comparison between the maximum angle of dilatancy calculated using the general definition (based on the shear strain), $\psi_{\gamma}$, and the equation proposed by Schanz and Vermeer (1996) (based on the angles of internal friction), $\psi_{\phi}$, shows that the proposed expression by Schanz and Vermeer (1996) underestimates the value of the maximum angle of dilatancy for both dense and loose specimens for high confining pressure. For low confining pressures, Schanz and Vermeer's equation gives higher values. Figure (6.7) shows the differences in maximum dilatancy angle using both equations versus confining pressure.

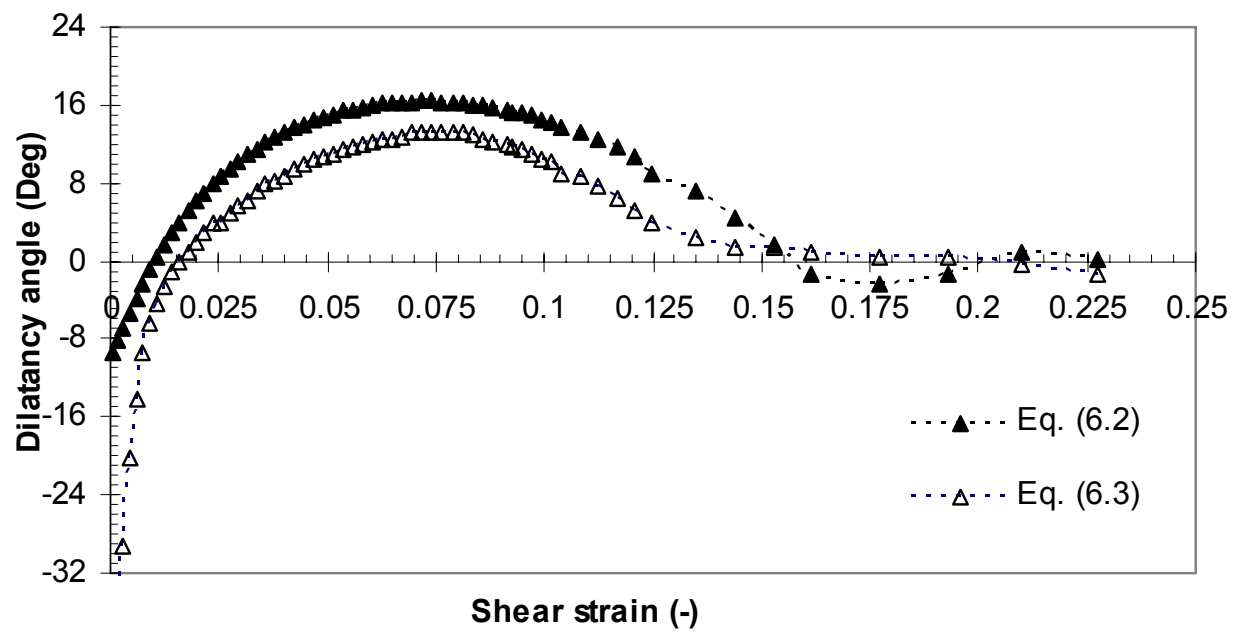

Figure (6.5) Mobilized angle of dilatancy $\left(\psi_{\mathrm{m}}\right)$ calculated using Equations (6.2) and (6.3) versus shear strain $\left(\gamma=\varepsilon_{1}-\varepsilon_{3}\right)$ in biaxial compression test on dry Hostun sand specimen tested under confining pressure of $100 \mathrm{kPa}$ 


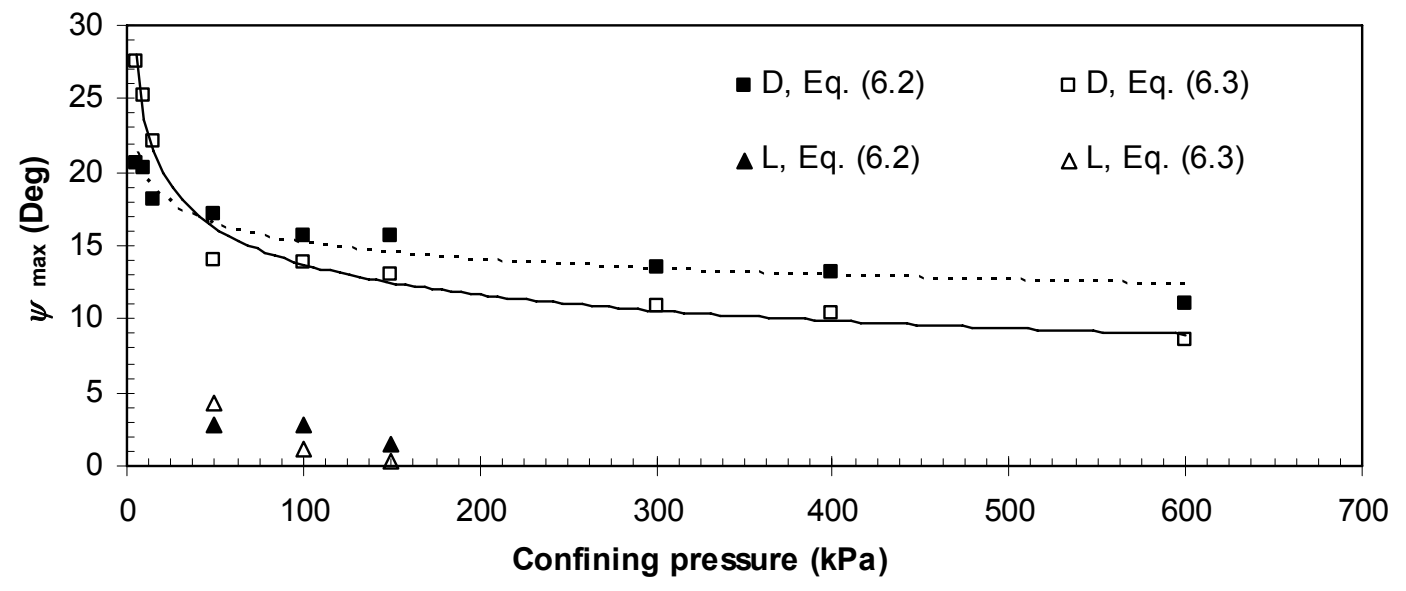

Figure (6.6) Maximum angle of dilatancy calculated using Equations (6.2) and (6.3) versus confining pressure for dense and loose specimens

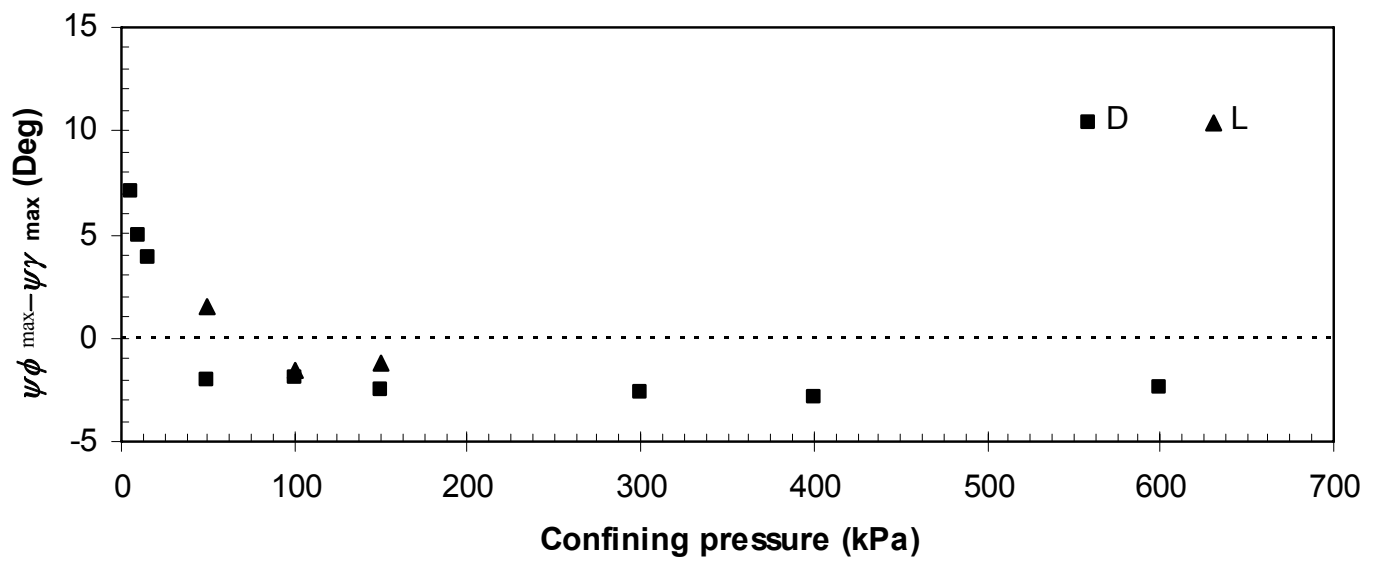

Figure (6.7) Differences in maximum dilatancy angle using both equations versus confining pressure for dense and loose specimens

Bolton (1986) examined the strength and dilatancy of 17 sands from plane-strain and triaxial tests. A simple correlation between the friction angle at peak, critical state friction angle, and dilatancy angle was proposed as follow:

$$
\phi_{p}=0.8 \psi+\phi_{c v}
$$

where $\phi_{\mathrm{p}}$ is the angle of friction, $\phi_{\mathrm{cv}}$ is the constant volume angle of friction, and $\psi$ is the angle of dilatancy.

Figure (6.8a) shows the maximum angle of friction at peak versus the maximum angle of dilatancy with comparison to Bolton's Equation. In this figure, the dilatancy angles, for the dense and loose specimens, were calculated using the general definition (i.e., Eq. (6.2)) and the equation proposed by Schanz and Vermeer (1996) (i.e., Eq. (6.3)). 
The experimental results of friction angles fit well with the values calculated using Bolton's equation. The best fitting lines of the experimental results of this study follow the following equations: $\phi_{\mathrm{p}}=0.77 \psi+\phi_{\mathrm{cv}}$ (if dilatancy angle is calculated using Eq. (6.2)) and $\phi_{\mathrm{p}}=0.71 \psi+\phi_{\mathrm{cv}}$ (if dilatancy angle is calculated using Eq. (6.3)). Both equations are very close to Bolton's equation (i.e., $\phi_{\mathrm{p}}=0.8 \psi+\phi_{\mathrm{cv}}$ ).

To evaluate the results of the present study, regarding the relationship between the maximum angle of dilatancy and maximum angle of friction in plane-strain conditions, data obtained from several researches is represented in Figure (6.8b).

The comparison reveals that the results of Hostun sand in the present study and that obtained in Grenoble fit well with Bolton's equation. The results obtained by Vardoulakis et al. (1978) on Karlsruhe sand $\left(\mathrm{d}_{60}=0.38 \mathrm{~mm}\right)$ and Alshibli and Sture (2000) for fine sand $\left(\mathrm{d}_{50}=0.22 \mathrm{~mm}\right)$ also agree well with Bolton's equation which is not the case of coarse sand $\left(\mathrm{d}_{50}=1.6 \mathrm{~mm}\right)$ tested by Alshibli and Sture (2000). In other researches as done by Wanatowski and Chu (2007) on Medium-grained poorly graded clean Changi sand $\left(\mathrm{d}_{50}=0.3 \mathrm{~mm}\right)$ and by Conforth $(1961)$ on Brasted sand $\left(\mathrm{d}_{60}=0.29\right.$ $\mathrm{mm}$ ), Bolton's equation correctly predicts the trend but it dose not agree well the experimental data. The fitting equations from several studies on different types of sands are presented in Table (6.2).

The relationship between the axial strain at peak, $\varepsilon_{1 \mathrm{p}}$, and the confining pressure for dense sand specimens is shown in Figure (6.9). The axial strain at peak increases as the confining pressure increases. Comparison with the results of triaxial and biaxial tests on dense Hostun sand specimens done in Grenoble is also shown in Figure (6.9). Good agreement was noticed between the present study's results and Grenoble's results.

Table (6.2) Comparison of fitting equations form several researches

\begin{tabular}{ccc}
\hline Reference & Material used & Fitting equation \\
\hline This study, using Eq. (6.2) & Hostun sand, $\mathrm{d}_{50}=0.36 \mathrm{~mm}$ & $\phi_{\mathrm{p}}=0.77 \psi+\phi_{\mathrm{cv}}$ \\
This study, using Eq. (6.3) & Hostun sand, $\mathrm{d}_{50}=0.36 \mathrm{~mm}$ & $\phi_{\mathrm{p}}=0.71 \psi+\phi_{\mathrm{cv}}$ \\
Hammad and Desrues (1991) & Hostun sand, $\mathrm{d}_{50}=0.36 \mathrm{~mm}$ & $\phi_{\mathrm{p}}=0.76 \psi+\phi_{\mathrm{cv}}$ \\
Alshibli and Sture (2000) & Fine sand, $\mathrm{d}_{50}=0.22 \mathrm{~mm}$ & $\phi_{\mathrm{p}}=0.78 \psi+\phi_{\mathrm{cv}}$ \\
Wanatowski and Chu (2007) & Medium-grained poorly graded & $\phi_{\mathrm{p}}=0.34 \psi+\phi_{\mathrm{cv}}$ \\
Conforth (1961) & Brasted sand, $\mathrm{d}_{60}=0.29 \mathrm{~mm}$ & $\phi_{\mathrm{p}}=0.3 \psi+\phi_{\mathrm{cv}}$ \\
Vardoulakis (1980) & Karlsruhe sand, $\mathrm{d}_{60}=0.38 \mathrm{~mm}$ & $\phi_{\mathrm{p}}=0.81 \psi+\phi_{\mathrm{cv}}$ \\
\hline
\end{tabular}




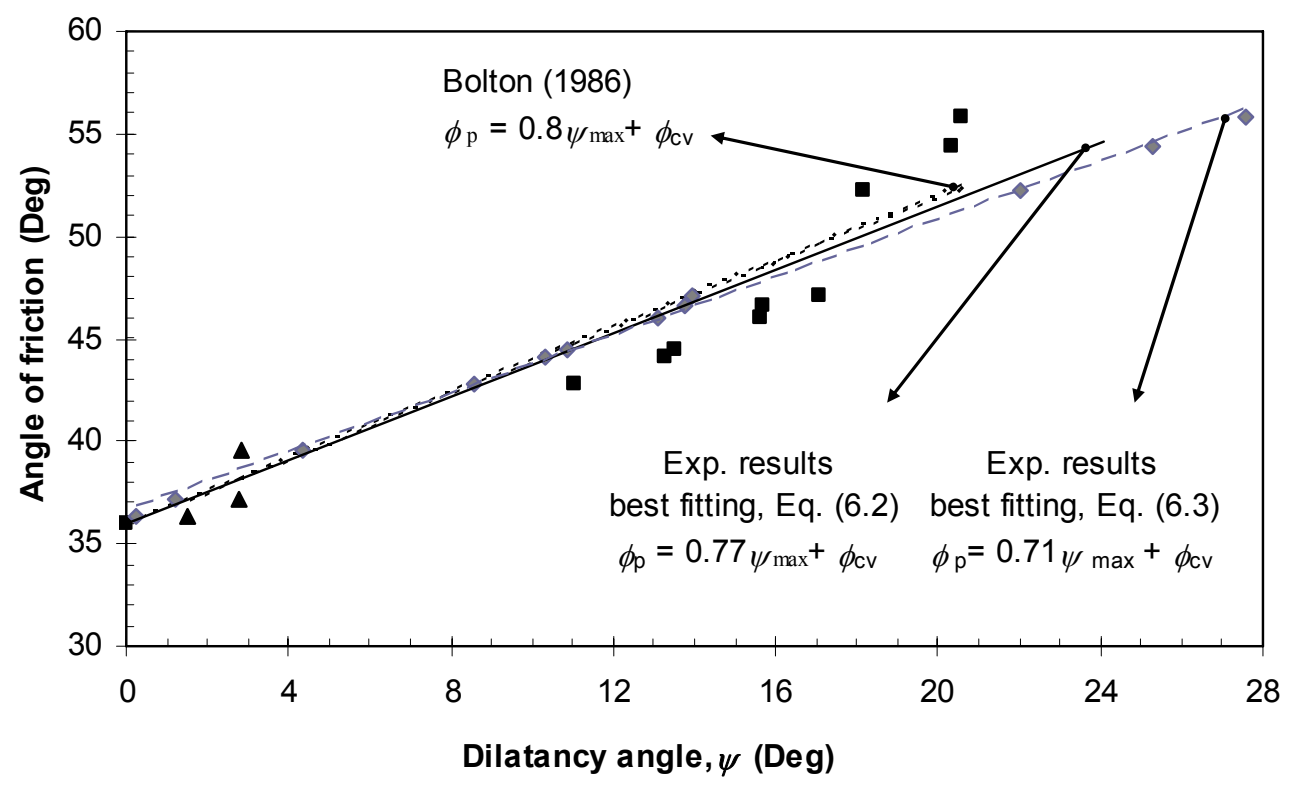

(a)

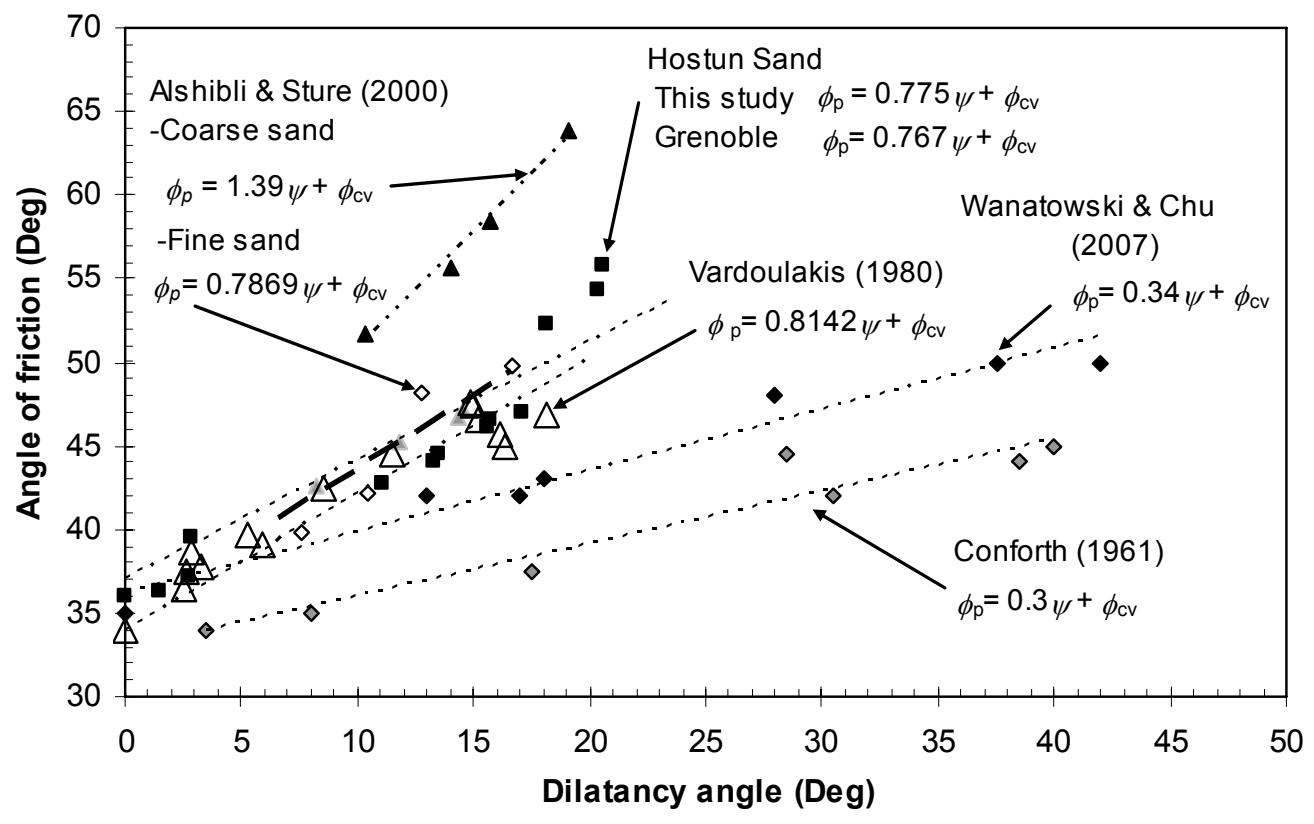

(b)

Figure (6.8) Maximum angle of dilatancy versus maximum angle of friction with comparison with Bolton's equation: (a) the results of the present study: the dilatancy angle was calculated using Equations (6.2) and (6.3); (b) the results of the present study with other biaxial results from the literatures 


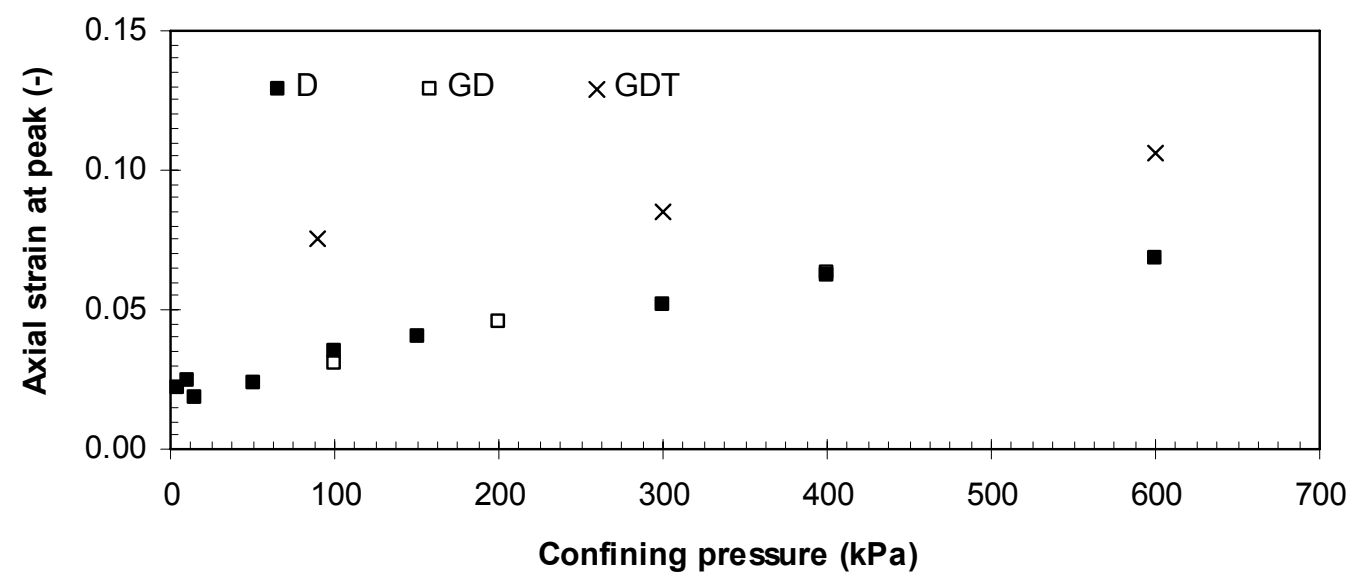

Figure (6.9) Axial strain at peak, $\varepsilon_{1 \mathrm{p}}$, versus confining pressure for dense Hostun sand (data of present study and from Grenoble)

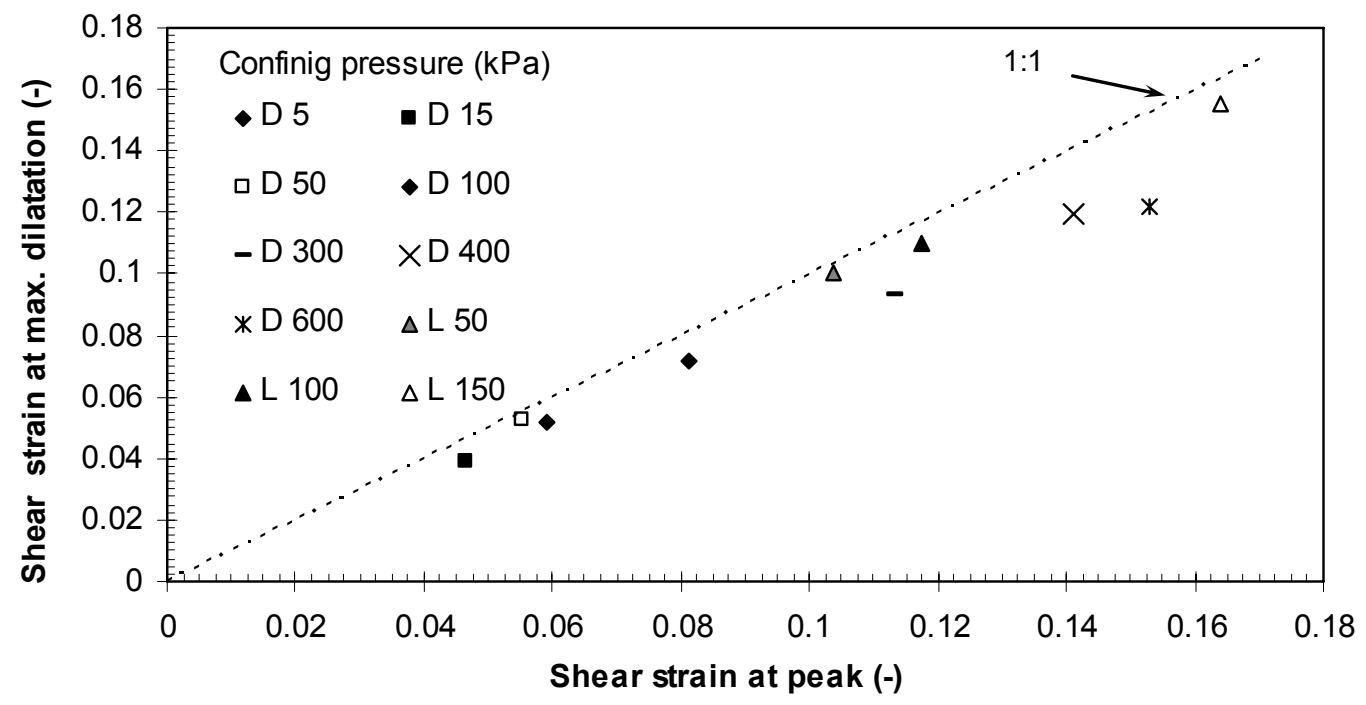

Figure (6.10) Shear strain at peak versus the shear strain at maximum dilation

Experimental results presented in Figure (6.9) show that the triaxial specimens fail at higher values of axial strain than the biaxial specimens do. This coincides with the results of several researches (e.g., Conforth, 1961; Lee, 1970; Marachi et al., 1981; Hanna, 2001).

From the stress-strain curves, it is found that the maximum rate of dilation occurs at shear strain slightly lower than that at the maximum deviator stress. Figure (6.10) shows the relationship between the shear strain at maximum deviator stress $\left(\gamma^{\Delta \sigma \max }\right)$ and the shear strain at maximum dilation $\left(\gamma^{\psi \max }\right)$. In addition, by plotting the difference $(\delta \gamma)=$ $\gamma^{\psi \max }-\gamma^{\Delta \sigma \max }$, it can be noticed that for the dense and loose specimens, the difference $(\delta \gamma)$ increases with increasing confining pressure as it shown in Figure (6.11). 


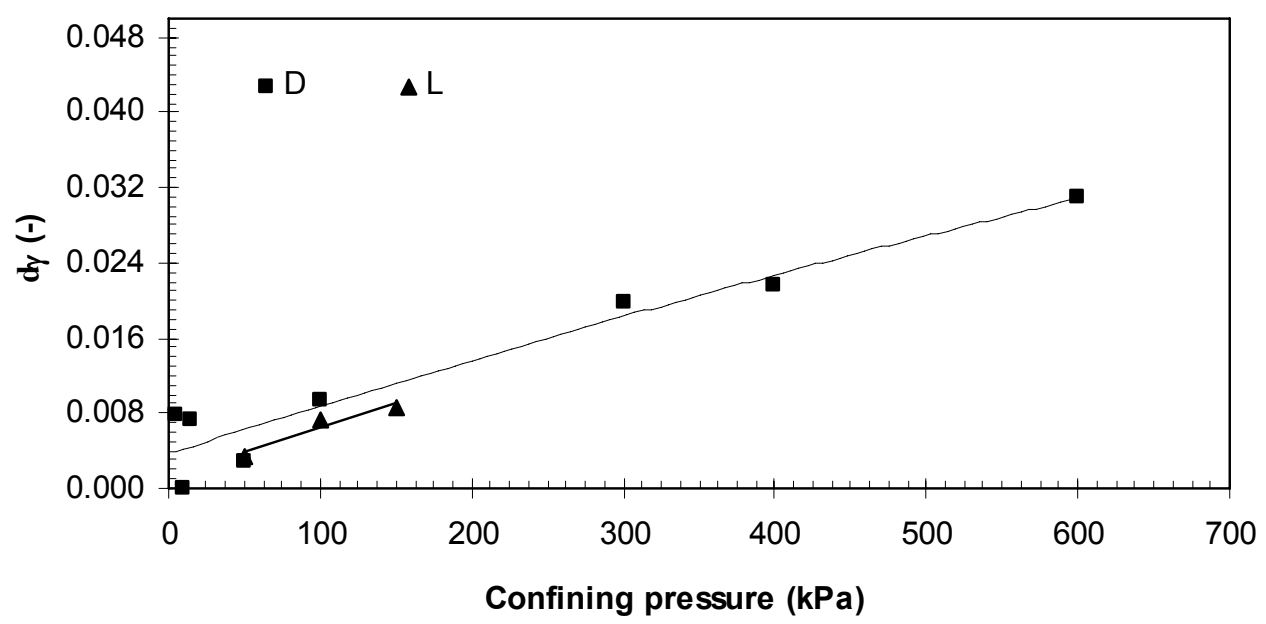

Figure (6.11) Confining pressure versus the difference between the shear strain at peak and the shear strain at maximum dilation $(\delta \gamma)$

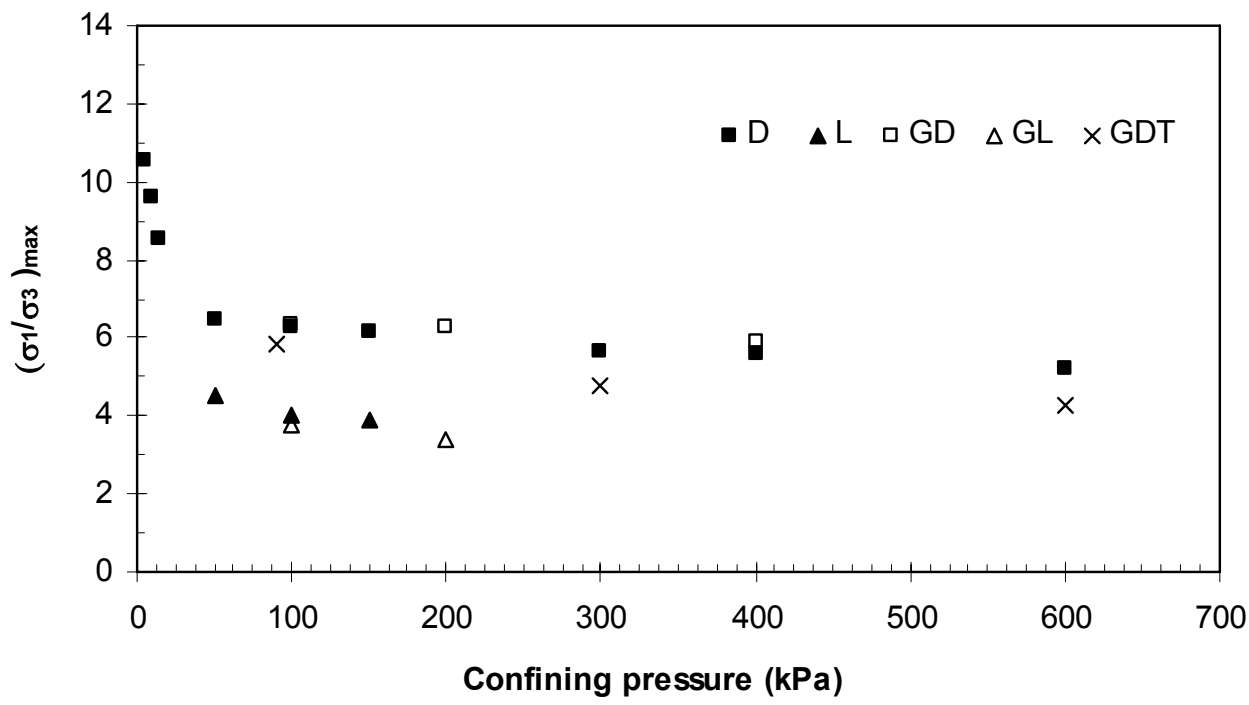

Figure (6.12) Stress ratio at peak and the confining pressure in the present study and in Grenoble's tests

Figure (6.12) shows the relationship between the stress ratio at peak, $\left(\sigma_{1} / \sigma_{3}\right)_{\max }$, and the applied confining pressure for the dense and loose Hostun sand specimens. The results of biaxial and triaxial tests obtained in Grenoble are also shown in the figure. Good agreement is found between the results of the current study and the results obtained in Grenoble for both loose and dense specimens.

The stress ratio at peak decreases as the confining pressure increases. The peak stress ratio in biaxial test is higher than that in triaxial test when specimens are tested under the same confining pressure. The same was observed in other researches (e.g., Marachi et al., 1981; Hanna, 2001) 
The changes in modulus of stiffness with the confining pressure are presented in Figures (6.13) and (6.14). The secant moduli of stiffness at peak $\left(\mathrm{E}_{100}\right)$ and at $50 \%$ of the peak stress $\left(\mathrm{E}_{50}\right)$ were determined as follows:

$$
\begin{aligned}
& E_{100}=\frac{\Delta \sigma_{\max }}{\varepsilon_{1}{ }^{\max }} \\
& E_{50}=\frac{0.5 \Delta \sigma_{\max }}{\varepsilon_{1}^{50 \%}}
\end{aligned}
$$

where $\Delta \sigma_{\max }=\left(\sigma^{\prime}{ }_{1}-\sigma^{\prime}{ }_{3}\right)_{\max }$ is the deviator stress at peak; $\varepsilon_{1}{ }^{\max }$ is the axial strain at peak; and $\varepsilon^{50 \%}$ is axial strain at $50 \%$ of the maximum deviator stress.

Figures (6.13) and (6.14) show the current study's results compared to the triaxial and biaxial results of Grenoble. The comparison shows good agreement, for both the dense and loose specimens, with Grenoble's results. The modulus of stiffness determined in plane-strain conditions is higher than that determined using the results of the triaxial test. Similar conclusion was also reported by Lee (1970).

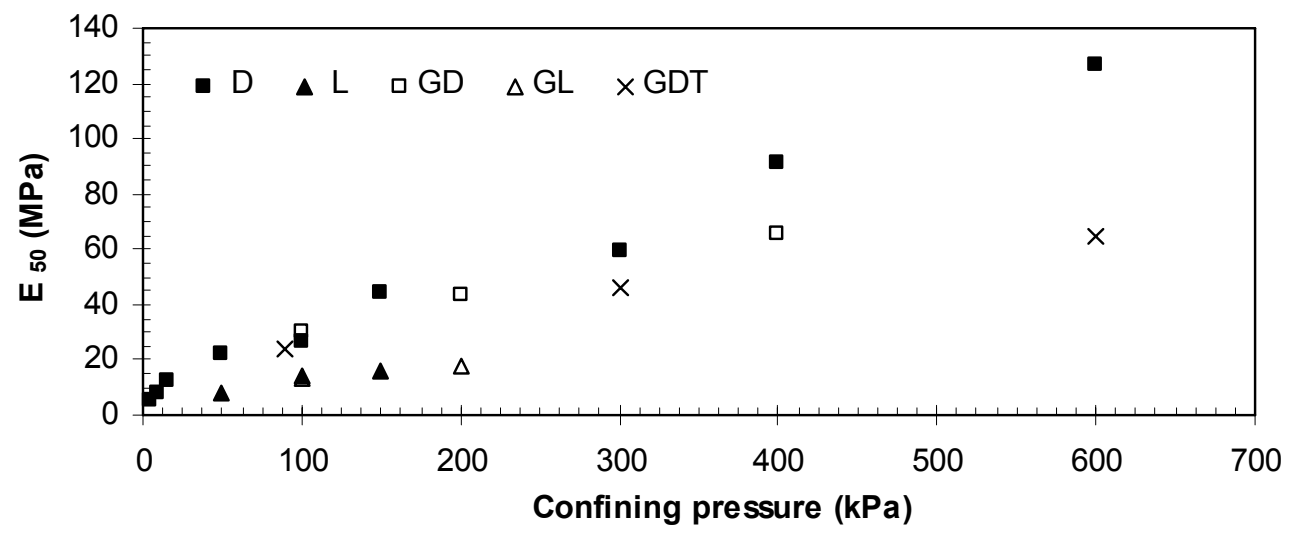

Figure (6.13) Secant modulus of stiffness $\left(\mathrm{E}_{50}\right)$ versus confining pressure

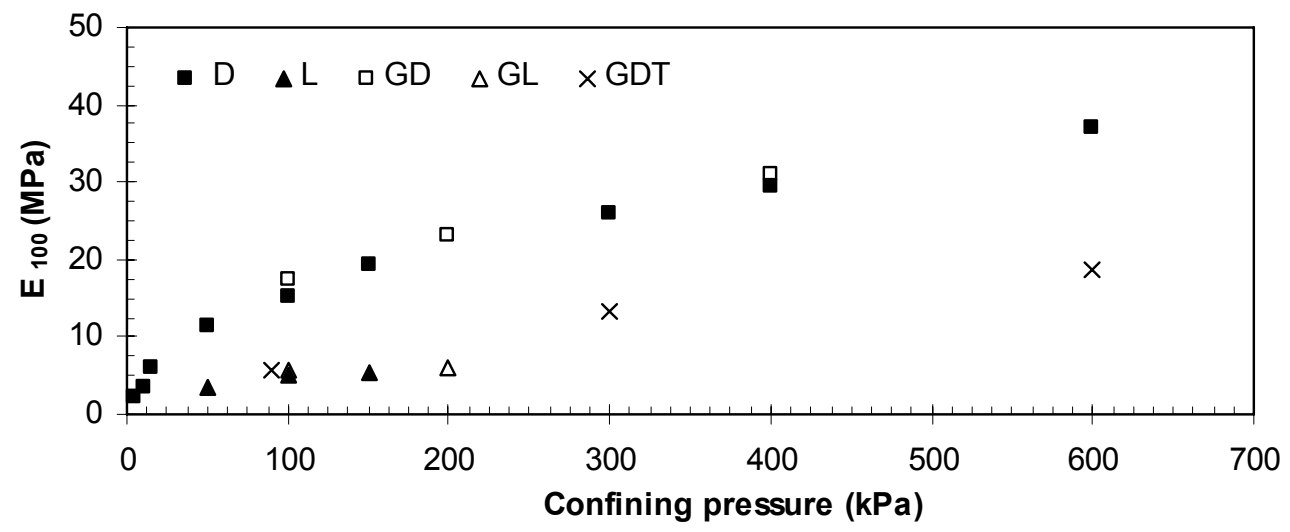

Figure (6.14) Secant modulus of stiffness $\left(\mathrm{E}_{100}\right)$ versus confining pressure 


\subsubsection{Shear banding in dry Hostun sand}

The confining pressure affects clearly the angle of the shear band inclination for the loose and dense Hostun sand specimens. By increasing the confining pressure the angle of shear band inclination, $\theta_{\mathrm{m}}$, decreases as it is shown in Figure (6.15). The angle of shear band inclination for dense sand specimen decreases from $68.7^{\circ}$ to $56.1^{\circ}$ when the confining pressure increases from 5 to $600 \mathrm{kPa}$. The angle of shear band inclination, $\theta_{\mathrm{m}}$, was measured at the end of the tests in respect to the direction of minor stress $\left(\sigma_{3}\right)$ as it is illustrated in Figure (5.16).

The same phenomenon was observed in biaxial tests on Hostun sand in several researches (e.g., Desrues, 1984; Hammad, 1991; Mokni, 1992), Karlsruhe sand (Vardoulakis et al., 1978), crushed silica sand (Alshibli and Sture, 2000), and Ottawa sand (Han, 1991). Figure (6.15) shows the measured angles of shear band inclination versus the confining pressure for Hostun sand (present study and Grenoble's results), Ottawa sand (Han, 1991), coarse, medium, and fine sand (Alshibli and Sture, 2000), and Toyoura sand (Tatsuoka et al. 1986, 1990).

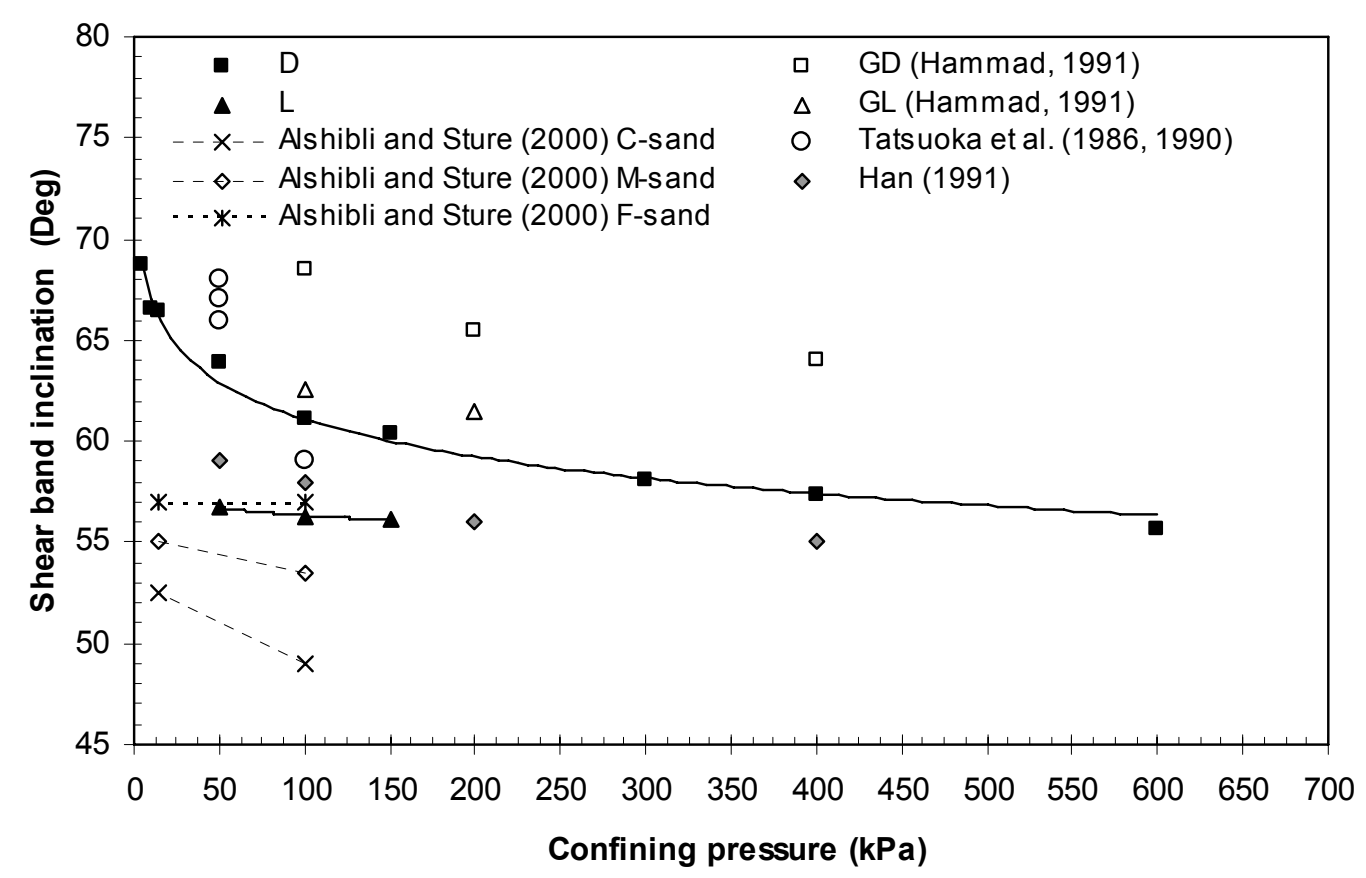

Figure (6.15) Comparison between the measured angle of shear band inclination in this study and other experimental measurements from the literatures (Hammad, 1991; Han, 1991; Alshibli and Sture, 2000; Tatsuoka et al. 1986, 1990) 
The measured angle of shear band inclination, $\theta_{\mathrm{m}}$, and three well-known theoretical solutions for shear band inclination that are the Coulomb's solution $\left(\theta_{\mathrm{C}}=\right.$ $\left.45^{\circ}+\phi / 2\right)$, the Arthur's solution $\left(\theta_{\mathrm{A}}=45^{\circ}+\psi / 2\right)$, and the Roscoe's solution $\left(\theta_{\mathrm{R}}=\right.$ $\left.45^{\circ}+\phi / 2+\psi / 2\right)$ are presented in Figures (6.16) and (5.17) for loose and dense sand, respectively. The Coulomb, Arthur, and Roscoe solutions are refereed to as C, A, and R, respectively.

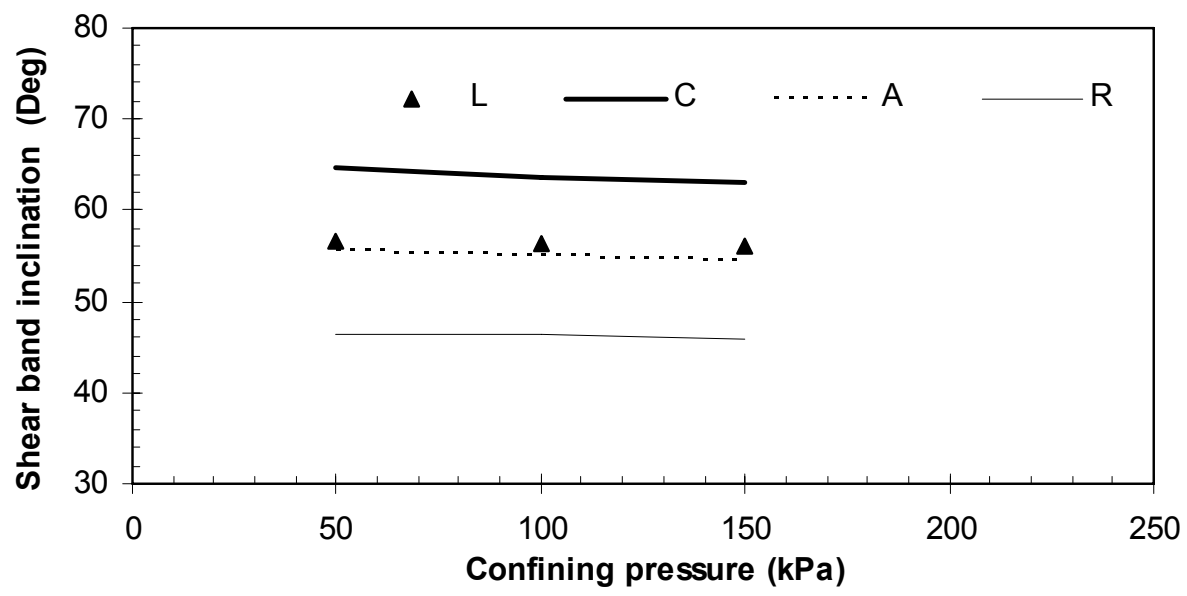

Figure (6.16) Theoretical and experimental shear band inclination versus confining pressure for the loose Hostun sand specimens

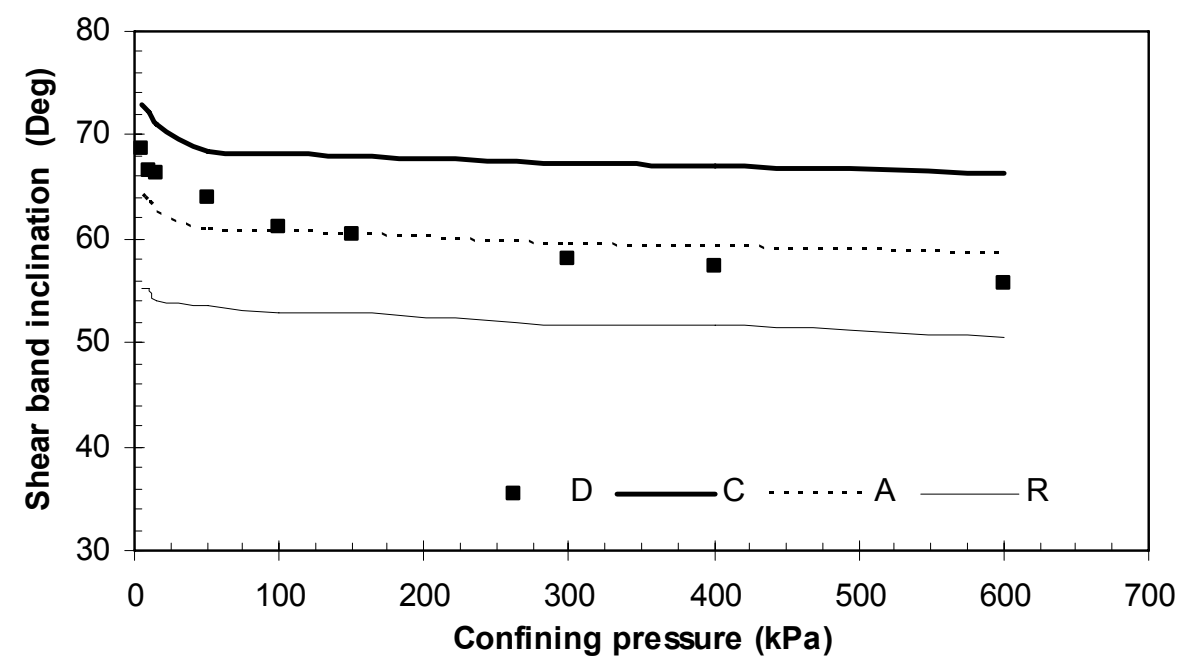

Figure (6.17) Theoretical and experimental shear band inclination versus confining pressure for the dense Hostun sand specimens 
It is of use also to show the relationship between the measured and the theoretical solutions of the angles of the shear band inclination using the data obtained in Grenoble. Figures (6.18) and (6.19) show the comparison between the theoretical and Grenoble's results for dense and loose Hostun sand, respectively.

The measured values of the shear band inclination, $\theta \mathrm{g}_{\mathrm{m}}$, in Grenoble's tests are very close to the Coulomb's solution $\left(\theta_{\mathrm{C}}=45^{\circ}+\phi / 2\right)$ especially for the loose sand; whereas the measured $\theta_{\mathrm{m}}$ in the current study, for both dense and loose sand, fits well with Arthur's solution $\left(\theta_{\mathrm{A}}=45^{\circ}+\psi / 2\right)$.

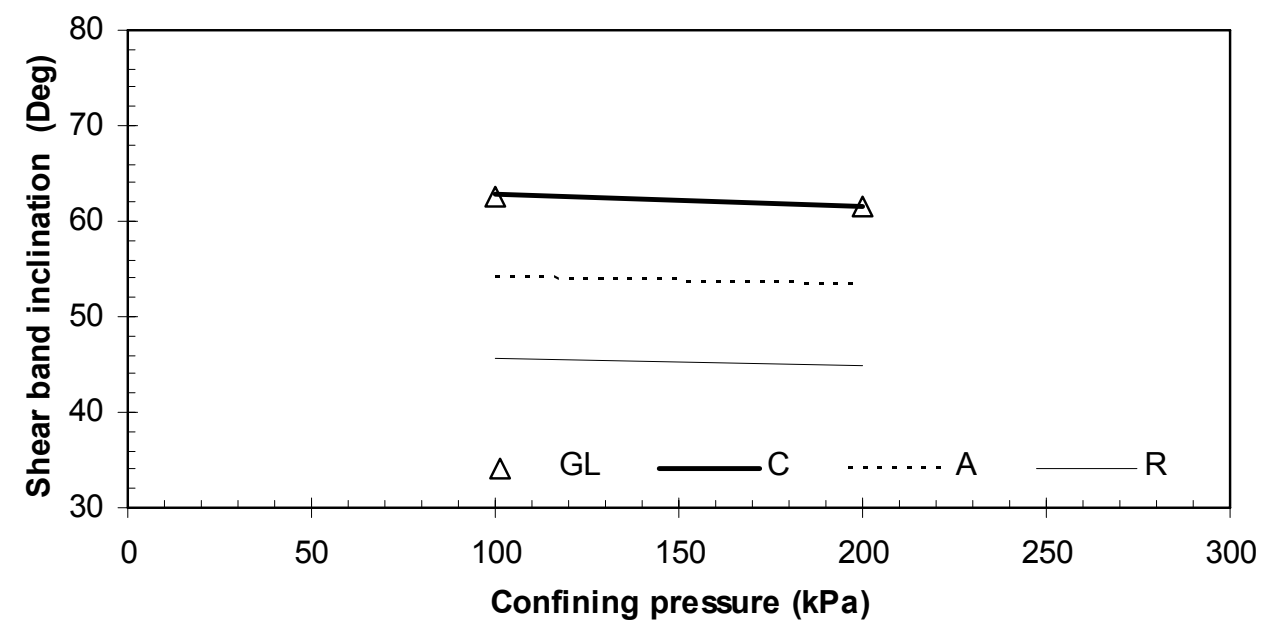

Figure (6.18) Theoretical and experimental shear band inclination versus confining pressure for loose sand specimens (data of Grenoble's biaxial tests)

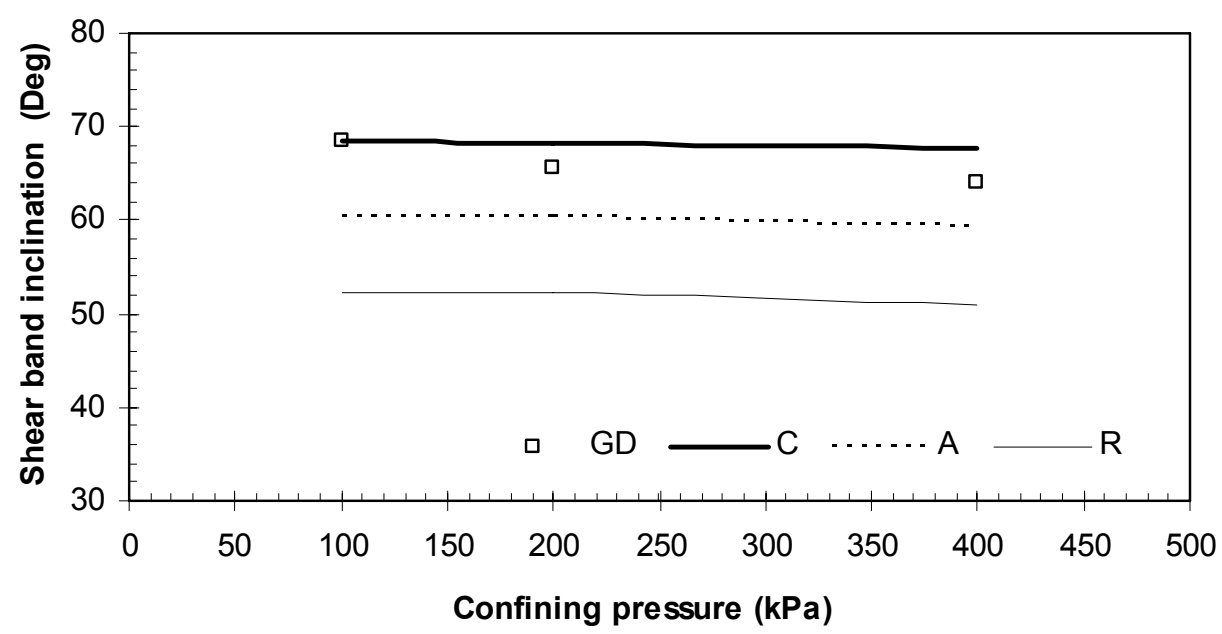

Figure (6.19) Theoretical and experimental shear band inclination versus confining pressure for dense sand specimens (data of Grenoble's biaxial tests) 
The differences between the measured angels of shear band inclination in the present study and Grenoble' results can be attributed to the different methods adopted in measuring the shear band inclination. In the current study the angle of the shear band inclination was measured at the end of the test manually using a scale, whereas in Grenoble's tests the shear band onset was determined using photogrammetry technique and the angle of the shear band inclination was measured at the onset of the shear band.

Observing the onset of the shear band in the tests done Grenoble was possible because the side platens used to impose the plane-strain conditions were made of transparent acrylic, whereas in the current version of the double-wall biaxial device these walls are made of stainless steel and it is not possible to observe the onset of the shear band.

The changes in the angle of shear band inclination due to continuing straining the specimen after the onset of the shear band were observed in several researches (e.g., Finno et al., 1996, 1997; Alshibli and Sture, 2000). Finno et al. (1997) reported differences of $3^{\circ}$ between the angle of shear band inclination measured at the onset of the shear band and at the end of the test. This observation suggests that comparing the shear band orientation angles from the literatures may not give accurate conclusions.

Table (6.3) summarizes the measured angles of shear band inclination of dry dense Hostun sand in this study and in the tests done by Hammad (1991) in Grenoble.

Table (6.3) Summary of the measured angles of shear band inclination

\begin{tabular}{ccccc}
\hline & \multicolumn{2}{c}{ Current study, $\theta_{\mathrm{m}}(\mathrm{Deg})$} & \multicolumn{2}{c}{ Grenoble, $\theta \mathrm{g}_{\mathrm{m}}(\mathrm{Deg})$} \\
\cline { 2 - 5 } Confining pressure $(\mathrm{kPa})$ & $\begin{array}{c}\text { Dense sand } \\
\left(\mathrm{e}_{0}=0.66\right)\end{array}$ & $\begin{array}{c}\text { Loose sand } \\
\left(\mathrm{e}_{0}=0.89\right)\end{array}$ & $\begin{array}{c}\text { Dense sand } \\
\left(\mathrm{e}_{0}=0.65\right)\end{array}$ & $\begin{array}{c}\text { Loose sand } \\
\left(\mathrm{e}_{0}=0.89\right)\end{array}$ \\
\hline 5 & 68.7 & & & \\
10 & 66.5 & & & \\
15 & 66.4 & & & \\
50 & 63.9 & 56.7 & 68.5 & \\
100 & 61.0 & 56.3 & & \\
150 & - & 56.1 & & \\
200 & - & & 65.5 & \\
300 & 60.4 & & & \\
400 & 58.1 & & & \\
600 & 56.1 & & & \\
\hline
\end{tabular}


Alshibli and Sture (2000) presented two photographs of a dense Ottawa sand specimen at different stages of loading (i.e., at axial strain of $9 \%$ and 19\%). The shear band is less steep at axial strain of $19 \%$ comparing to that at axial strain of $9 \%$. The angle of shear band inclination is $55.6^{\circ}$ and $48.7^{\circ}$ for the specimen at axial strain of $9 \%$ and 19 $\%$ respectively. The difference between the angles measured at two different stages of loading was about $6.9^{\circ}$.

The shear band inclination angle decreases by a few degrees between the first and the last available photographic increment (Finno et al., 1997). In the researches done concerning shear band inclination, the shear band inclination angles were measured at the onset of the shear bands when special techniques, such as stereophotogrammetry are available (e.g. Mokni, 1992). When such techniques are not available, the shear band inclinations were determined at the end of the tests (e.g., Han \& Vardoulakis, 1991).

Wanatowski and Chu (2005) used the measurements of the intermediate stress $\left(\sigma_{2}\right)$ to detect the onset of shear band within the tested specimen. The divergence of the local values of $\sigma_{2}$ (obtained from four individual pressure transducers, two in each wall) is considered as an indication of the onset of the shear band in the specimen.

Concerning the results of the current study, good agreement with Grenoble's results can be achieved by adding an additional inclination to the measured angle of about $7^{\circ}$ as shown in Figure (6.20). The figure shows the comparison between Grenoble's data and the modified angle of shear band inclination $\left(\theta_{\mathrm{m}}+7^{\circ}\right)$ for dense and loose sand.

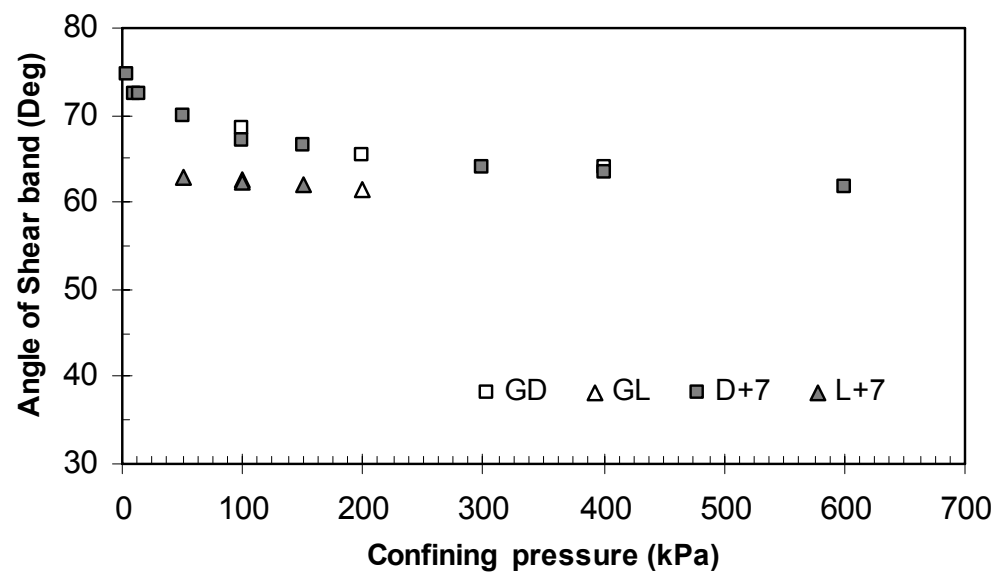

Figure (6.20) Comparison between the modified measured angle of shear band in the current study $\left(\theta_{\mathrm{m}}+7^{\circ}\right)$ and the results obtained in Grenoble $\left(\theta \mathrm{g}_{\mathrm{m}}\right)$ 
Measuring shear band thickness is very useful for a better understanding of the deformation and localization mechanisms of granular materials during shearing and to help in calibrating the theoretical models (Alshibli and Hasan, 2008).

The shear band thicknesses reported in the literature are in the range $8-20 \mathrm{~d}_{50}$ where $d_{50}$ is the mean particle size. Roscoe (1970) used the X-radiography techniques to measure the shear band thickness. He found that the shear band thickness is about $20 \mathrm{~d}_{50}$. Vardoulakis et al. (1980) found the shear band thickness to be about $16 \mathrm{~d}_{50}$. Batiste et al. (2004) reported that the shear band thickness varies in the range $8.33 \mathrm{~d}_{50}$ to $16.68 \mathrm{~d}_{50}$.

Oda and Iwashita (1999) reported that the ratio $t / d_{50}$ is in the range of 7-10. Higher ratios, over 30, were reported by Mokni (1992) and Harris et al. (1995) in loose sand specimens. A possible reason for this difference is that in looses sands, the contrast between inside and outside the shear band is not clear, and the shear band boundaries can easily move outward producing wider band (Oda and Iwashita, 1999).

Alshibli and Sture (1999) concluded from plane-strain tests on three types of sand (fine, medium, coarse) that, for the same sand, the shear band thickness is directly proportional to specimen dilatancy angle and that the normalized shear band thickness $\left(\mathrm{t} / \mathrm{d}_{50}\right)$ decreases as sand grain size increases and as density decreases. Alshibli and Hasan (2008) reported an average thickness of the shear band from $2.4 \mathrm{~mm}\left(10.9 \mathrm{~d}_{50}\right)$ to $3.0 \mathrm{~mm}$ $\left(13.6 \mathrm{~d}_{50}\right)$. Yoshida et al. (1994) reported shear band thickness of $6.2 \mathrm{~mm}$ and $2.8 \mathrm{~mm}$ $\left(20 \mathrm{~d}_{50}-9.3 \mathrm{~d}_{50}\right)$ in dense Hostun sand specimens tested under confining pressure of $80 \mathrm{kPa}$ and $400 \mathrm{kPa}$, respectively.

Regarding shear band thickness in Hostun sand, Mokni (1992) reported shear band thickness of 7.2-7.6 mm $\left(20.6 \mathrm{~d}_{50}-21.7 \mathrm{~d}_{50}\right)$ in dense specimens. His results confirmed that the shear band thickness increases with increasing the mean grain size.

As shown in Figure (5.11), the shear bands observed in biaxial tests have a noticeable thickness of about 5-7 mm $\left(14 \mathrm{~d}_{50}-20 \mathrm{~d}_{50}\right)$. The shear band can be seen through the membrane at the end of the test and it is measured using a scale. This method can lead to over-estimation of the shear band thickness because the measured thickness includes the thickness of the twisted membrane (Oda and Iwashita, 1999). The differences between the shear band thickness in the present study and obtained by Mokni (1992) for the same sand can be attributed mainly to the fact that he measured the thickness of the shear band at the onset of the shear band. Table (6.4) summarises the shear band thickness in this study and from the literatures 
Table (6.4) Thickness of shear band (this study and data from the literatures)

\begin{tabular}{|c|c|c|}
\hline Reference & Material & $\mathrm{t}(\mathrm{mm})$ \\
\hline Roscoe (1970) & Leighton Buzzard sand & $20 \mathrm{~d}_{50}$ \\
\hline \multirow{2}{*}{$\begin{array}{l}\text { Muehlhaus and Vardoulakis } \\
\text { (1987) }\end{array}$} & Fine sand, $\mathrm{d}_{50}=0.2 \mathrm{~mm}$ & $18.5 \mathrm{~d}_{50}$ \\
\hline & Karlsruhe sand, $\mathrm{d}_{50}=0.33 \mathrm{~mm}$ & $13 \mathrm{~d}_{50}$ \\
\hline Mokni (1992) & Hostun sand, $\mathrm{d}_{50}=0.32 \mathrm{~mm}$ & $20.6 d_{50}-21.7 d_{50}$ \\
\hline \multirow{2}{*}{ Oda and kazama (1998) } & Toyoura sand, $\mathrm{d}_{50}=0.2 \mathrm{~mm}$ & $8 \mathrm{~d}_{50}$ \\
\hline & Ticino sand, $\mathrm{d}_{50}=0.53 \mathrm{~mm}$ & $7-8 \mathrm{~d}_{50}$ \\
\hline Alshibli and Hasan (2008) & Ottawa sand, $\mathrm{d}_{50}=0.34 \mathrm{~mm}$ & $10.9 d_{50}-13.6 d_{50}$ \\
\hline Current study & Hostun sand, $\mathrm{d}_{50}=0.36 \mathrm{~mm}$ & $13.8 \mathrm{~d}_{50}-20 \mathrm{~d}_{50}$ \\
\hline
\end{tabular}

\subsection{Discussion of the biaxial tests' results on unsaturated Hostun sand}

Discussion of results of the biaxial results on unsaturated dense sand specimens will be presented in two sections. Firstly, the results relevant to the effect of the matric suction on the stress-strain behaviour will be discussed. The second section presents the effect of the matric suction on the shear band inclination angle.

\subsubsection{Stress-strain behaviour of unsaturated Hostun sand}

Figures (5.11), (5.12), and (5.13) showed the stress-strain curves in three sets of tests (i.e., B10, B50, and B100). The curves of the volumetric strain versus axial strain (in each set) are almost identical up to axial strain of about $4 \%$.

The shear strength of unsaturated sand is higher than that of saturated sand which represents the minimum shear strength of a soil. Figure (6.21) shows the effect of the matric suction on the maximum measured deviator stress in biaxial tests on unsaturated Hostun sand in three sets of tests. The soil water characteristic curve (SWCC) of dense Hostun sand is shown in the figure. It can be noticed that the maximum deviator stress is consistent with value of matric suction slightly higher than the air-entry value of the tested sand $(\mathrm{AEV}=1.7 \mathrm{kPa})$. Figure (6.21) shows that the maximum deviator stress, $\Delta \sigma_{\max }$, increases with increasing the matric suction. The maximum deviator stress is consistent with matric suction value of $2 \mathrm{kPa}$. Beyond this value of matric suction, the shear strength drops off to a lower value until it reaches, at high values of matric suction, the minimum shear strength (i.e., the shear strength at saturation conditions).

The shapes of the shear strength curves with respect to matric suction in the present study on unsaturated Huston sand are similar to those measured by Donald (1956). Figure (6.22) shows the results of direct shear tests conducted by Donald (1956) on different types of sands under low matric suctions (i.e., up to $40 \mathrm{kPa}$ ). The shear strength of the tested sands increases firstly by increasing the matric suction and reaches a 
peak point at specific value of matric suction. Beyond this value, the shear strength decreases and reaches, at high values of matric suction, its minimum value (i.e., the shear strength at fully saturated conditions).

A similar behaviour was observed, as shown in Figure (6.23), in the testing of a decomposed tuff from Hong Kong (Fredlund et al., 1996; Gan and Fredlund, 1996). In this figure, it is shown that the shear strength drops off at high matric suctions.

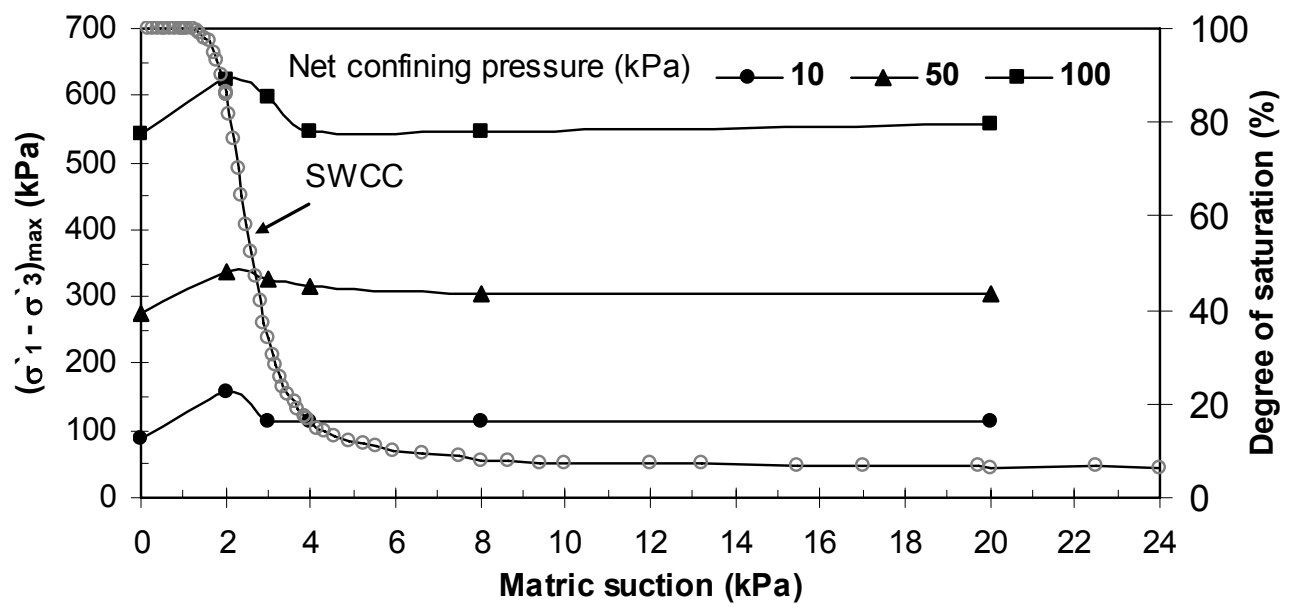

Figure (6.21) Effect of the matric suction on the maximum deviator stress
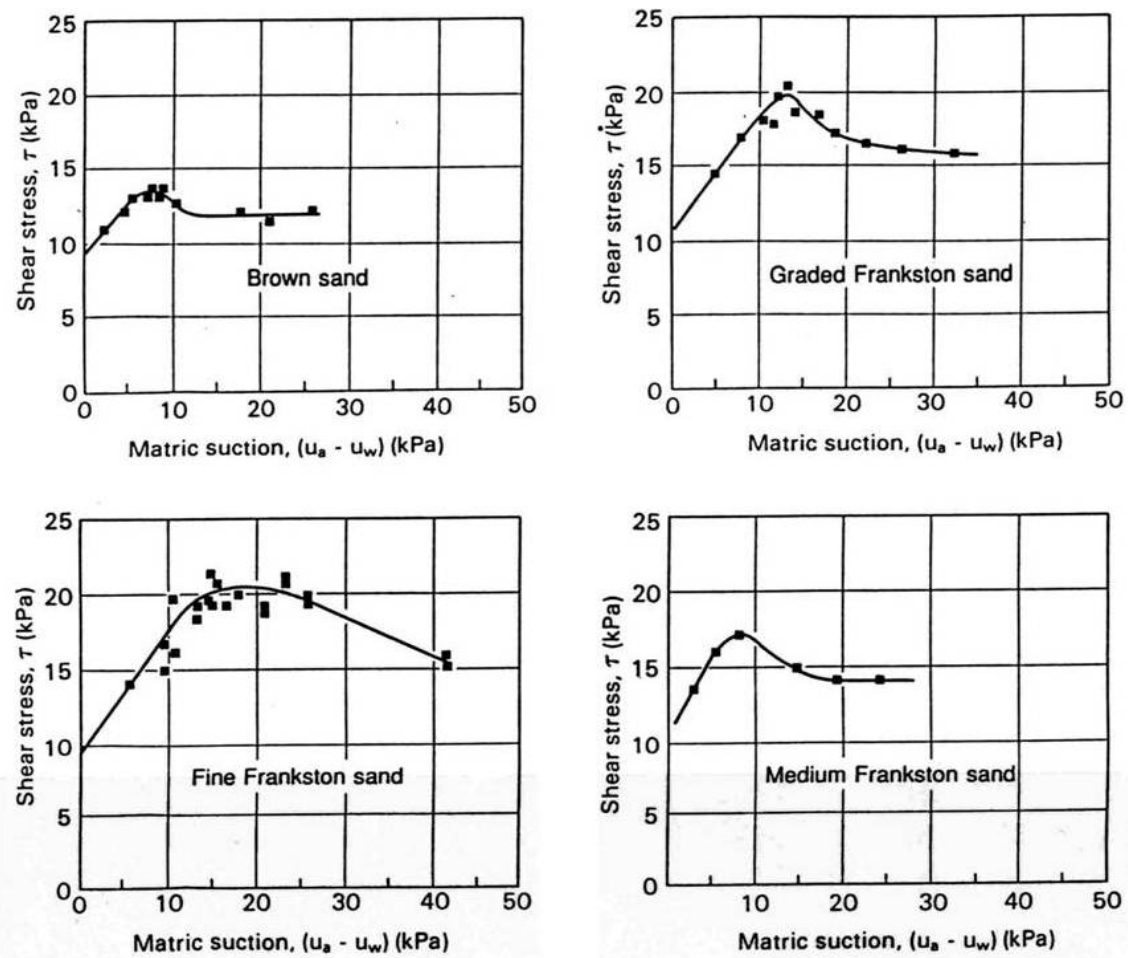

Figure (6.22) Results of direct shear tests on sands under low matric suctions (modified from Donald, 1956), Fredlund and Rahardjo (1993) 


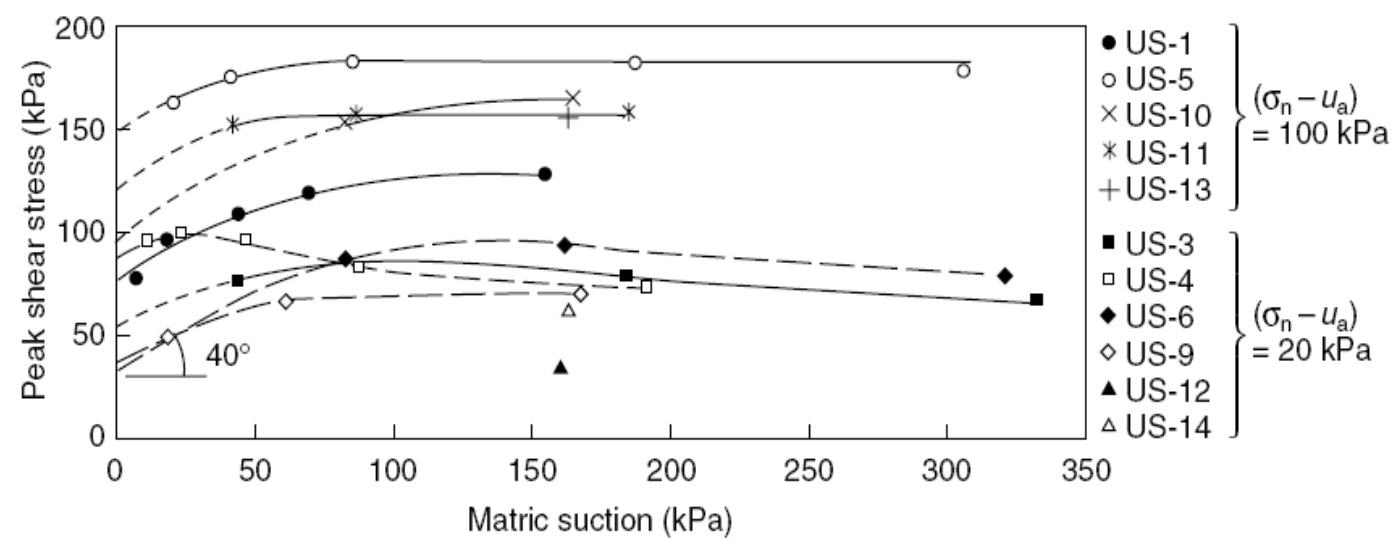

Figure (6.23) Peak shear strength versus suction envelope (Fredlund et al., 1996; Gan and Fredlund, 1996)

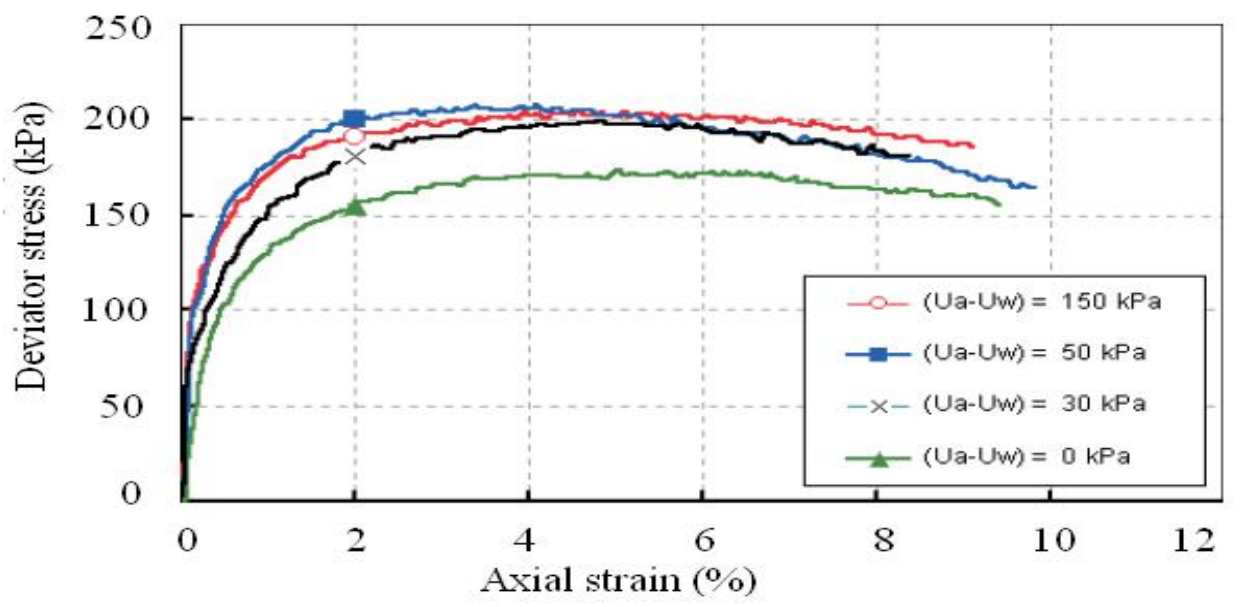

Figure (6.24) Stress-strain curves for sand at various matric suctions under the effect of $50 \mathrm{kPa}$ net confining pressure (Farouk et al., 2004)

Farouk et al. (2004) presented results of triaxial tests on unsaturated sand. As shown in Figure (6.24), increasing the matric suction results in increasing the maximum deviator stress. The maximum deviator stress is consistent with a matric suction of 50 $\mathrm{kPa}$. By further increasing of the matric suction to $150 \mathrm{kPa}$, the deviator stress decreases.

The behaviour of the unsaturated sand is relatively different compared to clayey soils behaviour regarding to the increasing of the shear strength with the matric suction. For clayey soils, the increase in shear strength continues up to high value of suction is reached whereas the unsaturated sands start to loose the additional strength deduced from the applied matric suction at low values of matric suction. 


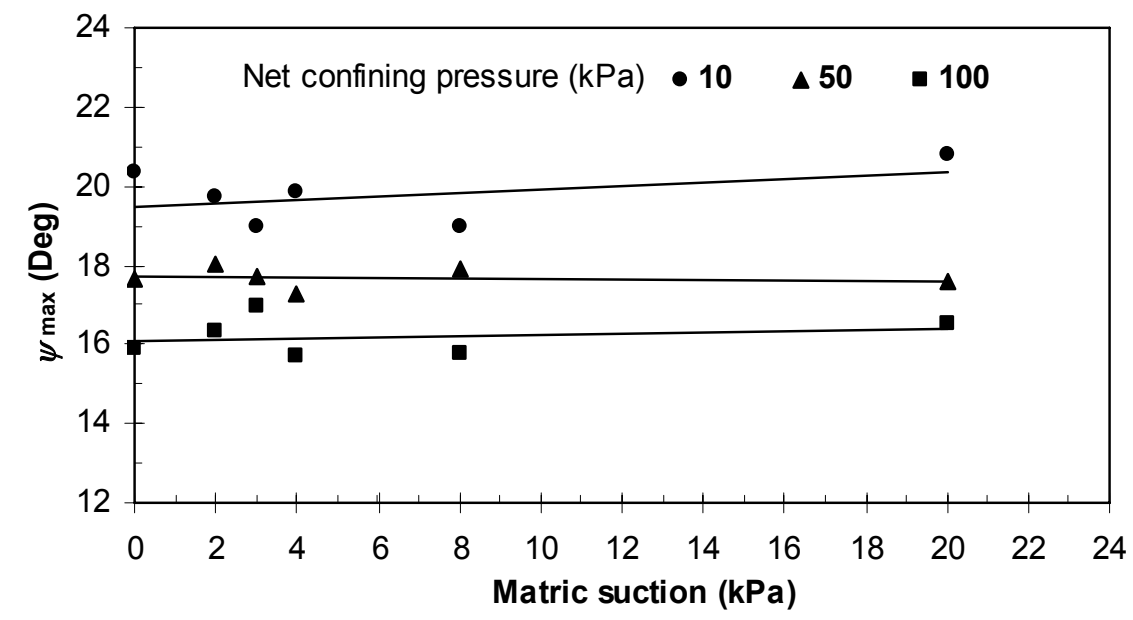

Figure (6.25) Effect of matric suction on the maximum angle of dilatancy

Figure (6.25) shows the relationship between the applied matric suction, $\left(u_{\mathrm{a}}-u_{\mathrm{w}}\right)$, and the maximum angle of dilatancy, $\psi_{\max }$. It can be concluded that the maximum angle of dilatancy is almost constant for unsaturated sand specimens when sheared under several values of matric suction at the same net confining pressure.

From the current study's results and other data obtained from the literatures, it is clear that data available are not enough to completely understand the effect of the matric suction on the dilation behaviour of unsaturated soil. More experimental studies are required on different types of unsaturated soils before the matric suction effect on the angle of dilatancy can clearly defined.

The relationship between the applied matric suction and the axial strain at peak, $\varepsilon_{\text {lpeak }}$, in the three set of tests is shown in Figure (6.26). It can be concluded that the matric suction, when the net confining pressure kept constant, affect very slightly the peak axial strain. Table (6.5) summarises the average strain at peak for each set.

Figure (6.27) shows the relationship between the shear strain at peak $\left(\gamma^{\Delta \sigma \max }\right)$ and the shear strain at maximum rate of dilation $\left(\gamma^{\psi \max }\right)$ for the three sets of tests. The maximum rate of dilation occurs at a shear strain slightly lower than that corresponding to the maximum deviator stress (i.e., peak). Almost all the points representing the tests on saturated and unsaturated Hostun sand for different values of net confining pressure and matric suction lie under the 1:1 line. The same phenomenon was observed for dry Hostun sand (dense and loose) tested under several confining pressures (see Figure (6.10)). 
Table (6.5) Axial strain at peak in the three set of tests

\begin{tabular}{cccc}
\hline Set & Net confining pressure $(\mathrm{kPa})$ & Axial strains at peak, $\varepsilon_{\text {1peak }}(-)$ & $\varepsilon_{1 \text { peak av. }}(-)$ \\
\hline B10 & 10 & $0.017-0.192$ & 0.021 \\
B50 & 50 & $0.0217-0.028$ & 0.025 \\
B100 & 100 & $0.033-0.04$ & 0.038 \\
\hline
\end{tabular}

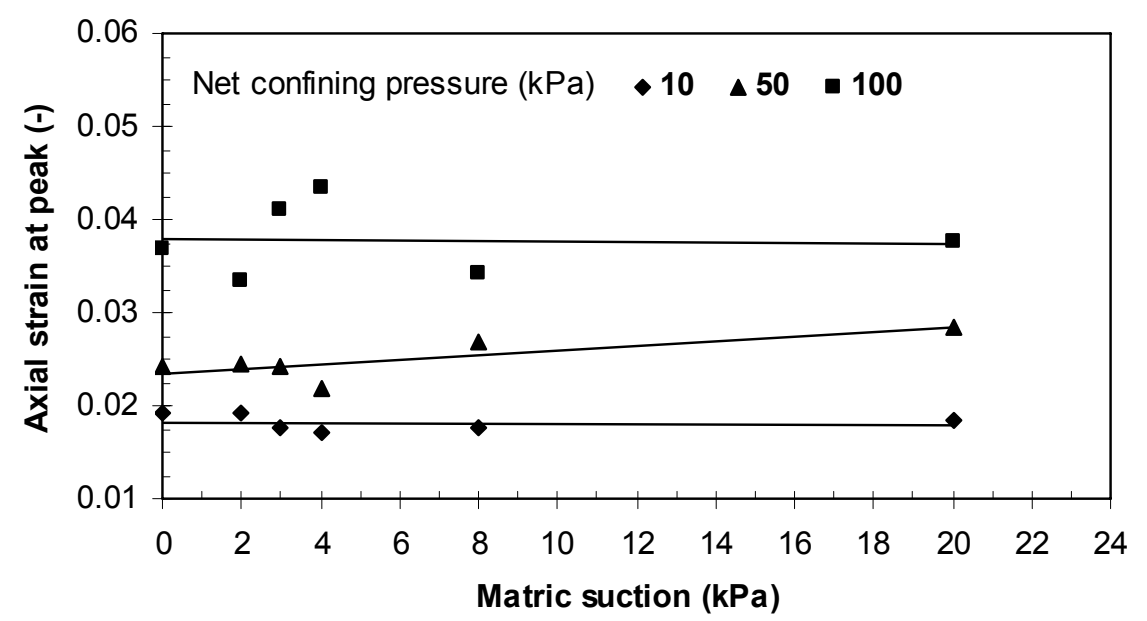

Figure (6.26) Matric suction versus axial strain at peak in the three sets of tests

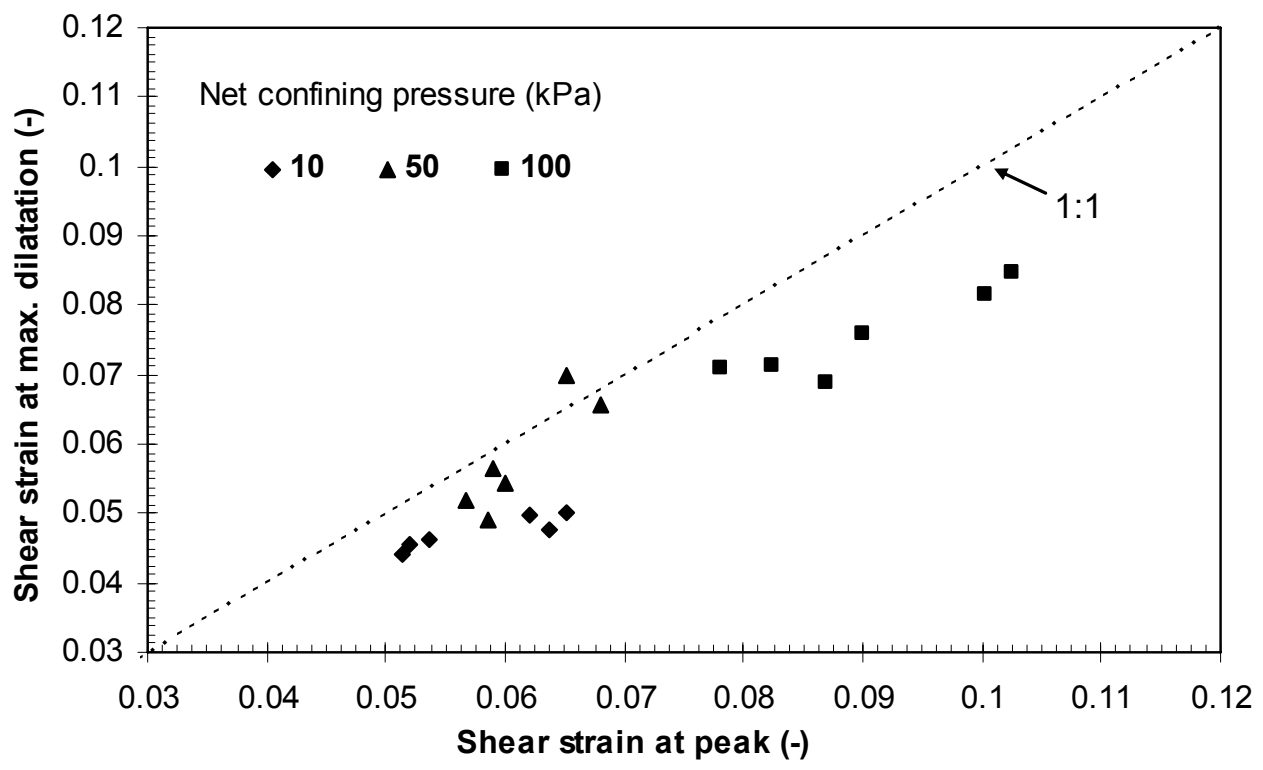

Figure (6.27) Shear strain at maximum rate of dilation versus shear strain at peak 


\subsubsection{Shear banding in unsaturated Hostun sand}

The relationship between the measured shear band inclination, $\theta_{\mathrm{m}}$, and the applied matric suction is shown in Figure (5.16). The angle of shear band inclination, $\theta_{\mathrm{m}}$, was measured at the end of the tests in respect to the direction of minor stress $\left(\sigma_{3}\right)$ as it is illustrated in Figure (5.16).

The measured angles of shear band inclination at the end of the test in the three sets of tests are summarized in Table (6.6). The table shows that the maximum differences in the measured angle of shear band inclination were $1.3^{\circ}, 1.1^{\circ}$, and $1.4^{\circ}$ for tests under net confining pressures of $10 \mathrm{kPa}, 50 \mathrm{kPa}$, and $100 \mathrm{k} \mathrm{Pa}$, respectively. It can be concluded that shearing unsaturated dense sand specimens under the same net confining pressure and different values of matric suction results in slight differences in the measured angle of shear band inclination. General conclusion can be drawn that the shear band characteristics are basically affected by the confining pressure.

As known to the author, in the available published researches, there are no experimental data regarding the effect of the matric suction on the characteristics of shear band (i.e., angle of inclination and shear band thickness).

\subsection{Discussion of the bearing capacity tests' results}

The load-settlement curves of the tests under different matric suction were presented in Figure (5.17). Analysing these curves showed that the ultimate bearing capacity of model strip footing increases by increasing the matric suction and reaches its maximum value at a value of matric suction (i.e., $2.1 \mathrm{kPa}$ ) slightly higher than the air entry value of the tested sand $(\mathrm{AEV}=1.7 \mathrm{kPa})$. Beyond this value of matric suction, the ultimate bearing capacity of the model strip footing starts to decrease by increasing the applied matric suction as shown in Figure (6.28). This observation coincides with the results of the tests on unsaturated Hostun sand tested in this study in new biaxial device.

Table (6.6) Angle of shear band inclination, $\theta_{\mathrm{m}}$, in unsaturated dense sand

\begin{tabular}{ccccccc}
\hline Matric suction $\left(u_{\mathrm{a}}-u_{\mathrm{w}}\right)(\mathrm{kPa})$ & 0 & 2 & 3 & 4 & 8 & 20 \\
\hline Net confining pressure $\left(\sigma_{3}-u_{\mathrm{a}}\right)(\mathrm{kPa})$ & \multicolumn{5}{c}{ Measured angle of shear band, $\theta_{\mathrm{m}}$ (degree) } \\
\hline 10 & 66.5 & 65.7 & 66.9 & 66.9 & 66.4 & 66.7 \\
50 & 63.9 & 62.9 & 63.5 & 63.5 & 63 & 62.9 \\
100 & 61.3 & 61.5 & 62.6 & 62.6 & 61.4 & 62.2 \\
\hline
\end{tabular}




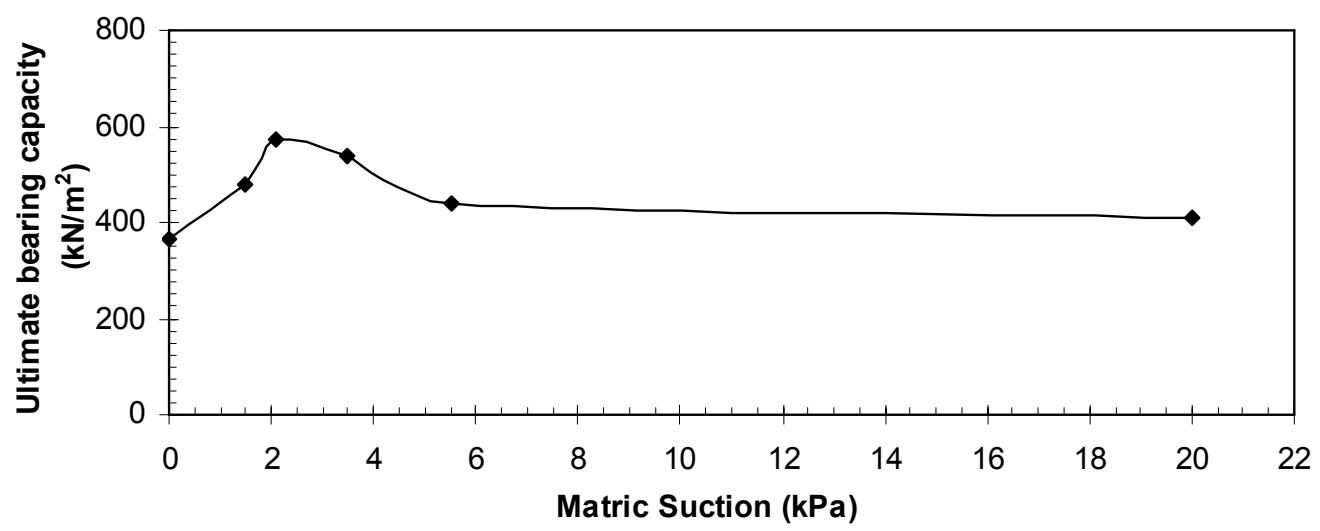

Figure (6.28) Ultimate bearing capacity versus matric suction

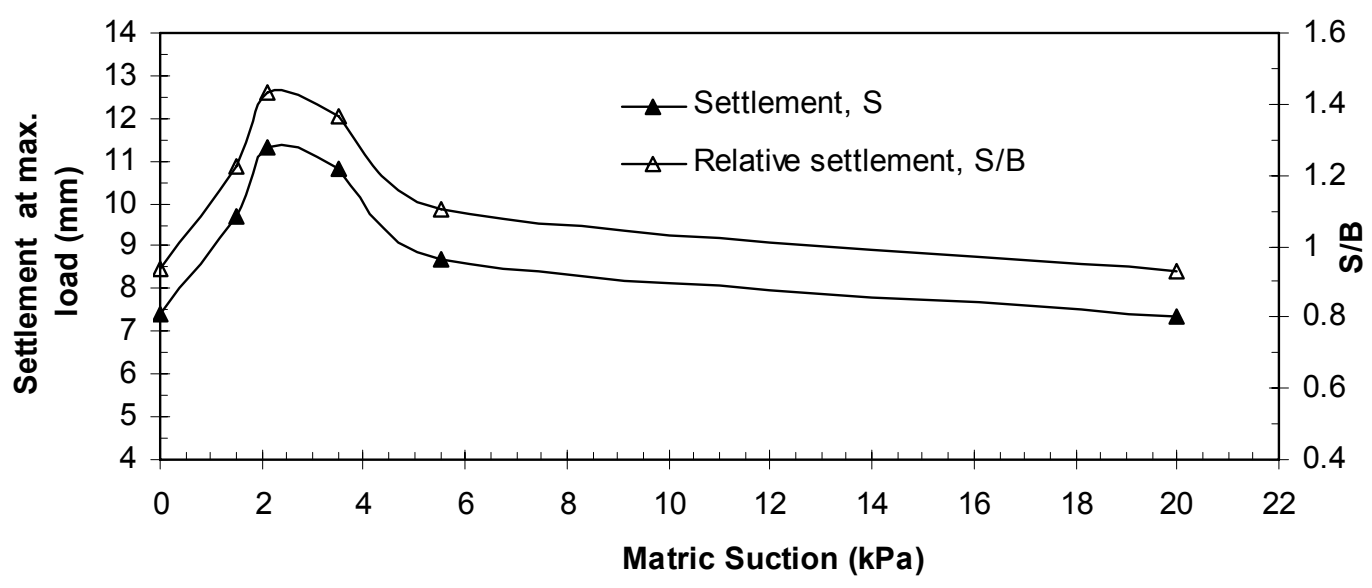

Figure (6.29) Settlement at maximum load versus matric suction

Figure (6.29) shows the settlement at peak load versus matric suction in bearing capacity tests. It can be seen that relatively large settlement is required to achieve the maximum bearing capacity.

The peak settlement of the model strip footing at peak increases by increasing the matric suction and reaches a maximum value at suction value of $2.1 \mathrm{kPa}$ which is consistent with the maximum ultimate bearing capacity of the model footing. For further increments of suction, the required settlement to reach the ultimate load decreases and reaches (at high value of suction) almost the same peak settlement of saturated sample.

For typical shallow foundations in granular soils, settlement considerations are more critical than bearing capacity considerations (Jeyapalan and Boehm, 1986; Tan and Duncan, 1991; Berardi and Lancellotta, 1994). The design of shallow foundations in granular soils is generally governed by the settlement criteria rather than by the bearing capacity (Sivakugan and Johnson, 2004). 


\subsection{Prediction of shear strength and bearing capacity of unsaturated sand}

Several empirical procedures were proposed for predicting the shear strength of unsaturated soil (e.g., Vanapalli et al., 1996; Fredlund et al., 1996; Oberg and Sallfours, 1997; Khalili and Khabbaz, 1998; Bao et al., 1998). In the proposed procedures, the key tools are the relationship between the water content or degree of saturation and soil suction and the saturated shear strength parameters.

In this study, two approaches will be adopted. The first is that proposed by Vanapalli et al. (1996). The second approach is that proposed by Khallili and Khabbaz (1998). The first method considers the concept of two stress state variables (Fredlund and Morgenstern, 1977) whereas the second method depends on the concept of single effective stress (Bishop, 1959). For predicting the ultimate bearing capacity, the approach presented by Vanapalli and Mohamed (2007) is used.

\subsubsection{Prediction of shear strength of unsaturated sand}

As mentioned in Chapter 2, two main shear strength equations of unsaturated soil were presented by Bishop (1959) and Fredlund and Morgenstern (1978). Bishop's equation is an extension of the shear strength equation of saturated soil considering one stress state variable (concept of effective stress). Fredlund and Morgenstern (1977) presented the concept of two stress state variables and used this concept in describing the mechanical behaviour of unsaturated soil.

Bishop (1959) proposed an equation to determine the shear strength of unsaturated soil as follow:

$$
\tau=c^{`}+\left[\left(\sigma-u_{a}\right)+\left(u_{a}-u_{w}\right) \chi\right] \tan \phi
$$

Fredlund et al. (1978) proposed the following equation to explain the shear strength of unsaturated soils:

$$
\tau=c^{`}+\left(\sigma-u_{a}\right) \tan \phi{ }^{`}+\left(u_{a}-u_{w}\right) \tan \phi^{b}
$$

Vanapalli et al. (1996) proposed a function for predicting the shear strength of an unsaturated soil using the soil-water characteristic curve and the saturated shear strength:

$$
\tau=c^{`}+\left(\sigma-u_{a}\right) \tan \phi+\left(u_{a}-u_{w}\right) s^{\kappa} \tan \phi
$$

where $\kappa$ is fitting parameter ( $\kappa=1$ for sands) and $S$ is the degree of saturation. 
Obergand Sallfors (1997) proposed an equation to predict the shear strength, $\tau$, of non-clayey soils as sands and silts as follow:

$$
\tau=c^{\prime}+\left(\sigma-u_{a}\right) \tan \phi{ }^{\prime}+\left(u_{a}-u_{w}\right) S \tan \phi^{\prime}
$$

Obergand Sallfors (1997) simply replaced the $\chi$ parameter in Bishop's equation with the degree of saturation. It can be noticed that this equation coincides with the equation proposed by Vanapalli et al. (1996) in case of sand (where $\kappa=1$ ). For interpreting the biaxial results, it is more convenient to write Equation (6.9) as follow:

$$
\frac{\left(\sigma_{1}-\sigma_{3}\right)}{2}=c^{\prime} \cos \varphi^{\prime}+\left(\frac{\left(\sigma_{1}+\sigma_{3}\right)}{2}-u_{a}\right) \sin \varphi^{\prime}+\left(u_{a}-u_{w}\right) \mathrm{S}^{\mathrm{k}} \tan \varphi^{\prime} \cos \varphi^{\prime}
$$

where $\sigma_{1}$ and $\sigma_{3}$ are the total major and minor principle stress, respectively.

According to Khallili and Khabbaz (1998), the parameter $\chi$ in the equation proposed by Bishop (1956) can be given as:

$$
\chi=\left[\frac{\left(u_{a}-u_{w}\right)_{f}}{\left(u_{a}-u_{w}\right)_{b}}\right]^{-0.55}
$$

where $\left(u_{\mathrm{a}}-u_{\mathrm{w}}\right)_{f}$ is the matric suction at failure and $\left(u_{\mathrm{a}}-u_{\mathrm{w}}\right)_{b}$ is the air entry value. By substituting the $\chi$ parameter in Bishops' equation, and by reshaping Equation (6.7) to be more convenient to represent the results of biaxial tests, the shear strength can be predicted using the following equation:

$$
\frac{\left(\sigma_{1}-\sigma_{3}\right)}{2}=c^{\prime} \cos \varphi^{\prime}+\left(\frac{\left(\sigma_{1}+\sigma_{3}\right)}{2}-u_{a}\right) \sin \varphi^{\prime}+\left(u_{a}-u_{w}\right)\left[\frac{\left(u_{a}-u_{w}\right)_{f}}{\left(u_{a}-u_{w}\right)_{b}}\right]^{-0.55} \tan \varphi^{\prime} \cos \varphi^{\prime}
$$

Using Equations (6.11) and (6.13), the shear strength of unsaturated Hostun sand was predicted and compared to the measured shear strength. Figure (6.30) shows the comparison between the measured $\mathrm{q}_{\max }, \mathrm{q}=\frac{\left(\sigma_{1}-\sigma_{3}\right)_{\max }}{2}$, and predicted $\mathrm{q}_{\mathrm{pre}}$ using both equations for specimens tested under net confining pressure of $10 \mathrm{kPa}, 50 \mathrm{kPa}$, and 100 $\mathrm{kPa}$, respectively.

From Figure (6.30), it can be concluded that Equation (6.11) underestimates the shear strength in the entire range of matric suction. Equation (6.13) underestimates the shear strength at low matric suctions (i.e., 0-5 kPa). 


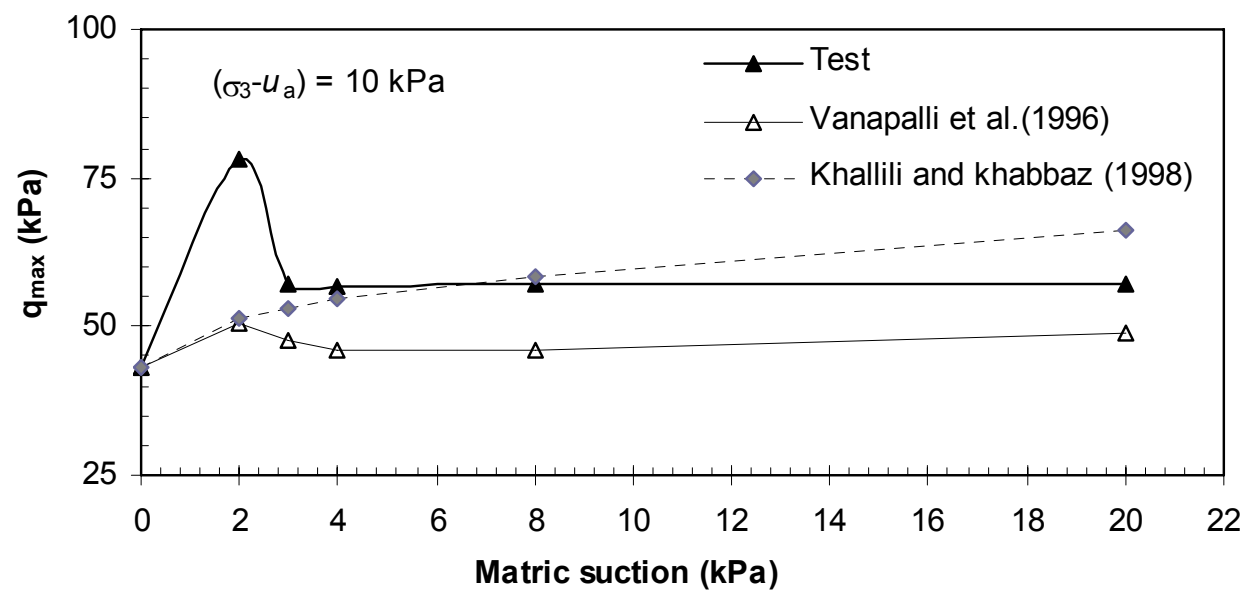

(a)

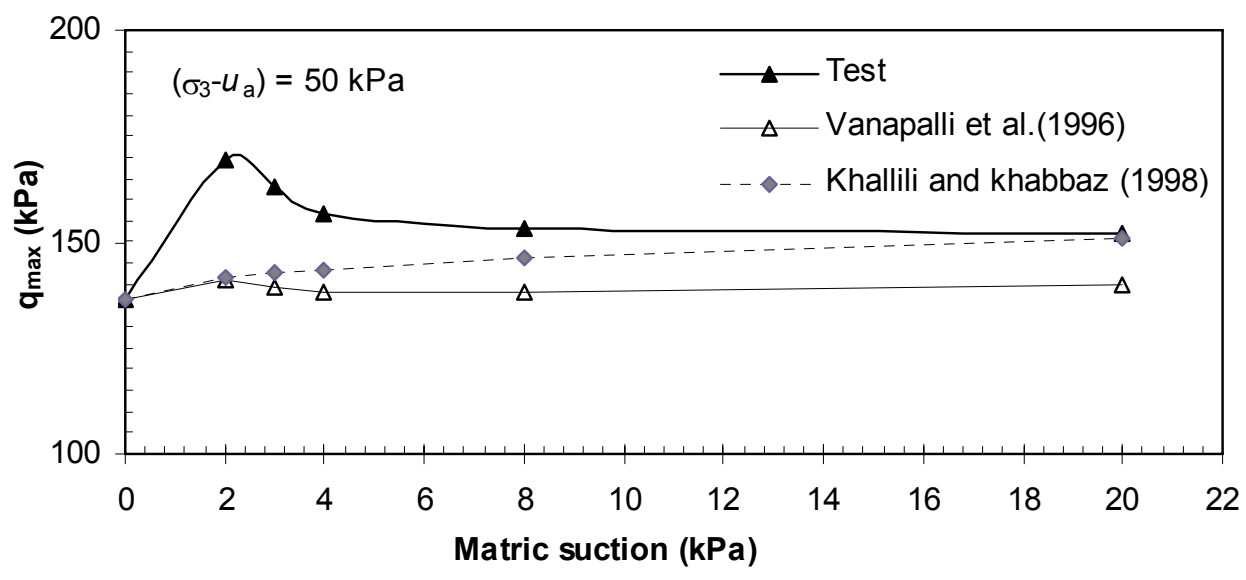

(b)

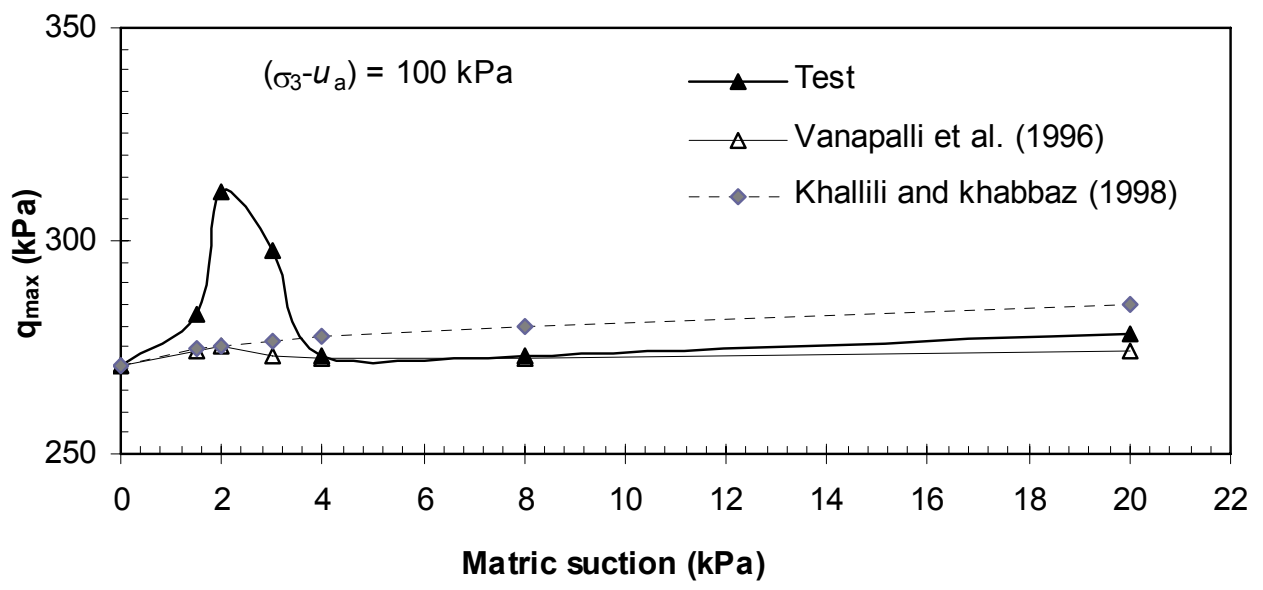

(c)

Figure (6.30) Measured and predicted shear strength versus matric suction for different net confining pressures: (a) $10 \mathrm{kPa}$; (b) $50 \mathrm{kPa}$; and (c) $100 \mathrm{kPa}$ 
The equation proposed by Vanapalli et al. (1996) (i.e., Eq. (6.11)) represents the changes in the shear strength with matric suction much better than that proposed by Khallili and Khabbaz (1998) (i.e., Eq. (6.13)) does. This can be attributed to the fact that the equation proposed by Vanapalli et al. (1996) is based on the concept of stress state variables, proposed by Fredlund and Morgenstern (1978), whereas the Equation proposed by Khallili and Khabbaz (1998) adopted the concept of single effective stress proposed by Bishop (1959).

Equation (6.11) provides better results of predicted shear strength comparing to Equation (6.13); but, the predicted shear strength using Equation (6.11) are lower than the measured shear strength for all values of matric suctions and confining pressures.

The equation proposed by Khallili and Khabbaz (1998) was also evaluated by Vanapalli and Fredlund (2000). They stated that Khallili and Khabbaz's procedure gave reasonable estimates for predicting the shear strength of two of the three soils analysed in low suction range, but does not provide good agreement for large suction ranges.

Vanapalli and Fredlund (2000) compared between different proposed procedures to predict the shear strength of unsaturated soil. Three types of soils (Madrid gray clay, Red silty clay, and Madrid clay sand) were used to evaluate the proposed procedure. These three soils were tested using modified direct shear equipment by Escario and Juca (1989). In this comparative study, Vanapalli and Fredlund (2000) concluded that the proposed procedure by Vanapalli et al. (1996) provides good comparison between the measured and predicted shear strength values for the three soils used.

Generally, the discrepancy between the predicted and measured shear strength in the tests done in this study can be explained by the fact that the prediction equations may not be suitable for this type of sand (i.e., uniform sand) which desaturated in a narrow range of suction. In addition, the fitting parameters used in the prediction equations may affect the results.

More experimental studies are necessary on different types of soils to better understand the shear strength behaviour of unsaturated soils and to develop better prediction procedures (Vanapalli and Fredlund, 2000). 


\subsubsection{Prediction of bearing capacity of unsaturated sand}

In Chapter 5, the load-settlement curves in bearing capacity tests on unsaturated sand for different value of suction are presented in Figure (5.17). The ultimate bearing capacity versus matric suction is presented in Figure (6.28). The ultimate bearing capacity of unsaturated specimen is 1.2-1.6 times higher in comparison with saturated specimen. Vanapalli and Mohamed (2007) proposed the following equation to predict the bearing capacity of shallow foundation on unsaturated soil:

$$
q_{u}=\left(c^{\prime}+\left(u_{a}-u_{w}\right)_{b}\left(\tan \phi^{\prime}-S^{\kappa} \tan \phi^{\prime}\right)+\left(u_{a}-u_{w}\right)_{a v r} S^{\kappa} \tan \phi^{\prime}\right) N_{c}+0.5 B \gamma N_{\gamma}
$$

where $\mathrm{q}_{\mathrm{u}}$ is the ultimate bearing capacity of the unsaturated soil, $c^{\prime}$ is the effective cohesion and $\phi^{`}$ is the angle of internal friction, $\left(u_{a}-u_{w}\right)_{\text {avr }}$ is the average value of matric suction in the pressure bulb, $\left(u_{a}-u_{w}\right)_{\mathrm{b}}$ is the air entry value of the soil, $N_{\gamma}, N_{c}$ are the bearing capacity factors, $\mathrm{S}$ is the degree of saturation, $\mathrm{B}$ is the width of the foundation, $\gamma$ is the unit weight of the soil, and $\kappa$ is a fitting parameter (for sand: $\kappa=1$ ). Figure (6.31) shows the relationship between the fitting parameter $\kappa$ and the plasticity index, $I_{p}$, for different types of soils as proposed by Vanapalli and Mohamed (2007).

Using Equation (6.14), the bearing capacity of surface model strip model footing on unsaturated Huston sand was calculated using the effective fiction angle $\phi^{\prime}=47.1^{\circ}$ and effective cohesion $\mathrm{c}^{\prime}=0 \mathrm{kPa}$ deduced from biaxial test under confining pressure of $\sigma_{3}=50 \mathrm{kPa}$. Figure (6.32) shows the comparison between the measured and predicted ultimate bearing capacity. The soil water characteristic curve (SWCC) of Hostun sand is also shown in the figure.

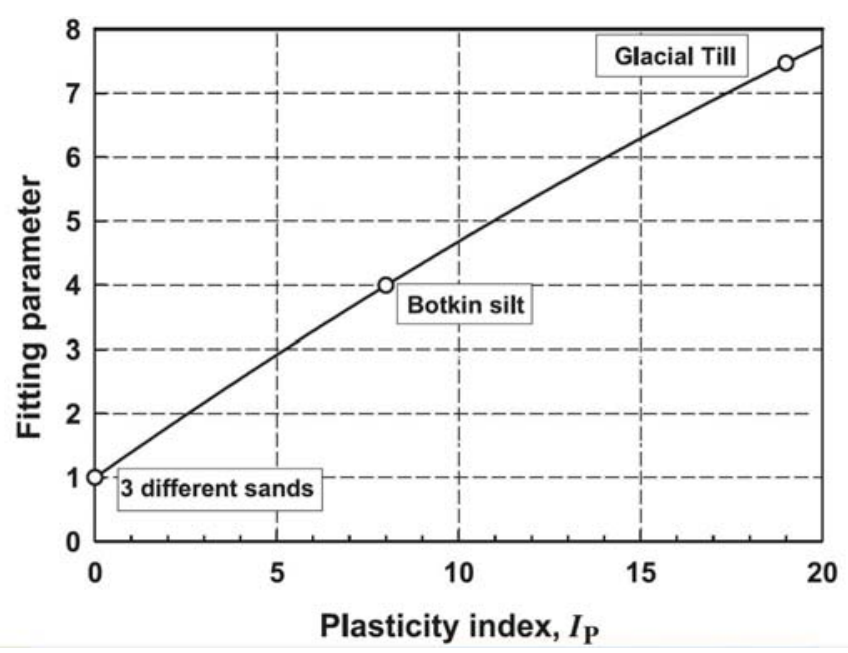

Figure (6.31) Fitting parameter, $\kappa$, versus plasticity index for naturally, compacted soils (Vanapalli and Mohamed, 2007) 


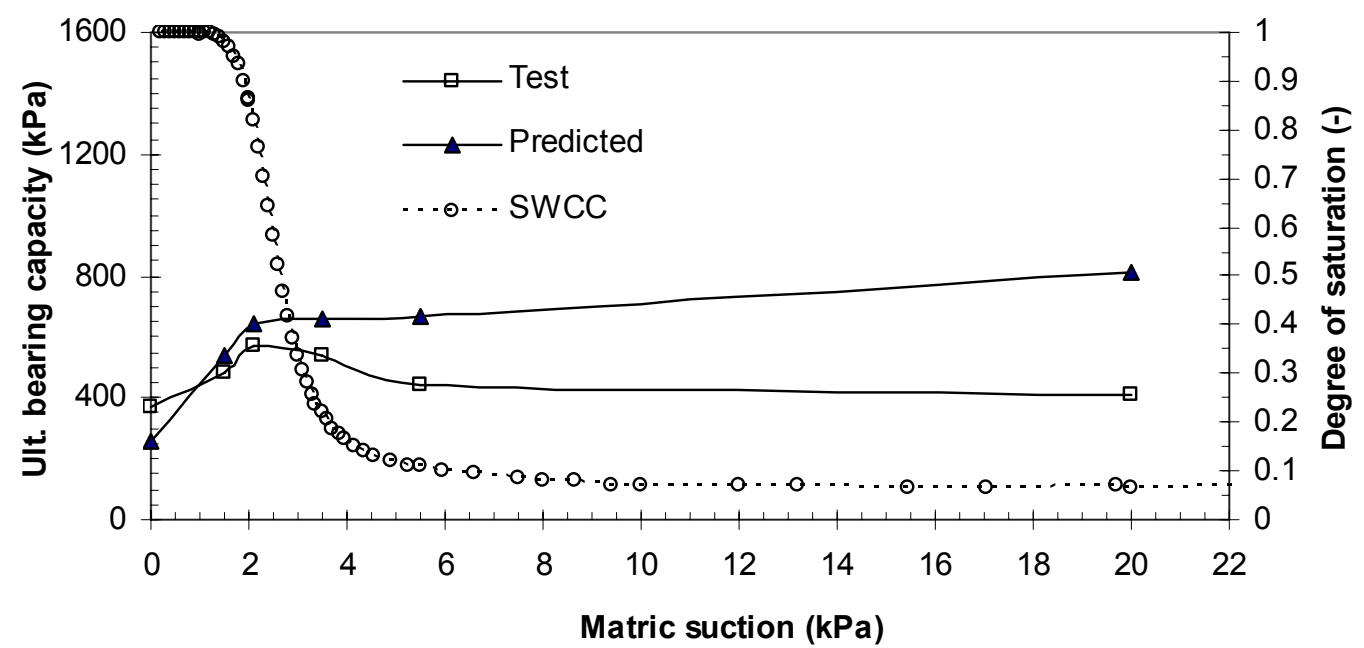

(6.32) Measured and predicted ultimate bearing capacity of unsaturated Hostun sand versus matric suction

Figure (6.32) reveals that Equation (6.14) over estimates the ultimate bearing capacity of unsaturated sand and fails to predict the trend of the relationship between the matric suction and the ultimate bearing capacity. In addition, even for saturated specimen, difference between the measured and predicted ultimate bearing capacity was observed. The calculated ultimate bearing capacity of the saturated sample is lower than the experimental result.

Regarding to this difference between the measured and predicted ultimate bearing capacity of saturated sample, factors such as the dependency of friction angle on the stress level, anisotropic shear strength, scale effect, progressive failure, and shear banding should be considered.

1- Dependency of friction angle on the stress level and anisotropic shear strength: the shear parameters which will be used in the design should be obtained from shear tests performed in the pressure range which will be faced in the field. The dependency of the friction angle on the stress level was discussed in several researches (e.g., De Beer, 1965; Das and Omar, 1994; Banimahd and Woodward, 2006; Tatsuoka et al., 1986; Tatsuoka, 2000). Bearing capacity factors $\left(\mathrm{N}_{\gamma}\right.$ and $\left.\mathrm{N}_{\mathrm{q}}\right)$ can be calculated using the classical equations for bearing capacity factors (Meyerhof, 1963; Vesic, 1973, 1975):

$$
\begin{aligned}
& N_{\gamma}=2\left(N_{q}+1\right) \tan \phi \\
& N_{q}=\tan ^{2}\left(45^{\circ}+\frac{\phi}{2}\right) e^{\pi \tan \phi}
\end{aligned}
$$


From the ultimate bearing capacity of saturated sample, the magnitude of $\mathrm{N}_{\gamma \text { test }}$ was obtained as follow:

$$
N_{\gamma t e s t}=\frac{2 q_{u}}{\gamma \cdot B}
$$

where $q_{u}$ is the ultimate bearing capacity of saturated sand sample, $\gamma$ is the soil unit weight, and $\mathrm{B}$ is the width of the footing.

Figure (6.33) shows $\mathrm{N}_{\gamma}$ (calculated using Eq. (6.15)) versus friction angle. The figure shows that $\mathrm{N}_{\gamma \text { test }}$ calculated from the experimental results is $\mathrm{N}_{\gamma \text { test }}=574.26$ which is higher than $\mathrm{N}_{\gamma}=407$ calculated using the friction angle from plane-strain test under confining pressure of $50 \mathrm{kPa}$ (i.e., $\phi^{`}=47.1^{\circ}$ ). If the effective friction angle $\phi^{`}=54^{\circ}$ from plane-strain compression test under confining pressure of $10 \mathrm{kPa}$ is used, a value of $\mathrm{N}_{\gamma}=$ 2140.24 is estimated which is significantly higher than $\mathrm{N}_{\gamma \text { test }}=574.26 . \mathrm{N}_{\gamma}$ will be very high as 3177.36 if the friction angle of $55.8^{\circ}$ (deduced from biaxial tests under confining pressure of $5 \mathrm{kPa}$ ) is used.

In practice, this over-estimation is balancing somehow by using an underestimated value of friction angle (Ttasuoka et al., 1991). This over-estimation is also due to the progressive mobilization of friction angle along the potential failure planes (Ttasuoka et al., 1991a; Ttasuoka, 2000).

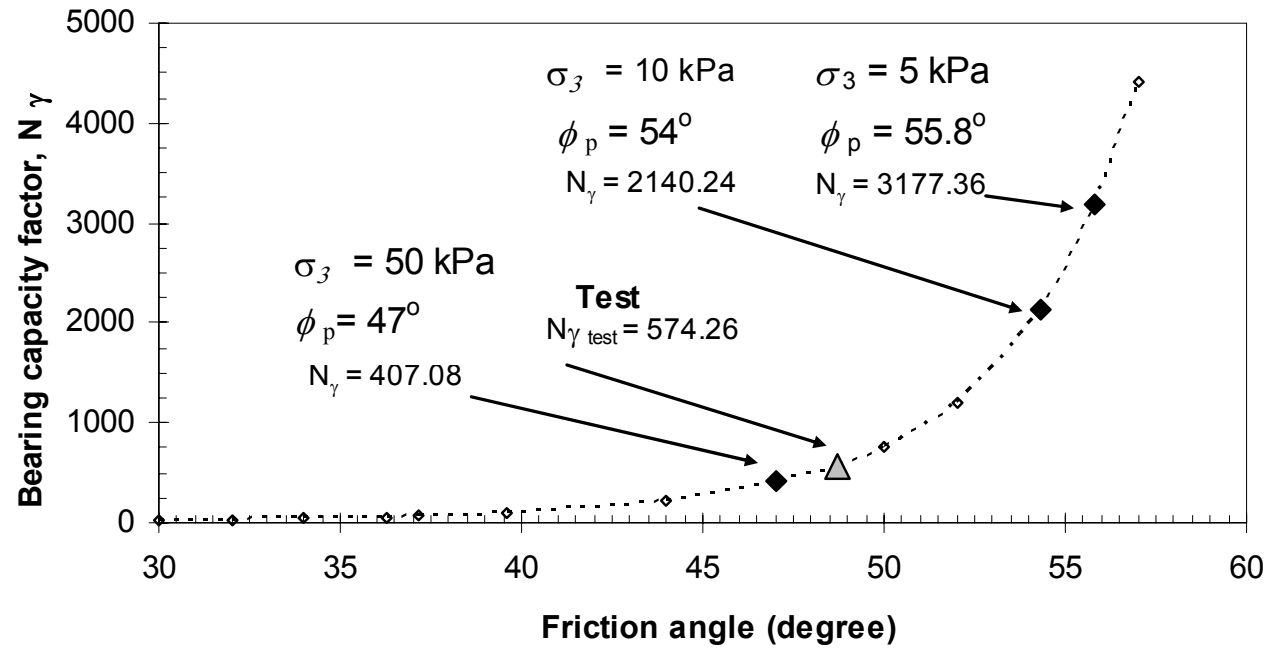

Figure (6.33) Bearing capacity factor $\left(\mathrm{N}_{\gamma}\right)$ versus friction angle 
Tatsuoka (2000) clarified that the stress-strain behaviour of the soil is over simplified in the classical soil mechanics. The classical theories ignore several factors such as the anisotropic strength, the effect of the pressure level on the internal angle of friction, shear banding phenomenon (thereby the effect of the grain size), and the different definition of $\phi$ between compression tests, simple and direct shear tests.

2- Progressive failure: Ttasuoka (2000) reported that the consideration of the pressure level-dependency of $\phi$ is not sufficient to explain the discrepancy between the classical theories and the real behaviour of sand but also the effect of progressive failure of sand bed should be considered. Examination of small-scale and large-scale data from Muhs (1963) indicated that accounting for the two effects of nonlinear strength behaviour and the strain restraint condition was not sufficient to account for discrepancies observed between experiment and prediction.

Muhs (1963) offered the explanation of progressive failure to account for these differences. As the load on the model footing is gradually increased, shear strength is not simultaneously mobilized at all points on the slip surface under the footing. Shear strength is first mobilized at points where shear strains are greatest, with strength mobilization progressing to other regions as shear strains develop through the soil body. When the peak load of the model footing is reached, only a percentage of the sand along the slip plane may be contributing a shear strength that is dependent on the peak friction angle of the sand. The remaining regions contribute shear strength dependent on a residual state friction angle. The failure of the ground is not simultaneous at all in the sense that at any moment of loading, the peak local strength is never mobilised simultaneously along the potential failure planes (Tatsuoka, 2000).

Yamaguchi et al. (1976) presented results that indicate that progressive failure becomes more prominent with increasing footing width, or increasing soil confinement, for a soil of a given relative density.

3- Scale effect: the classical bearing capacity equation a surface model strip footing on dry sand can be given as:

$$
q_{u}=0.5 B \cdot \gamma \cdot N_{\gamma}
$$

where $\mathrm{q}_{\mathrm{u}}$ is the ultimate bearing capacity, $\gamma$ is the soil unit weight; B is footing width; and $\mathrm{N}_{\gamma}$ is the bearing capacity factor.

Golder (1941) observed that bearing capacity does not, in general, increase linearly with footing width as predicted by Equation (6.17). The consequence of this 
effect is that bearing capacity factors determined from small-scale laboratory tests will generally be unconservative when extrapolated to field-size footings (Perkins and Madson, 2000).

The scale effect has been reviewed and discussed in several researches (e.g., De Beer, 1963, 1965, 1970; Ovesen, 1975; Yamaguchi et al., 1976; Kutter et al., 1988; Kusakabe et al., 1991, 1992).

The scale effect, as reported by De Beer (1965) is due in part to the nonlinear shape of the soil failure envelope. De Beer (1965) compiled several laboratory bearing capacity tests results to show that the magnitude of $\mathrm{N}_{\gamma}$ decreases with $\mathrm{B}$. Kumar and Khatri (2008) carried out FEM analysis for a smooth strip footing by taking two well defined $\phi-\sigma$ curves from the literature for Hostun and Toyoura sands. They reported that the magnitude of $\mathrm{N}_{\gamma}$ decreases considerably with increasing the footing width.

Kumar and Bhoi (2009) reported that for strip footing on sand of $70 \mathrm{~mm}$ wide, the value of $\mathrm{N}_{\gamma}$ was very high resulting in higher value of friction angle calculated from the back computations. In the present study, the width of the model footing is $80 \mathrm{~mm}$ and the value of $\mathrm{N}_{\gamma \text { test }}=574.2$ is higher than that calculated using classical solutions $\mathrm{N}_{\gamma}=407$.

Tatsuoka et al. (1991) presented the results of $1 \mathrm{~g}$ and centrifuge tests. The results showed that the ultimate bearing capacity and the corresponding settlement in $1 \mathrm{~g}$ tests for footing width of 230 and $500 \mathrm{~mm}$ were smaller than those in the corresponding centrifuge tests for footing width of 20 and $30 \mathrm{~mm}$.

4- Shear banding: Muehlhaus and Vardoulakis (1987) reported that the width of the shear bands is not affected by any geometrical dimensions of soil body other than its grain sizes. This conclusion is of great importance in understanding the phenomenon of progressive failure in granular soils.

Coumoulos (1968) using the X-ray techniques in simple shear tests, found that the void ratio in the shear zone is much higher than the average one. This agrees with recent observation (e.g., Desrues et al., 1996; Alshibli and Sture, 1999; Oda and Iwashita, 2000).

Oda and Iwashita (2000) reported that large voids appear in shear band, so that the resulting local void ratio can exceed the corresponding maximum one determined by the standard methods. For example, the void ratio inside the shear band in Soma sand is $\mathrm{e}_{\mathrm{band}}$ $=1.07$ is clearly higher than the maximum void ratio determined by the standard method $\left(\mathrm{e}_{\max }=0.872\right)$. Figure (6.34) shows a microscopic photograph of the shear band formed in Ticino sand presented by Oda and Iwashita (2000). 
The dark spots are the large vacant voids. Outside the shear band, the void ratio is close to the initial one. The experimental observations by Oda and Iwashita (2000) coincide with their numerical simulations. Figure (6.35) illustrates the formation of shear bands and the changes in the void ratio in the share bands formed under the model footing in bearing capacity test.

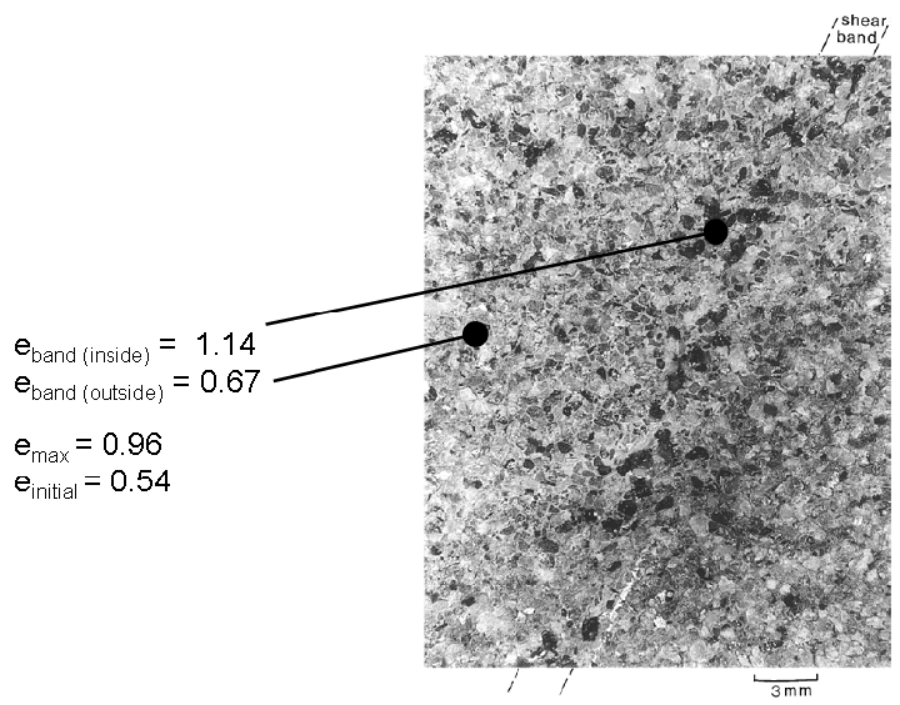

Figure (6.34) Large voids (dark spots) visible inside a shear band of Ticino sand (Oda and Iwashita, 2000)

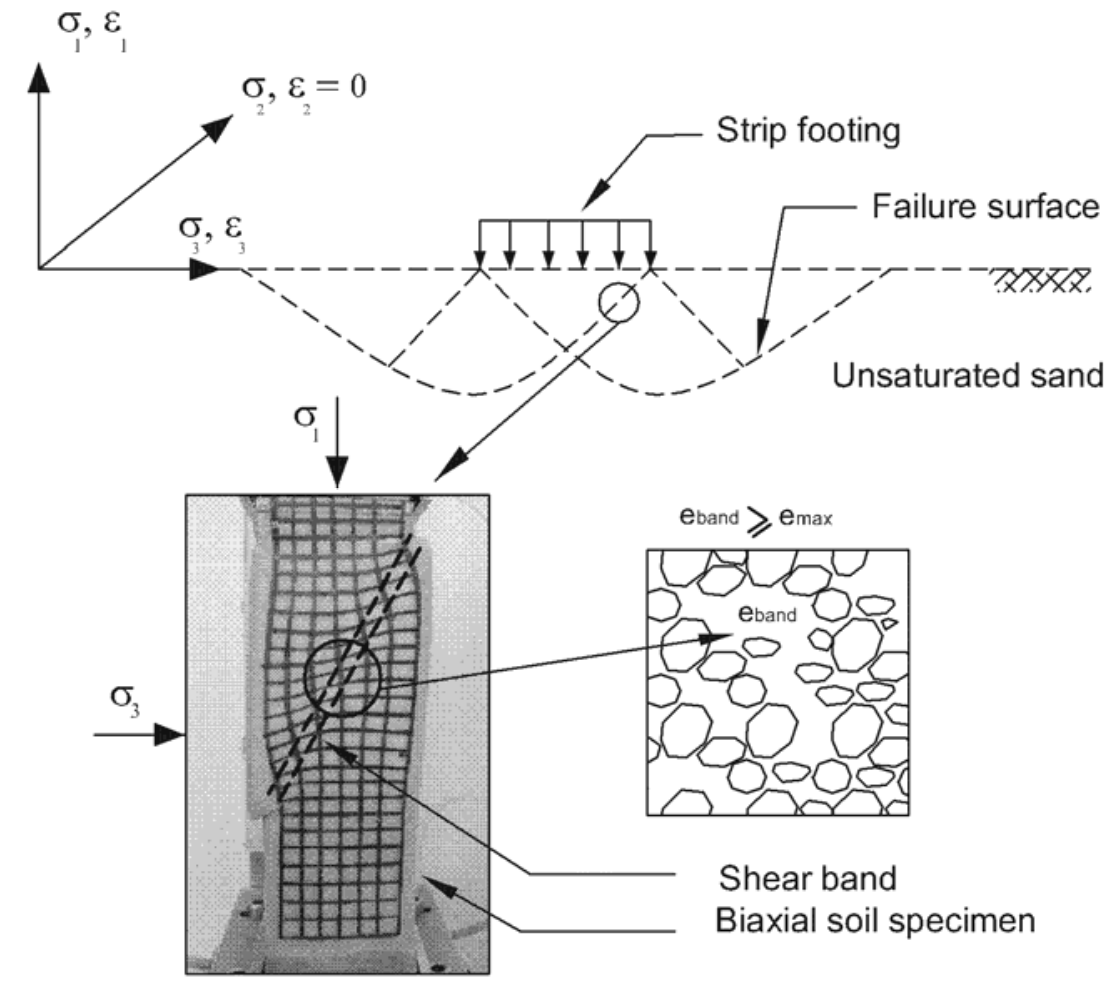

Figure (6.35) Shear banding under footing in bearing capacity test on unsaturated sand 
Ttasuoka et al. (1991) performed bearing capacity tests of strip footing ( $\mathrm{B}=500$ $\mathrm{mm}$ ) on Toyoura sand and compared the experimental results to FEM analyses. The FEM analyses were done using different procedures ( $a, b, c, d$, and e):

(a) The value of $\phi$ is isotropic and independent of pressure level. The $\phi$ value at low pressure level is the highest value for a given mass of sand.

(b) The pressure-dependency of $\phi$ was considered.

(c) In addition to the above, the factor of inherent anisotropy of the deformation and strength characteristics of the test sand (see Figure (6.34)) was considered.

(d) In addition to the above, the post-peak strain softening was considered.

(e) The strain localization into shear bands having a specific thickness was considered.

In this procedure, the properties of the sand were modelled as close as to the actual ones.

Figure (6.36) shows the he results of FEM analyses with comparison to the experimental results. The comparison showed that only the analysis (e), which considers the shear banding in sand, is close to the experimental results.

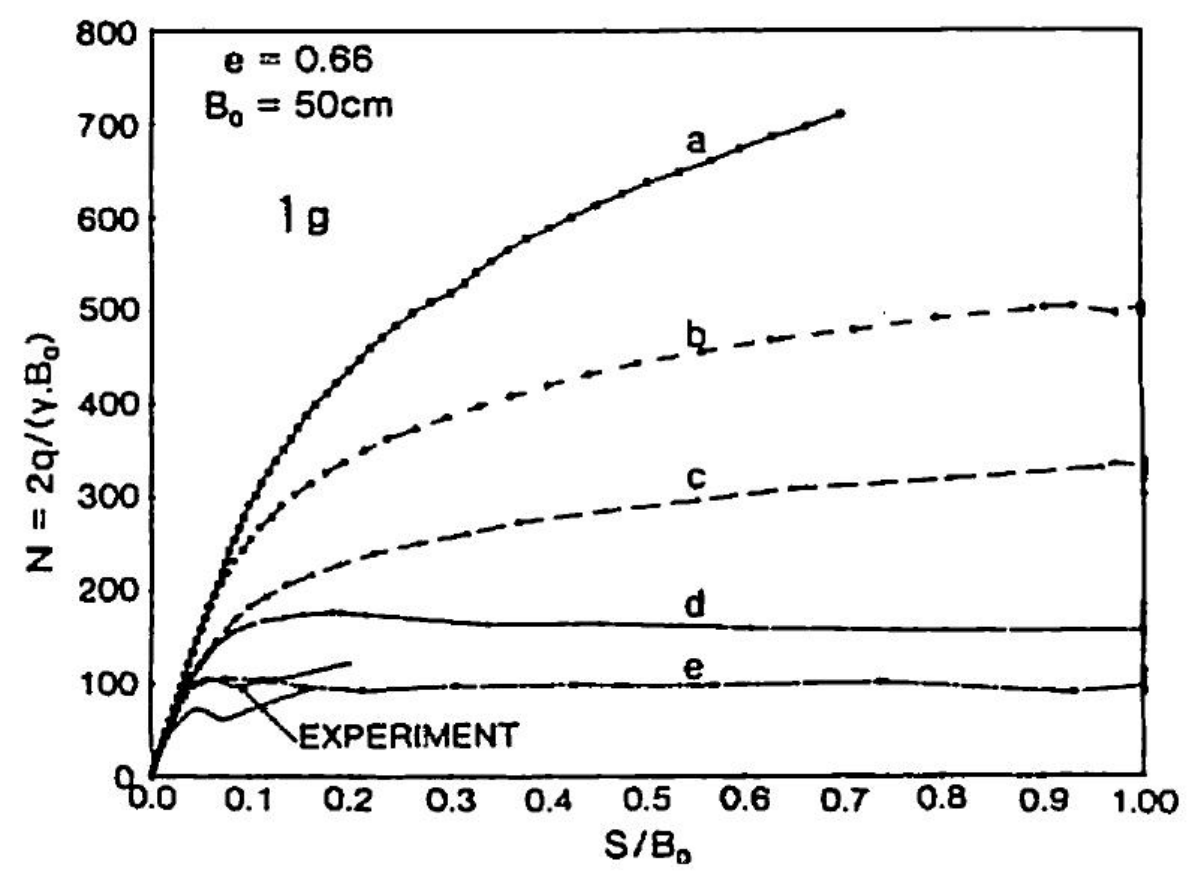

Figure (6.36) Experimental results of bearing capacity tests on Toyoura sand with comparison to the results of FEM analyses (Ttasuoka et al., 1991) 
Regarding to the predicted ultimate bearing capacity of unsaturated sand, it is clear that differences are observed between the predicted values using the approach proposed by Vanapalli and Mohamed (2007) and measured ones.

The differences can be attributed mainly to the shape of the soil water characteristic of the sand tested. As shown in Figure (6.32), Hostun sand is rapidly desaturated in a narrow range of matric suction.

In addition, the fitting parameter $\kappa=1$ may not be suitable for fine uniform sands. Figure (6.37) shows a comparison between the measured and predicted values using different values of $\kappa(\kappa=0.7,1$, and 2$)$. The comparison shows that using fitting parameter value of 2 may better represent the real behaviour of unsaturated sand in bearing capacity tests; but differences still are observed between the measured and predicted values.

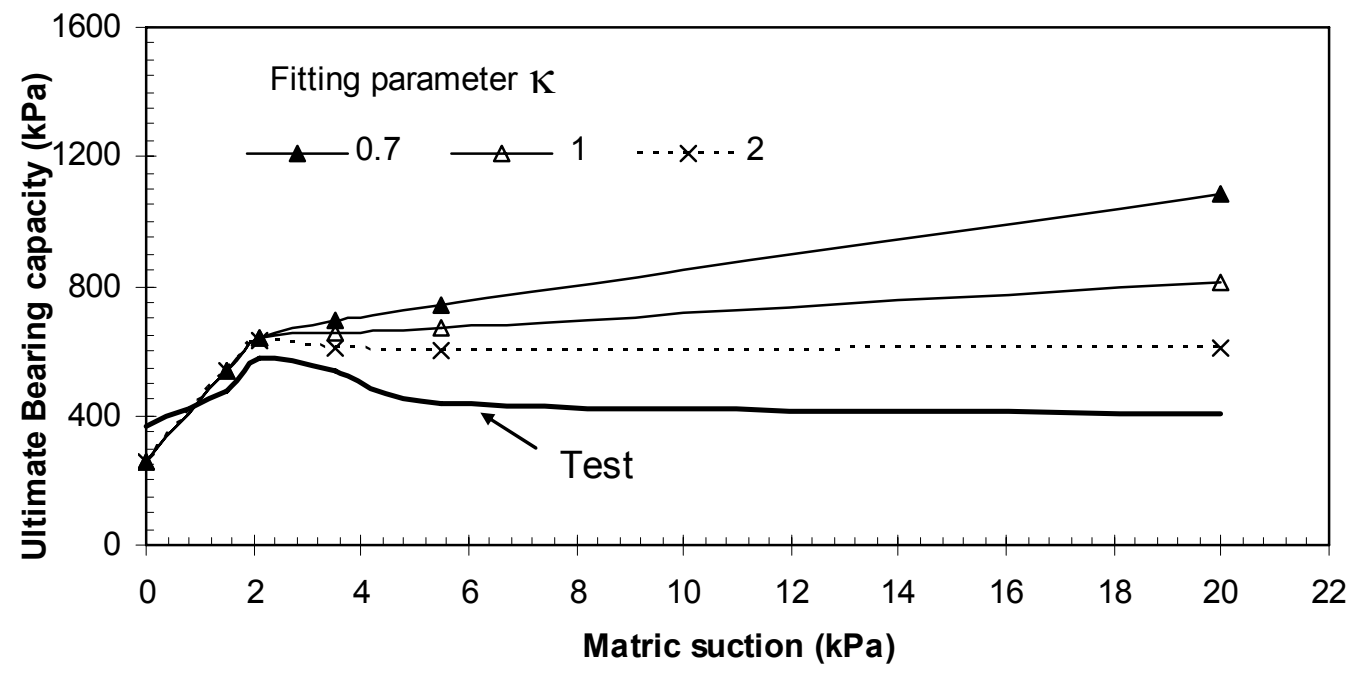

Figure (6.37) Effect of fitting parameter $(\kappa)$ on the predicted ultimate bearing capacity of model strip footing on unsaturated sand 


\subsection{Discussion of the results of soil water characteristic curves tests}

From Figure (5.23), it can be seen that the SWCC of Hostun Sand is located in a narrow range of suction whereas the SWCC of kaolin is located in a wide range of suction. Between these two curves, the SWCCs of sand-kaolin mixtures are located. From the experimental results, SWCC parameters (i.e., air-entry value, residual suction, and water-entry value) were obtained. These parameters were determined by adopting methods suggested by Fredlund and Xing (1994) as illustrated in Figure (6.38). Air-entry and water-entry values and residual suction are defined as follows:

Air-entry value, $\psi_{\mathrm{AEV}}$ : the air-entry value is the soil suction at which air starts to enter largest pores of the soil during drainage process.

Residual suction, $\psi_{\mathrm{r}}$ : The residual suction is the soil suction at which the water starts to be held in the soil by adsorption forces (Sillers, 1997).

Water-entry value, $\psi_{\mathrm{WEv}}$ : The water-entry value is the soil suction at which water starts to enter the smallest pores during wetting process. The water-entry value corresponds to the matric suction at which the water content of the soil starts to increase significantly during the wetting process (Yang et al., 2004).

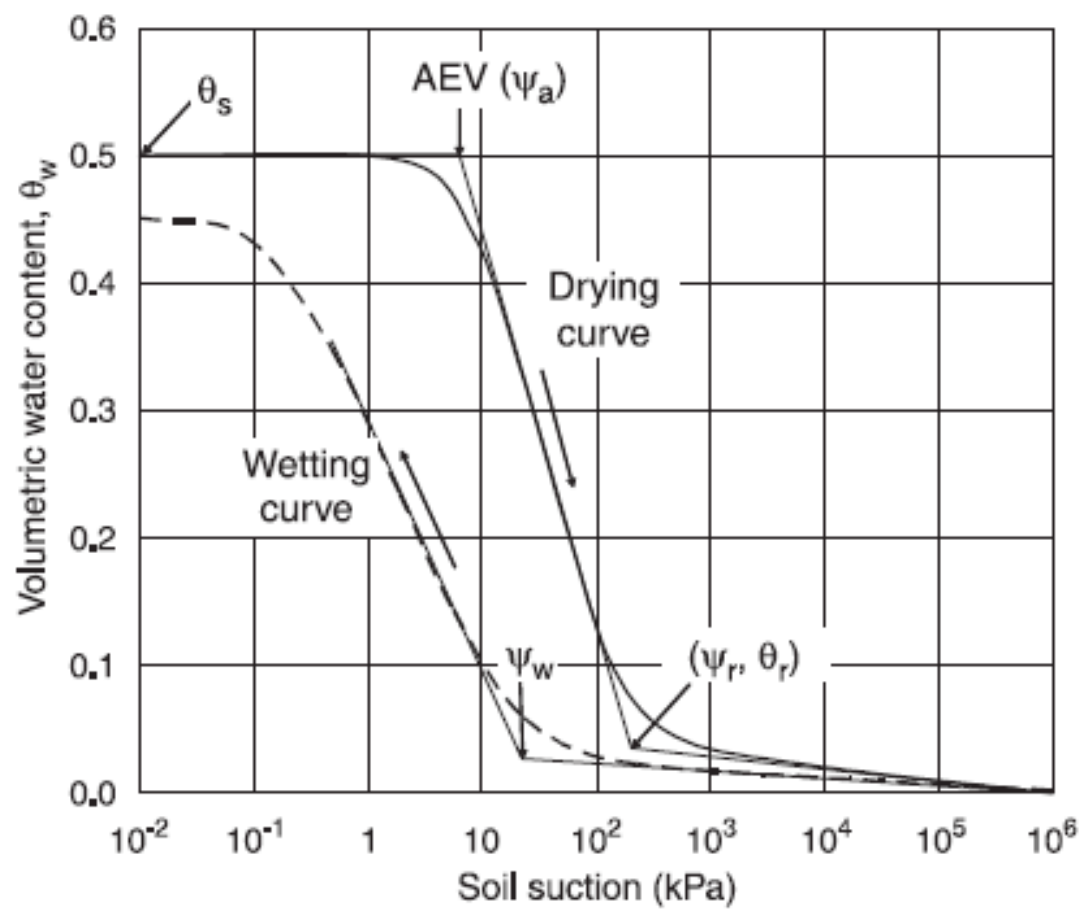

Figure (6.38) Idealized soil-water characteristic curves modified after Fredlund and Xing (1994) (Yang et al., 2004) 
Figure (6.39) shows the air entry value, residual suction, and water-entry value as a function of kaolin content in the soils tested. The air-entry value increases for the specimens with kaolin content higher than $10 \%$. The air-entry value for the Hostun sand specimen and the mixture A (5\% kaolin) was found to be similar $\left(\psi_{\mathrm{AEV}}=1.7 \mathrm{kPa}\right)$. For mixture $\mathrm{B}(10 \%$ kaolin $)$ the air-entry value is slightly higher $\left(\psi_{\mathrm{AEV}}=1.8 \mathrm{kPa}\right)$. For specimens with kaolin content less than $10 \%$, the large pores, due to large grains of the sand, are draining first. With further increase in fine content, the specimens reach higher air-entry values (mixture $\mathrm{C}\left(30 \%\right.$ kaolin): $\psi_{\mathrm{AEV}}=30 \mathrm{kPa}$, kaolin: $\left.\psi_{\mathrm{AEV}}=2000 \mathrm{kPa}\right)$

Besides increasing the air-entry value, increasing kaolin content results in increasing the residual suction. The residual suction increases with increasing the fine content (Hostun sand $\psi_{\mathrm{r}}=3.8 \mathrm{kPa}$, mixture A $\psi_{\mathrm{r}}=9 \mathrm{kPa}$, mixture B: $\psi_{\mathrm{r}}=12 \mathrm{kPa}$, mixture $\mathrm{C}: \psi_{\mathrm{r}}=10500 \mathrm{kPa}$, and kaolin: $\psi_{\mathrm{r}}=40000 \mathrm{kPa}$ ). It can be concluded that the ability of specimens to retain water increases by increasing kaolin content.

The water-entry value also increases by increasing kaolin content in the mixtures (Hostun sand: $\psi_{\mathrm{WEV}}=3 \mathrm{kPa}$, mixture A: $\psi_{\mathrm{WEV}}=6 \mathrm{kPa}$, mixture $\mathrm{B}: \psi_{\mathrm{WEV}}=7 \mathrm{kPa}$, mixture $\mathrm{C}: \psi_{\mathrm{WE} V}=6000 \mathrm{kPa}$, and kaolin: $\left.\psi_{\mathrm{WEV}}=11000 \mathrm{kPa}\right)$.

Hysteresis in the SWCCs indicates that the volumetric water content or degree of saturation in the soil is not unique at a specific matric suction value but is related to the wetting and drying history of the soil (Yang et al., 2004). The results show the influence of loading paths (either drying or wetting) on the shape of the curves. The drainage and wetting curves are not unique. The phenomenon of hysteresis was observed for all specimens. The hysteresis between drying and wetting paths increases with increasing the kaolin content in the specimens.

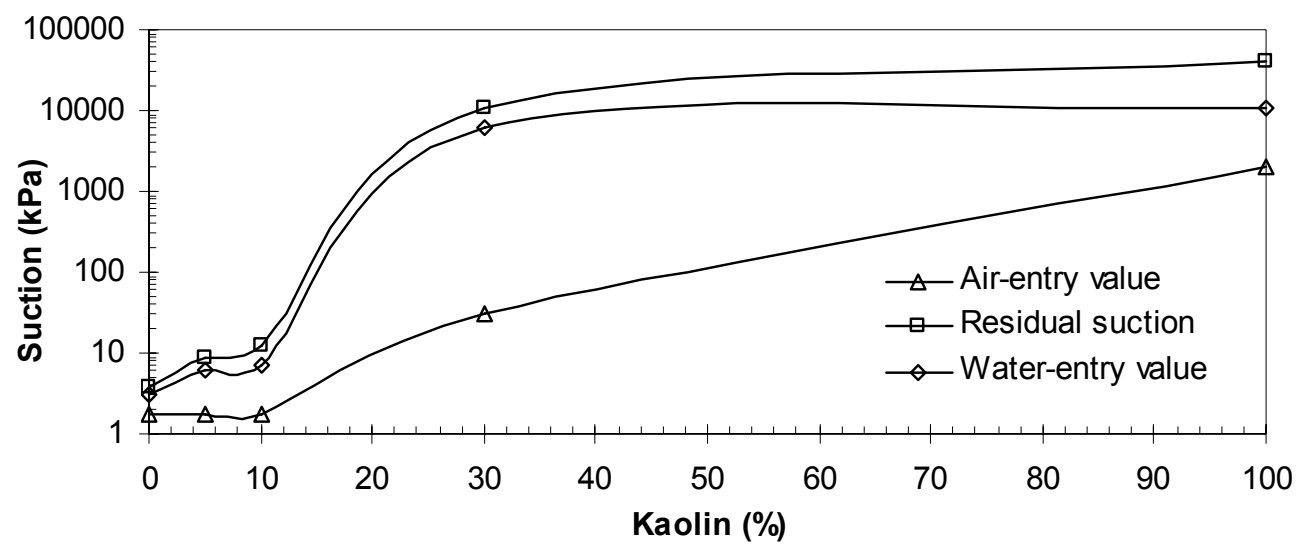

Figure (6.39) Influence of fine content on SWCC parameters 
The result of the current study show that in mixture A ( $5 \%$ kaolin), the pores sizes are governed by sand grains and the kaolin grains are partially coating the sand grains and the flow of the water due to the application of suction still governed with the pore size of sand. By further increment of fine content, the kaolin particles start to fill the pores in between the sand grains.

The results of this study show that there is a threshold kaolin content at which the behavior of the mixture starts differing clearly from the behavior of the sand (i.e., granular content) behavior. By exceeding this value of kaolin content, the behavior becomes more similar to the behavior of the kaolin (i.e., clayey content). In case of Huston sand and Spergauer kaolin it appears that kaolin less than $10 \%$ does not affect significantly on the microstructure of the mixture and thus on the saturation and disaturation behavior of the mixture.

Agus (2005) reported that a there is a limiting content beyond which bentonite dominates the behavior of the mixture. Chui and Schackelford (1998) measured the unsaturated hydraulic conductivity of compacted sand-kaolin mixtures for low suction values (i.e., suction $<60 \mathrm{kPa}$ ). The results of their tests showed that increasing the kaolin content results in increasing both the air-entry and water-entry values. Small changes in air-entry and water-entry values were observed when the kaolin is less than $10 \%$.

The characteristics of clean sand and pure clay have been studied extensively. In reality, sand deposits usually contain some fines consisting of non to low-plastic silts or clays (Ishihara, 1993). The mechanical behavior of sand-clay mixtures is completely different from that of sands. Increasing clay content generally results in increasing in the plasticity and the coefficient of secondary consolidation (creep) while the friction angle and permeability decrease (Daehyeon et al., 2005).

Effect of type of soil, fine content, and soil plasticity on soil behaviour have been studied in several researches (e.g., Chiu and Schackelford ,1998; Montañes, 2002; Yang et al., 2004; Daehyeon et al., 2005; Agus, 2005; Marinho, 2005; Thakur et al., 2005; Ghahremani et al., 2007; Cui et al. , 2008; Arifin, 2008).

Factors such as soil structure, initial water content, void ratio, and type of soil, mineralogy, and compaction method have significant effects on features of the SWCC. Among these factors, stress history and initial water content often have the greatest effect on soil structure, which in turn dominates the nature of the soil-water characteristic curve (Zhouh and Jian-lin, 2005). 
The main factors influencing the relationship between the degree of saturation and suction of the fine grained soils are the surface area and the cation exchange capacity. Pore water is retained by molecular bonding, electrical field polarization caused by the negative charge on the surface of the minerals, and Van der Waals attraction within the soil-pore water interface between the molecules as well as the exchangeable cation hydration (osmotic effects).

In coarse grained soils, the surface area is relatively small and the cation exchange capacity is not affecting the properties of coarse materials. The behaviour of coarse grained soils is mainly controlled by the contact forces between the grains and the matric suction (negative pore-water pressure). The influence of the sand on the mechanical behavior of sand-bentonite mixture takes effect at high sand content where the intergranular contact between sand grains exists (Agus, 2005).

Capillary forces are responsible for relatively low suction values (high water contents) governed by the pore-size distribution. At low values of water content (high suction values), where water is only available as a thin film on the grain surfaces, the dominant mechanism influencing the shape of the soil-water characteristic curve are the surface properties of the grains.

Controlled by relatively large pores, the air-entry value as well as the water-entry value of the sand is low. Clay absorbs a greater amount of pore water due to small pores, significant specific surface properties, and specific charge properties. The smaller pores retain the water up to a higher matric suction resulting in a high air-entry and water-entry values. Thus the capacity of water absorption is the highest for clays and their soil-water characteristic curves locate over a wide range of soil suctions.

The residual zone for the sand is generally very limited, because both specific surface properties and specific charge properties are relatively very small. The pore-size distribution mainly influences the shape and the slope of the SWCC. Poorly graded soils have steep soil-water characteristic curves, because the majority of pores are drained at a narrow range of soil suction. Well-graded soils have flatter soil-water characteristic curves, because of the different size pores, and they are drained over wider range of soil suction. Coarse-grain soils such as gravel and sand show a tendency to desaturated at a fast rate with increasing suction. The rate of desaturation decreases with an increasing in fine content. The slope of branch in transition zone for silty soil is steeper than that of kaolin (Nishimura and Fredlund, 2000). 
(Montañes, 2002) reported that the increase in bentonite content shifts the soil water characteristic curve and decrease the residual degree of saturation. The wetting paths for mixture with low fine content ( $5 \%$ and $10 \%$ bentonite) are strongly affected by the characteristics of the granular component (i.e., sand). Figure (6.40) show a scanned electron microscope image of sand-bentonite mixture with $10 \%$ bentonite content. The image shows how the sand particles are partially coated with bentonite.

Yang et al. (2004) investigated the effect of the soil type on the soil water characteristic curve. The soils tested were gravelly sand, medium sand, fine sand, and clayey sand. They reported that the coarse-grained soil has a lower air-entry value, lower residual soil suction, and lower water-entry value than a fine grained soil, and that the SWCC of a uniform soil has a steeper slope than that of a less uniform soil. In addition, they showed that there was considerable hysteresis between the drying and wetting curves for each soil.

Ghahremani et al. (2007) presented a series of scanned electron microscope (SEM) images. Figure (6.41a) presents the specimen with $10 \%$ clay content (images on the right side illustrate the rectangular on the left side). The images clearly illustrates that the clay particles are residing on the surface of sand grains. Figures (6.41b) presents the images of specimen with $30 \%$. Although the sand grains are gradually being confined with the clay particles, there are still sand grains in contact. The numbers of such sandsand contacts decreases by increasing the clay content. For $40 \%$ clay (Figure (6.41c)), the sand grains are confined the clay particles.

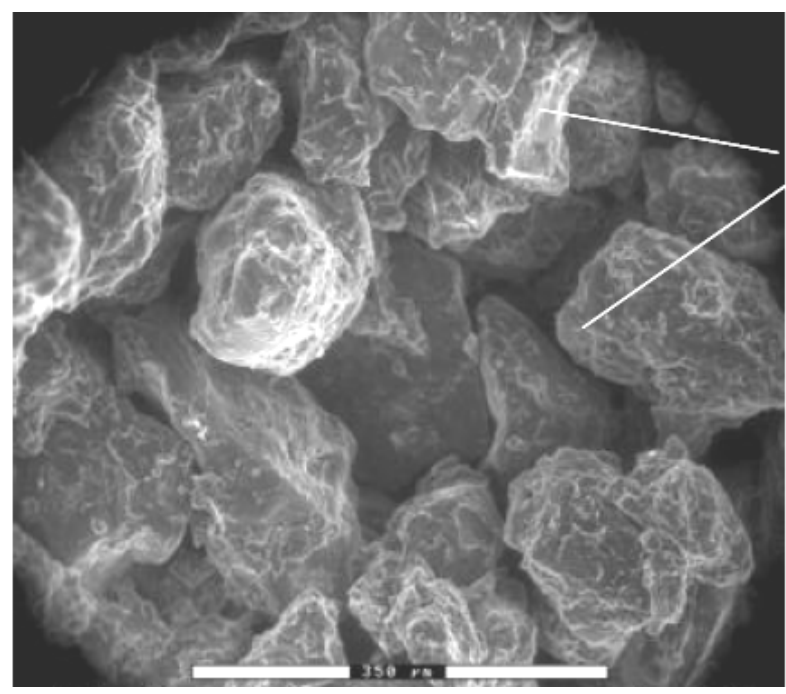

sand particles partially coated by bentonite

Figure (6.40) Sand particles coated partially with bentonite in sand-bentonite mixture (10\% bentonite) (Montañes, 2002) 

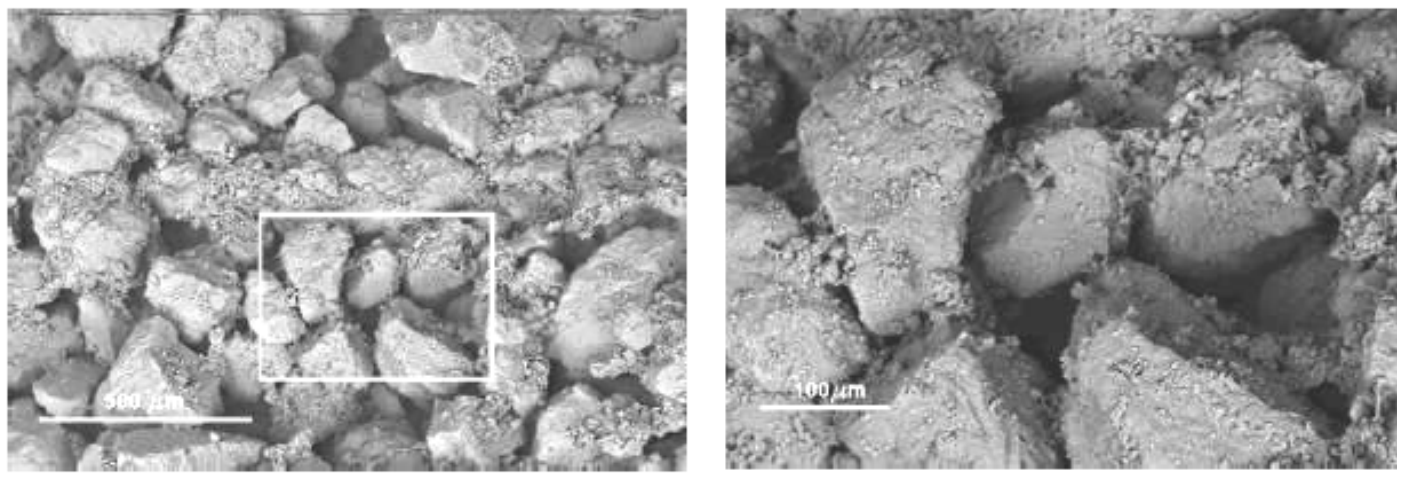

(a)
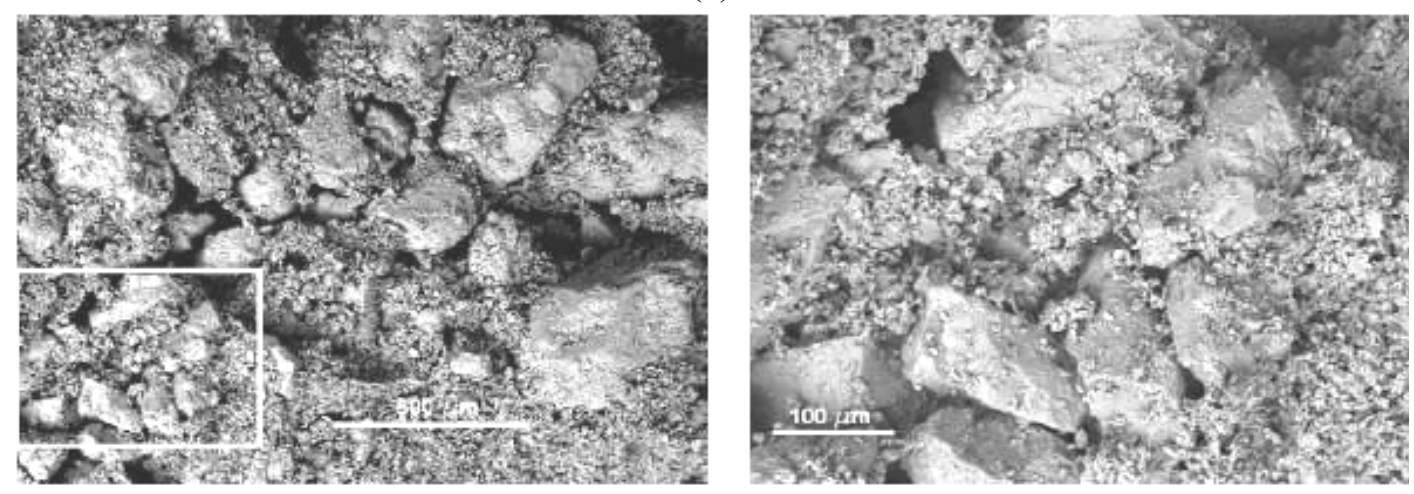

(b)
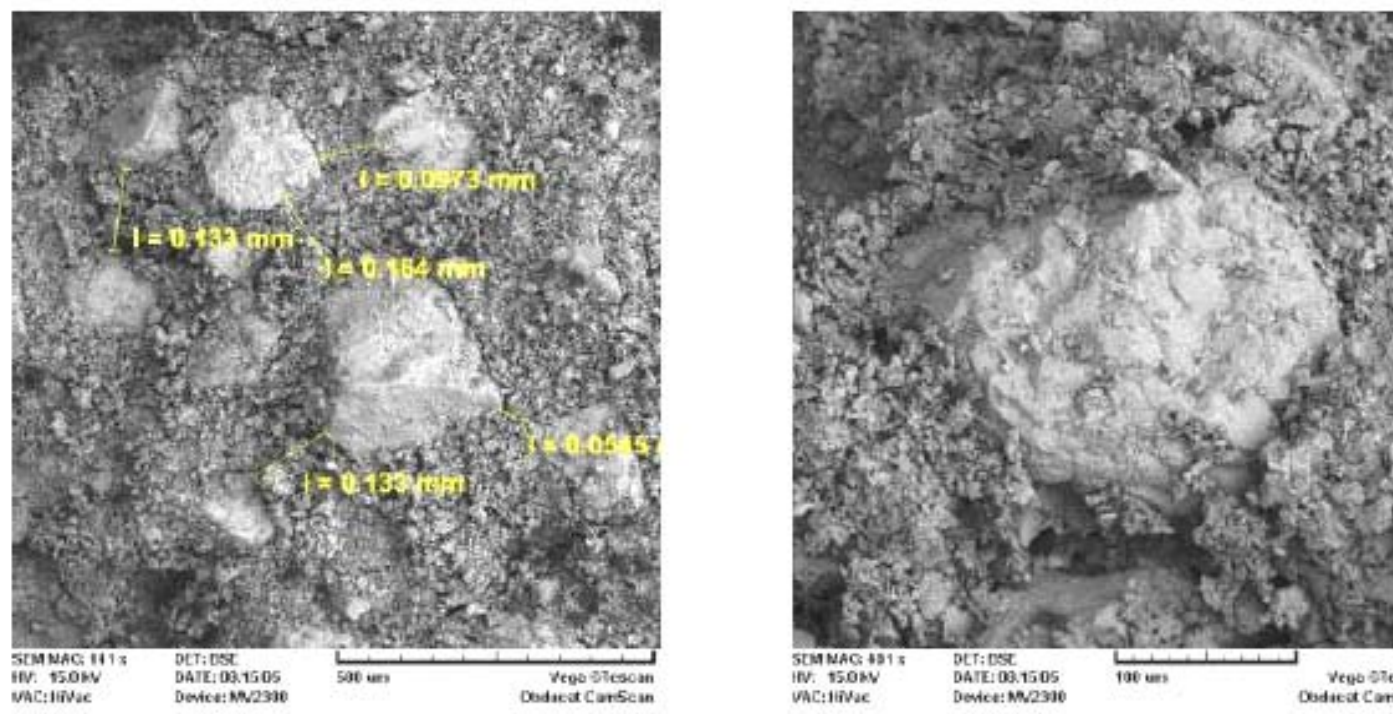

(c)

Figure (6.41) Scanned electron microscope (SEM) images for specimens with different clay content: (a) $10 \%$ clay; (b) $30 \%$ clay; and (c) $40 \%$ clay (Ghahremani et al., 2007) 


\section{CHAPTER 7}

\section{CONCLUSIONS AND RECOMMENDATIONS}

\subsection{Conclusions}

In this chapter, the main conclusions drawn from this study and recommendations for future research are presented. In this thesis, a new developed biaxial device has been presented and, using this new device, an experimental study on the mechanical behaviour of unsaturated sand in plane-strain condition has been performed. For the purposes of clarity, the derived conclusions have been grouped in three main sections as follows: conclusions from the biaxial tests using the new developed device, conclusion related to the bearing capacity tests, and finally the conclusions drawn from the SWCCs tests.

\subsubsection{The new developed double-wall biaxial device}

1. The calibration tests of the new device show that the new device is capable of testing dry, saturated, and unsaturated soil under plane-strain conditions in a very realistic way.

2. The new developed double-wall biaxial device enables several types of biaxial test to be performed:

- Measuring the volume changes of unsaturated sample.

- Determining the shear strength parameters for dry, saturated, and unsaturated granular materials in plane-strain conditions.

- Applying suction gradient within the soil specimen during the test.

- Studying the strain localization under partially saturated conditions.

- Performing compression biaxial tests with different end restrain conditions (i.e., fixed or free bottom end)

3. The calibrations tests using saturated soil specimen show that the system is capable of measuring the volume changes of the specimen by mean of the double-wall cell technique. The observed errors in the volume changes measurements of the saturated soil specimen were in the range $0.01-0.07 \%$.

4. The results of the null tests strongly support the use of the net stress and matric suction as two independent stress state variables to describe the behaviour of 
unsaturated soil. The maximum measured volumetric strain of the specimen in the null tests on sand-kaolin mixture specimen was about $0.07 \%$. With regard to the accepted absolute error proposed by Geiser et al. (2000), the measured values in the new device can be accepted. The significant amount of creep underlines that the creep of the inner cell in a double wall system should be taken into consideration in the analysis of the tests results regarding the volumetric strain.

\subsubsection{Biaxial tests on Hostun sand}

1. The friction angle of the dense sand specimens increases with the decreasing of the confining pressure. The maximum friction angle measured for confining pressure of $5 \mathrm{kPa}$ was $55.8^{\circ}$, whereas the value of $42.8^{\circ}$ was measured for the confining pressure of $600 \mathrm{kPa}$.

2. The maximum friction angle measured for the loose sand under confining pressure of $50 \mathrm{kPa}$ was $39.6^{\circ}$. For $150 \mathrm{kPa}$ confining pressure, friction angle of $36.7^{\circ}$ was measured.

3. Dilatancy angle decreases considerably by increasing the confining pressure. The maximum dilatancy angle was $20.5^{\circ}$ for the confining pressure of $5 \mathrm{kPa}$, whereas the dilatancy angle of $11.1^{\circ}$ was measured for confining pressure of $600 \mathrm{kPa}$.

4. The relationship between the dilatancy angle and the friction angle fits well with the equation proposed by Bolton (1986) for plane-strain state (i.e., $\phi_{\mathrm{p}}=\phi_{\mathrm{cv}}+0.8 \psi$ ). The results in the present study follow the equation: $\phi_{\mathrm{p}}=\phi_{\mathrm{cv}}+0.77 \psi$

5. Loose sand specimens exhibit small amount of dilation under low values of confining pressure. Beyond the value of $100 \mathrm{kPa}$ contraction was observed. The dilatancy angle of $2.7 \sim 2.8^{\circ}$ was measured for the range of pressure $50-100 \mathrm{kPa}$. No dilation was observed in the case of confining pressure of $150 \mathrm{kPa}$.

6. The angle of shear band inclination increases with the decreasing of the confining pressure. The maximum angle of shear band inclination $\left(\theta_{\mathrm{m}}=68.7^{\circ}\right)$, with respect to the direction of the plane of the major stress $\left(\sigma_{1}\right)$, was measured for the specimen tested under confining pressure of $5 \mathrm{kPa}$. Whereas for the specimen tested under $600 \mathrm{kPa}$ confining pressure, the measured shear band inclination angle was $\theta_{\mathrm{m}}=55.7^{\circ}$.

7. The results of the biaxial tests on unsaturated dense Huston sand show that the shear strength of unsaturated sand tends to increase with the increasing of the 
matric suction in the range between the fully saturated condition and a value of matric suction of $2 \mathrm{kPa}$ (almost at the beginning of the transition zone) which is slightly higher than the air entry value of the sand $(\mathrm{AEV}=1.7 \mathrm{kPa})$. Beyond this value of matric suction, the shear strength starts to decreases with the increasing of the matric suction. The minimum shear strength is that consistent with the fully saturated specimen.

8. The measurements of the thickness of the shear band show that the confining pressure does not affect the thickness of the shear band in the tested range of confining pressure (i.e., $5-600 \mathrm{kPa}$ ).

9. The comparisons between the measured and predicted shear strength of unsaturated Hostun sand, shown in Figure (6.30), show that there is a significant differences between the measured and predicted values. This can be attributed to the fact that the prediction equations do not take into consideration the dilation effect. In addition, the fitting parameters in these equations may need to be modified for such types of soils (i.e., uniform sands) which desaturated in a narrow range of matric suction.

10. It was found that changing the matric suction does not affect the maximum dilatancy angle and the angle of shear band inclination. It was noticed that both the maximum dilatancy angle and the angle of shear band inclination are sensitive to the changes in the net confining pressure.

\subsubsection{Bearing capacity tests of model strip footing on Hostun sand}

1. The ultimate bearing capacity of a model strip footing on unsaturated sand was found to increases by increasing the matric suction to a value slightly higher than the air entry value of the sand, beyond this value the ultimate bearing capacity starts to decrease to reach, in higher value of matric suction, the minimum ultimate bearing capacity (i.e., the ultimate bearing capacity at fully saturated conditions).

2. The bearing capacity tests show that the settlement required to reach the maximum load is influenced by the matric suction as shown in Figure (6.29). The required settlement to reach the peak load increases by increasing the matric suction up to matric suction slightly higher than the air entry value of the sand. By further increment of matric suction the settlement at peak starts to decrease. 
3. The measurements of the matric suction in different depths under the footing show that no significant changes in matric suction occurs during a low rate loading stage.

\subsubsection{Effect of fine contest on SWCCs}

1. The SWCCs of the sand, kaolin, and three kaolin-sand mixtures show that increasing the fine content (i.e., kaolin content) affects significantly the shape of the curve.

2. The air entry value, residual suction, and water-entry value increase by increasing fine content.

3. The SWCCs show that the loading paths (drying or wetting) influence the shape of the curves. For all soils tested, there is hysteresis between the drying and wetting curves.

\subsection{Recommendations and future work}

Based on the finding of the experimental work performed for this thesis, the following recommendations are presented:

1. Minor modifications to the current version of the biaxial device can provide the ability of measuring the intermediate stress, the displacement of the bottom end platen, and specimen deformation at several points along the specimen height. These measurements can be used to, for example, to detect the onset of the shear band in soil specimen.

2. The determination of the soil water characteristic curves for different sand-kaolin mixtures provides a base to test the shear strength of unsaturated sand-kaolin mixture under plane-strain conditions.

3. An extended experimental program on model footing with different depths (different $\mathrm{d} / \mathrm{B}$ ratios) and different shapes (i.e., square, rectangle, circular) can be performed to establish a new approach to determine the bearing capacity of footings on unsaturated soil. 


\section{REFERENCES}

Adachi, T., Oka, F., and Yashima, A. (eds.) (1998) Localization and Bifurcation Theory for Soils and Rocks, Balkema: Rotterdam.

Agus, S. S. (2005) An experimental study on hydro-mechanical characteristics of compacted bentonite-sand mixtures, $\mathrm{PhD}$ Thesis, Bauhaus-University Weimar, Germany.

Agus, S. S. and Schanz, T. (2003) Vapour equilibrium technique for tests on a highly compacted bentonite-sand mixture, In Proceedings of the International Conference on Problematic Soils, Nottingham, United Kingdom, pp. 467-474.

Agus, S. S., Leong, E. C., and Rahardjo, H. (2001) Soil-water characteristic curve of Singapore residual soils, Geotechnical and Geological Engineering, Vol. 19, pp. 285309.

Agus, S. S., Leong, E. C., and Rahardjo, H. (2003) A flexible wall permeameter for measurements of water and air coefficients of permeability of residual soils, Can. Geotech. J., 40, pp. 559-574.

Aitchison, G. D. (1965) Moisture Equilibria and moisture changes in soils beneath covered areas, Atichison, G. D., Ed., Australia: Butterworths, 1965, 278 pp.

Aitchison, G. D. (1973) The quantitative description of the stress deformation behavior of expansive soils, in Proc. $3^{\text {rd }}$ Int. Conf. Expansive Soils, Vol. 2, pp. 79-82.

Allersma, H. G. B. (1987) Optical analysis of stress and strain in photoelastic particle assemblies, PhD Thesis, Delft University of Technology, the Netherlands.

Allersma, H. G. B. (1993) New design of a biaxial apparatus for soft soil, Delft university of technology, Report No. 354.

Alshibli, K. A. and Akbas, I. S. (2007) Strain localization in clay: plane strain versus triaxial loading conditions, Geotech. Geol. Eng., 25, pp. 45-55.

Alshibli, K. A. and Hasan, A. (2008) Spatial variation of void ratio and shear band thickness in sand using X-ray computed tomography, Géotechnique, Vol. 58, No. 4, pp. 249-257.

Alshibli, K. A. and Sture, S. (1999) Sand shear band thickness measurements by digital imaging techniques, Journal of Computing in Civil Engineering, Vol. 13, No. 2, April, pp. 103-109. 
Alshibli, K. A. and Sture, S. (2000) Shear band formation in plane strain experimentations of sand, Journal of Geotechnical and Geoenvironmental Engineering, Vol. 126, No. 6, June, pp. 495-503.

Alshibli, K. A., Alsaleh, M. I., and Voyiadjis, G. Z. (2006) Modeling strain localization in granular materials using micropolar theory: numerical implementation and verification. Int. J. Numer. Anal. Methods Geomech. 30, No. 15, pp.1525-1544.

Alshibli, K. A., Godbold, D. L., and Hoffman, K. (2004) The Louisiana Plane Strain Apparatus for Soil Testing, Geotechnical Testing Journal, Vol. 27, No. 4, pp. 337-346.

Amat, A. (2007) Elastic stiffness moduli of Hostun sand, Master Thesis, Department of Civil Engineering, University of Bristol.

Arifin, Y. F. (2008) Thermo-hydro-mechanical behavior of compacted bentonite-sand mixtures: an experimental study, PhD Thesis, Bauhaus-Universität Weimar, Germany.

Arifin, Y. F. and Schanz, T. (2009) Osmotic suction of highly plastic clays, Acta Geotechnica, 4 (3), pp. 177-191.

Arthur, J. R. F., Chua, K. S., and Dunstan, T. (1977) Induced anisotropy in a sand, Géotechnique, Vol. 27, No. 1, pp. 13-30.

Arthur, J. R. F., Dunstan, T., Al-Ani, Q. A. J., and Assadi, A. (1977a) Plastic deformation and failure in granular media, Géotechnique, 27, pp. 53-74.

ASTM (1997) Annual Book of Standards, Volumes 04.08 and 04.09, Soil and rock, ASTM International, West Conshohocken. PA.

Aversa, S. and Nicotera, M. V. (2002) A triaxial and oedometer apparatus for testing unsaturated soils, Geotechnical Testing Journal, Vol. 25, No. 1, pp. 3-15.

Banimahd, M. and Woodward, P. K. (2006) Load-displacement and bearing capacity of foundations on granular soils using a multi-surface kinematic constitutive soil model, Int J. Numer. Anal. Methods Geomech, Wiley 30, pp. 865-886.

Bao, C., Gong, B., and Zhan, L. (1998) Properties of unsaturated soils and slope stability of expansive soils, Keynote Lecture, Proceedings of the 2nd International Conference on Unsaturated Soils (UNSAT 98), Beijing, China, 1, pp. 71-98.

Barden, L., Ismail, H., and Tong, P. (1969) Plane strain deformation of granular material at low and high pressures, Géotechnique, Vol. 9, No. 4, pp. 441-452.

Bardet, J. P. (1991) Orientation of Shear Bands in Frictional Soils, Journal of Engineering Mechanics, Vol. 117, No. 7, July, pp. 1466-1484. 
Batiste, S. N., Alshibli, K. A., Sture, S., and Lankton, M. (2004) Shear band characterization of triaxial sand specimens using computed tomography, Geotechnical Test. J. 27, No. 6, pp. 568-579.

Been, K., Jefferies, M. G., and Hachey, J. (1991) The critical state of sands, Géotechnique 41, No. 3, pp. 365-381.

Berardi, R. and Lancellotta, R. (1994) Prediction of settlements of footings on sand: accuracy and reliability, Proceedings of Settlement, 94, 1, pp. 640-651.

Billam, J. (1971) Some aspects of the behavior of granular materials at high pressures. In: Parry, R. H. G., Editor, 1971, Stress-strain behavior of soils, Proc. Roscoe Memorial Symposium, pp. 69-80.

Bishop, A. W. (1955) The use of the slip circle in the stability of slopes, Géotechnique, Vol. 5, No. 1, pp. 7-17.

Bishop, A. W. (1959) The principle of effective stress. Lecture delivered in Oslo, Norway, in 1955, published in Teknisk Ukeblad, Vol. 106, No. 39, pp. 859-863.

Bishop, A. W. (1966) The strength of soil as engineering materials, Sixth Rankine lecture, Géotechnique, Vol.16, No.2, pp. 91-130.

Bishop, A. W. and Donald, I. B. (1961) The experimental study of partly saturated soils in the triaxial apparatus, Proceedings, Fifth International Conference on Soil Mechanics and Foundation Engineering, Paris, Vol. 1, pp. 13-21.

Bishop, A. W., Alpan, I., Blight, G. E., and Donald, I. B. (1960) Factors Controlling the Shear Strength of Partly Saturated Cohesive Soils, in ASCE Res. Conf Shear Strength of Cohesive Soils (Univ. of Colorado, Boulder), pp. 503-532.

Bizzarri, A. and Allersma, H. G. B. (1998) Creep tests on reconstructed soft clay, performed by means of a biaxial device, Int. Symp. on Problematic Soils, Oct. 28-30, Sendai, Japan, pp. 645-648.

Bizzarri, A. and Allersma, H. G. B. (2003) Creep tests on reconstituted soft clay performed by means of a biaxial, Int. Workshop on Geotechnics of Soft Soil; Theory and Practice, 17-19 September, Noordwijkerhout, Netherlands, pp. 391-396.

Bizzarri, A., Allersma, H. G. B., and Koehorst, B. A. N (1995) Preliminary tests on soft clay with a biaxial apparatus, Int. Symp. On Compression and Consolidation of Clayey Soils, Hiroshima, A. A. Balkema, Rotterdam, pp. 27-32.

Blatz, J. A. and Graham, J. (2003) Elastic-plastic modeling of unsaturated soil using results from a new triaxial test with controlled suction, Géotechnique, Vol. 53, No. 1, pp. 113-122. 
Bolt, G. H. and Miller, R. D. (1958) Calculation of total and component potentials of water in soils, American Geophysicist Union Transportaion, 39, pp. 917-928.

Bolton, M. D. (1986) The strength and dilatancy of sands, Géotechnique, Vol. 36, No.1, pp. 65-78.

Bouferra, R., Benseddiq, N., and Shahrour, I. (2007) Saturation and Preloading Effects on the Cyclic Behavior of Sand, International Journal of Geomechanics, Vol. 7, No. 5, October 1, pp. 396-401.

Buckingham, E. (1907) Studies of the movement of soil moisture, USDA Bureau of Soils Bulletin, 38 .

Calvetti, F., Combe, G., and Lanier, J. (1997) Experimental micro-mechanical analysis of a 2D granular material: relation between structure evolution and loading path, Mechanics of Cohesive-frictional Materials, Vol. 2, pp. 121-163.

Campanella, R. G. and Vaid, Y. P. (1973) Influence of Stress Path on the Plane Strain Behaviour of a Sensitive Clay, 8th International Conference on Soil Mechanics and Foundation Engineering, Moscow, USSR, August, Vol. 1, pp. 85-92.

Chambon, R., Desrues, J., and Vardoulakis, I. (eds) (1994) Localisation and Bifurcation Theory for Soils and Rocks, Balkema.

Charlier, R., Chambon, R., Desrues, J., Hammad, W.(1991) shear band bifurcation in soil modelling: a rate type constitutive law for explicit localization, third int. conf. on Constitutive laws for Engng Materials, Tucson ,ed. Desai, .S. and Krempl, E. ,ASME press ,pp. 399-402.

Chiu, T.-F. and Shackelford, C. D. (1998) Unsaturated hydraulic conductivity of compacted sand-kaolin mixtures, J. Geotech. and Geoenvir. Engrg., Vol. 124, Issue 2, pp. 160-170.

Cliffton, A. W., Wilson, G. W., and Barbour, S. L. (1999) The Emergence of Unsaturated Soil Mechanics, Fredlund Volume, NRC Research Press (Ottawa).

Cornforth, D. H. (1961) Plane strain failure characteristics of a saturated sand, PhD Thesis, London.

Cornforth, D. H. (1964) Some Experiments on the Influence of Strain Conditions on the Strength of Sand, Géotechnique, Vol. 14, No. 2, pp. 143-167.

Cornforth, D. H. (1973) Prediction of drained strength of sands from relative density measurements, In Evaluation of relative density and its role in geotechnical projects involving cohesionless soils, ASTM Spec. Tech. Publ., 523, ASTM, pp. 281-303. 
Coulomb, C. A. (1776) Essai sur une application des régles de maximis et minimis á quelques problémes de statique, relatifs a Iárchitecture. Mém. de Math. et de Physic. Acad. Roy. des Sciences. Paris 7, pp. 343-382.

Coumoulos, D. G. (1968) A radiographic study of soils, PhD Thesis, University of Cambridge.

Craig, R. F. (1997) Soil Mechanics, 6th Edition, Spon Press.

Croney, D., Coleman, J. D., and Black, W. P. M. (1958) Movement and distribution of water in soil in relation to highway design and performance, Water and Its Conduction in Soils, Highway Res. Board, Special Report, Washington, DC, No. 40, pp. 226-252.

Croney, D., Coleman, J. D., and Bridge, P., (1952) The suction of moisture held in soil and other porous materials, Road Research Technical Paper, 24.

Cui, Y. J. and Delage, P. (1996) Yielding and plastic behaviour of an unsaturated silt, Géotechnique 46, No. 2, pp. 291-311.

Cui, Y. J., Tanga, A. M., Loiseaua, C., and Delagea, P. (2008) Determining the unsaturated hydraulic conductivity of a compacted sand-bentonite mixture under constant-volume and free-swell conditions, Physics and Chemistry of the Earth, Parts A/B/C, Volume 33, Supplement 1, pp. 462-471.

Cui, Y.-J., Tang, A.-M., Marcial, D., Terpereau, J.-M., Marchadier, G., and Boulay, X. (2007) Use of a Differential Pressure Transducer for the Monitoring of Soil Volume Change in Cyclic Triaxial Test on Unsaturated Soils, Geotechnical Testing Journal, Vol. 30, No. 3, pp. 227-233.

Cuisinier, O. and Masrouri, F. (2002) Influence of a suction cycle on the hydromechanical behaviour of a swelling soil, In Proceeding of the International Workshop on Environmental Geomechanics, Monte Verità, Switzerland (Eds. L. Vulliet, L. Laloui and B. Schrefler), EPFL Press, Lausanne, pp. 175-180.

Daehyeon, K., Myung, S., and Younghee, L. (2005) Effects of fine aggregate content on the mechanical properties of the compacted decomposed granitic soils, J. of Construction and Building Materials, No. 19, pp. 189-196.

Dantu, P. (1967) Ann. Ponts et Chaussées, IV.

Das, B. M. and Omar, M. T. (1994) The effects of foundation width on model tests for the bearing capacity of sand with geogrid reinforcement, Geotech. Geol. Eng., 12, pp. 133141.

De Beer, E. E. (1963) The scale effect in transposition of the results of deep sounding tests on the ultimate bearing capacity of piles and caisson foundations, Géotechnique, 13,1, pp. 39-75. 
De Beer, E. E. (1965) Bearing capacity and settlement of shallow foundations on sand Proc., Bearing Capacity and Settlement of Foundations Symp., Duke University, Durham, pp. 15-34.

De Beer, E. E. (1970) Experimental determination of the shape factors and bearing capacity factors of sand, Géotechnique, Vol. 20, No. 4, pp. 387-411.

De Gennaro, V., Canou, J., Dupla, J. C., and Benahmed, N. (2004) Influence of loading path on the undrained behaviour of a medium loose sand, Can. Geotech. J., 41, pp. 166-180.

Dembicki, E., Gudehus, G., and Sikora, Z. (eds) (1989) Numerical Methods for Localization and Bifurcation of Granular Bodies, Geotechnical Department, Technical University of Gdansk.

Desrues, J. (1984) La localisation de la déformation dans les matériaux granulaires, Thése de Doctorat es Science, USMG and INPG, Grenoble, France.

Desrues, J. (1995) Experimental strain localisation in plane strain tests on sands and weak rocks, in: Dynamic Plasticity and Structural Behaviors, Plasticity'95, Osaka S. Tanimura and A.S. Khan Ed., Gordon and Breach Publ., pp. 415-418.

Desrues, J. (1998) Localisation Patterns in Ductile and Brittle Geomaterials, Material Instabilities in Solids, edited by R. Borst and E. Giessen , John Wiley and Sons Ltd., pp. 137-158.

Desrues, J. and Hammad, W. (1989) Shear banding dependency on mean stress level in sand, international workshop "Numerical Methods For Localization And Bifurcation Of Granular Bodies” Gdansk-Karlsruhe September 25-30, pp. 57-67.

Desrues, J. and Mokni, M. (1999) Strain localization measurement in undrained planestrain biaxial tests on Hostun RF sand, Mech.Cohes.-Frict. Mater., 4, pp. 419-441.

Desrues, J., and Viggiani, G. (2004) Strain localization in sand: an overview of the experimental results obtained in Grenoble using stereophotogrammetry, Int. Journal for Numerical and Analytical methods in Geomechanics vol.28 No 4, pp. 279-321.

Desrues, J., Chambon, M., Mokni, M., and Mazerolle, F. (1996) Void ratio evolution inside shear bands in triaxial sand specimens studied by computed tomography, Géotechnique, 46, No. 3, pp. 1-18.

Desrues, L., Lanier, L., and Stutz, P. (1985) Localization of the deformation in tests on sand sample, Eng. Fracture Mechanics, 21, pp. 909-921.

Di prisco, C. and Imposimato, S. (1996) Time dependent mechanical behaviour of loose sands, Mechanics of Cohesive-Frictional Materials, Vol. 1, pp. 45-73. 
DIN (1987) Baugrund und Grundwasser. Benenen und Beschreiben von Boden und Fels. Deustche Institut für Normung e.V., Beuth Verlag, Berlin.

Donald, I. B. (1956) Shear Strength Measurements in Unsaturated Non-Cohesive Soils with Negative Pore Pressures, Proc. 2nd Australia-New Zealand Conf. on Soil Mechanics and Foundation Engineering, Christchurch, pp. 200-205.

Drescher, A., Vardoulakis, I. G., and Han, C. (1990) A Biaxial Apparatus for Testing Soils, Geotech. Test. J., Vol. 13, No. 3, pp. 226-234.

Duncan, J. and Seed, H. B. (1966) Strength variation along failure surfaces in clay, Proc. Am. Soc. Civ. Engrs 94, SM6, pp. 81-104.

Edlefsen, N. E. and Anderson, A. B. C. (1943) Thermodynamics of soil moisture. Hilgardia, 15, pp. 31-298.

Escario, V. and Juca, J. (1989) Shear strength and deformation of partly saturated soils Proceedings of the 12th International Conference on Soil Mechanics and Foundation Engineering, Rio de Janerio, 2, pp. 43-46.

Farouk, A., Lamboj, L., and Kos, J. (2004) Influence of Matric Suction on the Shear Strength Behaviour of Unsaturated Sand, Acta Polytechnica, Vol. 44, No. 4, pp. 11-17.

Fauziah, M. and Nikraz, H. R. (2007) Biaxial Testing of Overconsolidated Clay, The $1^{\text {st }}$ International Conference of European Asian Civil Engineering Forum (EACEF), 26-27 September, Jakarta, Indonesia, pp. A60-A66.

Fauziah, M. and Nikraz, H. R. (2007a) Stress-Strain Behaviour of Overconsolidated Clay Under Plane Strain Condition, $10^{\text {th }}$ Australia New Zealand Conference on Geomechanics, Brisbane, 21-24 October, Vol. 1.

Fauziah, M. and Nikraz, H. R. (2008) The behaviour of unsaturated compacted clay under plane strain condition, $3^{\text {rd }}$ International Conference on Evaluation, Monitoring, Simulation, Management and Remediation of the Geological Environment and Landscape, The New Forest, Ashurst Lodge, UK., pp. 77-86.

Finno, R. J. and Rechenmacher, A. L. (2003) Effects of Consolidation History on Critical State of Sand, J. Geotech. Geoenviron.Eng., Vol. 129, No. 4, pp. 350-360.

Finno, R. J. and Rhee, Y. (1993) Consolidation, pre- and postpeak shearing responses from internally instrumented biaxial compression device, ASTM, Geotechnical Testing J., 16 (4), pp. 496-509.

Finno, R. J., Harris, W. W., Mooney, M. A. and Viggiani, G. (1996) Strain Localization and Undrained Steady State of Sand, J. Geotech. Eng., Vol. 122, No. 6, pp. 462-473. 
Finno, R. J., Harris, W. W., Mooney, M. A., and Viggiani, G. (1997) Shear Bands in Plane Strain Compression of Loose Sand, Géotechnique, Vol. 47, No. 1, pp. 149-165.

Flavigny, E., Desrues, J., and Palayer, B. (1990) Note technique: Le sable d'Hostun RF, Rev. Fran. C.Geotech 53, pp. 67-70

Förster, W. (1998) Bodenmechanik, Teubner Verlag.

Fredlund, D. G. and Morgenstern, N. R. (1977) Stress state variables for unsaturated soils. Journal of the Soil Mechanics and Foundations Division, 103, pp. 447-466.

Fredlund, D. G. and Rahardjo, H. (1993) Soil Mechanics for Unsaturated Soils, John Wiley \& Sons.

Fredlund, D. G. and Xing, A. (1994) Equations for the soil-water characteristic curve, Canadian Geotechnical Journal, Vol. 31, pp. 521-532.

Fredlund, D. G., Morgenstem, N. R., and Widger, R. A. (1978) The Shear Strength of Unsaturated Soils, Can. Geotech. J., Vol. 15, No. 3, pp. 313-321.

Fredlund, D. G., Xing, A., Fredlund, M. D., and Barbour, S. L. (1996) The relationship of the unsaturated soil shear strength to the soil-water characteristic curve, Can. Geotech. J., 33, 3, pp. 440-448.

Fung, Y. C. (1977) A first course in continuum mechanics, 2nd ed. Englewood Cliffs.

Gachet, P., Klubertanz, G., Vulliet, L., and Laloui, L. (2003) Interfacial behaviour of unsaturated soil with small-scale models and use of image processing techniques, Geotech Testing Journal, 26(1), pp. 12-21.

Gan, J. K. M. and Fredlund, D. G. (1996) Shear strength characteristics of two saprolitic soils, Can. Geotech. J., 33, pp. 595-609.

Gan, J. K. M., Fredlund, D. G., and Rahardjo, H. (1988) Determination of the Shear Strength Parameters of an Unsaturated Soil Using the Direct Shear Test, Can. Geotech. J., Vol. 25, No. 3, pp. 500-510.

Geiser, F., Laloui, L., and Vulliet, L. (2000) On the volume measurement in unsaturated triaxial test, Proc., The Asian Conference on Unsaturated Soil, pp. 669-679.

Georgiadis, K., Potts, D. M., and Zdravkovic, L. (2004) Modelling the shear strength of soils in the general stress space, Computers and Geotechnics, 31, pp. 357-364.

Ghahremani, M., Ghalandarzadeh, A., Nowamooz, H., and Ghahremani, K. (2007) the undrained behavior of clayey sands, $60^{\text {th }}$ Canadian Geotechnical Conference, Octobre 24-27, Ottawa, Canada. 
Golder, H. Q. (1941) The ultimate bearing pressure of rectangular footings, J. Instn. of Civ. Engrs., 17, pp. 161-174.

Green, G. E. (1971) Strength and Deformation of Sand Measured in an Independent Stress Control Cell, Proceedings of the Roscoe Memorial Symposium: "Stress-Strain Behavior of Soils," Cambridge University, pp. 285-323.

Gudehus, G. and Nübel, K. (2004) Evolution of shear bands in sand, Géotechnique, Vol. 54, No. 3, pp. 187-201.

Hadamard, J. (1930) Lecons sur la propagation des ondes et les equations de l'hydrodynamique, Librarie scientifique, A. Hennann, Paris, France (in French).

Haines, W. B. (1930) The hysteresis effect in capillary properties and the modes of moisture distribution associated therewith, Journal of Agricultural Science, Vol. 20, pp. 96-105.

Hambly, E. C. (1969) Plane Strain Behavior of Soft clay, PhD Thesis, University of Cambridge, UK.

Hambly, E. C. (1972) Plane strain behaviour of remoulded normally consolidated Kaolin, Géotechnique, 22, pp. 301-317.

Hambly, E. C. and Roscoe, K. H. (1969) Observations and predictions of stresses and strains during plane strain of wet clays, Proc. $7^{\text {th }}$ Int. Conf., Mexico, 1, pp. 173-181.

Hammad, W. (1991) Modélisation non linéaire et tude expérimentale des bandes de cisaillement dans les sables, Thése de Doctorat de l'Université J. Fourier, Grenoble, France.

Han, C. (1991) Localization of deformation in sand, PhD thesis, University of Minnesota.

Han, C. and Drescher, A. (1993) Shear bands in biaxial tests on dry coarse sand, Soils and Foundations, Japanese Society of Soil Mechanics and Foundation Engineering, Vol. 33, No. 1, pp. 118-132.

Han, C. and Vardoulakis, I. G. (1991) Plane-Strain Compression Experiments on WaterSaturated Fine-Grained Sand, Géotechnique, Vol. 41, No. 1, pp. 49-78.

Hanna, A. (2001) Determination of plane-strain shear strength of sand from the results of triaxial tests, Can. Geotech. J., 38, pp. 1231-1240.

Hansen, B. (1958) Line ruptures regarded as narrow rupture zones: Basic equations based on kinematic considerations, in Conf. Earth Pressure Problems, Brussels, Belgium, 1, pp. 39-49.

Harris, W. W. (1994) Localization of loose granular soils and its effect on undrained steady state strength, $\mathrm{PhD}$ dissertation, Northwestern University. 
Harris, W. W., Viggiani, G., Mooney, M. A., and Finno R. J. (1995) Use of stereophotogrammetry to analyze the development of shear bands in sand, Geotechnical Testing Journal, Vol. 18, No. 4, pp. 405-420.

Hayashi, Y. and Allersma, H. G. B. (2004) Plane strain shear behaviour of flowable cement treated soil, Int. Conference on Engineering practice and performance of soft deposits, Osaka, June 2-4, pp. 201-204.

Head, K. H. (1986) Manual of soil laboratory testing, Vol. 3, London: Pentech Press.

Hilf, J. W. (1956) An Investigation of Pore-Water Pressure in Compacted Cohesive Soils, PhD Thesis, Tech. Memo. No. 654, U.S. Dep. of the Interior, Bureau of Reclamation, Design and Construction Div., Denver, CO, 654 pp.

Hill, R. (1962) Accelerations waves in solids, J. Mech. and Physics of Solids, 10, pp. 1-6.

Hill, R. and Hutchinson, R. W. (1974) Bifurcation phenomena in the plane tension test, J. Mech. and Physics of Solids, 23, pp. 239-264.

Hird, C. C. and Hajj, A. R. (1995) A simulation of tube sampling effects on the stiffness of clays, Geotechnical Testing Journal, 18(1), pp. 3-14.

Hoyos, L. R., Laloui, L., and Vassallo, R. (2008) Mechanical Testing in Unsaturated Soils, Geotech. Geol. Eng., 26, pp.675-689.

Ishihara, K. (1993) Liquefaction of natural deposits during earthquakes, Proc. $11^{\text {th }}$ Int. Conf. on Soil Mechanics and Foundation Engineering, San Francisco, 1, pp. 321-376.

Jeyapalan, J. K. and Boehm, R. (1986) Procedures for predicting settlements in sands. In Settlements of shallow foundations on cohesionless soils: design and performance, (ed. Martin, W. O.), Seattle, ASCE, pp. 1-22.

Khallili, N. and Khabbaz, M. H. (1998) A unique relationship for the determination of the shear strength of unsaturated soils, Géotechnique, 48(5), pp. 681-687.

Ko, H.-Y. and Davidson, L. W. (1973) Bearing capacity of footings in plane strain. J. Soil Mech. and Found, Div., ASCE, 99 (1), pp. 1-23.

Krahn, J., Fredlund, D. G., Lam, L., and Barbour, S. L. (1987) PCSEEP: A Finite Element Program for Modeling Seepage, Proc. of the 1st Canadian Symposium on Microcomputer Applications to Géotechnique (Regina, Canada), October 22-23, pp. 243-251.

Kumar, J. and Bhoi, M. K. (2009) Interference of Two Closely Spaced Strip Footings on Sand Using Model Tests, Journal of Geotechnical and Geoenvironmental Engineering, Vol. 135, No. 4, April 1, pp. 595-604. 
Kumar, J. and Khatri, V. N. (2008) Effect of Footing Width on Bearing Capacity Factor $\mathrm{N} \gamma$ for Smooth Strip Footings Journal of Geotechnical and Geoenvironmental Engineering, Vol. 134, No. 9, September 1, pp. 1299-1310.

Kuntsche, K. (1982) Materialverhalten von wassergesaettigtem Ton bei ebenen und zylindrischen Verformungen, Publications of the Institute of Soil and Rock Mechanics in Karlsruhe, No. 91.

Kusakabe, O., Maeda, Y., and Ohuchi, M. (1992) Large-scale loading tests of shallow footings in pneumatic caisson, J. Geotech. Engrg., ASCE, 118, 11, pp. 1681-1695.

Kusakabe, O., Yamaguchi, H., and Morikage, A. (1991) Experiment and analysis on the scale effect of $\mathrm{N}_{\gamma}$ for circular and rectangular footings, Proc., Int. Conf. Centrifuge '91, Balkema, Rotterdam, the Netherlands, pp. 179-186.

Kutter, B. L., Abghari, A., and Cheney, J. A. (1988) Strength parameters for bearing capacity of sand, Journal of Geotechnical Engineering, Vol. 114, No. 4, April, pp. 491498.

Labuz, J. and Drescher, A. (eds) (2003) Bifurcations and Instabilities in Geomechanics, Swets and Zeitlinger.

Lade, P. V. and Duncan, J. M., (1975) Elastoplastic Stress-Strain Theory for Cohesionless Soil," J. Geotechnical Engineering Division, ASCE, New York, Vol. 101, pp. 10371053.

Laloui, L., Péron, H., Geiser, F., Rifai, A., and Vulliet, L. (2006) Advances in volume measurement in unsaturated triaxial tests, Soils and Foundation, 46(3), pp. 341-349.

Lambe, T. W. and Whitman, R. V. (1979) Soil Mechanics (SI Version), John Wiley: New York.

Lancelot, L., Shahrour, I., and Al Mahmoud, M. (2006) Failure and dilatancy properties of sand at relatively low stresses, Journal of engineering mechanics, December, pp. 1396-1399.

Lee, K. L. (1970) Comparison of Plane Strain and Triaxial Tests on Sand, J. Soil Mech. Found. Div., Vol. 96, No. 3, pp. 901-923.

Lee, K. L. and Seed, H. B. (1967) Drained strength characteristics of sand, J. Soil Mech. Found. Div. ASCE 93, No. 6, pp. 117-141.

Leong, E. C., Agus, S. S., and Rhardjo, H. (2003) Volume change measurement of soil specimen in triaxial test, Geotechnical Testing Journal, Vol. 27, No.1, pp. 47-66. 
Leussink, H. and Wittke, W. (1963) Difference in Triaxial and Plain Strain Shear Strength, symposium, National Research Council of Canada and the American Society for Testing and Materials, Ottawa, Canada, Sept. 9.

Lins, Y. and Schanz, T. (2003) Determination of hydro-mechanical Properties of Sand. 1 st Int. Conf. Mechanics of Unsaturated Soil, $7^{\text {th }}-9^{\text {th }}$ March, Germany

Lins, Y., Schanz, T., and Fredlund, D. G. (2009) Modified Pressure Plate Apparatus and Column Testing Device for Measuring SWCC of Sand, Geotechnical Testing Journal, Vol. 32, No. 5, pp. 1-15.

Little, A. L. and Price, V. E. (1958) The use of an electric computer for slope stability analysis, Géotechnique, Vol. 8, No. 3, pp. 113-1 20.

Lloret, A., Villar, M. V., Sánchez, M., Gens, A., Pintado, X., and Alonso, E. E. (2003) Mechanical behaviour of heavily compacted bentonite under high suction changes, Géotechnique, Vol. 53, No. 1, pp. 27-40.

Lo, K. L. and Roy, M. (1973) Response of particulate materials at high pressures, Soils and Foundations, Vol. 13, No.1, pp. 61-76.

Lo, K. W., Mita, K. A., and Thangayah, T. (2000) plane strain testing of overconsolidated clay, international conference on geotechnical and geological engineering, 19-24 Nov., Melbourne, Australia.

Lu, N. and Likos, W. J. (2004) Unsaturated Soil Mechanics, John Wiley \& Sons, New Jersey.

Macari, E. J., Parker, J. K., and Costes, N. C. (1997) Measurement of volume changes in triaxial tests using digital imaging techniques, Geotechnical Testing Journal, 20(1), pp. 103-109.

Mandel, J. (1965) Generalization de la theorie de la plasticite de Koiter, International Journal of Solids and structures, 1, pp. 273-295 (in French).

Marachi, N., Duncan, J., Chan, C., and Seed, H. (1981) Plane-strain testing of sand, Laboratory shear strength of soils, ASTM STP 740, R. N. Yong, and F. C. Townsend, eds., ASTM, pp. 294-302.

Marinho, F. A. M. (2005) Nature of Soil-Water Characteristic Curve for Plastic Soils, J. Geotechnical and Geoenviromental Engineering, Vol. 131, No. 5, pp. 654-661.

Masuda, T., Tatsuoka, F., Yamada, S., and Sato, T. (1999) Stress-strain behaviour of sand in plane strain compression, extension and cyclic loading tests, Soils and Foundations, 39, 5, pp. 31-45. 
Matyas, E. L. and Radhakrishna, H. S. (1968) Volume Change Characteristics of Partially Saturated Soils, Géotechnique, Vol. 18, pp. 432-448.

Meyerhof, G. G. (1963) Some recent research on the bearing capacity of foundations, Can. Geotech. J., Ottawa, 1(1), pp. 16-26.

Miura, N. and Yamanouchi, T. (1973) Compressibility and drained shear characteristics of a sand under high confining pressures, Technology reports of the Yamaguchi University 1(2), pp. 271-290.

Mochizuki, A., Min, C., and Takahashi, S. (1993) Method for plane strain testing of sand, Proceedings of the Japan Society of Civil Engineers, No. 475, 3-24 Sep., pp. 99-107.

Mokni, M. (1992) Relations entre déformations en masse et déformations localisées dans les matériaux granulaires, Thése de Doctorat de l'Université J. Fourier, Grenoble, France.

Mokni, M. and Desrues, J. (1999) Strain localization measurements in undrained planestrain biaxial tests on Huston RF sand, Mechanics of Cohesive-Frictional Materials, 4, pp. 419-441.

Molenkamp, F. (1985) Comparison of frictional material models with respect to shear and initiation, Géotechnique, Vol. 35, No. 2, pp. 127-143.

Montañes, J. E. C. (2002) Suction and volume changes of compacted sand-bentonite mixtures, $\mathrm{PhD}$ thesis, University of London, $\mathrm{UK}$.

Mooney, M. A., Viggiani, G., and Finno, R. J. (1997) Undrained shear band deformation in Granular media, Journal of Engineering Mechanics, Vol. 123, No.6, pp. 577- 585.

Muehlhaus, H. B. and Vardoulakis, I. (1987) The thickness of shear bands in granular materials, Géotechnique, Vol. 37, No. 3, pp. 271-283.

Muehlhaus, H.-B., Dyskin, A., and Pasternak, E. (eds.) (2001) Bifurcation and Localisation Theory in Geomechanics, Swets and Zeitlinger.

Muhs, E. (1963) Ueber die Zulaessige Belastung nichtibindiger Boeden, Mitteilungen der Deutschen Forschungsgesellshaft Fuer Bodenmechanik (Degebo), Berlin, Heft 16, pp.102-121 (in German).

Nakai, Matsuoka, T. H., Okuno, M., and Tsuzuki, K. (1986) True triaxial tests on norma11y consolidated clay and analysis of the observed shear behavior using elastoplastic constitutive models, Soils and Foundations, 26(4), pp. 67-78.

Nakai, T. (2007) Modeling of soils behavior based on tij concept, Proc. of 13th Asian regional Conference on Soil Mechnics and Geotechnical Engineering, Kolkata, (Keynote paper), 2, pp. 69-89. 
Ng, C. W. W. and Chiu, A. C. F. (2003) Laboratory Study of Loose Saturated and Unsaturated Decomposed Granitic Soil, Journal of Geotechnical and Geoenvironmental Engineering, Vol. 129, No. 6, pp. 550-559.

Ng, C. W. W. and Zhou, R. Z. B. (2005) Effect of soil suction on dilatancy of an unsaturated soil, Proc. $16^{\text {th }}$ int. conf. of soil mech. Geotech. Eng., Osaka, Japan, Vol. 2, pp. 559-562.

Ng, C. W. W., Zhan, L. T., and Cui, Y. J. (2002) A new simple system for measuring volume changes in unsaturated soils, Canadian Geotechnical Jour., Vol. 39, pp. 757764.

Nicot, F., Sibille, L., Donzé, F., and Darve, F. (2005) Micro-mechanical interpretation of instability in granular materials, 7th International Workshop on Bifurcation, Instabilities and Degradation in Geomechanics, Chania.

Nishimura, T. and Fredlund, D. G. (2000) Relationship between shear strength and matric suction in an unsaturated silty soil,Asian Conference on Unsaturated Soils from theory to practice 18-19 may, Singapore., pp. 536-568.

Oberg, A. and Sallfors, G. (1997) Determination of shear strength parameters of nsaturated silts and sands based on the water retention curve, Geotechnical Testing Journal, GTJ, 20(1), pp. 40-48.

Oda, M. and Iwashita, K. (2000) Study on couple stress and shear band development in granular media based on numerical simulation analyses, International Journal of Engineering Science 38, pp. 1713-1740.

Oda, M. and Iwashita, K. (Eds.) (1999) Mechanics of granular materials: an introduction, Balkema.

Oda, M. and Kazama, H. (1998) Microstructure of shear bands and its relation to the mechanisms of dilatancy and failure of dense granular soils, Géotechnique, Vol. 48, No. 4, pp. 465-481.

Oda, M., Koshikawa, I., and Higuchi, T., (1978) Experimental study of anisotropic shear strength of sand by plane strain test, Soils and Foundations, 18(1), pp. 25-38.

Oger, L. (1987) Etude des corrélations structure-propriétés dans les milieux granulaires modkles, Thése de Doctorat es Sciences, Université de Rennes, France.

Ovesen, N. K. (1975) Centrifugal testing applied to bearing capacity problems of footings on sand, Géotechnique, Vol. 25, No. 2, pp. 394-401.

Papamichos, E. and Vardoulakis, I. G. (1995) Shear band formation in sand according to non-coaxial plasticity model, Géotechnique, Vol. 45, No. 4, pp. 649-661. 
Park, C. -S. and Tatsuoka, F. (1994) Anisotropic strength and deformations of sands in plane strain compression, Proc. of the 13th Int. Conf. on S.M.F.F., New Delhi, 1, pp. $1-4$.

Penman, A. D. M. (1956) A field piezometer apparatus, Géotechnique, Vol. 6, No. 2, pp. 57-65.

Peric, D. (1990) Localized deformation and failure analysis of pressure sensitive granular materials, PhD Thesis, University of Colorado.

Peric, D., Runesson, K., and Sture, S. (1992) Evaluation of plastic bifurcation for plane strain versus axisymmetry. J. Engrg. Mech., ASCE, 118, 3, pp. 512-524.

Perkins, S. W. and Madson, C.R. (2000) Bearing capacity of shallow foundations on sand: a relative density approach, Journal of Geotechnical and Geoenvironmental Engineering, Vol. 126, No. 6, pp. 521-530.

Peters, J., Lade, P., and Bro, A. (1988). Shear band formation in triaxial and plane strain tests, Advanced triaxial testing of soil and rock, ASTM STP 977, R. Donaghe, R. Chaney, and M. Silver, eds., ASTM, West Conshohocken, Pa., pp. 604-627.

Poulos, S. J., Castro, G., and France, J. W. (1985) Liquefaction Evaluation Procedure, J. Geotechnical Engineering, ASCE, 111 (6), pp. 772-791.

Pusch, R. and Yong, R. (2003) Water saturation and retention of hydrophilic clay buffer microstuctural aspects, Applied Clay Science, Elsevier, 23, pp. 61-68.

Rampino, C., Mancuso, C., and Vinale, F. (1999) Laboratory testing on an unsaturated soil:Equipment,Procedures, and First experimental Results, Canadian Geotechnical Journal, Vol. 36, pp. 1-12.

Reynolds, O. (1885) On the dilatancy of media composed of rigid particles in contact, with experimental illustrations, Phil. Mag., Series 5, 20, pp. 469-481.

Rice, J. R. (1976) The localization of plastic deformation, Proc. 14th Int. Congress on Theoretical and Applied Mech., Deift, the Netherlands, W. T. Koiter, ed., 1, pp. 207220.

Rice, J. R. and Rudnicki, J. W. (1980) A note on some features of the theory of localization of deformation, Int. J. Solids and Struct., 16, pp. 597-605.

Richards, B. G. (1966) The significance of moisture flow and equilibria in unsaturated soils in relation to the design of engineering structures built on shallow foundations in Australia. Symp. on permeability and capillary, Amer. Soc. Testimg Material, Atlantic City, NJ. 
Rifai A., Laloui, L., and Vulliet, L. (2002) Volume measurement in unsaturated triaxial test using liquid variation and image processing, In: Proc. of the $3^{\text {rd }}$ international conference on unsaturated soils, Recife, Brazil, Vol. 2, pp. 441-445.

Romero, E. (1999) Characterization and thermo-hydromechanical behavior of unsaturated Boom clay: an experimental study, $\mathrm{PhD}$ Thesis, Universitat Polite'cnica de Catalunya, Barcelona, Spain

Roscoe, K. (1953) An apparatus for the application of simple shear to soil samples, Proceedings of the $3^{\text {rd }}$ international conference on soil mechanics and foundation engineering, Switzerland, Vol. 1, p. 186.

Roscoe, K. (1970) The influence of strains in soil mechanics, Géotechnique, Vol. 20, No.2, pp. 129-170.

Rowe, P. W. (1962) The stress dilatancy relation for static equilibrium of an assembly of particles in contact. PYOC. R. Sot. A, 269, pp. 500-527.

Rowe, P. W. (1969) The relationship between the shear strength of sands in triaxial compression, plane strain and direct shear, Géotechnique, Vol. 19, No.1, pp.75-86.

Rowe, P. W. and Barden, L. (1964) Importance of Free Ends in Triaxial Testing, J. Soil Mech. Found. Div., Vol. 90, No. 1, pp. 1-15.

Rudnicki, J. W. and Rice, J. R. (1975) Conditions for localization of the deformation in pressuresensitive dilatant materials, J. Mech. Phys. Solids, 23, pp. 371-394.

Saada, A. S. and Townsend, F. C. (1981) State of the art: laboratory strength testing of soils. Laboratory shear strength of soils (eds. R. N. Yong \& F. C. Townsend), STP 740, Philadelphia: American Society for Testing and Materials. Scarpelli, G. \& Wood, D. M., pp. 7-77

Saada, A. S., Liang, L., Figueroa, J. L., and Cope, C. T. (1999) Bifurcation and Shear Band Propagation in Sands, Géotechnique, 49, 3, pp. 367-385.

Satija, B. S. and Gulhati, S. K. (1979) Strain Rate for Shearing Testing of Unsaturated Soil, Proc. 6th Asian Conf. on Soil Mechanics and Foundation Engineering, Singapore, pp. 83-86.

Scarpelli, G. and Wood, D. M. (1982) Experimental observations of shear band patterns in direct shear. Proceedings of the IUTAM symposium on deformation and failure of granular materials, eds. Vermeer, P. A. and Luger, H. J. Rotterdam: Balkema., pp. 473484.

Schanz, T., Agus, S. S., and Tscheschlok, G. (2004) Determination of hydro-mechanical properties of Trisoplast ${ }^{\circledR}$, Research Report Bo-015/03, Laboratory of Soil Mechanics, Bauhaus-Universität Weimar, Weimar, Germany. 
Schanz, T. and Vermeer, P. A. (1996) Angles of friction and dilatancy of sand, Géotechnique, Vol. 6, No. 1, pp. 145-51.

Schanz, T. (1998) Zur Modellierung des mechanischen Verhatltens von Reibungsmaterial ien, Mitteilung 45, Institut für Geotechnik, Universität Stuttgart.

Shahrour, I. and Rezaie, F. (1997) An Elastoplastic Constitutive Relation for the SoilStructure Interface Under Cyclic Loading, Compufers and Geotechnics, Vol. 21, No. 1, pp. 21-39.

Shaw, P. (1980) Stress-strain relationships for granular materials under repeated loading. PhD Thesis, University of Nottingham.

Shaw, P. and Brown, S. F. (1988) Behavior of dry granular materials under repeated load biaxial and triaxial stress conditions, Géotechnique, Vol. 38, No. 4, pp. 627-634.

Sillers, W. S. (1997) The mathematical representation of the soil-water characteristic curve, PhD Thesis, University of Saskatchewan.

Sivakugan, N. and Johnson, K. (2004) Settlement predictions in granular soils: a probabilistic approach, Géotechnique, Vol. 54, No. 7, pp. 499-502.

Sivakumar, R., Sivakumar, V., Blatz, J., and Vimalan, J. (2002) Twin-Cell Stress Path Apparatus for Testing Unsaturated Soils. Geotechnical Testing Journal, Vol. 29, Issue 2, pp. 175-197.

Sivakumar, V. (1993) A critical state framework for unsaturated soil, PhD Thesis, University of Sheffield, Sheffield.

Sterpi, D. (2000) Influence of the kinematic testing conditions on the mechanical response of a sand, Computers and Géotechnique, 26, pp. 23-41.

Stroud, M. A. (1971) The behaviour of sand at low stress levels in the simple shear apparatus, $\mathrm{PhD}$ Thesis, University of Cambridge, UK.

Tan, C. K. and Duncan, J. M. (1991) Settlement of footings on sands: accuracy and reliability. Proc. Geotech. Engng Cong., Colorado 1, pp. 446-455.

Tarantino, A., Mongiovi, L., and Bosco, G. (2000) An experimental investigation on the independent isotropic stress variables for unsaturated soils, Géotechnique, Vol. 50, No.3, pp. 275-282.

Tatsuoka, F. (2000) Impacts on Geotechnical Engineering of Several Recent Findings from Laboratory Stress-Strain Tests on Geomaterials, lecture note for the Burmister Lecture, 31 st, October, the Columbia University, N.Y., U.S.A. 
Tatsuoka, F., Goto, S., and Sakamoto, M. (1986a) Effects of some factors on strength and deformation characteristics of sand at low pressures, Soils and Foundations, 26-1, pp. 105-114.

Tatsuoka, F., Goto, S., Tanaka, T., Tani, K., and Kimura, Y. (1997) Particle size effects on bearing capacity of footings on granular material. In: Asaoka, Adachi and Oka, Editors, Deformation and Progressive Failure in Geomechnics, Pergamon, Nagoya (Japan), pp. 133-138.

Tatsuoka, F., Nakamura, S., Huang, C. C., and Tani, K. (1990) Strength anisotropy and shear band direction in plane strain tests of sand, Soils and Found., Vol. 30, No.1, pp. $35-54$.

Tatsuoka, F., Okahara, M., Tanaka, T., Tani, K., Morimoto, T., and Siddiquee, M. S. A. (1991a) Progressive failure and particle size effect in bearing capacity of a footing on sand, Proc. ASCE Geotech. Engineering Congress, Boulder, ASCE GSP, 27, pp. 788802 .

Tatsuoka, F., Sakamoto, M., Kawamura, T., and Fukushima, S. (1986) Strength and Deformation Characteristics of Sand in Plane Strain Compression at Extremely Low Pressures, Soils Found., Vol. 26, No. 1, pp. 65-84.

Tatsuoka, F., Siddiquee, M. S. A., Tanaka, T., and Okahara, M. (1991) A new aspect of a very old issue, Proceedings of the 9th Asian Regional Conference on SMFE, Bangkok, Vol. 2, 358.

Taylor, D. W. (1948) Fundamentals of soil mechanics, John Wiley, New York.

Tejchman, J. and Gudehus, G. (2001) Shearing of a narrow granular layer with polar quantities, International journal for numerical and analytical methods in geomechanics, 25, pp. 1-28.

Tejchman, J. and Wu, W. (1996) Numerical simulation of shear band formation with a hypoplastic constitutive model, Computers and Geotechnics, 18(1), pp. 71-84.

Tejchman, J., Herle, I., and Wehr, J. (1999) Fe-Studies on the Influence of Initial Void Ratio, Pressure Level and Mean Grain Diameter on Shear Localization, International Journal for Numerical and Analytical methods in Geomechanics, 23, pp. 2045-2074.

Terzaghi, K. (1943) Theoretical soil mechanics, Wiley Publications, New York.

Thakur, V. K. S., Sreedeep, S., and Singh, D. N. (2005) Parameters Affecting Soil-Water Characteristic Curves of Fine-Grained Soils, Journal of Geotechnical and Geoenvironmental Engineering, Vol. 131, No. 4, April 1, pp. 521-524.

Tillard, D. (1992) Etude de la rupture dans les geomateriaux cohesifs, applcaation a la marne de beaucaire, These de doctorat, UJF-INP6 Grenoble, France. 
Topolnicki, M., Gudehus, G., and Mazurkiewicz, B. K. (1990) Observed Stress-Strain Behavior of Remoulded Saturated Clay under Plane-Strain Conditions, Géotechnique, Vol. 40, No. 2, pp. 155-187.

Toyota, H., Sakai, N., and Nishimura, T. (2001) Effect of stress history due to unsaturation and drainage conditions on shear properties of unsaturated cohesive soil. Soils and Foundations, Vol. 41, No. 1, pp. 13-24.

University of Karlsruhe (1988) International workshop on limit analysis and bifurcation theory, Ingenieur-Archiv, 59, Special Issue.

Vanapalli, S. K. and Fredlund, D. G. (2000) Comparison of empirical procedures to predict the shear strength of unsaturated soils uses the soil-water characteristic curve. In Advances in Unsaturated Soils, Proceedings of Geo-Denver 2000, Denver, Colo., 5 8 August 2000, ASCE Special Publication 99, Edited by Shackelford, C. D., Houston, S. L. and Chang, N.-Y., pp. 195-209.

Vanapalli, S. K. and Mohamed, F. M. O. (2007) Bearing capacity of model footings in unsaturated soils, in Experimental Unsaturated Soil Mechanics, Springer Proceedings in Physics, Springer-Verlag Berlin Heidelberg, Vol. 112. pp. 483-493.

Vanapalli, S. K., Fredlund, D. G., Pufahl, D. E., and Clifton, A. W. (1996) Model for the prediction of shear strength with respect to soil suction, Canadian Geotechnical Journal, 33, 3, pp. 379-392.

Vardoulakis, I. G. (1977) Scherfugenbildung in Sandkörpern als Verzweigungsproblem, thesis, Institutes für Bodenmechanik und Felsmechanik der Universität Fridericiana in Karlsruhe, Germany.

Vardoulakis, I. G. (1978) Equilibrium bifurcation on granular earth bodies, Advances in the Application of Stability Analysis to Geotechnical instabilities, University of Waterloo Press, SM Study 13, Paper 3, pp. 65-119.

Vardoulakis, I. G. (1979) Bifurcation analysis of the triaxial test on sand samples, Acta Mechanica, Berlin, West Germany, 32, pp. 35-54.

Vardoulakis, I. G. (1980) Shear band inclination and shear band modulus of sand in biaxial tests, International Journal for Numerical and Analytical Methods in Geomechanics, Vol. 4, pp. 103-119.

Vardoulakis, I. G. (1981) Bifurcation analysis of the plane rectilinear deformation on dry samples, Int. J. Solids and Srruct., 17(11), pp. 1085-1101.

Vardoulakis, I. G. (1988) Stability and bifurcation in geomechanics, Proc. Numerical Methods in Geomech., Innsbruck, Austria, pp. 155-168. 
Vardoulakis, I. G. (1989) Shear banding and liquefaction in granular materials on the basis of a Cosserat continuum theory, Ingenieur Archiv., Berlin, Germany, 59(2), pp. 106-113.

Vardoulakis, I. G. and Aifantis, E. (1991) A gradient flow theory of plasticity for granular materials. Acta Mech. 87, pp. 197-217.

Vardoulakis, I. G. and Drescher, A. (1988) Development of biaxial apparatus for testing frictional and cohesive granular media, Final Report to the National Science Foundation, NSF Grant No. CEE 84-06500, University of Minnesota, USA.

Vardoulakis, I. G. and Goldscheider, M. (1981) Biaxial apparatus for testing shear bands in soils, Proc. 10th Int. Conf. Soil Mech. Fndn. Engng, Stockholm, 4, pp. 819-824.

Vardoulakis, I. G. and Graf, B. (1985) Calibration of constitutive models for granular materials using data from biaxial experiments, Géotechnique, 35, No. 3, pp. 299-317.

Vardoulakis, I. G. and Sulem, J. (1995) Bifurcation Analysis in Geomechanics (Blackie Academic and Professional.

Vardoulakis, I. G., Goldscheider, M., and Gudehus, G. (1978) Formation of shear bands in sand bodies as a bifurcation problem, International Journal for numerical and analytical methods in Geomechanics, Vol. 2, pp. 99-128.

Vermeer, P. A. (1982) A simple shear-band analysis using compliances, Proc. IUTAM Conf: on Deformation and Failure of Granular Materials (eds. P. A. Vermeer and H. J. Luger), pp. 439-499.

Vermeer, P. A. (1990) The Orientation of Shear Bands in Biaxial Tests, Géotechnique, Vol. 40, No. 2, p. 223-236.

Vesic, A. S. (1973) Analysis of ultimate loads of shallow foundations, J. Soil Mech. and Found. Div., ASCE, 99, 1, pp. 45-73.

Vesic, A. S. (1975) Bearing capacity of shallow foundations, In Foundation engineering handbook, Edited by Winterkorn, H. F. and Fang, H. Y., Van Nostrand Reinhold Co., New York, pp. 121-147.

Vesic, A. S. and Clough, G. W. (1968) Behavior of granular materials under high stresses. Journal of the Soil Mechanics and Foundation Division, ASCE, 94, 3, pp. 661-688.

Viggiani, G., Küntz, M., and Desrues, J. (2001) An experimental investigation of the relationships between grain size distribution and shear banding in sand, Continuous and Discontinuous Modelling of Cohesive-Frictional Materials, Edited by Vermeer, P. A. et al., Lecture Notes in Physics, Springer: Berlin, pp. 111-127. 
Wade, N. H. (1963) Plane strain failure characteristics of a saturated clay, PhD Thesis, London.

Wanatowski, D. (2005) Strain Softening and Instability of Sand under plane-strain Conditions, PhD Thesis, Nanyang Technology University.

Wanatowski, D. and Chu, J. (2006) Stress-Strain Behavior of a Granular Fill Measured by a New Plane-Strain Apparatus, Geotechnical Testing Journal, Vol. 29, No.2. pp. 149157.

Wanatowski, D. and Chu, J. (2007) Drained behaviour of Changi sand in triaxial and plane-strain compression, Geomechanics and Geoengineering: An International Journal, Vol. 2, No. 1, March 2007, pp. 29-39.

Wanatowski, D. and Chu, J. (2007a) static liquefaction of sand in plane strain, Canadian Geotechnical Journal, Vol. 44, pp. 299-313.

Wheeler, S. J. (1986) The stress-strain behavior of soils containing gas bubbles, PhD Thesis, Oxford University, Oxford, U. K.

Wheeler, S. J. (1988) The undrained shear strength of soils containing a large gas bubbles. Géotechnique, Vol. 28, No.3, pp. 399-413.

Wood, C. C. (1958) Shear strength and volume change characteristics of compacted soil under conditions of plane strain, $\mathrm{PhD}$ Thesis, University of London.

Wood, D. M. (1990) Critical State Soil Mechanics, McGraw-Hill, London.

Yamaguchi, H., Kimura, T., and Fujii, N. (1976) On the influence of progressive failure on the bearing capacity of shallow foundation in dense sand, Soil and Found., Tokyo, 16 (4), pp. 11-22.

Yamamuro, J. A. and Lade, P. V. (1996) Drained sand behavior in axisymmetric tests at high pressure. J Geotech Eng, 122, pp. 109-119.

Yang, H., Rahardjo, H., Leong, E.-C., and Fredlund, D. G. (2004) Factors affecting drying and wetting soil-water characteristic curves of sandy soils, Can. Geotech. J., 41, pp. $908-920$.

Yasin, S. J. M., Umetsu, K., Tatsuoka, F., Arthur, J. R. F., and Dunstan, T. (1999) PlaneStrain Strength and Deformation of Sands Affected by Batch Variations and Different Apparatus Types, Geotechnical Testing Journal, Vol. 22, No. 1, pp. 80-100.

Yin, J. H. (2003) Double cell triaxial system for continuous measurement of volume change of an unsaturated or saturated soil specimen in triaxial testing, Geotechnical Testing Journal, Vol. 26, No. 3, pp. 353-358. 
Yin, Z., ed. (1998) Settlement and consolidation of soil mass, China Electric Publication House (in Chinese).

Yoshida, T. and Tatsuoka, F. (1997) Deformation property of shear band in sand subjected to plane strain Compression and its relation to particle characteristics, Proc. $14^{\text {th }}$ ICSMFE, Hamburg, 1, pp. 237-240.

Yoshida, T., Tatsuoka, F., Siddiquee, M. S. A., and Kamegai, Y. (1995) Shear banding in sands observed plane strain compression, Localisation and Bifurcation Theory for Soils and Rocks (Chambon et al., eds.), Balkema, pp. 165-179.

Yoshida, T., Tatsuoka, F., Siddiquee, M. S. A., Kamegai, Y., and Park, C.-S. (1993) Shear banding in sands observed in plane strain compression. In Proceedings of the 3rd International Workshop "Localization and Bifurcation Theory for Soils and Rocks" Grenoble (Aussois), France, 6-9 September, edited by Chambon, R., Desrues, J., and Vardoulakis, I., A. A. Balkema, Rotterdam, the Netherlands, pp. 165-179.

Zhan, T. L. T. and Ng, C. W. W. (2006) Shear strength characteristics of an unsaturated expansive clay, Canadian Geotechnical Journal, Vol. 43, 7, pp. 751-763.

Zhou, J. and Jian-lin, Y. U. (2005) Influences affecting the soil-water characteristic curve, Journal of Zhejiang University, 6A (8), pp. 797-804. 